DOI: $10.24275 /$ uama.2463.7648

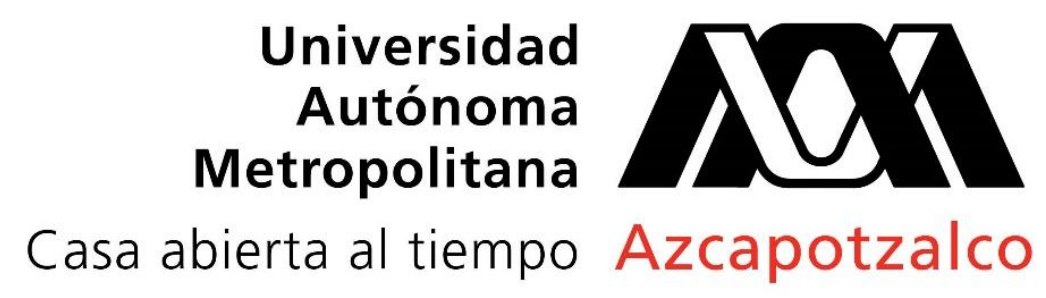

\title{
GUADALAJARA Y LA PRODUCCIÓN DE SU ESPACIO PÚBLICO: CENTRO Y PERIFERIA HUENTITÁN Y CRUZ DE PLAZAS
}

L.D.I. Adriana Betancourt Esquivel

Tesis para optar el grado de Maestra en Diseño y Estudios Urbanos

Miembros del jurado:

Dra. Elizabeth Espinosa Dorantes

Directora de tesis

Dra. Maruja Redondo Gómez

Dra. Carla Filipe Narciso

Dr. Christof Göbel

Dr. Vicente Guzmán Ríos

Ciudad de México, mayo 2021 


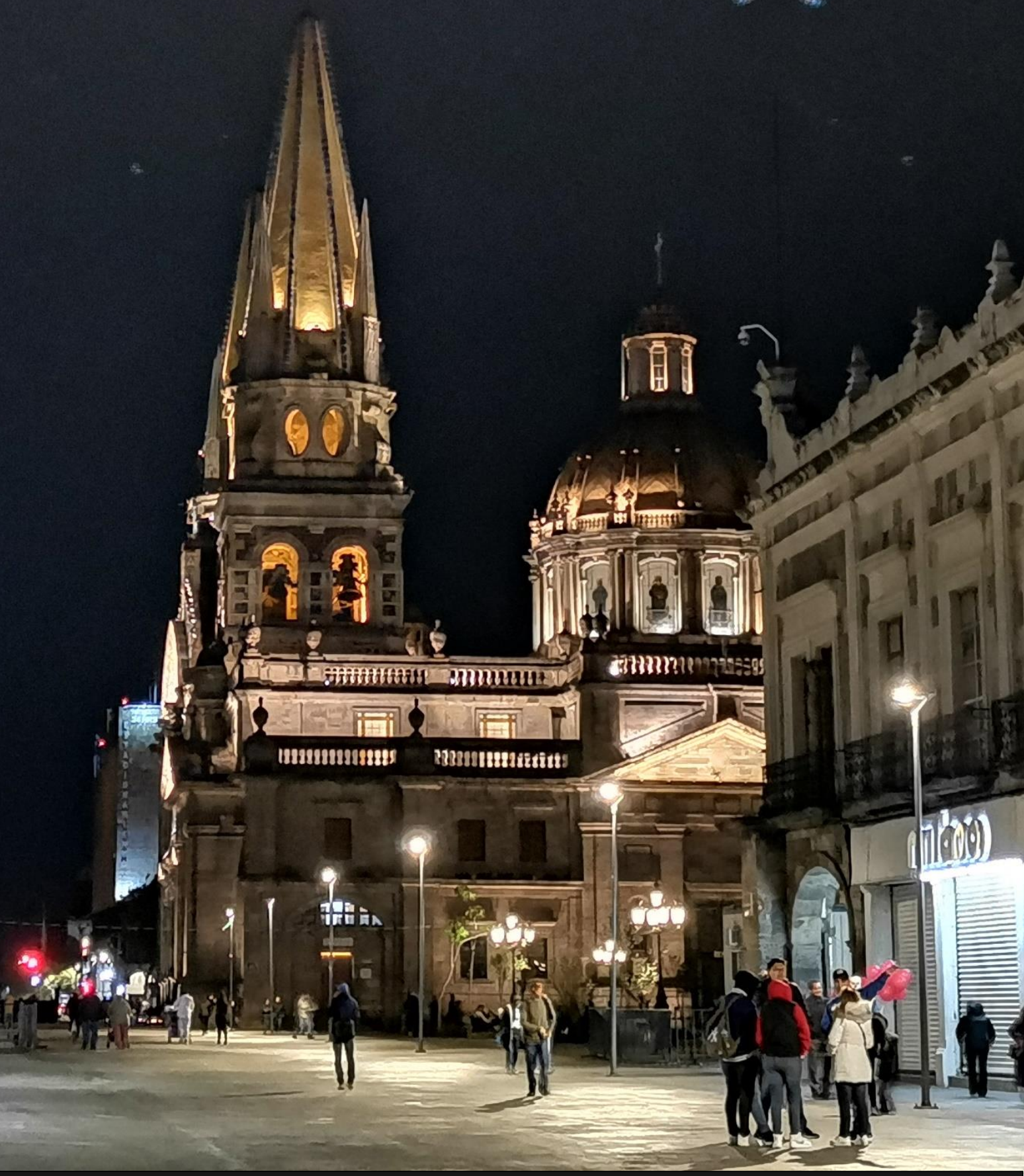

GUADALAJARA Y LA PRODUCCIÓN DE SU ESPACIO PÚBLICO: CENTRO Y PERIFERIA HUENTITÁN Y CRUZ DE PLAZAS 
A Juanita y Abrahamsito por todo su cariño y apoyo en este viaje emprendido durante mi proceso de maestría, por siempre estar y abrazarme a la distancia.

A mi asesora la Dra. Elizabeth Espinosa por la constancia, perseverancia y sobre todo motivación que me brindó durante este camino de investigación, por siempre mostrarse accesible supervisando y aportando a mi trabajo y hacerme retomar el rumbo cuando me divagaba. Mi más sincero respeto y admiración por su labor como investigadora.

A mi hermano Arturo por existir y estar, a mi sobrina Bolita por motivarme a querer ser una guía y ejemplo para ella de que las mujeres podemos hacer lo que queramos en la vida.

A Isaac por apoyarme y creer en mí siempre, a Almendra por siempre motivarme y echarme porras en este viaje, a Sabina, Diana y Liz por coincidir y conectar en los pasillos de la Universidad. A todos ustedes gracias por sus buenos deseos y sentimientos hacia mi conclusión de maestría y desarrollo profesional.

A mis amigos y colegas del Huerto Tlacuache, Jaasiel, Iván, Alán, Conchita, Beto, Joahana y doña Gloria por enseñarme otras formas de producción y apropiación de los espacios públicos. A todos los vecinos y usuarios de los parques Natural de Huentitán y Mirador por no dejar de luchar, usar y apropiarse de los espacios de la colonia para revitalizarlos y llenarlos de vida.

Gracias también a mis compañeros (ahora amigos) de la maestría Eve, Arturo, Iskar y Tamara por acogerme en CDMX y dejarme aprender de ellos, a la UAM por admitirme y permitirme ver desde otra perspectiva la educación pública dentro de sus aulas. A todos mis profesores de la maestría, de todos ellos me llevo un aprendizaje.

Al Dr. Diego A. Barrado Timón por recibirme en una estancia de investigación en la Universidad Autónoma de Madrid, su orientación y aprendizaje.

Finalmente agradecer al Consejo Nacional de Ciencia y Tecnología CONACYT por el apoyo brindado para el desarrollo y conclusión de esta investigación.

Por el tiempo, paciencia, comprensión y apoyo de todos, gratitud, gracias por estar. 
Dedicado a todas aquellas personas que luchan, se apropian y quieren espacios humanos para vivir la ciudad, a todos ustedes que sueñan ciudades y un mundo mejor. 
El espacio público es un concepto que se ha abordado desde diversas formas y dimensiones, desde las regulaciones jurídicas de sus usos, y, por tanto, de sus relaciones; hasta su configuración física y soporte de socialización para la vida cotidiana (espacio social), lo cual permite establecer que, en su conformación y sus modos de producción, (esta última idea asumida en el sentido de creación por medio de formas y procesos), dan como resultado la configuración del espacio público, lo cual puede abarcar lo tangible (material) o lo simbólico (inmaterial). Al realizar una revisión histórica de los procesos de generación de espacios públicos, parece ser que su creación compete exclusivamente a los estudiosos de la ciudad, sin embargo, la praxis urbana que aporta la ciudadanía es donde se condensa la esencia de la ciudad y por tanto es necesario valorar la interacción de los usuarios en el diseño del espacio urbano y en específico del espacio público. En resumen, es recuperar el carácter del urbanismo como instrumento de transformación social.

Por tanto, una intención inicial de la investigación es aportar al debate profesional e institucional la necesidad de repensar la forma de hacer urbanismo, no mediante la sustitución del urbanismo desarrollado por intervenciones en espacios públicos con participación vecinal, ya que, aunque hay que reconocer su valor e incorporar el conocimiento, en forma de herramientas para una aplicación consciente y eficaz, también deben mostrarse las evidencias de sus limitaciones.

Por ello, en la presente investigación nos proponemos analizar las formas de producción del espacio público de dos zonas de Guadalajara; su zona centro, Cruz de Plazas y Parque Morelos ubicados en el corazón del casco histórico y la zona periférica norte con el Parque Mirador y Parque Natural de Huentitán localizados dentro del barrio de origen indio Huentitán a fin de identificar sus formas de producción y señalar la importancia de los espacios públicos periféricos no solo para los habitantes de la zona, sino en conjunto para toda la metrópoli, ya que al no conocer la mirada de quienes usan estos espacios periféricos se producen espacios desligados a los espacios públicos centrales y no se valoriza su importancia para la red de espacios públicos de la ciudad, 
lo que trae como consecuencia no solo un debilitamiento en su accesibilidad para la ciudadanía, sino también escenarios de espacios urbanos inviables, espacios públicos fragmentados, pensados desde/para el automóvil que no favorecen la proximidad entre actividades y personas y, por tanto, no generan la complejidad de usos, la versatilidad y la diversidad necesarias en la ciudad.

Mediante una aproximación cualitativa desde el ámbito de la geografía humanista y la etnografía urbana se busca identificar las transformaciones relevantes de la producción de los espacios públicos; de manera que los resultados obtenidos den cuenta de las características y formas de producción en cada uno de los espacios a analizar, es decir es necesario distinguir cómo la ciudadanía tiene un papel primordial en la producción social y simbólica del espacio. Estos resultados deben de poner en evidencia la vigencia e importancia del espacio público de la periferia de Guadalajara, en específico de Huentitán y como el espacio público de los parques deben ser nodos articuladores de la dimensión humana de espacio público para la ciudad, que denoten la relevancia ciudadana en la producción del espacio público y la contribución de las manifestaciones de las personas al fortalecimiento y democratización del espacio; sin olvidar el rol que los estudiosos deben asumir, no solo como diseñadores del espacio público sino como mediadores entre los requerimientos de la ciudadanía y todos los agentes que operan en la ciudad.

Palabras clave. Espacio público, producción del espacio, ciudadanía, participación ciudadana, morfología, áreas verdes, espacio físico, espacio simbólico, nuevo urbanismo. 


\section{AGRADECIMIENTOS}

\section{RESUMEN}

INTRODUCCIÓN.

CAPÍTULO 1. Lo público del espacio en las ciudades..........................................................

Espacio público y su conformación. .....................................................................................17

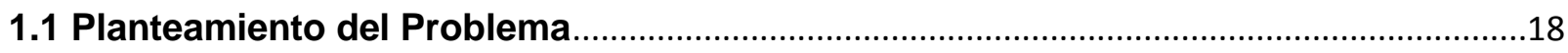

1.2 Definiciones de conceptos de espacio público y participación ciudadana ..................18

1.2.1 Primer acercamiento, la producción del espacio ………………………………........18

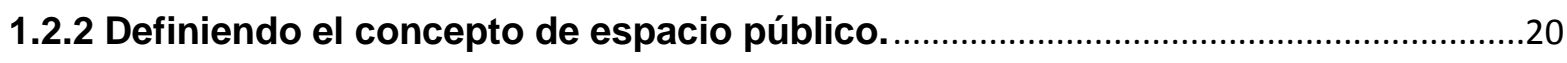

1.2.3 El carácter morfológico del espacio público: elementos urbano- arquitectónicos

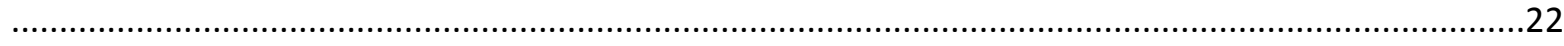

1.2.4 Clasificaciones espaciales del espacio público en la ciudad .................................26

1.2.5 El espacio público y su conformación a través de la historia .................................31

1.2.6 Los jardines históricos como nuevas formas de espacio público ............................36

1.2.7 Modelos de ciudad Latinoamericana y espacio público............................................39

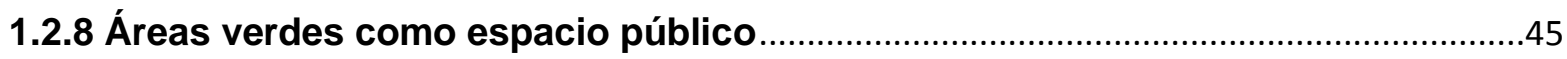

1.2.9 Espacio público contemporáneo y los criterios que ...............................................4

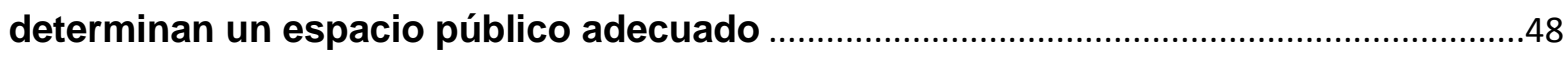

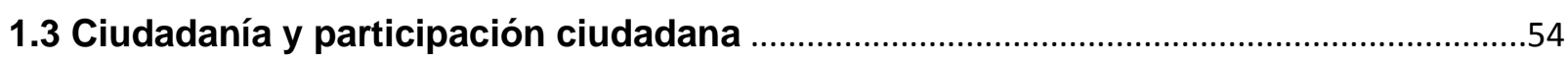

1.3.1 Participación ciudadana como proceso de construcción del espacio público....56

1.3.2 Aspiraciones sociales y la necesidad de las interacciones en el espacio público

.

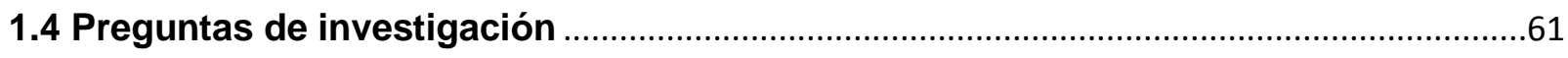

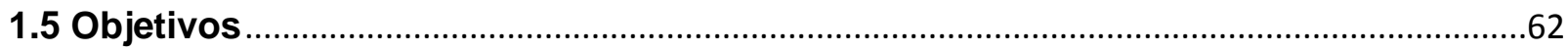

1.6 Estado de la cuestión del arte ...................................................................................62

1.7 Planteamiento metodológico y corrientes del pensamiento que se enfocan en los espacios y las personas.....................................................................................................64

1.7.1 Geografía humanista ...........................................................................................64 
1.7.2 Geografía de la percepción

1.7.3 Etnografía Urbana

1.8 Propuesta del método a utilizar: variables e indicadores a aplicar en los espacios públicos

Conclusiones capítulo 1 .70

CAPÍTULO 2. Guadalajara, espacio público y su estructura urbana.

2.1 Guadalajara, del virreinato a las leyes de Reforma. La configuración espacial homogénea primaria de la ciudad (1542-1896).

2.1.1. Guadalajara, periodo $1542-1732$ .78

2.1.2. Guadalajara, periodo 1732-1741 .84

2.1.3. Guadalajara, periodo 1741-1753 .86

2.1.4. Guadalajara, periodo $1753-1800$ .88

2.1.5. Guadalajara, periodo $1800-1850$ .91

2.1.6. Guadalajara, periodo 1850-1897 Leyes de Reforma. .94

2.2 Aparición de las “Colonias” y entubamiento del río San Juan de Dios como primeros elementos modernizadores de la ciudad (1897-1947)

2.3 Guadalajara Moderna. De Cruz de Plazas y ensanches en la ciudad (1947-2000)....104

2.4 Guadalajara contemporánea. Megaproyectos en la Perla Tapatía (2000-2018) ........109

Conclusiones capítulo 2 .112

CAPÍTULO 3. Espacio público en el siglo XXI centro y periferia. .116

Producción del espacio público en la Cruz de Plazas y en .... 116

la Periferia norte-Huentitán de Guadalajara. 116

3.1 Producción y del espacio público en la zona Centro de Guadalajara 117

3.1.1 Cruz de Plazas 119

3.1.1.1 Plaza Liberación 121

3.1.1.2 Plaza de Armas 128

3.1.1.3 Rotonda de Jaliscienses ilustres. .133

3.1.1.4 Plaza Guadalajara . 139

3.1.2-Parque Morelos. 144

3.2 Producción del espacio público en la zona periférica del norte de Guadalajara ......151

3.2.1 Parque Mirador Independencia. 152 
3.2.2-Parque Natural de Huentitán ...................................................................................175

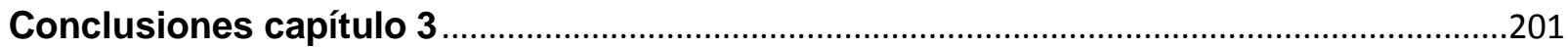

4. Huentitán: retos y oportunidades para la producción de espacio público con

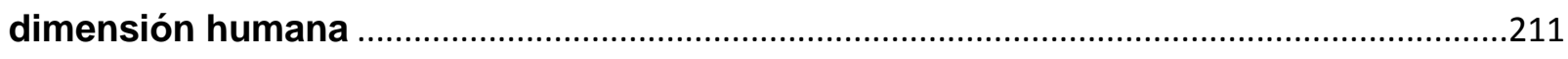

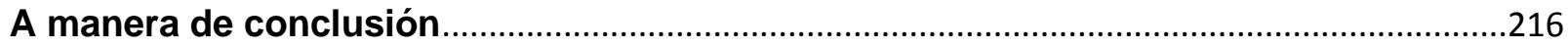

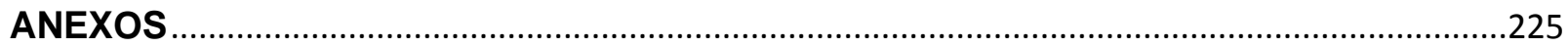

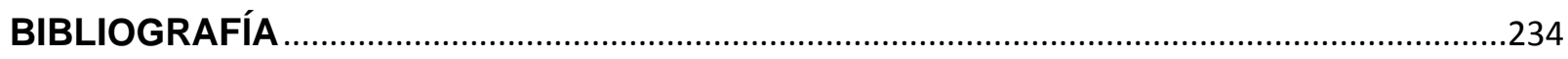

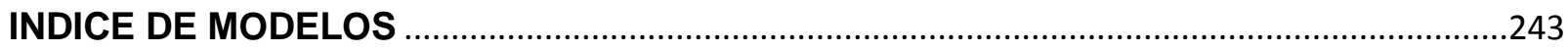

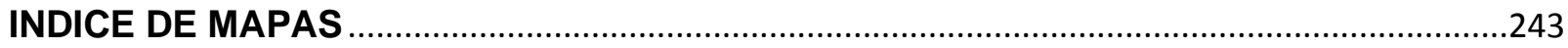

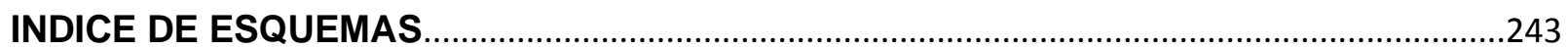

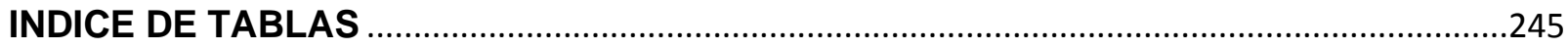




\section{INTRODUCCIÓN}

Esta investigación se realiza a partir de identificar que los espacios públicos de las periferias de las ciudades se perciben como espacios extraños a los espacios centrales, puesto que la producción del espacio público en muchas ocasiones se relaciona al trabajo de arquitectos, urbanistas, planificadores urbanos o la esfera política, los cuales no conocen las realidades del territorio y de las personas, lo que ocasiona espacios públicos desligados y con un debilitamiento en sus usos, apropiaciones y accesibilidad por no tener ese conocimiento ciudadano y no integrar las actividades de la población al momento de la toma de decisiones en el proceso de conformación de la producción del espacio público material en las periferias.

La existencia de un número creciente de movimientos ciudadanos en torno a la gestión y diseño del espacio público y la movilidad en sus barrios, plantean un escenario de especial interés para la puesta en valor de estrategias basadas en procesos participativos, sin embargo también es necesaria la reflexión sobre las cualidades de los procesos de producción de espacio público realizados a través de políticas públicas; esto es se requiere identificar los componentes que si bien ponen énfasis en la participación ciudadana, también valoran el diseño y la gestión de los espacios públicos a escala de barrio y su potencial transformador en el desarrollo urbano, de manera que la interrelación de ambos criterios permitan un urbanismo ágil que no solo dé respuesta a las necesidades de la ciudadanía, sino que considere este conocimiento en la toma de decisiones en todas las fases de los proyectos y procesos.

Por tanto, el objetivo de esta tesis es estudiar el espacio público en el centro y periferia de Guadalajara para comprender cuáles son los elementos o configurantes morfológicos, materiales, físicos y simbólicos que han permitido su producción, empleando espacios de estas zonas como referentes de procesos de producción derivados de políticas públicas y de participación ciudadana. El estudio se realizará mediante el análisis de los procesos de crecimiento de la ciudad y en específico de la estructuración de espacios públicos y su relación con la expansión de la metrópoli. El 
estudio abarca la fundación de Guadalajara y la producción de espacios públicos periféricos.

Para realizar la investigación se consideraron dos arquetipos de espacio público; el primero es un espacio público de origen fundacional en que el espacio público es el protagonista y este en constante remozamiento. El segundo es que el espacio público tenga la característica de que en ellos se hayan proyectado o se estén ejecutando proyectos que han segregado y fragmentado el espacio de uso público a la comunidad.

Por lo que se eligió la ciudad de Guadalajara y dos de sus zonas; la zona de Huentitán y el centro histórico de Guadalajara, ya que ambas áreas tienen espacios que cumplen con las condiciones antes descritas. Ambas zonas y sus espacios están insertos en diferentes escalas que surgieron en momentos distintos pero relevantes del desarrollo urbano de la ciudad; es necesario destacar la zona periférica norte con el barrio de origen prehispánico Huentitán y sus dos parques, Natural de Huentitán y Mirador Independencia, debido a que ambos han sido intervenidos y se les ha modificado su uso de suelo de espacio público y área verde para destinarlos a megaproyectos de índole privado que no han tomado en cuenta la opinión de la comunidad cercana. En el caso del casco fundacional de la capital de la Nueva Galicia, la Cruz de Plazas y Parque Morelos ${ }^{1}$, localizados en la zona centro de la ciudad, representan espacios urbano-históricos de disfrute ciudadano, los cuales están en constante remodelación y atención, por consecuente no se ven alterados para disminuir o segregar su extensión y denominación de espacio público, ambos espacios han sido proyectados e intervenidos desde las propuestas de los planificadores (ver mapa A).

\footnotetext{
${ }^{1} 1$ La elección de las áreas y espacios de estudio se justifica a partir del contexto de las dos Guadalajaras, ya que se trata de un par de espacios verdes de uso público localizados en un pueblo de origen indígena colonizado y domesticado del poblado de Huentitlán y de la ciudad de los españoles, es decir la ciudad fundacional y sus espacios públicos centrales como lo son la plaza (s) central y el primer parque público de la ciudad. En el primer caso ambos parques parte de su terreno han sido proyectados en megaproyectos e incluso intervenidos, segregando y disminuyendo no solo áreas verdes para la ciudad, sino a su vez espacios para el disfrute público a la ciudadanía de la periferia de la ciudad. En el segundo caso estos espacios públicos a lo largo del tiempo siempre han sido proyectados como espacios públicos y del disfrute colectivo, por lo cual el primero debería considerarse como un espacio estructurante para el territorio de la ciudad y una red de espacios públicos inexistente.
} 


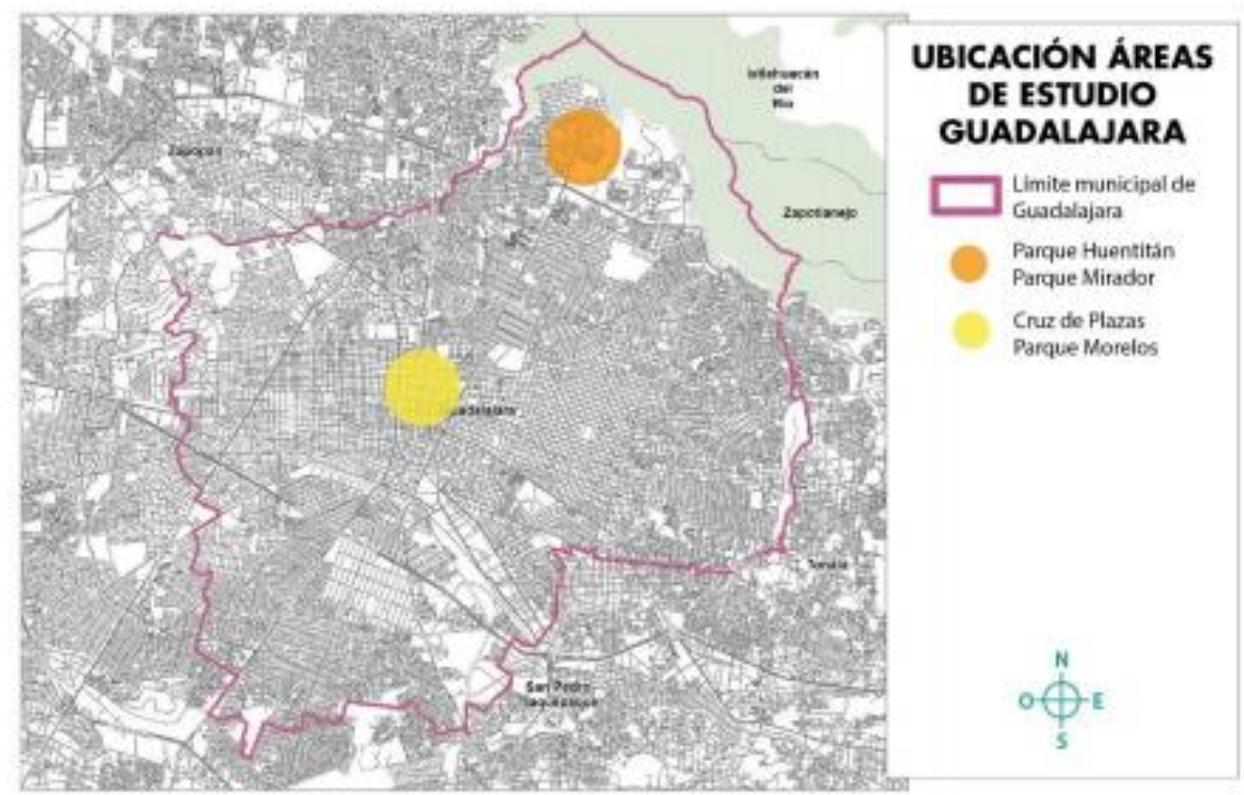

Mapa A. Ubicación áreas de estudio de la investigación. Elaboración propia.

Es importante señalar que tanto los espacios públicos centrales como periféricos tienen un valor para la ciudadanía, valor que se pretende identificar a partir de indicadores de sociabilidad, comodidad, imagen, usos y actividades que serán analizados en el trascurso de la investigación.

En el caso de la periferia norte de Huentitán, la ciudadanía, además, refiere valores de impacto ambiental en los parques Natural de Huentitán y Mirador Independencia, los cuales se encuentran en riesgo por el crecimiento de la ciudad que ha acotado sus espacios, de ahí la relevancia de analizar la red de espacios públicos que a través del tiempo se han producido en la ciudad de Guadalajara, así como la importancia en la estructuración de la ciudad.

Con la finalidad de obtener información que permita lograr lo anterior se ha planteado una pregunta central ¿La producción de los espacios públicos periféricos tienen una relevancia menor, mayor o igual a los espacios públicos centrales para las ciudades? Y cómo interrogantes secundarias: ¿Por qué los espacios públicos periféricos se perciben como espacios menos relevantes que los espacios públicos centrales en la ciudad? ¿Cómo fueron conformándose los espacios públicos de Guadalajara en relación 
con el crecimiento de la ciudad y su traza urbana? ¿Qué elementos de la construcción del espacio social, son visibles en la concepción material del espacio público?

Para fines prácticos el trabajo se estructura en cuatro secciones:

1. Planteamiento metodológico y corrientes del pensamiento que se enfocan en los espacios y las personas, conceptos teóricos de espacio público, producción del espacio y participación ciudadana, su definición, aspectos simbólicos-materiales, actores, áreas verdes como espacio público e indicadores para su evaluación.

2. Guadalajara y su contexto histórico urbano, aspectos físicos morfológicos de su desarrollo, análisis simbólico y material del área de estudio.

3. Espacio público en tiempos contemporáneos, la producción del espacio y la medición de estos mediante indicadores que determinen si son espacios públicos adecuados para la ciudadanía en la periferia norte de Huentitán y la zona centro del casco histórico, las dimensiones y usos actuales de los espacios públicos periféricos y centrales. Huentitán su crecimiento, de pueblo de indios a barrio periférico de la ciudad, donde también se realizará un análisis del crecimiento del barrio y usos actuales de dos de sus áreas verdes que fungen como espacios públicos importantes y articuladores para la ciudad.

4. Como parte de las conclusiones se tiene un apartado acerca de los retos y oportunidades para la producción de espacio público con dimensión humana en Huentitán en el que se recalca la importancia del estudio de la zona periférica Norte de Guadalajara en relación con la centralidad principal del casco histórico de Guadalajara. En una última sección se destaca como el espacio público periférico tiene el potencial de ser un nodo articulador no solo para el desarrollo de Huentitán, sino que a la par se vincula e integra con el desarrollo de la ciudad en su conjunto, es decir, se evidencia la importancia de los espacios públicos periféricos con relación a la centralidad de Guadalajara.

Este trabajo busca indagar si el espacio social, que es multidimensional y en el que se relacionan varios procesos y elementos de las relaciones sociales (Lefebvre, 2013) a través de la interacción entre actores sociales, se materializa en el espacio 
público, así como determinar si la participación ciudadana en la producción del espacio público es clave para el éxito de estos, puesto que son las personas que al utilizarlo le dan vida, es decir, indicar si las condiciones físicas de un espacio público reflejan vida colectiva e identidad o si generan vida social colectiva e identidad. Para ello se determinará si los espacios de las zonas de estudio y su producción responden a ideas de autores clásicos o a las ideas planteadas por autores de la corriente del nuevo urbanismo que se centra más en el aspecto simbólico y de apropiación que en el de las cualidades físicas, si manifiestan criterios más relacionados con el valor material (como espacios de orden social y cívico) o a un valor ciudadano simbólico de apropiación e identidad, puesto que la producción del espacio público también incluye las relaciones e interacciones sociales que se producen, ya sean de carácter necesario, opcional o social y que dependiendo de la calidad del espacio, las personas querrán estar ahí, permanecer y realizar actividades en él.

El espacio público y su producción se ha estudiado desde diversas perspectivas, sin embargo, su configuración física y soporte de socialización para la vida cotidiana permiten comprender al espacio público y su producción desde aspectos de prácticas sociales, morfología, percepción del espacio, lugares, etc. y con ello comprender mejor las dinámicas que se originan y generan entre la ciudad, sus espacios y sus habitantes.

Si bien existe una amplia diversidad de espacios públicos, el análisis histórico y morfológico, que se plantea realizar, se concentrará en la relación calle, plaza, atrio, áreas verdes como el jardín y parques debido a que estos espacios definen límites sociales y físicos en el espacio urbano de las ciudades.

La investigación es sobre todo de carácter descriptivo y cualitativo, ese es su origen y la esencia que conforman este trabajo, por lo que se estará abordando por medio de las metodologías de corrientes de pensamiento enfocadas en ver la sociedad, el entorno y su evolución en el contexto territorial, tal es el caso de la geografía humanista, la geografía de la percepción y, el comportamiento en el que Jesús González, Santis y Ganga y Yago la bordan desde la idea de la organización espacial de las actividades humanas, las relaciones y comportamientos entre la sociedad y su entorno, 
así como la etnografía urbana a partir de los trabajos de Claudina Peralta, Gayou y Kathrin Wildner mediante la observación y descripción del registro de datos de las actividades que habitualmente hace una comunidad determinada; con esta investigación se busca analizar las diferencias en la producción de espacio público en las zonas centrales y periféricas de la ciudad de Guadalajara.

Este tema se eligió como punto de partida para la investigación debido a que el espacio público es un sitio de uso colectivo y uno de los elementos más importantes para las ciudades y las personas, por lo que con la finalidad de obtener el punto de vista del nativo, en relación con la vida y su visión del mundo, como lo plantea Malonowski citado por Spradley en su texto la entrevista etnográfica (1979), así como, describir y comprender otras formas de lo que es el mundo para las personas, aprender de ellos, y así, obtener una interpretación y comprensión cultural y realidad social del espacio, la investigación aplicara métodos cualitativos que proponen la metodología de la geografía humanista y etnografía urbana para estudiar y analizar los espacios públicos centrales y periféricos planteados. También parte del análisis se apoya en la idea del caminante y observación que propone de De Certeau, el cual retoma las ideas de Walter Benjamín sobre el "flâneur", viandante que recorre la ciudad y sus paisajes, dotándolos de un valor simbólico, en el que el caminante interpreta a la ciudad, sus calles y pasajes a partir de los acontecimientos de lo cotidiano (Benjamín, 2004: 58).

Al analizar lo anterior el aporte teórico metodológico de este trabajo será determinar si los espacios públicos de las periferias son importantes para las ciudades o no, explicar la producción física material y simbólica de los espacios públicos periféricos y centrales de Guadalajara, cómo la ciudad fue creciendo en relación con sus espacios públicos hasta alcanzar a la periferia de la ciudad, así como la importancia, valor físico y carga simbólica que tienen los espacios públicos periféricos del área norte para vecinos de la zona y para todos los habitantes de la ciudad en el cual la participación ciudadana es clave para dotar de valor a estos espacios y en que los espacios públicos periféricos sean considerados espacios importantes como nodos articuladores para las ciudades, por tal motivo se pretende analizar los conceptos de espacio público y participación 
ciudadana, apoyándose en aproximaciones metodológicas y teóricas que ayuden a la elaboración de los productos a obtener de este trabajo; modelos relacionales de crecimiento y expansión urbana de la ciudad de Guadalajara con respecto a sus espacios públicos en su historia urbana, esquemas de elementos físicos y morfológicos de Cruz de plazas y parques; Morelos, Huentitán y Mirador y tablas y gráficas de indicadores de calidad del espacio en cuanto a conexiones, comodidad e imagen, usos, actividades y sociabilidad, lo cual nos permitirá dar cuenta de la importancia que tienen estos espacios y del papel de las personas en la producción de sus espacios públicos, puesto que los espacios públicos como los parques de las periferias no solo son importantes en un sentido ambiental, sino también integran un territorio en el que se desarrolla la vida de la comunidad y en el que estos espacios deben permanecer como espacios públicos para el encuentro de la ciudadanía y no planear proyectos que segmenten o nieguen el uso de los mismos a las personas.

Por lo tanto como parte del resultado de esta investigación se pondrá a disposición de los diferentes colectivos y asociaciones de vecinos de la periferia norte de Guadalajara para que la información generada sea utilizada para defender sus parques y tengan herramientas para el diálogo con las autoridades correspondientes y puedan mostrar datos que demuestren la importancia y valor que tienen los espacios públicos periféricos para la metrópoli y como estos espacios deben estar ligados a una red de espacios para la ciudad.

Para comprender mejor el cuerpo de la investigación y planteamientos ver en Anexos la matriz teórico-metodológica. 


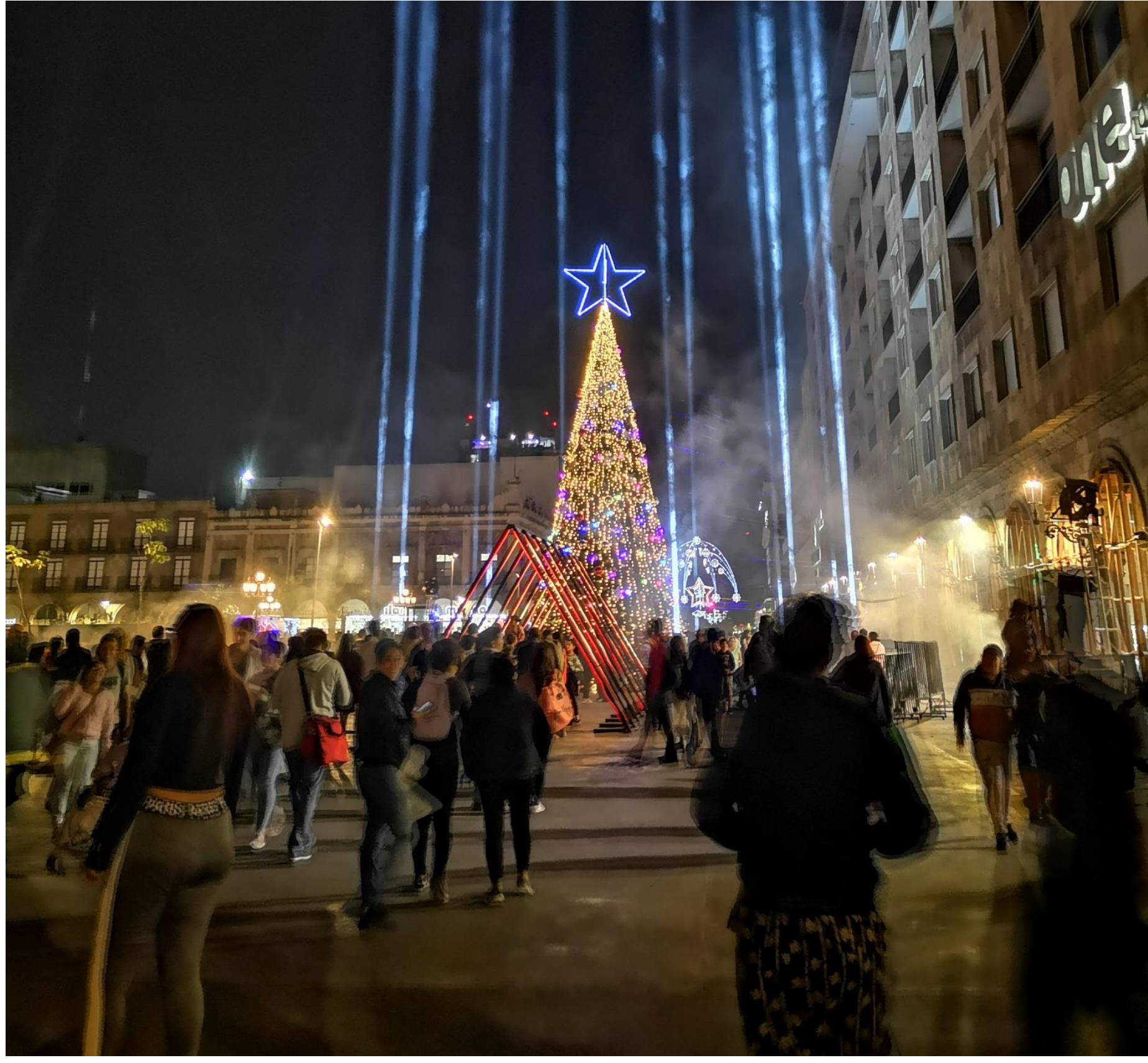

Paseo Alcalde Centro de Guadalajara. Diciembre 2019. Fuente propia.

CAPÍTULO 1. Lo público del espacio en las ciudades. Espacio público y su conformación. 
"Las ciudades tienen la capacidad de proporcionar algo para todo el mundo, sólo porque, y sólo cuando, se crean para todo el mundo."

Jane Jacobs

\subsection{Planteamiento del Problema}

En este apartado se explica el problema principal que aborda la investigación en relación a que los espacios públicos periféricos se perciben como lugares ajenos a los espacios públicos centrales, ya que en muchas ocasiones la producción del espacio público se relaciona como el quehacer de expertos; arquitectos, urbanistas, planificadores urbanos, políticos, existiendo un interés mínimo por parte de ellos en conocer a la ciudadanía y sus realidades para el diseño de sus espacios públicos, lo que puede traer como consecuente espacios públicos desligados unos con otros y por lo tanto un debilitamiento en su accesibilidad, usos o apropiaciones debido a la carencia de no integrar y conocer las actividades de la sociedad al momento de la toma de decisiones para la producción física material de espacios públicos en las periferias de las ciudades.

\subsection{Definiciones de conceptos de espacio público y participación ciudadana}

1.2.1 Primer acercamiento, la producción del espacio Antes de adentrarnos al tema de esta investigación sobre la producción del espacio público es necesario comprender qué es el espacio y cómo se produce, de tal manera que para abordarlo tomaremos a autores que profundizaron en el concepto de espacio y producción del espacio.

El espacio tiene distintas dimensiones, desde un medio físico donde se sitúan cuerpos y masas en movimiento o entendido desde un modo ontológico como lo planteaba Heidegger; desde el modo propio de ser del ser humano en la que la espacialidad del hombre se plantea desde la constitución del mundo entendido como un horizonte de significación (Hernando, 2019).

Diversos expertos han abordado el estudio del espacio para definir o acotar las formas de producción del mismo, para Lefebvre el espacio es más que un escenario o receptáculo pasivo de la realidad social, para él el espacio es un ámbito que permite la 
interacción social, para ello plantea tres dimensiones: el espacio percibido, el espacio concebido y el espacio vivido (Lefebvre, 2013: 15-20), en donde cada forma particular tiene una representación del espacio; la primera representa al espacio desde la experiencia material vinculada a la realidad cotidiana, la segunda es el espacio de los científicos y expertos en el tema de espacio, los planificadores, un espacio de signos y ordenación, y la tercera, el espacio donde se encuentran los lugares de la acción y pasión, aquellos espacios donde se someten las reglas de la coherencia.

Por otra parte Edward Soja en los 80 retoma las formas de producción del espacio de Lefebvre y crea su propia trialéctica del espacio urbano (Soja, 2008: 39-40), de acuerdo con Soja la producción de este puede ser abordado de tres maneras distintas; en un primer acercamiento el espacio puede ser estudiado como "prácticas espaciales materializadas", aquí el espacio urbano es percibido físico y empíricamente como un proceso de configuraciones y prácticas de la vida, en una segunda visión la idea del espacio se vuelve más mental, ya que se conceptualiza en imágenes, pensamientos y representaciones, este es el espacio concebido por la imaginación (el imaginario urbano). Por último, se encuentra el espacio enteramente vivido, un espacio que es real pero simultáneamente imaginario, virtual y real, un lugar de experiencias individuales y colectivas, a este espacio Soja lo compara como quien escribe una biografía porque es la interpretación del tiempo vivido de los individuos.

Por otro lado, de De Certeau hace una distinción entre espacio y lugar (De Certeau, 2000: 129), siendo el lugar donde los elementos se distribuyen en relaciones de coexistencia, los elementos están unos al lado del otro, cada uno colocados en un sitio distinto que cada uno define, es pues un indicador de estabilidad, una configuración de posiciones. De Certeau señala a su vez al espacio como aquel que toma en consideración los vectores de dirección, variables del tiempo y velocidad, por tanto un espacio de cruzamiento de movilidades, pero a diferencia del lugar carece de un sitio propio, de ahí podemos entender que el espacio es el lugar practicado, material y simbólico, además de transformar la calle trazada por los urbanistas como el espacio por intervención de los caminantes, siendo el acto de caminar un efecto de triple función (De Certeau, 2000: 
110): un proceso de apropiación del sistema topográfico por parte del peatón, una realización espacial del lugar, implicando relaciones entre posiciones diferenciadas y el andar como una primera definición de espacio de mención, es caminando como los individuos recorren atajos y caminos, como una primera forma de apropiación de su espacio, convirtiendo el caminante cada significante del espacio con cada paso recorrido.

\subsubsection{Definiendo el concepto de espacio público.}

El espacio público es el lugar de confluencia entre individuos, es un concepto difuso o indefinido, ya que puede incluir plazas, parques, calles, centros comerciales, andadores, plazoletas e incluso la opinión pública de quienes transitan en estos lugares.

Abordar el espacio público no solo conlleva el entender su definición, es abarcar cuáles son los componentes que lo conforman y sus características. El espacio público es un concepto importante en la historia de conformación de las ciudades, Aristóteles es uno de los primeros en definirlo al establecer al ágora como espacio esencial para la vida social en la ciudad, ya que este sitio se distingue del espacio privado por ser el lugar de lo común y lo social, el espacio del pueblo, donde la vida pública se manifestaba, la zona en que los ciudadanos podían discutir y decidir cuestiones en cuanto a política, cultura, económicas, etc. diferenciado del espacio privado que hace alusión a lo individual en la vivienda.

Por otro lado, Jane Jacobs (2011) en su obra muerte y vida de las grandes ciudades aborda y define al espacio público como un lugar en que las actividades de la vida diaria están en transición, en que los espacios se conectan con otros lugares, donde la vida de la ciudad está en su espacio público y calles puesto que los individuos se comparten con la comunidad.

Para Jordi Borja el espacio público puede entenderse como todo aquello que tiene un carácter abierto y que representa una estructura dinámica definida por características simbólicas, materiales y componerse de diferentes dimensiones (sociales- espaciales). De acuerdo con Borja: 
El espacio público supone pues dominio público, uso social colectivo y multifuncionalidad. Se caracteriza físicamente por su accesibilidad, lo que le hace un factor de centralidad. La calidad del espacio público se podrá evaluar sobre todo por la intensidad y la calidad de las relaciones sociales que facilita, por su fuerza mixturante de grupos $y$ comportamientos y por su capacidad de estimular la identificación simbólica, la expresión y la integración cultural. Por ello es conveniente que el espacio público tenga algunas calidades formales como la continuidad del diseño urbano y la facultad ordenadora del mismo, la generosidad de sus formas, de su imagen y de sus materiales y la adaptabilidad a usos diversos a través de los tiempos (Borja, 2000: 29)

Desde el punto de vista de Borja, un espacio público puede interpretarse como todo aquel que permita la mixtura social, se vuelve el lugar para el ejercicio de la ciudadanía, en el que diversos individuos se identifiquen y se relacionen en él a diferentes escalas, donde la mezcla de ideas, pensamientos, emociones y expresiones se manifiestan, definiéndolo por su estructura física y las relaciones simbólicas que se construyen en él. Además, también lo define como un sistema de red que incluye calles, plazas, infraestructuras, equipamientos y espacios de uso colectivo que permiten una diversidad social y resumido como un espacio tanto físico, simbólico y político (2000).

Patricia Ramírez Kuri establece al espacio público en un enfoque histórico, como lugares de intercambio, comunicación y encuentro en el que actúan de manera activa referentes como la vida social, la cultura y la política y que esto genera cambios en la estructura social urbana por la redimensión de la ciudad contemporánea (Kuri, 2015). Para Kuri en la construcción simbólica y social de la ciudad el espacio público es un elemento primordial del orden urbano en el que se puede expresar como los habitantes usan y tienen acceso a recursos tanto culturas políticos y sociales.

Jan Gehl arquitecto danés en su libro ciudades para la gente hace referencia al espacio público como áreas multifuncionales en las que se producen interacciones sociales, intercambio económico y manifestación cultural para un amplio espectro de 
actores, en el que un buen diseño de espacio público alienta a la ciudadanía a su uso y además transmitir una sensación de pertenencia e identidad. Su planteamiento general de espacio público se define como un lugar de encuentro abierto entre personas y escenario en el cual pueden suceder eventos de distintos indoles; actos políticos, manifestaciones, protestas, encuentros comunitarios, entre otros. Gehl también refiere que es un espacio para caminar, realizar paseos o paradas cortas, interactuar con otros, tener encuentros, realizar actividades recreativas, un sitio para el comercio y el intercambio (Gehl 2014)

"Un punto de encuentro y de expresión comunitaria, así como de esparcimiento, integración y cohesión social. El espacio público comprende todas aquellas áreas de servicio y uso común, como son: plazas, alamedas, áreas verdes, parques, jardines, espacios deportivos y culturales, calles, avenidas, camellones, bosques y lagos, entre otros (El Asunto Urbano)

Por otra parte, el arquitecto Rafael Atehortúa Arroyave en el prólogo del libro uso y apropiación de los espacios públicos (2013) deben ser entendidos como una herramienta que la ciudad ofrece y en el que cada usuario se inventa la diversidad de usos y apropiaciones posibles de acuerdo con el tiempo, circunstancias individuales de sentimientos, momentos como una experiencia de vida.

\subsubsection{El carácter morfológico del espacio público: elementos urbano-} arquitectónicos

El espacio público además de ser un punto de reunión y apropiación ciudadana, un espectador de las relaciones y manifestaciones de quienes lo habitan y transitan, alberga una serie de elementos urbanos y arquitectónicos que le dotan una morfología física característica, Kevin Lynch (1985: 42) lo define como el "entorno físico" aquella pauta espacial de los inertes y permanentes objetos físicos de una ciudad, donde a dichos objetos se les añade términos modificadores que hagan referencia a su uso o cualidad. En su libro imagen de la ciudad, Lynch hace hincapié que el medio físico tiene ciertas 
cualidades que otorgan significado e identidad al espacio y que en conjunto dotan de una estructura a las ciudades (Lynch, 1985: 61-63).

Basándose en este entorno físico con significado de identidad propuesto por Lynch los espacios públicos se componen de dos grupos de elementos: arquitectura y mobiliario:

\section{A) Arquitectura}

\begin{tabular}{|c|c|c|c|}
\hline \multicolumn{4}{|c|}{ ELEMENTOS MORFO-ARQUITECTÓNICOS } \\
\hline Senda & $\begin{array}{l}\text { Conductos que sigue el observador } \\
\text { (caminante). }\end{array}$ & $\begin{array}{l}\text {-Senderos } \\
\text {-Andadores } \\
\text {-Callejones } \\
\text {-Aceras }\end{array}$ & $\begin{array}{l}\text {-Calles } \\
\text {-Líneas de tránsito } \\
\text {-Líneas férreas }\end{array}$ \\
\hline Borde & $\begin{array}{l}\text { Los límites entre dos fases, rupturas lineales } \\
\text { de la continuidad (fronteras entre dos } \\
\text { espacios). }\end{array}$ & \multicolumn{2}{|c|}{$\begin{array}{l}\text {-Edificaciones (edificios-casas) } \\
\text {-Muros/bardas/cercas } \\
\text {-Cruces de ferrocarril }\end{array}$} \\
\hline Hitos & $\begin{array}{l}\text { Son un punto de referencia, un objeto físico } \\
\text { definido que puede verse desde diferentes } \\
\text { ángulos y distancias. }\end{array}$ & $\begin{array}{l}\text {-Iglesias,catedrales } \\
\text {-Edificios históricos } \\
\text {-Edificios } \\
\text { administrativos } \\
\text {-Museos }\end{array}$ & $\begin{array}{l}\text {-Monumentos } \\
\text {-Esculturas } \\
\text {-Puentes } \\
\text {-Rotondas } \\
\text {-Torres }\end{array}$ \\
\hline Nodo & $\begin{array}{l}\text { Puntos estratégicos de una ciudad a los que } \\
\text { puede ingresar un observador, pueden ser } \\
\text { sitios de confluencia o convergencia, } \\
\text { momentos de paso de una estructura a otra, } \\
\text { puntos en la ciudad que son foco de tránsito. }\end{array}$ & \multicolumn{2}{|c|}{$\begin{array}{l}\text {-Plazas } \\
\text {-Centros de transferencia modal } \\
\text {-Glorietas }\end{array}$} \\
\hline Barrio & $\begin{array}{l}\text { Secciones de la ciudad que son reconocibles } \\
\text { como si tuviesen un carácter que los } \\
\text { identifica por medio de caracteres } \\
\text { bidimensionales. }\end{array}$ & \multicolumn{2}{|l|}{$\begin{array}{l}\text {-Distritos } \\
\text {-Colonias }\end{array}$} \\
\hline
\end{tabular}


La arquitectura por su parte comprende a los componentes construidos en el entorno urbano, esto está relacionado con la planificación de acuerdo con aspectos prácticos de la vida de la ciudad en conjunto con la armonía y forma de los entornos ${ }^{2}$. (Ver tabla A).

\section{B) Mobiliario}

El mobiliario puede concebirse como el conjunto de piezas/objetos instalados en la vía pública, es un ingrediente diferenciador de las ciudades debido a que otorga de identidad al entorno urbano, tiene además como finalidad principal el facilitar las necesidades de los ciudadanos y mejorar su calidad de interacción y uso adecuado en los espacios públicos y ser a la par un apoyo a la infraestructura de equipamiento urbano y de la imagen urbana de la ciudad. De forma simplificada se puede decir que el mobiliario urbano son todos aquellos muebles que están en el entorno urbano y que a pesar de llamarse mobiliario (móviles) la mayoría se encuentran fijos o semifijos a sus emplazamientos, es necesario señalar que el mobiliario urbano tiene si propia clasificación de acuerdo con sus características, funciones y usos destinados (Ver tabla B).

El mobiliario urbano no solo permite a las personas tener una experiencia más agradable en las ciudades, son un integrante necesario que indica u orienta el cómo puede funcionar de manera óptima un espacio público, ya que por la forma en que están diseñados pueden optimizar la experiencia de uso de los espacios de las personas y mejorar la imagen urbana e incluso a la vez pueden contribuir como un indicador de calidad de los espacios públicos.

\footnotetext{
2 Para profundizar se sugiere consultar a detalle la obra de Kevin Lynch la Buena forma de la ciudad (1985)
} 


\begin{tabular}{|c|c|}
\hline Elementos de ambientación & $\begin{array}{l}\text {-luminarias (peatonales y vehiculares) } \\
\text {-Protectores de árboles. } \\
\text {-Jardineras } \\
\text {-Quioscos } \\
\text {-Fuentes } \\
\text {-Relojes }\end{array}$ \\
\hline Elementos de recreación & $\begin{array}{l}\text {-Juegos } \\
\text {-Aparatos de ejercicio } \\
\text {-Canchas }\end{array}$ \\
\hline Elementos de descanso y contemplación & $\begin{array}{l}\text {-Bancas/bancos } \\
\text {-Camastros } \\
\text {-Mesas de picnic }\end{array}$ \\
\hline Elementos de salud e higiene & -Depósitos para la basura \\
\hline Elementos de seguridad & $\begin{array}{l}\text {-Barandales } \\
\text {-Pasamanos } \\
\text {-Bolardos } \\
\text {-Cámaras de seguridad } \\
\text {-Sirenas }\end{array}$ \\
\hline Elementos viales & $\begin{array}{l}\text {-Parquímetros } \\
\text {-Ciclopuertos } \\
\text {-Estaciones de bicicletas } \\
\text {-Delimitadores } \\
\text {-Rampas }\end{array}$ \\
\hline Elementos orientativos indicativos & $\begin{array}{l}\text {-Señalética vertical } \\
\text {-Señalética horizontal }\end{array}$ \\
\hline
\end{tabular}

Tabla B) Elementos morfo-mobiliario. Elaboración propia con base a Edgar de los Santos (2017)

Estas distribuciones están dotadas de elementos (arquitectónicos-mobiliario) que le brindan una mejor lectura semiótica e interpretativa de función y usos a las personas, por lo cual para una lectura morfológica del espacio público es preciso determinar y tener presente cuáles son los elementos que lo conforman a un nivel material/físico. 
Soja (2008: 48) plantea indagar, encontrar y explicar los patrones morfológicos del espacio urbano porque reflejan continuidades de las ciudades y otorgan un sentido práctico y teórico a la especificidad espacial del urbanismo.

Por otro lado Lefebvre (2013:92) aborda las representaciones del espacio como aquellas que vinculan a las relaciones de producción al orden que imponen, y por consecuente a los signos, códigos y relaciones, este espacio conceptualizado es el de los expertos, donde estos signos y códigos (como el mobiliario y los elementos arquitectónicos del espacio) se relacionan y tratan de provocar un espacio dominante dentro del espacio social, no obstante este espacio social envuelve a las cosas producidas y comprende sus relaciones en su coexistencia y simultaneidad en un orden físico, es decir, los elementos morfológicos apoyan a la configuración del espacio de los expertos, pero a su vez reafirman el concepto del espacio percibido de las personas mediante la práctica espacial en un contexto urbano y la relación de uso e interacción con los elementos del entorno.

\subsubsection{Clasificaciones espaciales del espacio público en la ciudad}

Como ya se ha mencionado, el espacio público es un espacio abierto que permite el libre tránsito, adaptabilidad de usos y actividades, como lo sugiere Lefebvre (2013: 92) "La práctica espacial que engloba producción y reproducción, lugares específicos y conjuntos espaciales propios de cada formación social (...) Las representaciones del espacio, que se vinculan a las relaciones de producción (...)"es pues el espacio público un espacio para el encuentro, un espacio de flexibilidad de usos, un lugar común de la ciudad, donde su producción es por medio de significados otorgados por la sociedad, del pensamiento reflexivo y crear con ellos espacios de representación o espacios materializados por el pensamiento reflexivo de expertos a partir de la abstracción de las realidades individuales o colectivas, Lefebvre señala una búsqueda del espacio físico y emocional producto de las vivencias y percepción de los individuos que lo usan, así como un espacio multifuncional construido no solo de significados particulares y colectivos, sino a la par espacios de interpretación por expertos urbanistas, arquitectos, diseñadores, etc. 
Por su parte Soja (2008: 39-40) interpreta al espacio como "un espacio urbano estudiado como un complejo de "prácticas espaciales" materializadas(...) el espacio urbano es percibido física y empíricamente como forma y procesos, como prácticas de la vida urbana(...) La especificidad espacial del urbanismo es investigada como un espacio enteramente vivido, un lugar simultáneamente real e imaginario, actual y virtual, lugar de experiencia y agencias estructuradas, individuales y colectivas", desde esta visión de espacio de Soja podemos hablar de una perspectiva integral de la cotidianeidad de las personas y sus espacios, no solo centrándonos en un espacio material, si no ahondar en las interpretaciones y representaciones que suceden y se tienen en él, el cual interesa analizar la espacialidad y comportamiento de los espacios en el entorno habitual de las personas.

No obstante, el espacio está conformado por una serie de elementos físicos, materiales, tangibles que le otorgan una vocación específica, tal como lo define el Colegio de Arquitectos de México el espacio público es un punto de encuentro y de expresión comunitaria que permite la cohesión social, que contiene áreas de servicio y uso común, como son: plazas, alamedas, áreas verdes, parques, jardines, espacios deportivos y culturales, calles, avenidas, camellones, bosques y lagos, entre otros". (elasuntourbano.mx, 2015).

De la idea de Borja sobre el espacio público como espacio de la representación ciudadana y la idea de espacio público desde la visión del Colegio de Arquitectos de México y las contribuciones del espacio de Lefebvre y Soja, el espacio público es un punto de encuentro común conformado por una serie de clasificaciones espaciales que en conjunto fungen como componentes articuladores de la ciudad, ya que estos espacios pueden identificarse y definirse por sus componentes urbanos o arquitectónicos que tienen en su estructura física.

Lynch (1985: 36-44) en su libro "La buena forma de la ciudad", postula que las distribuciones espaciales del entorno se ven plasmadas en mapas bidimensionales como; mapas topográficos, mapas que muestran la ocupación del terreno, planos de calles, planos de condiciones de viviendas etc. y que estos a su vez tienen una serie de 
indicadores que nos permiten visualizar e identificar capacidades o condiciones del espacio, facilitando la interpretación de los espacios según su clasificación espacial y su vocación, por otro lado tomando la idea de producción del espacio, Henry Lefebvre (2013:130) en su obra la producción del espacio nos habla sobre el espacio social, aquel espacio que conjuga diferentes dimensiones, que envuelve a las cosas producidas en un código unitario de un lenguaje común relativo a la ciudad, es decir, entre esta idea de Lynch sobre el ordenamiento del espacio plasmado de manera física tangible y representado de manera gráfica está la idea de Lefebvre quién nos habla de un espacio social, aquel construido a su vez con un lenguaje de la ciudad, un lenguaje relacionado con las formas que componen al espacio y su resultado como una producción de la sociedad según sus usos y apropiaciones, entendiendo como usos y apropiaciones a las clasificaciones espaciales que conforman al espacio público en las ciudades. Por su parte Soja considera que el espacio urbano puede ser apreciado de forma interna como un sistema espacial en sí mismo, pero a su vez un sistema externamente dentro de otro sistema más grande de espacios urbanos similares (Soja, 2008: 130), con base en esta consideración de Soja es como vemos representadas a las formas espaciales, como parte de un todo conjunto, en la que cada componente en que se distribuye el espacio tiene relación con un todo que conforma a la ciudad y sus espacios.

Es así como el espacio público puede constituirse de diversas formas según sus características/elementos que lo conforman (De los Santos 2017), y a su vez dividirse en diferentes clasificaciones que tengan un significado y valor tangible establecido por la sociedad y/o expertos en relación con los elementos que lo constituyen como lo propone Edgar De los Santos (Ver tabla C).

La información plasmada en la tabla $\mathrm{C}$ busca ser únicamente una breve guía general de como los espacios del entorno físico se pueden clasificar y estos a su vez subdividir en una especificidad concreta. 


\begin{tabular}{|c|c|c|c|}
\hline \multicolumn{4}{|c|}{ ELEMENTOS ESPACIALES-ESPACIO PÚBLICO } \\
\hline \multirow{4}{*}{ Elementos naturales } & $\begin{array}{l}\text {-Áreas de conservación } \\
\text { y preservación del } \\
\text { sistema orográfico }\end{array}$ & \multicolumn{2}{|c|}{$\begin{array}{l}\text {-Barrancas } \\
\text {-Montañas/cerros/Colinas } \\
\text {-Volcanes }\end{array}$} \\
\hline & $\begin{array}{l}\text {-Áreas de conservación } \\
\text { y preservación de } \\
\text { elementos hídricos. }\end{array}$ & $\begin{array}{l}\text {-Cuencas } \\
\text {-Playas }\end{array}$ & $\begin{array}{l}\text {--Manantiales } \\
\text {-Ríos/arroyos }\end{array}$ \\
\hline & $\begin{array}{l}\text {-Elementos artificiales } \\
\text { construidos. }\end{array}$ & \multicolumn{2}{|c|}{$\begin{array}{l}\text {-Canales de desagüe/ diques, represas } \\
\text {-Alcantarillas }\end{array}$} \\
\hline & $\begin{array}{l}\text {-Áreas de interés } \\
\text { ambiental-paisajístico. }\end{array}$ & \multicolumn{2}{|l|}{-Parques naturales } \\
\hline \multirow{2}{*}{$\begin{array}{l}\text { Elementos } \\
\text { constitutivos } \\
\text { artificiales } \\
\text { construido }\end{array}$} & $\begin{array}{l}\text { Áreas integrantes de } \\
\text { perfiles peatonales y } \\
\text { vehiculares. }\end{array}$ & $\begin{array}{l}\text {-Áreas de Zonas de } \\
\text { mobiliario urbano } \\
\text {-Señalización } \\
\text {-Bulevares }\end{array}$ & $\begin{array}{l}\text {-Ciclovías } \\
\text {-Estacionamientos }\end{array}$ \\
\hline & $\begin{array}{l}\text {-Áreas de encuentro } \\
\text { (Componentes de } \\
\text { cruces e intersecciones). }\end{array}$ & $\begin{array}{l}\text {-Parques urbanos } \\
\text {-Plazas }\end{array}$ & $\begin{array}{l}\text {-Túneles/viaductos } \\
\text {-Espacios } \\
\text { deportivos/culturales }\end{array}$ \\
\hline
\end{tabular}

Con base a lo analizado en los elementos morfológicos - arquitectónicos y de mobiliario, y a las clasificaciones espaciales del espacio público, se determinó seleccionar de manera concisa ciertos elementos a analizar como pilares para esta investigación, los cuales están relacionados con la idea de Lynch de que el medio físico tiene la cualidad de conferir significado e identidad a los espacios públicos en los paisajes y con ello generar una estructura en el espacio urbano de las ciudades (ver esquema 1). Dichas clasificaciones fueron seleccionadas con el criterio de establecer un parámetro de espacios y elementos que estuvieran relacionados con espacios públicos al aire libre, evocando aquellos espacios de la ciudad de los indios en los cuales las actividades de encuentro ciudadano se llevaban a cabo en espacios no techados (plazas públicas o ceremoniales, espacios deportivos), pero a su vez a los nuevos espacios configurados por los españoles en relación con las formas urbanísticas europeas (plaza, bulevares, parques, atrios de iglesias, centros deportivos). 


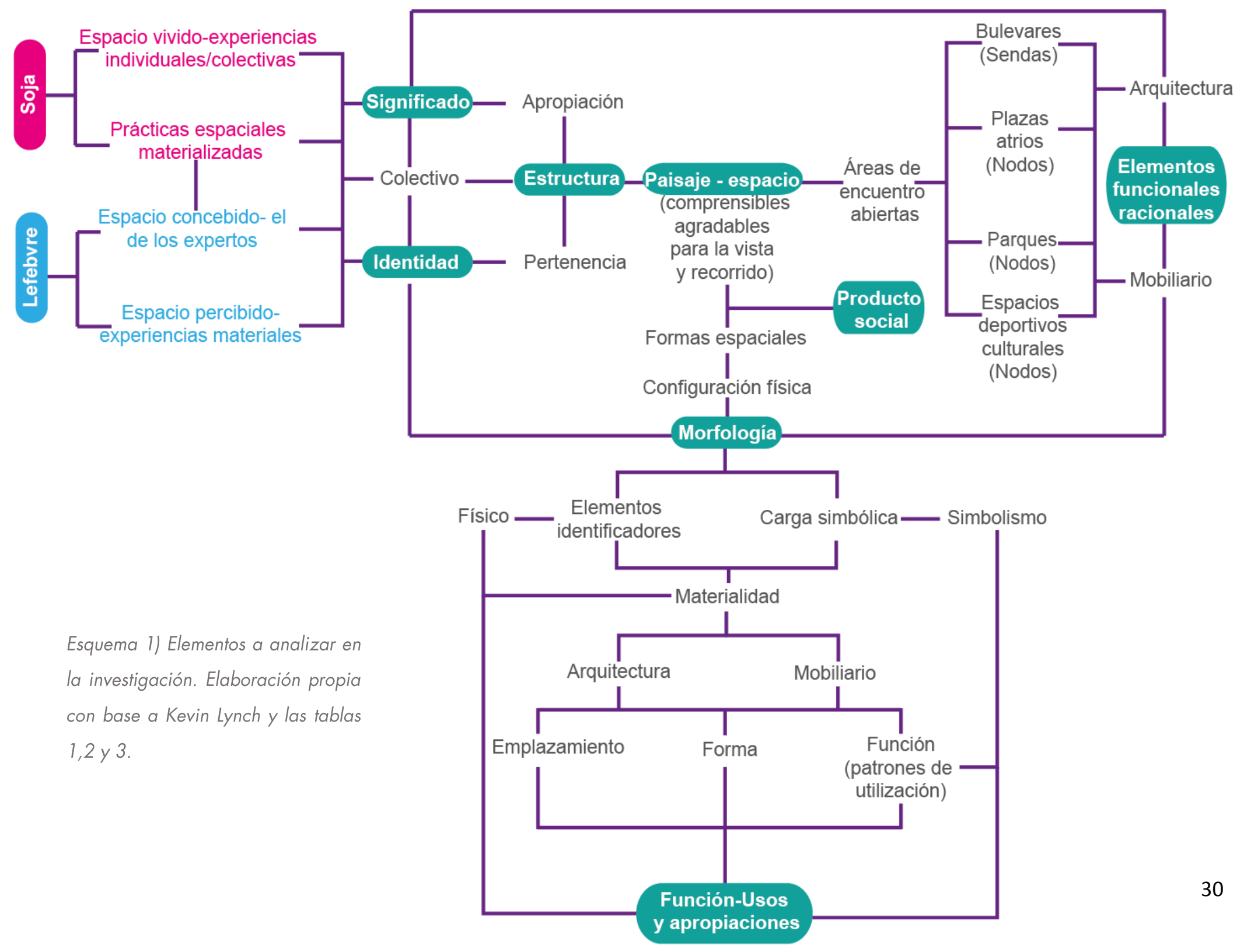




\subsubsection{El espacio público y su conformación a través de la historia}

Como se abordó en el apartado 1.2.2 el espacio público hace referencia a todo lugar abierto que permita el encuentro, mixtura social y el intercambio en diferentes escalas; social, cultural, política, una mezcla de emociones, pensamientos, una construcción simbólica pero también una herramienta que ofrecen las ciudades para que cada individuo ejecute diversidad de usos y apropiaciones. En los apartados previos se observa y analiza que el espacio público tiene elementos morfológicos (arquitectónicos y mobiliario) y elementos espaciales, en los que se encuentran los artificiales y construidos, como lo son las áreas de encuentro, tal es el caso de las Plazas públicas, las cuales aparecen en diversos libros de historia urbana como los primeros espacios públicos para las ciudades.

Las plazas públicas de las urbes y de cualquier poblado, juegan y han jugado un papel determinante donde la gente y los individuos hacen espacio público y ciudad, es decir, la plaza pública es un referente para locales y externos, ya que tiene una cualidad que la hace única en comparación con la calle u otros espacios abiertos, tiene la característica de ser un espacio que promueve y genera la inclusión o exclusión de los individuos o grupos sociales que convergen en su espacio físico.

Las plazas actúan como elementos articuladores espaciales, organizando todos los demás que convergen en ella. Las plazas son una parte dinámica de la estructura que determina la organización del espacio urbano en constante transformación. (Redondo, 2013:17)

Es pues así que la plaza pública juega un papel importante, si no es que fundamental como la primera forma de construcción del espacio público en la sociedad a través de la historia y hasta nuestros tiempos, puesto que permite la posibilidad de encuentros, interacciones en relación con otros espacios. Históricamente, la plaza en diferentes modelos de ciudad ha sido el eje rector determinante para el crecimiento y trazo de las 
metrópolis no solo por ser la sede del poder político y religioso, si no a su vez por ser el desarrollo más óptimo y sencillo de hacer debido a que permite la oferta de servicios y bienes de una manera más oportuna y beneficiosa en un espacio concentrado en el cual confluyen conexiones hacia otros espacios a través de redes de flujos económicos, viales, culturales, turísticos, etc.

No obstante, el espacio público va más allá

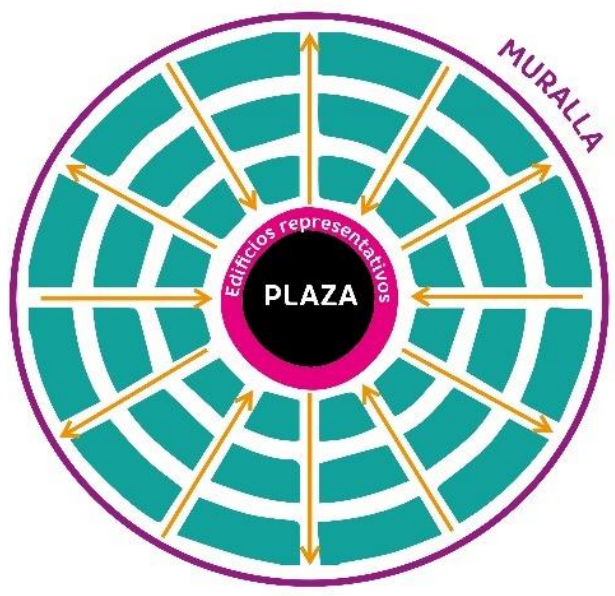

Ilustración 1) esquema de modelo radiocéntrico. Elaboración propia. de la plaza, también considera a otros espacios como lo son los jardines, atrios, parques, la calle, los bulevares, alamedas, paseos, por mencionar algunos y como se muestra en la Tabla C.

Desde las primeras formas de ciudad todas las ciudades se diferencian unas de otras, la polis griega no tiene nada que ver con la ciudad medieval, encontramos que la ciudad griega estableció como uno de sus criterios de modelo de ciudad la arquitectura, es por ello que para los griegos los monumentos eran elementos fundamentales en su conformación de ciudad, siendo el ágora (o plaza pública) el espacio que posibilitaba los encuentros de los ciudadanos y donde la colocación de sus edificios respondía a la localización según su función, con un crecimiento más bien orgánico sin ningún planteamiento estético (Redondo, 2013:19-20), la practicidad de situar a los edificios cercanos unos de otros en torno al ágora daba pie a una tipología meramente formal, por otro lado, para los romanos, su centralidad radicaba en el foro, ahí se integraban plazas, edificios colosales y espacios abiertos, y que a diferencia del ágora este espacio fue el que dio un aspecto más concreto a la forma de la plaza como un punto de centralidad en las ciudades.

La ciudad medieval respondía más a un modelo radiocéntrico (ver ilustración 1), donde las calles más importantes partían del interior y se extendían radialmente 
hasta las puertas del recinto en las murallas (Chueca,1968) además de que el mercado se situaba al centro en conjunto con los edificios más representativos como; el ayuntamiento y la catedral.

Sin embargo, por el crecimiento de la ciudad el mercado fue desplazado al extramuro y las calles se organizaron con relación al centro de la urbe, además que el concepto de patios que existía aplicado en los castillos fue retomado y trasladado a las ciudades (Redondo, 2013: 20-21), dando paso al nacimiento de las plazas, las cuales posteriormente formaron parte de un sistema del ensanchamiento de las calles pero, pese a esta finalidad otorgada, las plazas lograron mantener su carácter de significado de lugar para el encuentro y la permanencia entre los ciudadanos, y es gracias a este modelo radiocéntrico que la plaza se mantiene como ombligo principal para la ciudad, donde la vida pública y de calle gira en torno a ella.

En el Renacimiento los modelos y teorías de estructuración y forma de ciudad seguían manteniendo el predominio de la plaza como eje rector para el encuentro, tal es el caso de Vitrubio, en el que escritos realizados por él plasma a la ciudad con características de girar en torno a una centralidad, en el que se expresa una forma radiocéntrica rodeada por una muralla defensiva.

En los modelos desarrollados por León Bautista Alberti, Antonio Averlino II Filarete y Francesco de Giorgio Martini se visualiza una forma de estrella (ver ilustración 2) fortificada donde la centralidad se ve representada en una forma radial geométrica a partir de un espacio central abierto (la plaza central que fungía como espacio público y de encuentro ciudadano)(Redondo, 2013: 21), donde tres elementos principales dominaban al diseñar; el primero la calle principal rectilínea, los barrios basándose en un trazado reticular y los recintos

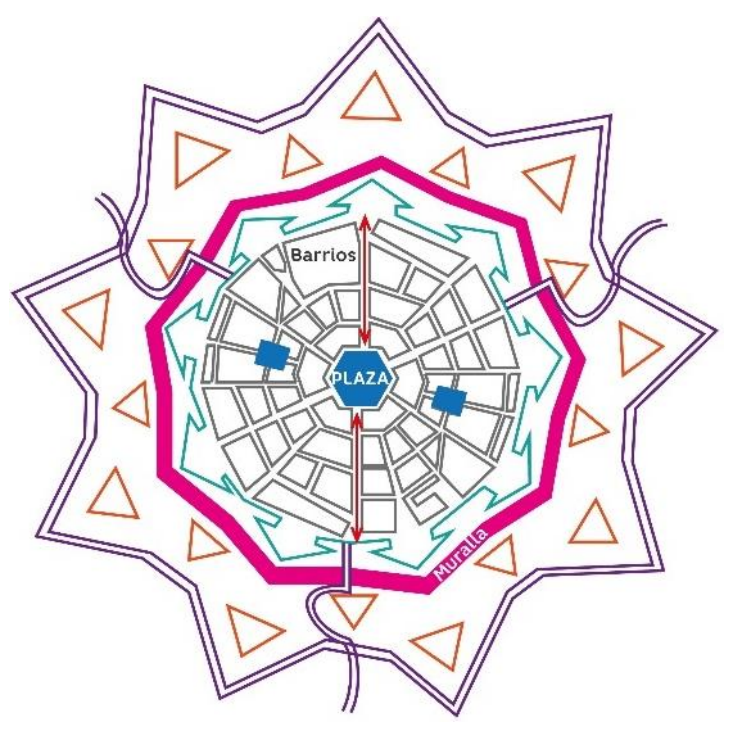

Ilustración 2) Ciudad medieval bajo el modelo radiocéntrico. Elaboración propia. 
espaciales (plazas). Aunado a ello la importancia de la simetría y el remate de perspectivas en edificios, así como el uso de estatuas en referencia con los edificios.

De esta manera en el período renacentista la plaza como eje articulador para la vida pública y encuentros sigue siendo una constante al verse plasmada en modelos donde juega un papel fundamental de centralidad, incluso llegando a inferirse que la plaza como espacio público tiene un rol primordial como punto de partida para la conformación de las ciudades porque es partir de su centro donde converge y se expanden las actividades de la sociedad como un lugar para la convivencia, dialogo, y de la ciudad misma para la cultura, la economía y la vida en sociedad.

Por otro lado en Hispanoamérica, el papel de las plazas como espacio público en la conformación y edificación de las ciudades, estuvo reguladas por las leyes de Indias de 1573 dictadas por Felipe II, estas leyes buscaron normar aspectos políticos, económicos y sociales de los pobladores y además, se establecía el trazo reticular basado en calles y manzanas, las orientaciones del trazado, la forma que debía seguir la Plaza Mayor, la muralla, y los elementos que la conformaban (Redondo, 2013: 23) Tal fue el caso de la ciudad de Guadalajara como capital del reino de la Nueva Galicia.

Ya en el siglo XVII y XVIII durante el barroco la ciudad medieval se caracterizaba principalmente por la importancia de lo pictórico, además de mantener el valor renacentista de la perspectiva donde tres aspectos eran dominantes: la línea recta, la perspectiva monumental y la uniformidad (Chueca,1968). El uso de las estatuas se relacionó en ocupar el centro de la plaza para un uso más dramático, puesto que este periodo busca exaltar las emociones y sentimientos y por consecuente exagerar la imagen de la ciudad. Es así como se puede connotar que la plaza durante el barroco buscaba enaltecer su espacio de centro cívico mediante diversas manifestaciones y usos pictóricos, esculturales y arquitectónicos.

Con la llegada de la Revolución Industrial hubo muchos cambios no solo económicos y sociales, sino que influyó también en las formas de construcción de 


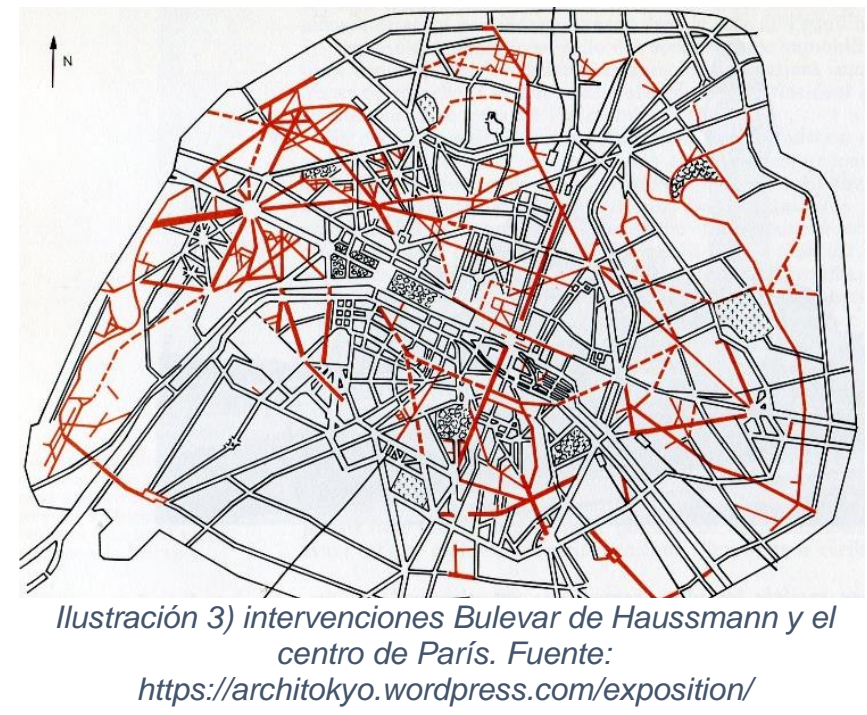

https://architokyo.wordpress.com/exposition/

las ciudades, es en esta etapa cuando se da inicio a un nuevo concepto de ciudad, surgiendo con ello una nueva concepción que posteriormente se convierte en un área de estudio: el urbanismo (Redondo,2013: 25-26). Es durante el desarrollo de la ciudad industrial donde el núcleo como centralidad se ve desbordado y sobrepasado, pues gracias a la oferta laboral y desarrollo traído por la industria comenzaron las migraciones y sobrepoblación de ciudades, lo cual ocasionó el desplazamiento de los individuos de las clases acomodadas hacia las periferias y con ello un fenómeno de degradación en las condiciones higiénicas.

Fue durante este periodo cuando la Plaza Mayor como eje central de la ciudad o espacio centralizador y comunitario pierde su carácter de elemento principal al ser sustituido por la calle como el componente más importante en la urbe y espacio de los encuentros y eventos espaciales, tal es el caso del Plan del Barón de Haussmann para París uno de los ejemplos más significativos de este nuevo modelo (ver ilustración 3), en el que se destacan las siguientes características; (Redondo, 2013: 28).

a) los espacios abiertos de la ciudad son el nuevo aire que precede a los hitos urbanos y edificios monumentales.

b) los nuevos espacios públicos son ahora las vías de tránsito, ya no es más la plaza pública, esto debido a que no es accesible para todos los ciudadanos.

c) los encuentros de vialidades son ahora los nuevos espacios para la colocación de algún monumento que actué como tensión visual.

d) toman gran importancia el parque y áreas arboladas con grandes avenidas. 
Es así como en la ciudad industrial la plaza pública era un elemento de ámbito principal de la ciudad y se ve difuminado y remplazado por las calles, las cuales se desempeñan como el nuevo espacio público, permitiendo con ello quizá una nueva dualidad de entendimiento del espacio, donde este se puede dar en cualquier espacio abierto siempre y cuando permita el libre acceso, movilización y encuentros de los ciudadanos mediante diversificación de actividades y manifestaciones.

1.2.6 Los jardines históricos como nuevas formas de espacio público

Como ya se mencionó, históricamente la plaza fue el primer espacio público abierto debido a su función de permitir el encuentro y la manifestación pública. Sin embargo, la historia de los espacios abiertos también se ve reflejada en la evolución de los jardines reales al rescatar un papel importante en la historia de los medios urbanos.

Rodríguez y Llandent en su libro "Zonas verdes y espacios libres en la ciudad" hacen un recuento histórico de los diferentes jardines históricos y su importancia hasta convertirse en espacios verdes abiertos (1982; 15-25).

Las primeras noticias que se tiene de los jardines son del contexto literario con el caso del Jardín del Génesis en el que se habla de la existencia de un lugar paradisiaco, un paraje natural verde. Por su parte el imperio persa es uno de los primeros jardines que se sabe de su existencia, estos jardines formaban parte de las viviendas y templos reales, su función se relacionaba con la regulación del microclima, es decir, una especie de pequeños Oasis en zonas desérticas.

Quizás uno de los jardines más famosos y referente urbano histórico son los Jardines colgantes de Babilonia en Mesopotamia, el rey mandó construirlos para su esposa dentro del palacio de Nabucodonosor y que debido a su majestuosidad y belleza fueron considerados una obra maestra de la arquitectura, razón por la que se encuentra dentro de las 7 maravillas del mundo antiguo.

Los egipcios por su parte también construyeron jardines que formaban parte de sus templos y conjuntos reales, en los cuales un elemento recurrente era el agua 
a través de la utilización de estanques rodeados de vegetaciones simétricas sencillas y separadas por alamedas rectas.

Estos tres primeros ejemplos de jardines nos hablan de la importancia que tenían las áreas verdes en el desarrollo del medio urbano, no obstante, dichos jardines eran de carácter privado para el disfrute de la nobleza o formaban parte del culto a la divinidad e incluso moderadores del microclima local.

Los jardines griegos tenían una composición más geométrica en la que predominaba un elemento de agua. Su uso estaba relacionado con un aspecto religioso al servicio del templo por los sacerdotes, donde probablemente en determinadas fechas o días de solemnidad se abrían al público.

Es por ello por lo que se puede considerar a Grecia como la primera región del mundo antiguo en que por primera ocasión los espacios verdes asumen una función pública al ser considerados como lugares de reunión, reflexión y conversación, dando paso al nacimiento del concepto de espacio público y las primeras aproximaciones de que los grandes espacios verdes propiedad de la nobleza pasarán a ser parte de los espacios abiertos al servicio de la comunidad.

En la edad media el jardín árabe era cerrado al exterior, ya que tenía como finalidad la intimidad y el aislamiento, los jardines tenían un carácter íntimo para cultivar el recreo de los sentidos mediante el uso del agua, por tal motivo se encontraban confinados dentro de los palacios. Uno de los jardines más representativos de estos Alcázares son los de la Alhambra en Granada España.

Tanto las viviendas reales como palacios y conventos tenían sus jardines, los ciudadanos disponían de estos espacios verdes indispensables para algunas celebraciones, aunque, los días de fiesta habitualmente la población se reunía en lugares situados extramuros.

Durante el renacimiento los grecorromanos mantenían una relación entre la arquitectura y los cánones estéticos que se veía reflejada en la jardinería debido a que se tenía la idea de la cualidad ordenadora de la naturaleza. 
Los jardines renacentistas eran una manifestación y reflejo de las costumbres y vida de la época, exigía vivir, producir asombro y ser una especie de espectáculo donde la composición del jardín se relacionaba con el derroche y grandiosidad. Uno de los jardines más representativos de este periodo fue el Versalles del Palacio de Versalles en Francia, los cuales durante el reinado de Luis XIV mandó abrir las rejas para el regocijo y goce del público parisino.

No es hasta el siglo XVIII que hay un cambio radical, a causa de que el jardín clásico comienza a transformarse en parque natural, la naturaleza se irá colocando en avenidas arboladas con trazado geométrico y es hasta el siglo XIX que por presión de la población se despierta la necesidad de más espacios verdes para el reposo y recreación de la ciudadanía, es así como nacen los parques con combinación de jardín clásico y jardín paisajista (Rodríguez,1982; 37-39).

Es durante este periodo que se produce una gran transformación y recuperación de parques privados antiguos de la nobleza y corte, donde paulatinamente pasar a ser propiedad pública para los ciudadanos.

Las ciudades comienzan a crecer fuera de las murallas, razón necesaria para generar propuestas y planes de ensanches con tendencia a exigencia de más espacios verdes que son imposibles de lograr dentro del casco histórico, y para ello se sitúan en las extensiones fuera de la muralla, un ejemplo muy claro de una propuesta de ensanche que tomaba como eje rector y articulador las áreas verdes es el plan de Cerdá para la ciudad de Barcelona, Cerdà aspiraba a una ciudad que, a pesar de haber arrebatado el terreno al campo, se articulase a través de calles anchas y espacios verdes (Ajuntament de Barcelona 2019).

A lo largo del siglo XIX se impone la función pública de los parques y áreas verdes como elementos que favorecen al saneamiento e higiene de las ciudades por la alta densificación de población que presentaban. A su vez, además de restaurar y transformar antiguos parques se van creando nuevos espacios verdes de propiedad municipal. 
Es así como los jardines históricamente tienen un gran peso e influencia en el desarrollo y vida de las personas, que bien, aunque inicialmente tenían un carácter privado y cumplía con funciones estéticas, reguladores del clima, ordenación y efectos en la psique, posteriormente se abrieron para el disfrute ciudadano, pasando a conformar y ser parte articuladora de ordenación del territorio en los planes urbanísticos posteriores, dotando de jardines, parques y alamedas a las ciudades, ya que los espacios verdes estaban altamente relacionados con valores higienistas y estéticos tal como lo plantea Ebenezar Howard en sus propuestas de la ciudad jardín o como ejes articuladores de las ciudades como lo propone Cerdá para Barcelona en los planes de ensanche de la ciudad catalana.

\subsubsection{Modelos de ciudad Latinoamericana y espacio público}

Sin embargo, dirigiendo los antecedentes hacia una perspectiva situada en América Latina (donde se encuentra ubicada la zona de estudio) y tomando como punto inicial al ser humano, que desde tiempos primitivos ha buscado consolidarse en grupos para la ejecución de actividades comunitarias para su supervivencia, lo que representan los primeros modelos de organización social del hombre, permitiendo el desarrollo y asentamiento de estructuras físico-territoriales como aldeas o villas para su establecimiento y ocupación en el territorio. Estas primeras formas de asentamientos fueron evolucionando a lo largo de la historia, consolidando posteriormente las primeras formas de ciudad en el territorio.

El desarrollo de los modelos de ciudad latinoamericana y su forma desde la perspectiva de Borsdorf puede dividirse en cuatro momentos

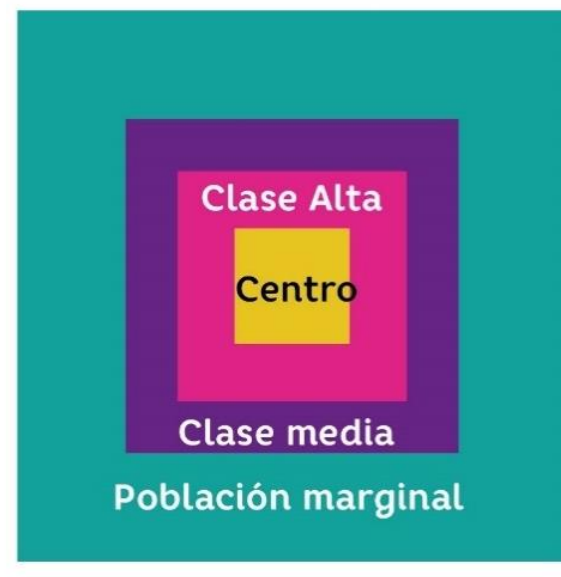

Ilustración 4) Estructura ciudad Colonial Fuente: (Borsdof, 2003) y elaboración propia. importantes; la ciudad colonial, la ciudad sectorial, la ciudad polarizada y la ciudad fragmentada (Borsdorf, 2003: 37-46) donde cada una de estas etapas significan elementos socioespaciales, económicos y elementos de desarrollo urbano. 


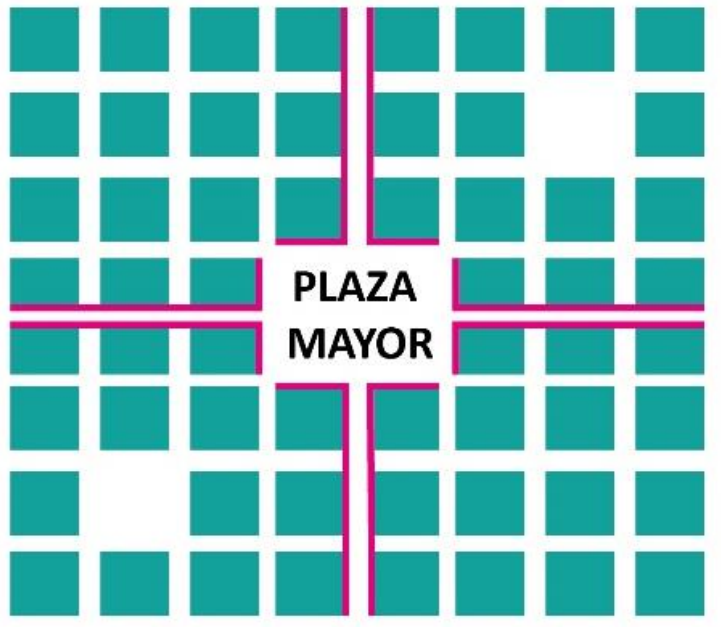

Ilustración 5) esquema de ciudad hispanoamericana. Elaboración propia

La ciudad colonial es aquella ciudad compacta, con una estructura social circular (ver ilustración 4), tiene una fuerte centralización y una gradiente social centro periferia, así como una estructura socio-espacial en círculos: en el centro se encontraba situada la Plaza Mayor, en el primer radio la aristocracia, en el segundo radio la clase media y en el último radio la población marginal-pobre. Una de sus condiciones básicas y dominantes fue su orientación hacia un solo centro (plaza) (ver ilustración 5). La Plaza Mayor o plaza de armas era la encargada de las actividades cívicas (núcleo de la vida social) y de encuentro como lugar de lo público (espacio público) además de fungir como clave para la estructura de la red de calles urbanas.

Este modelo de ciudad planteado por Borsdorf es un primer acercamiento al modelo fundacional de Guadalajara, porque al ser una ciudad fundada por españoles su estructura inicial corresponde a la radiocéntrica, donde la plaza es el punto principal de la estructura urbana y que a partir de ahí se traza la retícula de red de calles.

Por su parte, la ciudad posee una estructura lineal que evidencia el crecimiento de los sectores de la clase alta, orientándose hacia un bulevar principal y el progreso de las primeras zonas industriales. Este tipo de ciudad rompe con el esquema de la estructura circular, confluyendo la expansión lineal del centro que de ser un centro administrativo se convierte en un centro comercial (ver ilustración 6). 


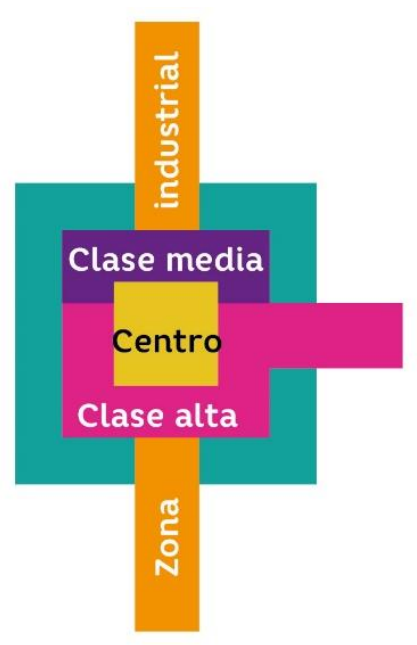

Ilustración 6) Estructura ciudad Sectorial. Fuente: (Borsdof, 2003) y elaboración propia.

Esta forma de urbanización de ciudad se ve fuertemente caracterizada por las modas urbanísticas del "bulevar francés" que era denominado alameda, paseo o prado, los cuales pretendían dar un espacio público a los habitantes de la ciudad para que pudiesen pasear, relacionarse y divertirse con otros.

Cabe señalar que entre los años 50 y 70 con la ciudad moderna se impulsa la producción en masa de viviendas en las periferias de las ciudades (Redondo, 2013: 30), posteriormente con la ciudad contemporánea surge un nuevo modelo basado en el interés por recuperar, conservar y rehabilitar los cascos históricos de la ciudad, en que la labor de los urbanistas se focalizaba en articular las periferias con el núcleo urbano.

Por otro lado, Guadalajara también formo parte de un proceso urbanístico que partió desde su centralidad (el casco histórico). En los 50 la plaza cívica como centro rompe su esquema a modo de espacio único para dar paso a una nueva formación de plazas centrales en representación de cruz (Cruz de plazas), pasando a una nueva transición de modernidad y por consiguiente nuevos y más amplios espacios públicos caminables dentro del centro histórico.

La ciudad polarizada es aquella donde la industrialización rápida alrededor de líneas ferroviarias y autopistas reforzó el crecimiento de algunos sectores. Los barrios de la clase baja y grupos marginales se expandieron hacia el centro por medio de estructuras de pasaje (vecindades), dando como resultante el nacimiento de barrios marginales periféricos, localizados y edificados no dentro del perímetro urbano, sino más bien en lotes aislados fuera de la ciudad. Sin embargo, los ricos se alejaban del centro de la ciudad en busca de barrios exclusivos con calles amplias y más áreas verdes. Gracias a este crecimiento de la ciudad fue como surgen los primeros centros comerciales y los primeros clubes de campo, los cuales implementaban la idea de un estilo de vida campestre dentro de la ciudad, 
recuperando de cierta manera las ideas de Baumeister, donde expone que debe existir una estrecha relación entre la naturaleza y el ser humano ya que esta es un elemento de consolidación de salud de los habitantes (Sánchez, 2008: 55-60).

La tipología expansionista de ciudad refleja un marcado contraste entre ciudad rica y una ciudad pobre que se fue intensificando por el crecimiento celular fuera del perímetro urbano, reflejo de la ciudad latinoamericana de los años 70-80 donde los flujos migratorios se dirigieron a las zonas centrales y desde ahí hacia los barrios marginales periféricos (Borsdorf, 2003: 37-46) (ver ilustración 7)

Esta forma de ciudad propicio segregación entre los grupos sociales, lo cual ocasionó espacios públicos inadecuados, mal diseñados o privatizados al volverse una ciudad cada vez más segregada que para poder acceder a espacios recreativos de calidad (como el mall o los clubes de campo) era necesario poseer cierto estatus económico.

Por último, la ciudad fragmentada tiene una tendencia sector-lineal y crecimiento celular. Lo que caracteriza principalmente a esta ciudad es que las zonas periféricas y periurbanas volvieron a ser atractivas para las clases medias y altas, elementos económicos y barrios habitacionales se dispersan y mezclan en espacios pequeños: urbanizaciones de lujo se comienzan a localizar en barrios pobres, el crecimiento de los centros comerciales "mall" se expande por toda la ciudad, los barrios pobres entran en los sectores de las clases altas, dando paso a un proceso de exclusión por medio de barreras y muros que aseguran que la pobreza no entre en la élite de la riqueza. Un elemento característico de esta ciudad son los barrios cerrados, esas urbanizaciones con departamentos o casas y con una infraestructura

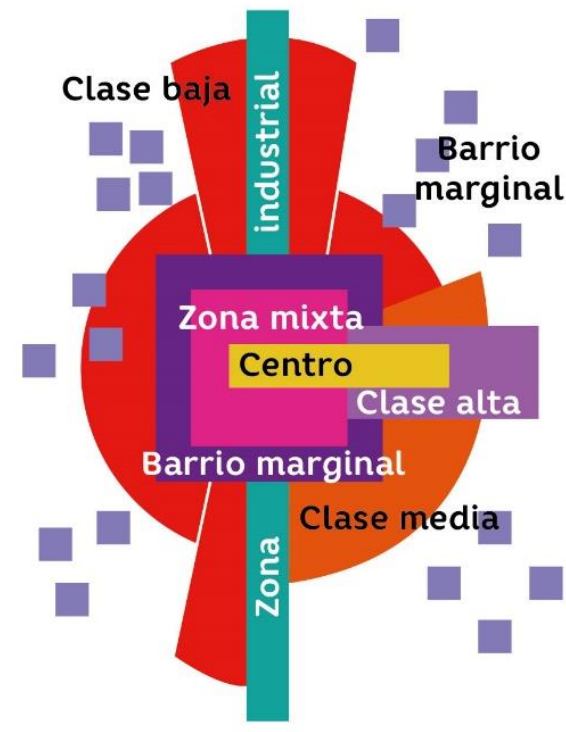

Ilustración 7) Estructura ciudad Polarizada. Fuente: (Borsdof, 2003) y elaboración propia 
común, cercados en sus alrededores y separados del espacio público por una barrera o puerta vigilada por cámaras de vídeo o seguridad.

En este modelo la fragmentación está representada por la localización de "malls" en toda la ciudad, autopistas intraurbanas y aeropuertos, presencia de barrios cerrados en el perímetro urbano y la periferia, los cuales se clasifican en: urbanos, suburbanos y gigantes (Borsdorf, 200; 45). Los barrios urbanos son urbanizaciones densas (casas o edificios) y sus habitantes pertenecen a una clase media-baja, los barrios cerrados suburbanos constituidos por edificios más amplios y equipados con amplias y extensas áreas verdes e infraestructura de lujo habitados por la clase media alta-alta y de los grandes barrios periféricos cerrados donde solo en algunas ciudades de Latinoamérica han sido registrados: Nordelta en Buenos Aires o Alphaville en Sao Paulo (Borsdorf, 2003: 37-46) (ver ilustración 8).

De este modo se crean zonas de inconexión que reducen los lugares de encuentro entre las personas y que además se ve marcado por las divisiones de clases sociales de la población, logrando con ello que los espacios públicos pierdan su vitalidad al estar dentro de barrios cerrados o dentro de centros comerciales.

La ciudad fragmentada ha afectado en las transformaciones de los espacios públicos como espacios de convivencia social, puesto que sugiere repensar la relación pública privada debido a la proliferación de fraccionamientos que han provocado el cerramiento y aislamiento (tanto en el interior de estos como en el exterior), incrementando así la exclusión social y de alguna manera el "secuestro" de los espacios públicos. Guadalajara no fue la excepción a este fenómeno porque en los años 90 como parte de la expansión de la ciudad y su zona metropolitana inicia la construcción de fraccionamientos campestres y en el 2000 comienza el boom de construcción de colonias residenciales caracterizadas por ser lugares cerrados, conjuntos aislados del contexto urbano como células independientes con sistemas de seguridad. 
En contraste, algo que permaneció de los modelos de ciudad anteriormente analizados fue la permanencia de la Plaza Mayor de la ciudad colonial como factor estructural fundamental de las ciudades, como elemento geométrico de vital importancia para la conformación de las nuevas ciudades hispanoamericanas, destacando su importancia como componente directriz para la generación de la traza y organización en torno a ella,

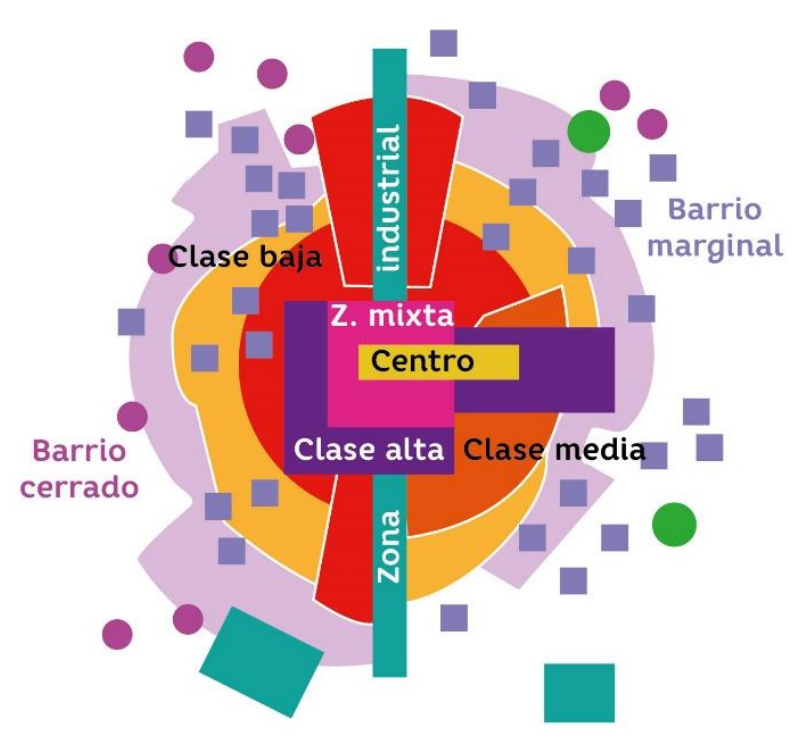
enfatizando su relevancia como punto de focalización para las actividades y funciones de la vida social, de poder, esparcimiento y recreación, así como la permanencia y ubicación de los edificios principales del poder y la iglesia alrededor de la misma debido a que ahí se llevaban a cabo todos los festejos y actividades relacionadas con el gobierno y la justicia lo cual otorgaba un carácter cívico para la población.

Ya para el siglo XIX se empiezan a gestar nuevos conceptos urbanos, tal es el caso de los famosos bulevares que plantea Borsdorf en la ciudad sectorial, esos elementos urbanos con forma de avenida ancha arbolada como parte de la morfología de la ciudad. Estas nuevas formas respondían a dos premisas; la primera se distribuye desde una calzada central y la segunda es donde se concebía alrededor de un paseo (Redondo, 2013: 29), un ejemplo de estos bulevares en Guadalajara fue la construcción del Parque Alameda en 1750 (actual Parque Morelos), que además de ser Alameda fue el primer paseo y jardín público de la ciudad, inclusive el primer caso donde las áreas verdes desempeñan el papel de espacio público. Otro caso en la ciudad fue el del paseo Lafayette (1899) en las Colonias, que funciono como un eje y espacio abierto para la recreación y paseo 
para quienes vivía cerca de ahí, y actualmente el camellón de la Calzada Independencia como "bulevar", ya que cruza por el centro de una de las avenidas principales de la ciudad, se encuentra arbolado y tiene algunos caminamientos que permiten el tránsito interno, además de permitir conectar la periferia con el centro de la urbe.

En el México del siglo XIX, la situación del proceso de urbanismo se vio marcada por la multiplicación de las plazas públicas y el comercio, además de que muchas de las festividades celebradas en la plaza mayor comenzaron a ser reubicadas y destinadas a plazas específicas, dotando de una especificidad a los espacios de las plazas, por lo cual, se le fue dando un nuevo carácter, imagen y uso, pero sin perder su sentido de espacio para el encuentro ciudadano como articulador de espacio público en las ciudades, por ende la forma de la plaza no se vio modificada totalmente, sino como expone Maruja Redondo en su artículo "Evolución de la plaza en la estructura urbana" (2006), a la plaza se le dio un mejoramiento en el aspecto estético y ornamental con la aplicación y uso de quioscos, jardineras, bancos de descanso y colocación de árboles suficientes para el disfrute y goce de la comunidad, contribuyendo con ello a que la plaza fuese un catalizador de espacio público en relación con la calidad del espacio urbano.

\subsection{8 Áreas verdes como espacio público}

Como abordamos al inicio del capítulo, podemos definir al espacio público como aquel espacio que permite la interpretación de diferentes formas al ser un escenario bifuncional que posibilita la adaptabilidad de las necesidades de las personas, des la posición de Lefebvre, es el espacio de las prácticas espaciales de lo cotidiano, en que cada individuo le otorga un significado (2013) y que desde una perspectiva ecológica, podemos considerar que existen factores de los espacios públicos que contribuyen a mejorar las condiciones ambientales de las ciudades. 
Teniendo en consideración la carta de Atenas $^{3}$ las áreas verdes tienen un papel importante en el desarrollo de las ciudades. Esta carta define una serie de exigencias indispensables para transformar al medio urbano y hacerlo más apto para la convivencia de las personas. Las áreas verdes figuran en esta carta al proclamar que el sol, el verdor y el espacio son las tres materias primas del urbanismo (Rodríguez y Llandent,1982; 48).

Unos de los aspectos más positivos de la carta en relación con las áreas verdes son:

1- Las zonas verdes como elementos reguladores del medio ambiente, su existencia es beneficiosa cuando es proyectada de manera racional, en especial contra la contaminación atmosférica, el ruido y el mantenimiento del equilibrio entre clima, suelo y vegetación.

2- Relación psicológica de los individuos, las áreas verdes influyen directamente en la psiquis del hombre.

3- Los espacios verdes constituyen un marco físico para las relaciones sociales.

4- Soporte de las actividades de recreo y descanso (aire libre).

5- Mejora de la imagen estética de la ciudad (imagen urbana)

Es con ello que la carta de Atenas es un primer referente de la importancia de los espacios públicos verdes, ya que las áreas verdes contribuyen a un desarrollo óptimo de la personalidad tanto física, psíquica y espiritual de las personas que viven en las ciudades.

Al retomar los postulados de la carta de Atenas, las áreas verdes como espacios para actividades de ocio y que mejoran la imagen de la ciudad así como las distribuciones espaciales del espacio público; elementos naturales (áreas de interés ambiental-paisajístico como parques naturales) y los componentes constitutivos artificiales construidos (áreas de encuentro como los parques urbanos)

\footnotetext{
${ }^{3}$ La carta de Atenas es un manifiesto urbanístico redactado en 1993 durante el Congreso Internacional de Arquitectura Moderna (CIAM) y que fue publicado en 1942 por Le Corbusier (Quaresma, 2019).
} 
las áreas verdes se encuentran dentro de las categorías de espacio público, ya que además de dotar de beneficios ambientales, psicológicos y sociales, proporcionan y proveen de espacios para el encuentro, el descanso, esparcimiento y la recreación.

Bajo las ideas de Castells en la cuestión urbana (2014), Borja y Muxi mencionan en espacio público ciudad y ciudadanía (2000), que el espacio público facilita la mixtura social, ya que:

"las formas espaciales pueden acentuar o modificar ciertos sistemas de comportamientos, por medio de la interacción de componentes sociales que combinan en ellas" Los medios urbanos específicos deben, por lo tanto, ser comprendidos en cuanto a productos sociales" (Castells, 2014; 133)

Al ser el espacio público un hábitat abierto permite una multiplicidad de relaciones, espacios de socialización, comunicación y combinación de las clases sociales.

Tal como menciona Borja y Muxi el espacio público supone dominio público, social colectivo y multifuncionalidad (Borja y Muxi, 2000; 28), puesto que es un lugar de identificación y relaciones de contacto entre personas, expresión comunitaria y animación urbana, es así como la mixtura social permite espacios públicos integradores, dado que son espacios híbridos/heterogéneos y se diferencian según su función social, cultural o simbólica, desde una perspectiva social las áreas verdes benefician la interacción, comunicación e incluso la construcción de una identidad.

Es a base de estos autores que en esta investigación plantemos la idea de que las áreas verdes además de brindar de servicios ecológicos y medioambientales son espacios públicos que propician la mixtura social, puesto que posibilitan la interacción de diversos componentes sociales para el cumplimiento de funciones de integración social. 


\subsubsection{Espacio público contemporáneo y los criterios que determinan un espacio público adecuado}

Nada es estático y todo está en constante cambio y evolución, el urbanismo no se encuentra exento de ello, por ello surgen nuevas propuestas de urbanismo para la planeación y construcción de las ciudades y sus espacios (públicos), tal es el caso del urbanismo P2P (peer to peer), diseño persona a persona o como el teórico urbanista Nikos A. Salingaros lo define, el urbanismo a escala de las personas. Este modelo de urbanismo propone sustituir los métodos tradicionales de diseño urbano que sigue reglas preestablecidas donde urbanistas, arquitectos, expertos o políticos son quienes tomas las decisiones de cómo hacer ciudad, considerándolos como los únicos agentes capaces para tomar las decisiones (Bauwens, 2010).

La propuesta de P2P se basa en construir ciudades, pero con una escala humana enfocada en la participación ciudadana y en 5 principios básicos: derecho a elegir el entorno en que se vivirá, la ciudadanía debe tener acceso a información relativa a ese entorno, derecho a participar e involucrarse en el diseño e incluso en su construcción física, responsabilidad de los practicantes del urbanismo P2P a generar y transferir el conocimiento de las prácticas y crear repositorios de conocimiento que permita mejorar dichas prácticas.

Otra propuesta es el Nuevo Urbanismo, que tiene un enfoque de planificación y desarrollo basado en los principios de cómo se han construido las ciudades en los últimos siglos: se centra en las calles y manzanas transitables, viviendas y tiendas cercanas y a espacios públicos accesibles. Este nuevo urbanismo también se enfoca principalmente en el diseño urbano a una escala humana (Congress for the New Urbanism, 2019). Es decir, consiste en involucrar a la ciudadanía en la planeación de sus entornos y promueve la restauración y creación de entornos y comunidades diversas, transitables, compactas, vibrantes y de uso mixto, así como la promoción y uso del transporte público por sobre el auto privado.

El Nuevo Urbanismo sigue una serie de principios (newurbanism.org, 2019): caminabilidad, conectividad, uso mixto y diversidad, vivienda mixta, arquitectura de 
calidad y diseño urbano, estructura tradicional de barrio, aumento de la densidad, transporte inteligente, sostenibilidad y calidad de vida

El espacio público tiene diversas dimensiones que van desde aspectos morfológicos, sociales y nuevas propuestas para su producción, lo cual en muchas ocasiones puede resultar impreciso o complejo determinar criterios para evaluar si un espacio público funciona o no funciona, sumando a ello la perspectiva de quién lo evalúa. Por ello, varios expertos en el tema han realizado y propuesto rubricas 0 indicadores de evaluación del espacio, tal es el caso de los indicadores propuesto por Project for Public Spaces (PPS). Proyectos para ¿QUÉ HACE A UN LUGAR EXCELENTE?

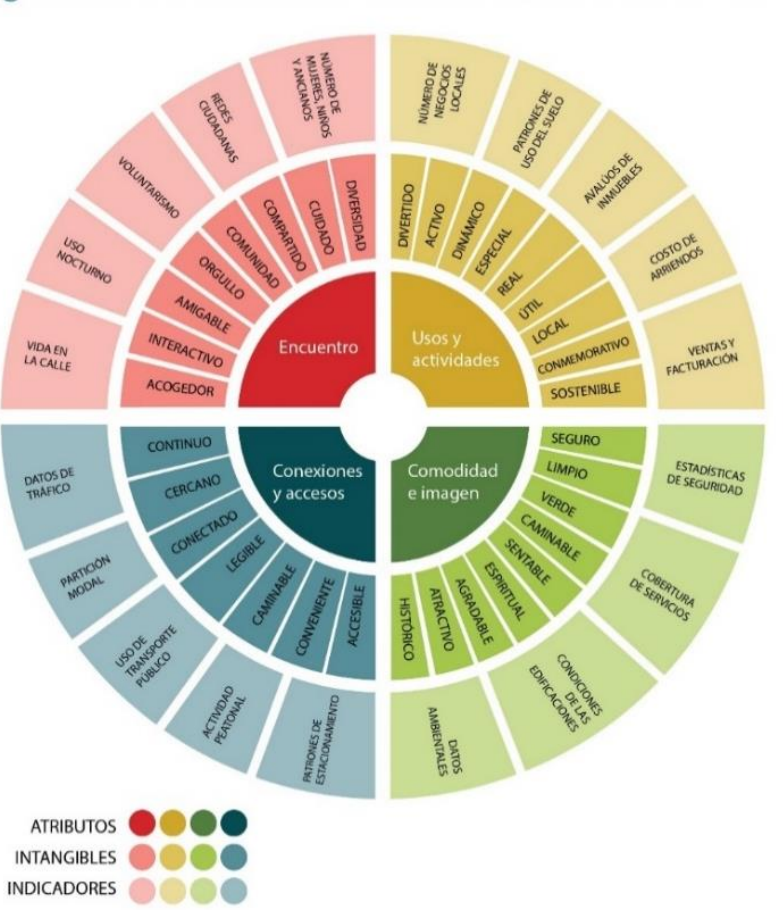
Espacios Públicos (por sus siglas en inglés) es una organización sin fines de Ilustración 9) Rubrica de indicadores para determinar qué criterios determinan a un buen espacio público. Fuente: PPS lucro dedicada a ayudar a las personas a producir y sostener espacios públicos para construir comunidades fuertes (PPS 2019). Con base en su experiencia y años de trabajo en diversas partes del mundo entre profesionales, ciudadanía y espacio público han elaborado unas variables para determinar cuáles son los criterios que determinan a un buen espacio público dentro de las ciudades.

Está rúbrica de variables está dividida en cuatro importantes factores (ilustración 9):

1-Accesible (Accesos y conexiones)

2-Usos y actividades
3-Comodidad e imagen

4-Sociabilidad 
1-Accesible (Accesos y conexiones).

Estás conexiones se relacionan tanto con el entorno visual como el físico, es decir, un espacio público es exitoso cuando es fácil de alcanzar, atravesarlo y es visible tanto de cerca como de lejos y debe tener una buena conexión con los edificios y su entorno.

\section{2- Usos y actividades.}

Si un espacio es atractivo en cuanto a tener algo que hacer para ir y venir a un lugar determinado es un indicador de que dicho espacio funciona. Para poder evaluar este criterio hay que tomar en cuenta algunos principios:

-Equilibrio entre hombres y mujeres.

-Personas de diferentes edades usando los espacios.

-El espacio se utiliza durante todo el día.

-Un espacio que se utiliza más en grupo, es decir hay mayor socialización y por ello es más interesante y divertido para las personas.

-Qué tipo de actividades se llevan a cabo.

-Qué partes del espacio se utilizan más y cuáles no.

3- Comodidad e imagen.

Esté indicador está relacionado con las percepciones de seguridad, limpieza y la disponibilidad de lugares para sentarse a descansar y observar. Para poder determinar la comodidad e imagen de un espacio es necesario observar si hay mujeres, hombres, niños, ancianos, si hay suficientes sitios para sentarse, hay opciones de sombras, la percepción de seguridad, la primera impresión que causa esté sitio, observar si las personas se hacen fotografías es en él.

4-Sociabilidad.

Se puede decir que un espacio cumple su función social cuando las personas se reúnen con sus amigos, conocen y saludad a sus vecinos o a otros individuos, se sienten 
cómodos interactuando con extraños o sienten un apego al espacio y su comunidad. Para este indicador es preciso observar si las personas van y se reúnen con más personas, si están solas o en grupo, si hablan entre ellos, si llevan a otras personas y hablan bien del lugar.

El estudio madrileño Paisaje Transversal basa su metodología de trabajo en lo que ellos llaman "la triple dimensión del espacio público" y los procesos de co-diseño (Paisaje Transversal, 2018). La triple dimensión consiste en alcanzar un nivel de calidad tanto ambiental y socioeconómico del espacio público cumpliendo con ciertos estándares para que eso suceda.

Para llegar a eso el estudio madrileño partió de diferentes teorías existentes sobre el espacio público y las sintetizo en tres sistemas que interrelacionados aseguran la calidad de los espacios que diseñan:

1- Accesibilidad y conectividad, es decir continuidad del espacio en relación con su entorno próximo y conexión con otros espacios de la ciudad en cuanto a seguridad y accesibilidad.

2- Confort e imagen, vela por criterios paisajísticos y que el diseño se adapte a necesidades climáticas, ecológicas y medioambientales.

3- Uso y gestión, esta dimensión refiere a las actividades y relaciones de los usuarios.

De acuerdo con estas tres dimensiones Paisaje Transversal define lo que ellos denominan un lugar, ya que en conjunto estas tres dimensiones ofrecen condicionantes necesarias que permean el conectar y acoger a las personas, actividades y elementos naturales.

Por otro parte, la Dra. Maritza A. Rangel en el artículo publicado "Indicadores de calidad de los espacios públicos urbanos para la vida cotidiana en ciudades intermedias" (Rangel, 2009: 5) de la Universidad de los Andes (ULA) argumenta que la calidad ambiental de las ciudades está ampliamente determinada por la capacidad de sus espacios para fomentar la vida pública de los ciudadanos tal como lo formula Borja en "El 
espacio público, ciudad y ciudadanía", razón importante para tener en cuenta al momento de medir el espacio público, ya que la calidad de un espacio se puede evaluar por la intensidad de las actividades y eficacia de las relaciones que se desarrollan en él y a la vez al promover o estimular identidades simbólicas e integración de las personas en relación con su espacio.

La Dra. Rangel determina tres grandes aspectos de carácter general que son referentes para la evaluación de la calidad ambiental ${ }^{4}$, ya que ella relaciona a la vida ciudadana una particularidad importante de la calidad ambiental urbana (Rangel, 2009: $6-8)$.

Los tres aspectos que ella enuncia son los siguientes (ver ilustración 10):

1- Físico Naturales

2- Urbano arquitectónicos

3- Socio-culturales

Los primeros se refieren a las condiciones climatológicas y orográficas de los espacios en correspondencia con la región en la que se encuentran situados, puesto que esto puede causar diferentes efectos sobre la sensación de confort y satisfacción de un espacio.

Los segundos se relaciona con las características morfológicas de los espacios, es decir sus características espaciales, funcionales, estéticas y de servicios, dado que estas pueden influir en los sentimientos de satisfacción o insatisfacción de las personas en torno al sitio (agente causal de bienestar psico-físico).

El tercer aspecto está vinculado con patrones culturales de respuesta a principios convencionales de convivencia entre lo individual y social.

\footnotetext{
${ }^{4}$ La Dra. Rangel determina que el concepto de "calidad ambiental" se sustenta en tres principios básicos: 1- La satisfacción de los habitantes y la participación de los individuos en las decisiones y conciliación entre intereses individuales y colectivo ambiental (Rangel, 2009: 6)
} 
Por su parte el Arq. Jan Gehl conocido por su trabajo en proyectos urbanos con escala humana, es defensor de la idea de poner las necesidades de la población que usa y vive las ciudades por delante de todo, él propone como necesaria la visión humana para el planeamiento urbano y además reforzar la función social del espacio público como lugar de

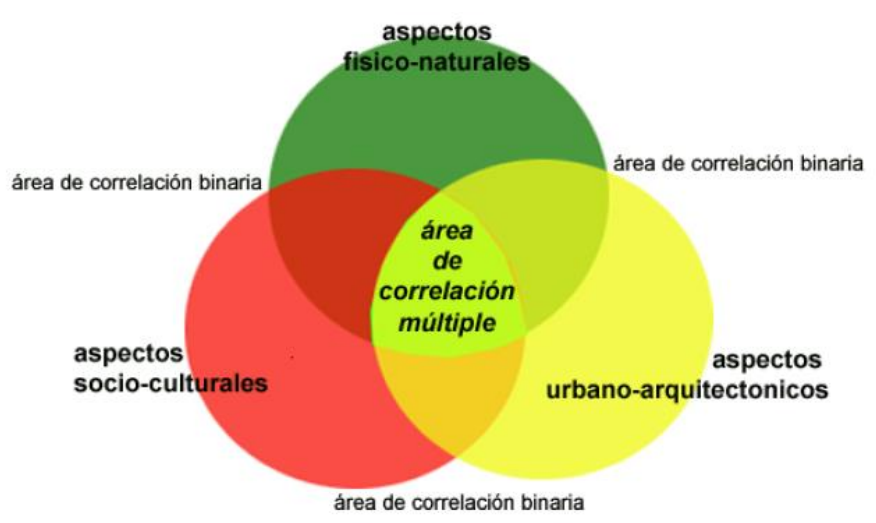

Ilustración 10) Elementos para la medición de la Calidad Ambiental Urbana. Mérida, Facultad de Arquitectura y Diseño de la Universidad de Los Andes. 2004

encuentro a razón de herramienta que permite promover y desarrollar una sociedad sostenible, abierta y democrática. (Gehl, 2014: 6).

A su vez este arquitecto recalca la importancia de tener y concebir espacios públicos ricos y variados en encuentros que ofrezcan propuestas de encuentros sociales y culturales diversos, para ello en su libro "How to study public life" propone una serie de pasos a considerar para determinar una evaluación del espacio público y determinar cómo es la vida que se desarrolla en dicho sitio, esto lo hace bajo la observación y la toma de datos de frecuencia de actividades, número de personas mujeres y hombres, formas de acceso al espacio, formas de desplazamiento a través de mapeos, fotografías o levantamientos de información.

Basándonos en lo que proponen y han trabajado Rangel, Gehl, PPS y Paisaje Transversal se ha elaborado una propuesta de tablas de variables para medir por medio de indicadores características cualitativas del espacio público, para esto se tomó como sustento las cuatro variables propuestas por PPS; sociabilidad, usos-actividades, conexiones-accesos y comodidad e imagen. De la triple dimensión propuesta por Paisaje Transversal se tomó como referencia; accesibilidad y conectividad, confort e imagen y uso y gestión. Estas tablas a su vez están basadas en dos de los aspectos propuestos por Rangel para determinar la calidad ambiental; físico natural (en relación con la 
sensación climática en correspondencia con las áreas verdes o arbolado), urbano arquitectónico y socio cultural.

Todo esto con la intención de ahondar en los diferentes aspectos del espacio público a través de preguntas y la construcción de indicadores de medición que faciliten concretar si un espacio público es exitoso.

1.3 Ciudadanía y participación ciudadana

Patricia Ramírez Kuri (2007) considera que las ciudades dan origen a la ciudadanía puesto que estas en proporción a las diferentes practicas sociales, económicas, políticas y culturales son manifestaciones de formas de pertenecer y participar en la sociedad. La ciudad insinúa al espacio social en que se ejecutan distintas maneras de poder, gobierno, civilidad, convivencia, cohesión, conflicto, en el que estas maneras transmiten discursos que se materializan con el entorno construido en concordancia con las practicas ciudadanas.

De acuerdo con la teoría social del siglo XX y los análisis sociológicos clásicos de Weber, Durkheim, Toennies y Parson se entiende por ciudadanía como el conjunto de prácticas sociales que definen el ser miembro de una sociedad diferenciada en la cultura y las instituciones, en que la solidaridad social se sustenta en valores universales.

Por otra parte la ciudadanía desde un enfoque sociológico contemporáneo conforme a los trabajos de Marshall y a como lo analiza Kuri la participación ciudadana se puede dividir en tres dimensiones, primera; la civil o legal que hace referencia a los derechos de propiedad, amparo y juicio individual, segunda; a una dimensión política como aquella que se desarrolla con la democracia institucional del sistema de partidos y órganos de gobierno y tercera; la dimensión social la cual incluye derechos laborales, seguros, servicios de salud y educación institucionalizados en un Estado de bienestar.

El concepto de ciudadanía no es un concepto uniforme, debido a que sus formas pueden corresponder y estar situadas a diversos contextos históricos, tradiciones sociales y culturales, por lo que estas distintas formas de ciudadanía pueden ser desde 
arriba o abajo o desarrollarse en el espacio público o espacio privado, de manera que la ciudadanía puede explorarse y abordase por medio de las diferentes regiones y Estados.

Kuri señala que de manera esquemática se puede plantear que la ciudadanía en México surge vinculada a la modernidad, a procesos políticos y sociales modernizadores, como una condición de estatus y membresía a la nación, un concepto ligado a un modelo de ciudadano educado, cívico y político.

Para Jordi Borja (2000) la ciudadanía se entiende como un estatus que reconoce los mismos derechos y deberes para todos los que viven y conviven en un mismo territorio con continuidad relacional, física y que ofrece diversidad de actividades.

En el Reglamento de participación ciudadana de Guadalajara el concepto de participación ciudadana se define como un principio fundamental en la organización política y social del municipio entendida como el derecho de los habitantes de Guadalajara para intervenir en las decisiones públicas, deliberar, discutir y cooperar con las entidades de gobierno e incidir en la formulación y ejecución y evaluación de políticas y actos de gobierno.

Olga Segovia (2007) en su texto "Gestión participativa de espacios públicos: tres experiencias" refiere a la participación ciudadana en los espacios públicos como el acto de involucrar a las personas para diseñar, construir estos espacios con los grupos que los usan ya que esto conlleva el generar vida social colectiva e identidad, lo cual contribuye a que la ciudadanía tenga incidencia en acciones y actores que mejoren su calidad de vida, alejando la inseguridad y desconfianza en la convivencia de los barrios puesto que interacción, sociabilidad y seguridad van conjuntamente. Enfatiza la importancia que los ciudadanos especialmente los de menores ingresos requieren de espacios que permitan y posibiliten integración, encuentro e interrelación social y a participar activamente en las decisiones que afectan la organización de su hábitat y calidad de sus espacios públicos, ya que el uso y apropiación de estos influye tanto en las dimensiones sociales, culturales y en las condiciones físicas vinculadas al tamaño, 
forma, coherencia, regularidad de lo construido y el conjunto de elementos o mobiliario que lo componen.

\subsubsection{Participación ciudadana como proceso de construcción del espacio público}

Según Jordi Borja y su conceptualización del espacio público este se puede valorar por su intensidad y calidad de las relaciones sociales que permite y facilita, así como por la capacidad de mezclar comportamientos y grupos (Borja, 2000:15) interpretando con ello que el espacio público es por excelencia el lugar para el ejercicio de la ciudadanía, no obstante el espacio público históricamente ha sido configurado y construido por expertos urbanistas, arquitectos e ingenieros, como muestra de esto se puede observar en las diferentes escuelas internacionales del estudio del paisaje como lo plantea Lynch en su libro "La morfología de las ciudades" expone que el paisaje urbano y su morfología debe incluir referencias a las diversas tradiciones nacionales que han existido (Lynch, 1985: 23-33), en las cuales las distribuciones espaciales y la descripción de las formas dieron como resultado cinco tradiciones de estudios morfológicos para la concepción y producción del espacio (Capel, 2002: 19-23) (ver Tabla D)

Como se observa en la tabla $\mathrm{D}$, el espacio público desde concepciones historicistas ha sido estudiado por expertos, los cuales definieron y elaboraron parámetros para su producción y construcción. Retomando la idea de Capel (2002: 19-23) que el paisaje se puede usar para comprender y abordar aspectos para cuestionar los elementos del espacio en relación con la sociedad que los produce e interpreta en la estructura morfológica del espacio, podríamos hablar de una estrecha relación entre espacio, espacio público y paisaje, ya que el segundo está constituido por el primero y tercero, donde el paisaje brinda significados e identidades al espacio y entornos y en el que el paisaje se constituye por los espacios públicos por medio de las interpretaciones de las personas cuando los usan, dando como consecuente una estructura que se constituye por los elementos urbanos y simbólicos de dichos espacios públicos. 


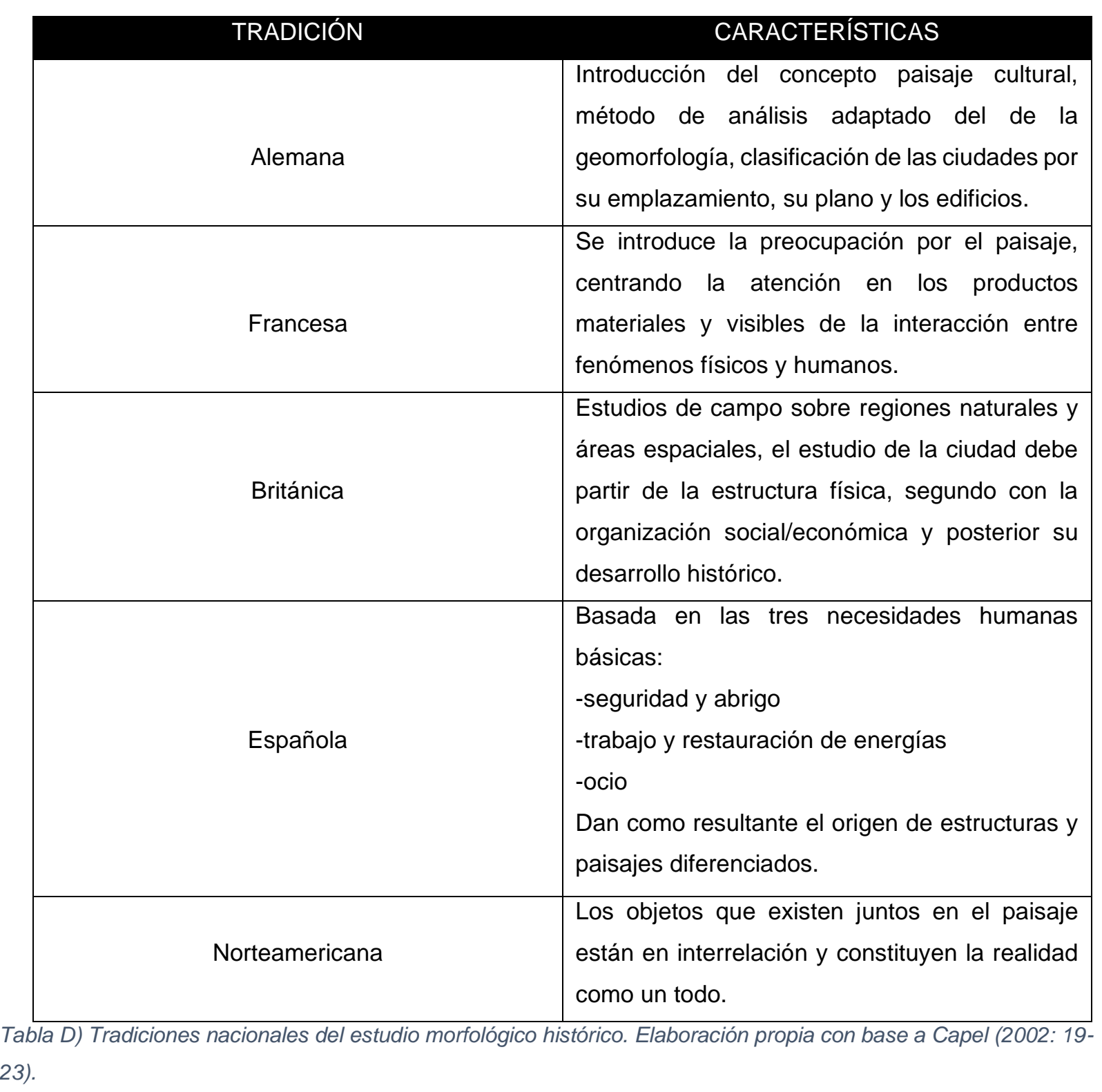

Sin embargo, como argumenta Borja acerca de la importancia del espacio público como sitio de encuentro y manifestación de la ciudadanía es que el espacio debería entenderse como un ejercicio de producción de la ciudadanía, ya que es ella quién lo utiliza, lo dinamiza y le da vida. Como alude Lefebvre, el espacio es una construcción social, y al ser una construcción social responde a la obra de una colectividad, por lo cual enfocando al espacio con relación a los espacios públicos (puesto que este forma parte de ellos) responde a una práctica espacial de conjuntos espaciales propios de cada formación social, que se puede interpretar como que cada grupo de individuos sociales 
tienen necesidades y características diferentes unos de otros, por lo cual los expertos del espacio y espacios públicos deben tener un acercamiento con la ciudadanía para poder empaparse del conocimiento de todas esas prácticas y apropiaciones del espacio y con ello generar y proponer espacios que tengan un sentido para las personas que lo habitan y usan.

No obstante Soja (2008: 39) en su primer concepto de espacio, el de las prácticas espaciales materializadas que tiene como función reproducir las formas concretas y patrones del urbanismo, hace énfasis en la interpretación de la espacialidad urbana, aludiendo la manera en que la ciudadanía percibe y vive sus espacios, sin embargo, estos espacios son espacios que fueron gestionados y producidos por profesionales expertos, por lo que la interpretación y vivencia del espacio para las personas está estrechamente ligada con la percepción que tienen estos profesionales en correspondencia con el espacio, induciendo quizá a usar y utilizar de cierta forma los espacios a los individuos usuarios y provocando con ello desinterés o poca identidad con el espacio en cuestión dando como resultante espacios abandonados o en desuso.

Borja en su texto "Revolución urbana y derechos ciudadanos" nos presenta a la ciudad con una recurrente practica de arquitectura urbanicida, donde se vende a la ciudad al mejor postor, en la que el urbanismo prioriza el proyecto sobre el plan, el proyecto arquitectónico sustituye en muchos casos al urbanístico y en que el promotor inmobiliario y el arquitecto imponen sus intereses (Borja, 2012: 42).

A partir de las opiniones de estos autores que recalcan la percepción de las personas en relación con sus espacios de la cotidianeidad, y el planteamiento de Borja sobre el interés privado antes del bien público colectivo, es necesario empezar a crear mecanismos que involucren a los ciudadanos en la toma de decisiones y la producción de sus espacios y espacios públicos, teniendo como puntos de oportunidad los proyectos y gestión de los espacios y equipamientos como una forma de producir ciudadanía y desarrollo de la misma, haciéndolos partícipes en estos procesos para dotar de un valor agregado al espacio. Es importante involucrar la participación ciudadana, ya que es 
confiar en el capital creativo de quienes se involucran, estimulando y propiciando a tener una mejor relación de sentido de apropiación y pertenencia del espacio público.

\subsubsection{Aspiraciones sociales y la necesidad de las interacciones en el espacio} público

Algunos espacios de las ciudades son espacios con un alto valor de significación por las dinámicas y actividades que producen dentro de su contexto, ya sea por sus características económicas, culturales o de sus flujos dentro de un espacio con una actividad especifica o no especifica, en realidad lo relevante de los espacios no son sus denominaciones si no las oportunidades de uso que se producen en él.

Por una parte, Jordi Borja considera que el espacio público es la ciudad:

La historia de la ciudad es la de su espacio público. Las relaciones entre los habitantes y entre el poder y la ciudadanía se materializan, se expresan en la conformación de las calles, las plazas, los parques, los lugares de encuentro ciudadano, en los monumentos. La ciudad entendida como sistema, de redes o de conjunto de elementos - tanto si son calles y plazas como si son infraestructuras de comunicación (estaciones de trenes y autobuses), áreas comerciales, equipamientos culturales es decir espacios de uso colectivos debido a la apropiación progresiva de la gente - que permiten el paseo y el encuentro, que ordenan cada zona de la ciudad y le dan sentido, que son el ámbito físico de la expresión colectiva y de la diversidad social y cultural. Es decir que el espacio público es a un tiempo el espacio principal del urbanismo, de la cultura urbana y de la ciudadanía. Es un espacio físico, simbólico y político (Borja, 2000: 8)

La idea anterior permite entender que la ciudad son sus ciudadanos, puesto que son ellos quienes animan y dan vida a los espacios en las urbes, es a partir de las dinámicas e interacciones que realizan lo que le da un carácter social a partir de sus usos, 
apropiaciones y aspiraciones sociales en la que el espacio deja de ser un componente estático para convertirse en un mecanismo vivo.

Con base a que el espacio permite interacciones sociales Jan Gehl, arquitecto danés estudioso de las personas y sus relaciones y comportamientos en las ciudades manifiesta que en los espacios públicos hay una relación de necesidad de contactos entre los individuos (Gehl, 2013: 23), estas relaciones de contacto las clasifica según su nivel de intensidad (ver tabla E).

\begin{tabular}{|l|l|l|}
\hline \multicolumn{4}{|c|}{ RELACIONES DE CONTACTO } \\
\hline \multicolumn{1}{|c|}{ INTENSIDAD } & \multicolumn{1}{|c|}{ INTENSIDAD } \\
ALTA & \multicolumn{1}{c|}{ MEDIA } & \multicolumn{1}{c|}{ INTENSIDAD BAJA } \\
\hline -Amigos íntimos & -Conocidos & -Contactos pasivos (ver-oír) \\
& -Contactos & -Contactos a un nivel modesto \\
& casuales & $\begin{array}{l}\text {-Posible punto de partida para contactos a otros niveles } \\
\text {-Posibilidad de mantener contactos ya establecidos }\end{array}$ \\
& & $\begin{array}{l}\text {-Fuente de información sobre el mundo social externo } \\
\text { Fuente de inspiración u oferta de experiencia } \\
\text { estimulante. }\end{array}$ \\
\hline
\end{tabular}

Tabla E) Relaciones de contactos en el espacio urbano. Elaboración propia con Base a Gehl (2013: 23).

Las interacciones sociales que mayormente predominan en los espacios públicos son las relacionadas con ver y oír, contactos pasivos que no requieren un trato directo, ya que desde una simple caminata los sentidos del oído y la vista están activos, permitiendo cruzar de manera fugaz o momentánea sonidos y elementos visuales, como manifiesta Gehl la vida entre los edificios el estar con más personas, el oír, verlas, el recibir un estímulo de ellas constituye experiencias positivas, debido a que el espacio público nos permite ese deseo aspiracional de querer estar en contacto con otros, esto debido a que no hay nada más interesante para las personas que mirar a otras personas, establecer ya sea interacciones directas o indirectas con otros individuos.

A su vez Gehl propone tres tipos de actividades exteriores (ver tabla F). 


\begin{tabular}{|c|c|c|}
\hline \multicolumn{3}{|c|}{ ACTIVIDADES EXTERIORES } \\
\hline NECESARIAS & OPCIONALES & SOCIALES \\
\hline $\begin{array}{l}\text { Actividades obligatorias: } \\
\text {-Ir a la escuela/trabajo } \\
\text {-Compras } \\
\text {-Esperar el autobús o a } \\
\text { alguien, etc. }\end{array}$ & $\begin{array}{l}\text { Aquellas que se realizan si se } \\
\text { tiene el deseo de hacerlo o si } \\
\text { el tiempo y lugar lo permiten: } \\
\text {-Dar un paseo } \\
\text {-Pasar el rato } \\
\text {-Tomar aire, ver el paisaje } \\
\text {-Actividades recreativas, etc }\end{array}$ & $\begin{array}{l}\text { Aquellas que dependen de la } \\
\text { presencia de otras personas } \\
\text { en los espacios: públicos. } \\
\text {-Saludos } \\
\text {-Juegos infantiles } \\
\text {-Conversaciones, etc. }\end{array}$ \\
\hline
\end{tabular}

Tabla F), Actividades exteriores en la ciudad. Elaboración propia con Base a Gehl (2013: 23).

"En esta mezcla de actividades realizadas en el exterior influyen una serie de condiciones. El entorno físico es una de ellas: un factor que impacta en las actividades en diversas medidas y de diferentes maneras" (Gehl, 2013: 17).

De acuerdo a estas ideas de las formas de utilización, interacción y aspiración de uso de los espacios en las ciudades, se justifica que el espacio público es un elemento estructural de la vida de las personas en las ciudades, por lo cual si los espacios públicos son de poca calidad, solo las actividades estrictamente necesarias serán realizadas y el nivel de interacción de los individuos será mínimo y furtivo (ver y oír a los otros), en contra parte, si los espacios exteriores tienen características y elementos (urbanoarquitectónicos) que faciliten y mejoren la experiencia de los usuarios, las interacciones sociales serán mejores y positivas, por lo cual sus aspiraciones sociales se intensificaran, obteniendo como resultado el deseo de querer pasar mayor tiempo y temporalidad en los espacios públicos.

\subsection{Preguntas de investigación}

¿Por qué los espacios públicos periféricos se perciben como espacios menos relevantes que los espacios públicos centrales de la ciudad?

¿Cómo fueron conformándose los espacios públicos de Guadalajara en relación con el crecimiento de la ciudad y su traza urbana? 
¿Qué elementos de la construcción del espacio social, son visibles en la concepción material del espacio público?

Objetivo principal.

1.5 Objetivos

Estudiar el espacio público en el centro y periferia de Guadalajara para comprender cuáles son los elementos o configurantes morfológicos, materiales, físicos y simbólicos que han permitido su producción, lo anterior mediante el estudio de los procesos de crecimiento de la ciudad y en específico la estructuración de espacios públicos y su relación con la expansión de la metrópoli. El estudio abarcará la fundación de Guadalajara y la producción de espacios públicos periféricos.

Objetivos específicos.

- Explicar la importancia de los espacios públicos periféricos en relación con la centralidad de las ciudades.

- Describir el crecimiento de la ciudad de Guadalajara, desde su centro hasta su periferia norte en relación con la producción física material de sus espacios públicos.

- Analizar la sociabilidad, comodidad, imagen, accesibilidad, actividades y usos de la ciudadanía en los espacios públicos.

\subsection{Estado de la cuestión del arte}

Acorde con la clasificación de espacio público planteada para el desarrollo de la investigación y con base a los autores analizados con anterioridad, se plantean como grandes ejes de investigación lo referente a la participación ciudadana y al espacio público (ver esquema $A$ ). 


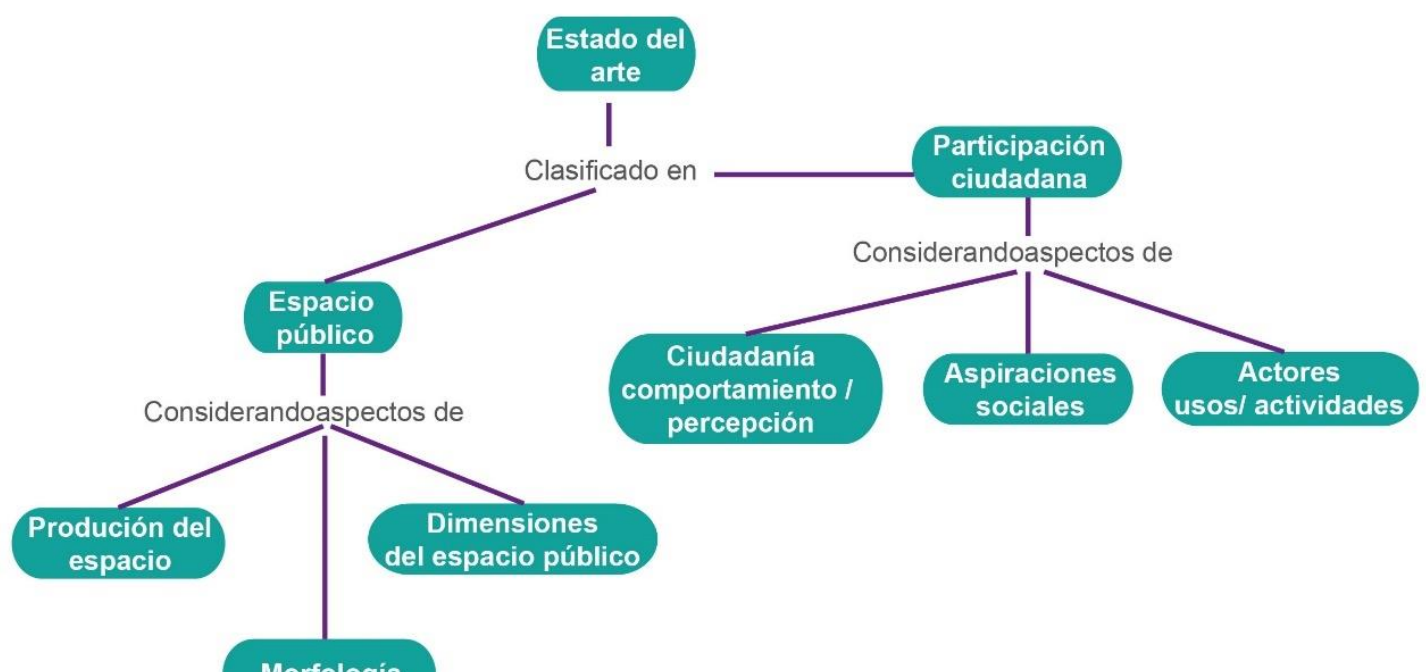

Morfologia

Esquema A) Categorías analizadas en el estado de la cuestión del arte. Elaboración propia.

Los autores y trabajos revisados previamente se centran en el estudio del espacio público y la participación ciudadana, ya que analizan y plantean formas de producir el espacio público, tal es el caso de Lefebvre y Soja con sus trialécticas de la producción del espacio, así como los antecedentes de Borja (2000) y sus aportes a la ciudad en su trabajo "El espacio público, ciudad y ciudadanía".

El punto de vista de Jane Jacobs sobre la percepción ciudadana de los espacios públicos y sus fuertes críticas respecto a la forma en que se planean las ciudades, haciendo énfasis en producir espacios basados en las necesidades de la población y no diseñados desde las oficinas por expertos que no tienen noción de la zona a trabajar.

Dentro de la bibliografía se analizaron textos sobre espacios públicos y construcción social, participación ciudadana y formas de apropiación del espacio público, entre ellos Kuri, Muxi, Borja que analizan las actividades que se generan dentro de estos espacios.

En los nuevos planteamientos se analizan textos de Jan Gehl sobre las formas de hacer espacio público y cómo estudiar el espacio público para producir ciudades con escala humana, así como textos referentes a el nuevo urbanismo, urbanismo peer to peer 
o los del urbanismo social presentados por Project for Public Spaces organización sin fines de lucro enfocada a ayudar a las personas a producir y sostener espacios públicos.

En trabajos de relevancia académica están los elaborados por Manuel López Moreno en su libro la cuadrícula en el cual hace un recuento histórico de la forma de crecimiento de la ciudad de Guadalajara (2011), el trabajo de investigación de Christian O. Grimaldo (2018) sobre la barranca de Huentitán en el que realiza una descripción significativa sobre la materialidad, las apropiaciones e imaginarios urbanos de esa bella área natural de Guadalajara, así como textos elaborados por el departamentos de Ciencias y Artes para el Diseño de la Universidad Autónoma Metropolitana donde se presentan varias opiniones de diversos investigadores sobre los estudios urbanos en el espacio público.

\subsection{Planteamiento metodológico y corrientes del pensamiento que se enfocan en los espacios y las personas.} El presente trabajo de investigación es principalmente de carácter descriptivo, ese es su origen y esencia. Para la construcción de esta investigación el planteamiento metodológico sigue las corrientes de pensamiento enfocadas en ver la sociedad, el entorno y su evolución en el contexto territorial.

1.7.1 Geografía humanista

La geografía humanista surge en los años 70, está basada en teorías existencialistas $^{5}$ y en la fenomenología de Edmund Husserl ${ }^{6}$, surge con una visión que destaca los aspectos humanos a partir de los significados, intenciones, propósitos, valores y principios del humano, es decir, una suma de un conocimiento empático a través de la experiencia vivida. La geografía humana es la ciencia de la organización espacial de las actividades humanas y de las relaciones entre la sociedad y su entorno, esta se ocupa de los espacios y los patrones de interacción social, las ideas que tenemos de

\footnotetext{
${ }^{5}$ El existencialismo se centra en el análisis de la condición humana, las emociones, significados de la vida, la libertad y responsabilidad individual.

${ }^{6}$ Fenomenología significa el estudio del fenómeno e implica la descripción de las cosas como las experimentamos.
} 
otras regiones y el significado que pueden tener lugares simbólicos (Institue of Geography, 2021).

De acuerdo como lo analiza Jesús Gonzales (2003) la geografía humanista mira el entorno, ve el lugar y a las personas, como viven en una serie de localizaciones, tienen experiencias vitales significativas, el interés de los espacios ocupados por la experiencia, es decir, se hace referencia a la experiencia como algo que no puede estar separado del mundo externo, lo que resulta interesante para el caso de estudio de los espacios públicos del centro de Guadalajara y la periferia de Huentitán por las experiencias de las personas de vivir en la ciudad y en mi caso particular por ser habitante de la periferia de Guadalajara.

Como reflexionan Santis y Ganga (2004) de los estudios de Ronald J. Johnston la geografía humanista ve y trata a las personas como individuos que obran constante y recíprocamente con el ambiente, el medio, con ellos mismos y el entorno que esta cambiando, señala también que considera como la gente interpreta y se relaciona con el mundo.

La geografía humanista centra parte de sus estudios en preguntas como: ¿Cómo la gente comprende sus mundos y los significados que ellos dan a lugares, cosas y sucesos en la superficie terrestre? ¿Qué existe?

Para responder este tipo de preguntas la metodología de la geografía humanista se centra en involucrarse para entender y comprender cómo la gente ve su mundo, no asumir que cada ser humano es igual a otro, sino encontrar la diferencia entre los individuos y los significados que cada uno le da, demostrar que es importante entender a los seres humanos (personas), su entorno y cómo se conectan con él y así establecer cómo se comportan en ciertos espacios, es decir, la geografía humanista se interesa en el cómo las personas interpretan y se relacionan con su entorno. 


\subsubsection{Geografía de la percepción}

Dentro de la geografía humanista surgen nuevos planteamientos para el análisis del territorio, tal es el caso de la geografía de la percepción y el comportamiento (Yago 2012). Esta geografía propone una visión que recoge las experiencias personales de los ciudadanos por medio de sus sensaciones, emociones y preferencias, encaminando a una visión interior de esa misma realidad, pero hacia el espacio vivido y subjetivo.

Los geógrafos humanistas señalan que la utilización del espacio no está únicamente condicionada por factores sociales y económicos, naciendo con ello la geografía del comportamiento y la percepción, influenciada por otras disciplinas como la psicología o sociología las cuales dan paso a abrir el pensamiento existencialista y fenomenológico y en consecuente la aparición de imágenes mentales que apoyan e indican los caminos que usamos para movernos/ desplazarnos, los espacios que frecuentamos y los sentimientos en relación con el territorio

Conforme el autor, las personas almacenamos imágenes que después se convierten en mapas mentales que compartimos con otras personas, pero centrándose en el análisis de lo subjetivo, para ello las principales técnicas que usa esta geografía son: la encuesta, el mapa mental, la entrevista, el análisis complementario de fuentes de datos.

\subsubsection{Etnografía Urbana}

La investigadora Claudina Peralta (2009) describe de manera general a la etnografía como una rama de la antropología que se enfoca a la observación y descripción de los diversos aspectos de una cultura, pueblo determinado o comunidad. Dentro de su concepto retoma la idea de Duranti en la que afirma " la etnografía es la descripción escrita de la organización social de las actividades, los recursos simbólicos y materiales, y las practicas interpretativas que caracterizan a un grupo particular de individuos", es decir, define a la etnografía como un método de investigación que permite interactuar con una comunidad específica para conocer y registrar datos de esa comunidad como; organización, cultura, costumbres, saberes, intereses, entre otros. Ella 
señala que para llevar a cabo la práctica etnográfica el investigador debe prepararse para vincularse a la comunidad que desea investigar y conocer, para ello será necesario acercarse al grupo y permitir que la personas también se acerquen, observar, conversar, registrar, hacerse amigo o miembro del grupo.

Juan Luis Álvarez Gayou (2003) en su libro "Como hacer investigación cualitativa" aborda a la etnografía como una interpretación y descripción de un grupo o de un sistema social o cultural y refiriendo a los estudios de Wolcott se le considera como una manera de mirar en el que el propósito de la investigación se enfoca en describir lo que las personas de un sitio o contexto determinado hacen habitualmente explicando los significados que le atribuyen a ese comportamiento. Para poder llevar a cabo el estudio etnográfico se requiere un estudio prolongado del grupo comúnmente a través de la observación participante, este tipo de observación consiste en que el investigador está inmerso en las actividades cotidianas del grupo o realiza entrevistas con los miembros.

Kathrin Wildner (2004) pone en manifiesto la importancia de la etnología urbana en relación con el espacio urbano en el sentido de que se deben conocer las interrogantes sobre los procesos sociales al momento de proyectar ciudades, organización social, significación simbólica, indagar sobre las cuestiones del espacio urbano a un nivel local por medio de distintas técnicas de métodos cualitativos:

- Paseos de observación y cartografía, propone la figura del flâneur de Walter Benjamin como el caminante que deambula para describir la vida cotidiana.

- Observación participante y entrevistas.

- Análisis situacional.

- Mapas cognitivos.

- Puntos de observación. 


\subsection{Propuesta del método a utilizar: variables e indicadores a aplicar en los}

espacios públicos

Para el trabajo de esta investigación se utilizarán métodos empleados por la geografía humanista, la geografía de la percepción y el comportamiento y la etnografía urbana para analizar la producción de los espacios públicos del centro y periferia de Guadalajara, la obtención de datos para su análisis será a través de; análisis situacional, puntos de observación, encuestas, paseos de observación, cartografía, fuentes documentales.

A su vez se elaboraron 2 herramientas de trabajo (ver anexos):

1- Tablas de Variables basadas en 4 aspectos: sociabilidad, usos y actividades, comodidad e imagen, accesos y conexiones.

2- Encuesta que abarca los 4 aspectos de PPS y que considera los aspectos propuestos por la Dra. Rangel: Físico natural, urbano arquitectónicos, socioculturales.

Estas herramientas ayudarán a la investigación a determinar la forma de producción de los espacios que serán estudiados, si responden a una vertiente basada en las ideas de producción de los autores clásicos como Lefebvre o, a formas de producción que reconoce a nuevas ideas del urbanismo con autores como Gehl y los nuevos modelos que hacen referencia a formas de producción de los espacios públicos con un carácter más simbólico y de apropiación más allá de sus características físicas.

Con el uso de los instrumentos antes descritos y el resultado de los mismos, se aportará a la investigación en la manera de producción de los espacios centrales y periféricos en la actualidad, la cual contribuirá a determinar el carácter de producción de la zona centro y la periferia, si responden a criterios de diseño de valor físico del entorno como espacio cívico y de orden social o si por el contrario responden más a un valor simbólico ciudadano de uso del territorio y de apropiación, o en todo caso, si es una mezcla de ambos criterios, o incluso si de acuerdo a sus características físicas y simbólicas ambos espacios podrían ser considerados como centralidades para la ciudad y por consiguiente podrían existir más espacios que pueden formar una red de nodos de centralidades. 
Las tablas y encuestas serán aplicadas en los espacios públicos periféricos (Parque Mirador y Parque Natural de Huentitán) en el periodo de una hora por la mañana y por la tarde un fin de semana y dos días entre semana para medir y comparar las frecuencias de usos y tiempos de los espacios públicos de estas áreas verdes. El tamaño de la muestra para las encuestas será de 50 personas para el Parque Natural de Huentitán y 50 para el Parque Mirador Independencia en un rango de edad mayor a 15 años, debido a que, en esta etapa de vida (adolescencia) en adelante se tiene una percepción más crítica del entorno en el que se desarrollan y desenvuelven los individuos puesto que es el período del bachillerato (preparatoria) previo a ingresar a la universidad e iniciar la juventud.

Sin embargo, para los espacios centrales solo se aplicarán las tablas 3) comodidad e imagen y 4) conexiones y accesos, debido a que estas tablas están relacionadas con aspectos del entorno visual y es necesario su análisis cualitativo para determinar si los espacios son de fácil acceso y visibilidad en correspondencia con los demás elementos espaciales, y también, conocer la percepción de seguridad, limpieza y disponibilidad de lugares para sentarse a descansar y observar.

Las tablas 1) sociabilidad, 2) usos y actividades y la encuesta no serán aplicadas a la Cruz de Plazas ni Parque Morelos, puesto que la vocación de los espacios públicos centrales desde sus orígenes fue la de espacios para el encuentro cívico, además de que ya se han realizado rigurosas investigaciones y publicaciones previas sobre los usos y actividades de estos espacios, aunado a ello que su uso de suelo no ha sido cambiado para proyectos de índole privado y de segregación social como ha sucedido en los parques de la periferia norte puesto que estos espacios centrales son sitios de tránsito abierto y nodos conectores de la ciudad en términos de poder, económicos, culturales, sociales, turísticos y de movilidad. 


\section{Conclusiones capítulo 1}

Lo planteado en este primer capítulo deja una idea introductoria acerca de qué es espacio, como un sitio físico geográfico, su diferenciación con el espacio público como un espacio del territorio que sirve de punto de reunión entre diversos actores, de libre acceso y que permite la diversificación de actividades. El espacio público tiene condicionantes de formas, es decir la morfología vista desde un punto de estudio y análisis de la producción, modificación o transformaciones de su estructura urbana y los elementos que lo componen; 1-arquitectónicos, todo el entorno construido que envuelve los espacios y que Lynch hace una clasificación de ellos; las sendas como todo aquel espacio que permite al flâneur o caminante andar, el borde como los limites o rupturas de la continuidad que pueden ser edificios, muros, cruces, los hitos como puntos de referencia como edificios, monumentos, esculturas, rotondas etc. nodos aquellos puntos estratégicos de la ciudad, de convergencia, confluencia o de estructura de tránsito y finalmente, el barrio que son secciones de las urbes reconocidas por poseer un carácter que los hace identificables. 2-mobiliario urbano, "el diablo está en los detalles" debido a que estos elementos urbanos dotan de un valor a los espacios urbanos de acuerdo a la clasificación a la que pertenezcan, puesto que no es lo mismo el uso y función de un elemento de ambientación (jardineras) a uno de contemplación y descanso (como las bancas) uno de recreación (juegos o aparatos de ejercicio), y que dependiendo de en donde se encuentran situados y dispuestos son un orientador para que las personas puedan tener una buena o mala experiencia en el espacio público.

No se puede dejar de lado los elementos espaciales de los espacios públicos, la estructura de estos es compleja al constituirse tanto de elementos naturales: áreas de conservación y preservación o áreas de interés paisajístico: parques naturales. En contraparte tenemos todos aquellos elementos constituidos de manera artificial como pueden ser áreas de encuentro con los parques urbanos, plazas, espacios deportivos 0 culturales.

Todos los elementos físicos materiales que envuelven al espacio público tienen una función y son una pieza clave y fundamental para dotar de significado e identidad el 
medio físico de los espacios público como lo plantea Lynch, ya que el espacio público necesita de estos elementos para el goce y disfrute de las personas, ser un apoyo para la realización y ejecución de distintas actividades, el espacio público confiere tener elementos que facilite la realización de acciones y encuentros por parte de la ciudadanía.

Cuando se piensa en espacio público no se puede solo tener una imagen mental de plazas públicas, que, si bien estas históricamente fueron el primer espacio público reconocido, las áreas verdes también fueron y son espacios públicos para las ciudades, puesto que estas son de gran valor desde una perspectiva del entorno físico natural y a su vez de importancia psicosocial, medioambiental, de paisaje e imagen urbana para las urbes. Por ello por medio de la carta de Atenas (1993) es que se plasma un primer referente del papel tan importante que tienen los espacios públicos que son áreas verdes porque además de contribuir al desarrollo psicosocial estos espacios proveen a las ciudades sitios para el esparcimiento, recreación, encuentro y descanso y que incluso cuentan con elementos arquitectónicos y de mobiliario urbano para mejorar la experiencia de las personas.

Desde las ideas de Lefebvre y Soja de producción del espacio y aterrizándolo a la perspectiva de espacio público desde la teoría y estudio de Borja en el que para él además de ser un entorno físico constituido por distintos factores es que se plantea que el espacio público es el lugar por excelencia para el ejercicio de la ciudadanía, sin embargo para poder haber llegado hasta este punto evidentemente hubo corrientes 0 escuelas a lo largo de la historia que se enfocaron al estudio morfológico de las ciudades: alemana, francesa, británica, española y norteamericana, cada una hizo sus aportaciones de las cuales podemos rescatar lo siguiente; de la tradición alemana el concepto de paisaje cultural, tradición francesa centrar su atención en el resultado visible material, la tradición británica el estudio de la ciudad a través de su estructura física y social, de la tradición española que se basaba en tres necesidades humanas donde el ocio se contempla como un punto importante para las personas en las ciudades y por último la tradición norteamericana en la que todo está interrelacionado. Estas tradiciones del estudio morfológico de las ciudades deja en claro que históricamente el estudio y 
producción de las ciudades y sus espacios y espacios público es algo que solo confiere a los estudiosos y expertos en el tema, pero sin embargo es necesaria una relación con la sociedad que los produce e interpreta desde su perspectiva y formas de producción individuales y de su realidad, experiencias y medios construidos para otorgar un valor a ese medio físico como un sitio para la manifestación y encuentro y ser realmente un espacio de construcción social como lo llega a plantear Lefebvre o como lo interpreta Soja, de prácticas espaciales que se materializan.

Otro punto importante de la producción del espacio público son las relaciones sociales y los tipos de interacciones sociales y relaciones de contacto que se generan que van desde actividades necesarias, opcionales y sociales, y que dependiendo de la calidad de los espacios públicos (los elementos físicos con los que posea) será el equivalente del mayor número de personas a querer estar ahí de acuerdo con la siguiente relación; a mejor espacios públicos más ganas de permanecer y realizar actividades en él, espacios públicos deplorables y sin atractivos menos interés. De acuerdo con esto nos lleva a precisar que son necesarios criterios que determinen si un espacio es un buen espacio de acuerdo con indicadores de accesibilidad, comodidad/imagen, usos/actividades y sociabilidad, es decir, existe una relación en la que mejor y buena conexión de un espacio público para poder acceder a él en sistemas de trasporte público, caminando y que este a la par conectado con otros espacios, en que este espacio se perciba como un lugar agradable, seguro, limpio, que invite a hacer algo ahí o que exista una programación del espacio con dinámicas varias y en el que las personas de distintos grupos de edades se reúnen y congregan para convivir y que incluso recomienden a otros a acudir, podemos determinar que un espacio público es exitoso. 


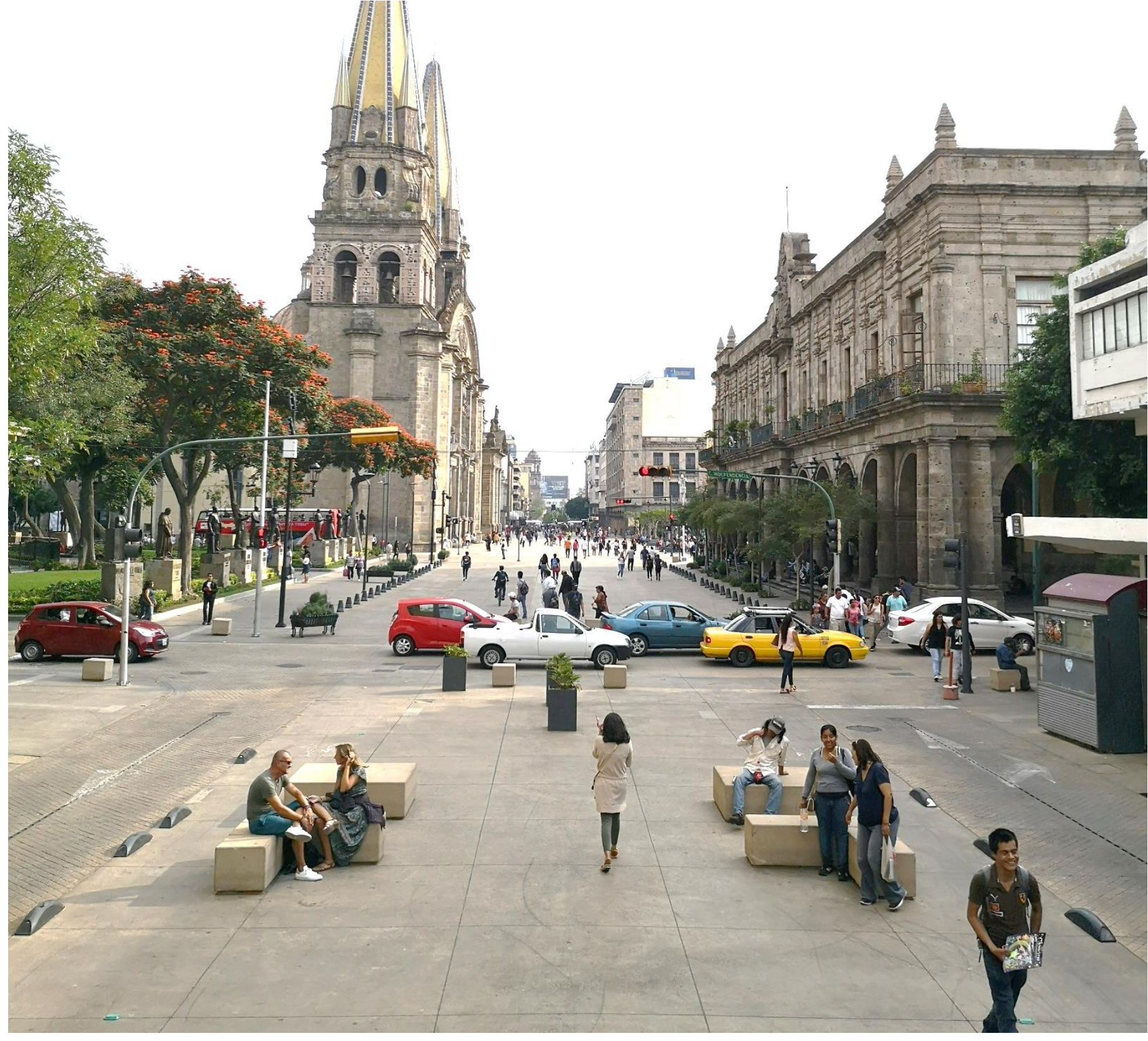

Un domingo en Paseo Alcalde con vista hacia la Catedral de Guadalajara. Enero 2020. Fuente propia.

CAPÍTULO 2. Guadalajara, espacio público y su estructura urbana. 
"Una ciudad la configuran personas, dentro de las fronteras de las posibilidades que esto ofrece $y$, por tanto, tiene una identidad distintiva, que consiste en mucho más que una aglomeración de edificios".

Deyan Sudjic

Guadalajara es la capital del estado de Jalisco, mejor conocida como la Perla Tapatía, característica por el tequila, su mariachi, la birria, tortas ahogadas, las icónicas torres de su catedral y las chivas de Guadalajara, es y ha sido desde sus inicios una ciudad en constante movimiento y cambio urbano desde su fundación, su morfología urbano-arquitectónica ha pasado por varias transiciones de influencias arquitectónicas. En sus inicios fundacionales la ciudad estaba sustentada principalmente en un cuadro en damero que permitió el desarrollo de una traza cuadricular como forma principal de su organización en la que el espacio público ha formado parte de su estructura urbana. A su vez Guadalajara ha pasado por diversas metamorfosis y evoluciones históricas debido a que en un inicio su fundación fue complicada y nada certera, antes de asentarse en el Valle de Atemajac actual ubicación y donde desarrollo su crecimiento, paso por tres anteriores fundaciones.

Guadalajara es una ciudad ubicada en la parte central del estado de Jalisco, está conurbada con los municipios de Zapopan, Tlaquepaque, Tonalá, Tlajomulco de Zúñiga, El Salto, Juanacatlán e Ixtlahuacán de los Membrillos. De acuerdo con datos del Instituto Nacional de Estadística y Geografía (INEGI) conforme al Censo de Población y Vivienda 2010, el Área Metropolitana de Guadalajara tiene 4.434.878 de habitantes, es decir en una superficie de $2.734 \mathrm{~km} 2$, esta cantidad arroja una densidad poblacional de 1,622 habitantes por km2, siendo Guadalajara el municipio más poblado con cerca de 1.5 millones de tapatíos (Gob. Del Edo. De Jalisco, 2018) y el eje rector y corazón de la Zona Metropolitana de Guadalajara.

En la actualidad esta urbe tiene la categoría de metrópolis por el número de sus habitantes, sin embargo, la Perla Tapatía desde su fundación se posicionó como ciudad fundacional y capital de la Nueva Galicia, debido a que se proyectó para ser un centro de trabajo, tener un gobierno que obedeciera a la corona española, una traza determinada 
por las Leyes de Indias y ser conector con otras ciudades españolas de la Colonia en México, tal como señala Borja y Muxi en Espacio público ciudad y ciudadanía $(2000,27)$ se puede describir que el espacio público de Guadalajara en su fundación tuvo su origen desde una dimensión jurídica, porque se sometía a una regulación específica por parte de la administración propietaria (en este caso los reyes católicos) quienes poseían la facultad de dominio sobre el suelo para garantizar la accesibilidad y condiciones de utilización.

Dejando de lado la dimensión jurídica fundacional de Guadalajara, esta ciudad tiene una gran identidad nacional que vive en la construcción social del mexicano, empezando por la palabra "Tapatío", que hace referencia a aquellas personas que viven en la ciudad, diversos investigadores coinciden que la palabra tapatío tiene su origen en el vocablo tlapatiotl (utilizado por los indios en el valle de Atemajac para designar una unidad monetaria y comercial equivalente a tres), esta palabra se fue transformando en su uso debido a que en Guadalajara todo se vendía en grupos de tres (bientapatios.blogspot 2018), por esto y más razones como las características torres de la catedral, su peculiar oferta gastronómica (la birria, las tortas ahogadas y el tequila) hacen de Guadalajara una ciudad vibrante, no solo por su gente, su clima cálido, su cocina y su riqueza patrimonial arquitectónica de diferentes estilos, si no por ser una ciudad que ha pasado por diversas transformaciones y modernizaciones morfológicas para llegar a ser la ciudad que es en la actualidad.

\subsection{Guadalajara, del virreinato a las leyes de Reforma. La configuración espacial homogénea primaria de la ciudad (1542-1896)}

La primera de sus fundaciones fue el 3 de diciembre de 1531 por orden y mandato de Nuño de Guzmán, Nuño expidió un comunicado a Juan de Oñate en el que le daba instrucciones de fundar una Villa de inmediato en los terrenos de Nochistlán. Fue así como Oñate se traslada a Nochistlán y el 5 de enero de 1532 funda dicha Villa con el nombre de Guadalajara en honor al poblado Guadalajara en España de donde era 
originario Nuño (García, 1992, 15-35). La fundación de Guadalajara en Nochistlán fue para constituirla como lugar para celebrar las reuniones de cabildo y la morada de Oñate.

El trazo de la villa no pasaba de las 16 manzanas, tenía una disposición de calles (todas rectas y sin empedrar) de norte a sur y otras tantas de oriente a poniente, la calle de en medio estaba destinada como la principal debido a que pasaba por la plaza y el solar de obras públicas. Cada manzana contenía 4 casas grandes, existía una plaza de gran tamaño y alrededor de ella las principales construcciones; al poniente la iglesia de San Pedro, al Sur la manzana entera fue destinada para la morada de Nuño de Guzmán, al Oriente se localizaba la morada de Oñate y en el norte el solar de obras públicas (ver mapa 1).

En mayo de 1533 Nuño de Guzmán llega a Guadalajara con el motivo de reunir a los alcaldes ordinarios y vecinos de la villa y tratar juntos la suerte de la población, fue que el 19 de mayo de ese mismo año la votación quedo con 19 pobladores a favor del cambio y 4 en contra. Es a partir de este consenso que Guadalajara se traslada hacía Tonalá y queda fundada en julio de 1533, no obstante, no todos sus moradores migran hacia la nueva ubicación, algunos decidieron irse hacia Tlacotlán y otros a Tetlán, dejando la recién Guadalajara poco poblada por la división de sus

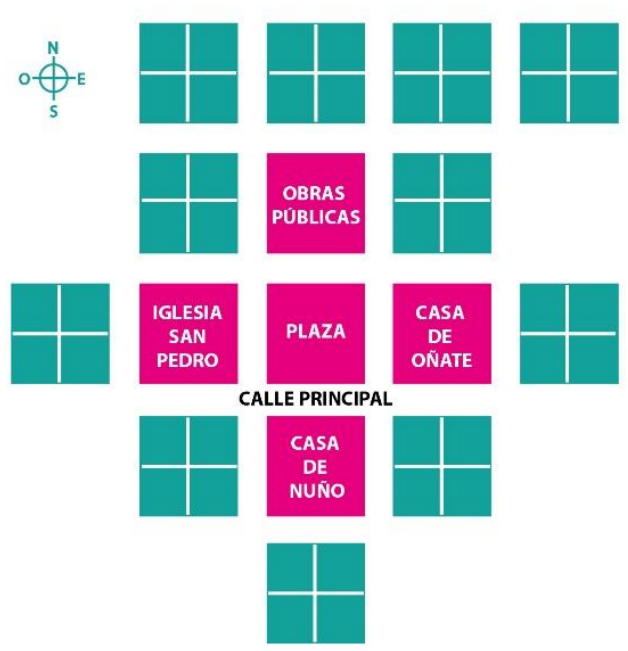

Mapa 1) Mapa Guadalajara- Nochistlán. Fuente: (La cuadricula. Eduardo López Moreno) elaboración propia habitantes, por tal motivo fue que Guadalajara duró aproximadamente entre 8 y 10 meses en ese lugar antes de que se decidiera su cambio un 12 de marzo de 1535 a Tlacotlán.

Desafortunadamente el nuevo punto de la tercera fundación en Tlacotlán no pudo ser peor, puesto que eran constantemente atacados por los originarios indígenas de la zona (Caxcanes, Tecuexes y Tzacatecos), basados en textos de cronistas como el del Padre Tello se deduce que en septiembre de 1541 ocurrió un fuerte ataque a la ciudad, en la que los indígenas lograron penetrar las murallas, fosas y entraron destruyendo todo, 
la ciudad quedo devastada, motivo suficiente para que el 30 de septiembre del mismo año se congregaran los vecinos en el cabildo y concluyeran la nueva sede de la ciudad, sin embargo, nada se resolvía sobre su nueva ubicación y es que doña Beatriz Hernández invocando el nombre del Rey exclamó "Yo soy de parecer que nos pasemos al Valle de Atemajac" (Gómez, 1992, 15-35) a lo que el gobernador asintió y se decide trasladar Guadalajara a esta nueva ubicación (ver mapa 2).

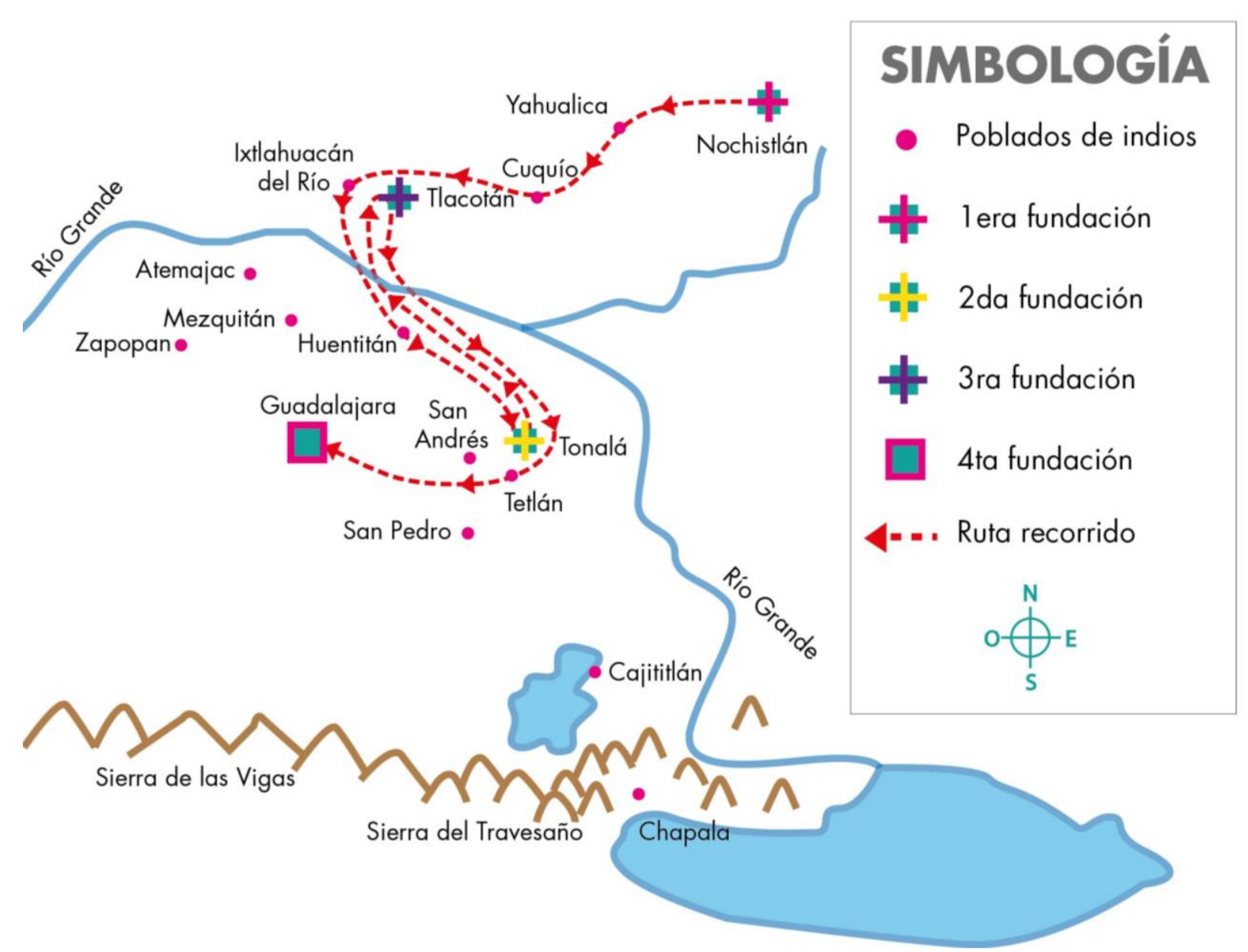

Mapa 2) Diferentes fundaciones de Guadalajara. Elaboración propia. Fuente: La cuadrícula. Eduardo López Moreno. Mapa de la enciclopedia "El territorio mexicano"

Después de tomada la decisión se manda publicar un bando en la plaza pública de Tetlán, en el cual se exponía la nueva fundación de la ciudad y quienes desearán mudarse de la nueva Villa podían hacerlo sin problema alguno. 
Fue con ello que el 14 de febrero de 1542 queda fundada Guadalajara en el Valle de Atemajac y fue hasta el 7 de enero de 1561 por ordenanzas del Palacio Guadalajara queda promulgada como capital constituida del reino de Nueva Galicia predominando la autoridad eclesiástica, levantando iglesias y conventos (la primera iglesia fue la capilla de San Miguel que actualmente se encuentra a un costado del palacio de justicia y la segunda iglesia con la catedral y la colocación de su primera piedra en 1561 por Fray Pedro Ayala).

2.1.1. Guadalajara, periodo $1542-1732$

Guadalajara durante su proceso de fundación y hasta su establecimiento definitivo representó una centralidad ${ }^{7}$, donde las leyes de Indias dictaban que la plaza mayor se encontrase en el centro del asentamiento, es en esta forma que el espacio público es el eje articulador de la ciudad y determinador de la forma, donde la plaza funge un papel primordial de gran importancia cívica ciudadana al contener los edificios del gobierno y el clero a su alrededor.

Al analizar la plaza y la distribución de la primera Guadalajara se connota que el espacio público es un espacio concebido como lo define Lefebvre (2013; 92), el de los expertos, el espacio en correspondencia con las relaciones y formas de producción, en el que dicho orden fue establecido por Felipe II en 1573 con las leyes de Indias con un fin determinado en el espacio, el cual era seguir un trazo reticular basado en las calles y manzanas con la plaza cívica en su centro. Esta forma de espacio concebido inició una homogenización de la traza urbana en forma de cuadrícula-retícula en la ciudad y la manera en que se estructuraban los espacios públicos abiertos al aire libre como plazas, atrios de templos, parques (bulevares, alamedas) o portales.

La colonización fue un símbolo de dominación y poder con una manifestación espacial que quedó plasmada con el nacimiento de Guadalajara, esto contribuyó con la

\footnotetext{
7 De acuerdo con el Plan de Ordenamiento Territorial Metropolitano POTmet, elaborado por el Instituto Metropolitano de Planeación (IMEPLAN) una centralidad son aquellas unidades urbanas vinculadas por una estructura vial y que desempeña una función definida esencialmente por su concentración de empleo, población, transporte, prestación de servicios además de caracterizarse por su potencial de generar identidad y arraigo entre sus habitantes.
} 
construcción de conjuntos de elementos formales/materiales y simbólicos que determinaron espacialmente la ciudad a partir de las leyes de Indias, con base a las cuales se debía contar con:

-Un espacio público central (Plaza mayor)

-Autoridad religiosa (Templo)

-Ayuntamiento/ Audiencia

-Obras Públicas

-Solares de los principales (habitantes de la clase alta) y en gradación hacia las periferias los ciudadanos de menos poder adquisitivo

-Terrenos comunales (ejidos)

-Garitas (o aduanas para entrar a la ciudad, en las que se cobraba un peaje o impuesto a los comerciantes que venían de pueblos cercanos a vender sus productos, como: mezcal, quesos, frutas de todo tipo, tabaco, vinos, ropa, etc.)

La fundación definitiva de la ciudad inicialmente estaba constituida por doce manzanas bordeadas por un río en su extremo oriente, el cual posteriormente causaría distorsiones sobre la cuadrícula del trazado de la ciudad (López, 2001, 22-23), Guadalajara fue instalada al costado de los asentamientos indígenas (Analco). Debido a la característica de encontrarse fuera de los asentamientos de indios la ciudad formaba desde su constitución una cierta segregación espacial que aún se ve reflejada en la actualidad.

La división de su fundación al estar dispuesta en dos partes separadas por el Río San Juan de Dios (actual avenida Calzada Independencia), barrera natural que le otorgo a la ciudad un carácter de estructura de núcleo dispuesta por una centralidad y circundada por asentamientos indígenas: Mexicaltzingo al sur, Analco al sur-oriente y Mezquitán al norte, que en simultáneo formaban una especie de cinturón defensivo que envolvía a la ciudad (ver mapa 3). 


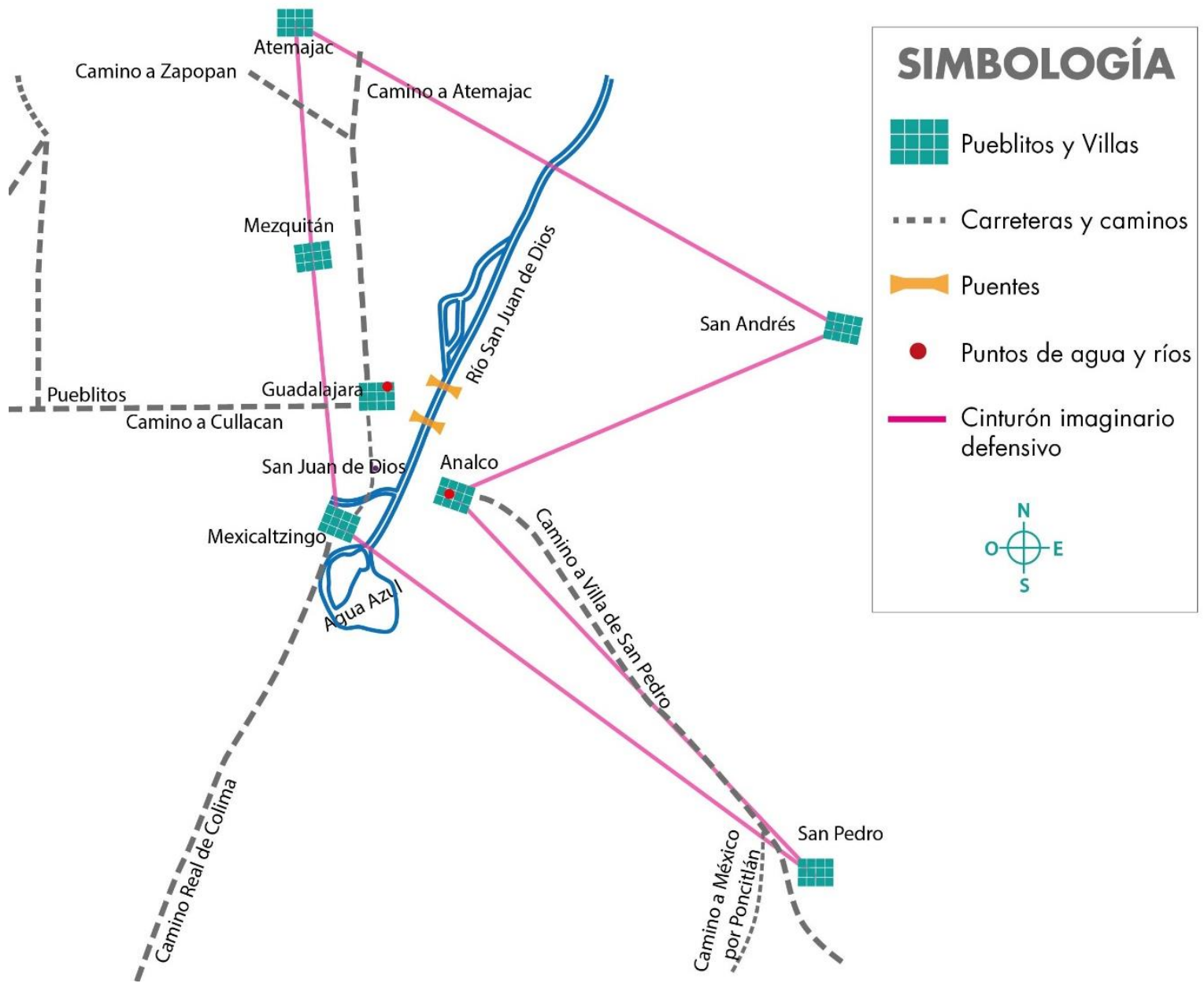

Mapa 3) Guadalajara y su región en la fundación. Elaboración propia. Fuente: La cuadrícula. Eduardo López Moreno.

Fue así como Guadalajara desde sus orígenes se constituye como sede de poderes y asiento de administradores eclesiásticos (dimensión jurídica desde la visión de los reyes católicos y del espacio concebido desde los expertos), muestra de ello son los vestigios que quedan en la actualidad por los diversos templos y conventos distribuidos en las diferentes zonas y barrios de la ciudad.

Para el año 1560 la ciudad tenía aproximadamente una extensión de 80 hectáreas en la que estaban distribuidos los 63 habitantes originarios de la fundación (López, 2001, 22-23) y como mencionamos a los extremos de la ciudad estaban los ejidos como 
reservas territoriales propiedad del estado destinadas para expandir la urbanización, previendo el desbordamiento de expansión de su núcleo fundacional.

Durante este periodo del siglo XVI se dio pie y marcha a algunas edificaciones importantes en la ciudad, entre ellas destacan construcciones provisionales de las primeras parroquias (Vázquez 1992, 40-41), una de las cuales sería la Catedral (la primera como mencionamos ubicada a un costado de Palacio Nacional en lo que hoy es Santa María de Gracia y la segunda al costado Norte de la actual Catedral) iniciando su construcción definitiva como parroquia del Sagrario, ambas ubicadas a un lado de la plaza fundacional de la ciudad.

Otros de los edificios importantes durante este siglo fueron: la edificación del convento de Santa María de Gracia, los hospitales de San Miguel y Santa Veracruz o de San Juan de Dios y la construcción de los principales vecinos del centro y demás habitantes españoles. Algo importante de señalar es que las casas de los indígenas fueron chozas y a sus barrios se les denominó arrabales, tal como Mexicaltzingo y Analco.

Desde su fundación Guadalajara tuvo problemas con el abastecimiento de agua porque en aquel siglo el río San Juan de Dios era usado para generar energía hidráulica a la ciudad, en este periodo también se construyó el primer puente sobre el río para el paso del camino a México.

Cuando Guadalajara quedo fundada en el Valle de Atemajac en 1542 su traza correspondía más a la de una cuadricula (ver esquema 2), pero con el paso de los años y el crecimiento se trasformó para cambiar a una forma reticular (ver esquema 3). La forma de la ciudad se mantuvo bajo un esquema reticular y cuadricular por factores estéticos, de ordenamiento y control del espacio.
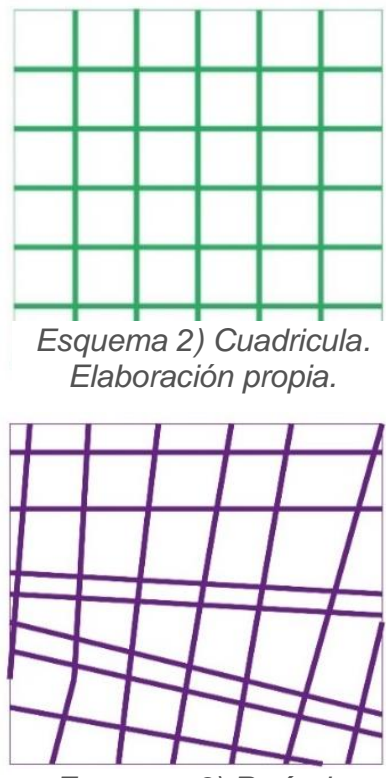

Esquema 3) Retícula. Elaboración propia.

La estructura territorial de la ciudad se relacionaba al modelo colonial conformado por: solares, ejido, dehesas, tierra de propios, territorio y términos (ver esquema 4). 


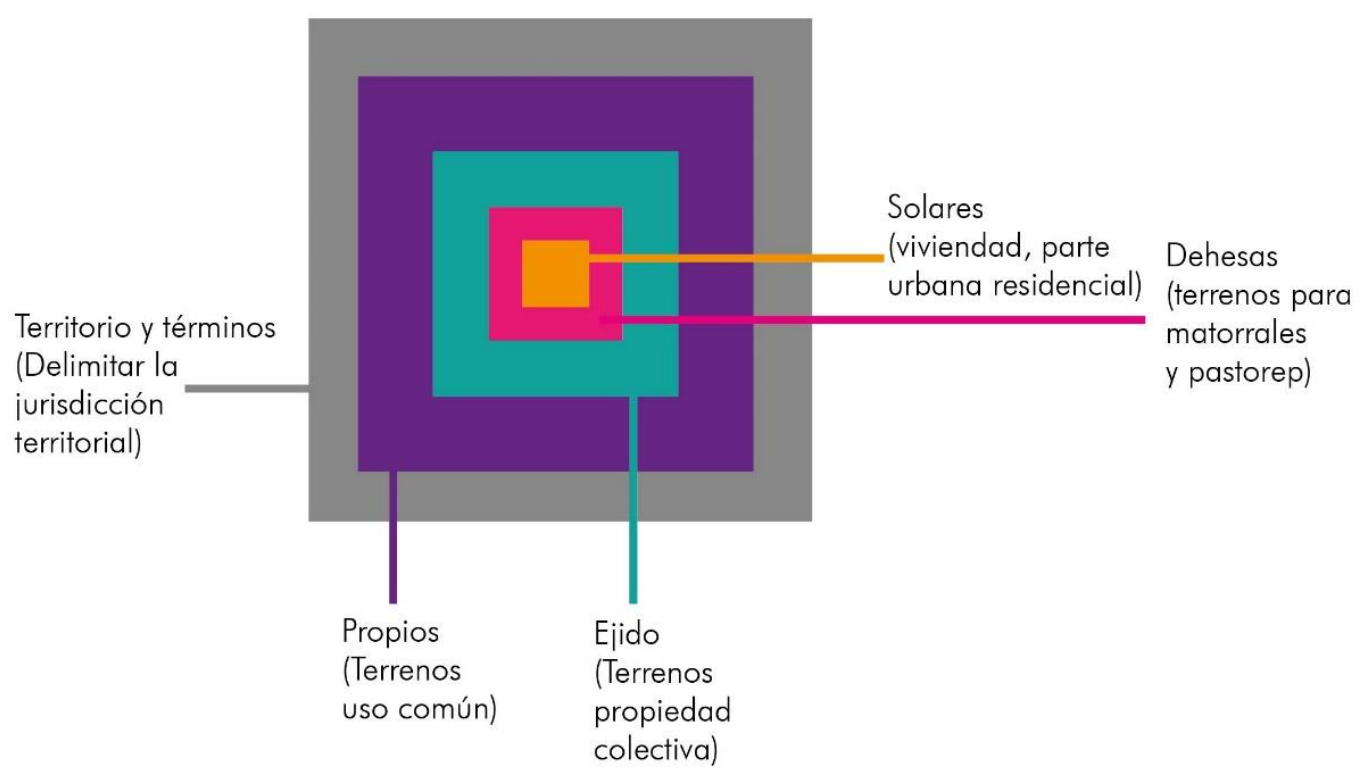

Esquema 4) Estructura territorial de la ciudad colonial. Fuente: La cuadrícula. Eduardo López Moreno (elaboración propia).

La ciudad se ordenaba en un trazo un tanto impreciso, el punto central y los ejes (calles) definen la inclinación general de la traza, que pese al modelo de la cuadrícula que plantea un espacio isótropo y homogéneo (López 2001: 29), las particularidades que presentaba el paisaje y la forma de producción le dieron la característica de ordenarse en una retícula ortogonal, es decir, al fundarse Guadalajara se siguió un modelo de ordenamiento cuadricular ( de dimensiones simétricas en todas su direcciones) para fines de control espacial, pero al ir extendiéndose la ciudad y debido a las diversas características del terreno, su traza cuadricular tuvo que adaptarse y cambiar a una traza reticular con líneas horizontales y verticales en diferentes direcciones pero de forma asimétrica.

En resumen, las características morfológicas de este periodo corresponderían desde la perspectiva de Lefebvre a un espacio dominante y manipulado por el poder, dando como consecuente un espacio concebido por las autoridades y tecnócratas (los reyes y las Leyes de Indias), en otros términos, un espacio formal cuantificable que abordado desde el punto de vista de Soja correspondería a un espacio del uso de las 
edificaciones y la traza de la ciudad, que tiende a inclinarse hacia la homogenización del mismo, puesto que las ciudades que fueron cascos fundacionales en época de la colonia en México seguían este mismo ordenamiento y trazo espacial.

Algunos sucesos relevantes durante este periodo fueron, ver tabla 1.

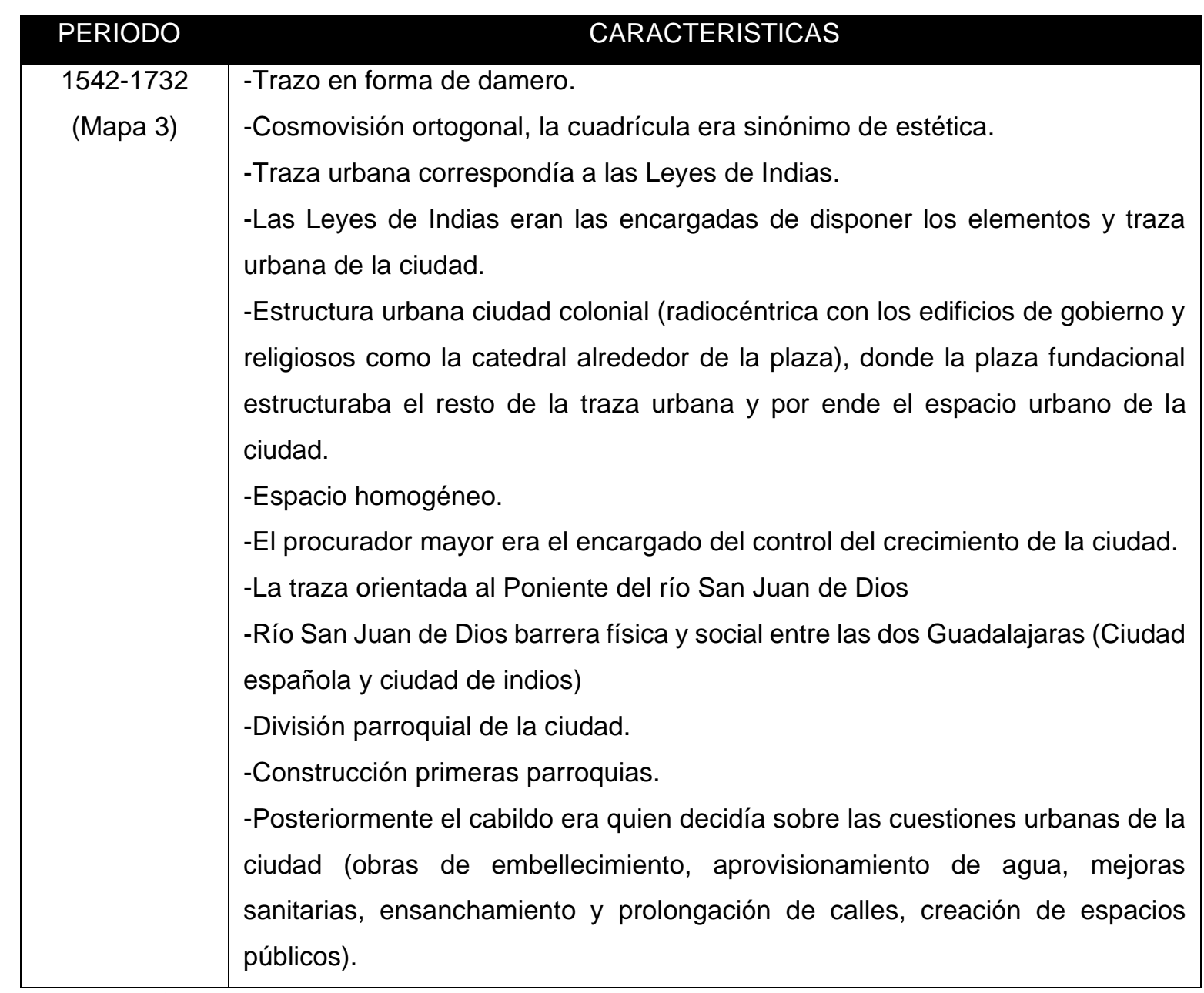

Tabla 1) Guadalajara en 1542-1732. Elaboración propia. Fuente: La cuadrícula. Eduardo López Moreno.

En este periodo la tendencia del crecimiento de la ciudad desde su fundación se vio orientado hacia el lado Poniente en relación del río San Juan de Dios (el cual servía como barrera natural entre la ciudad española y el pueblo de indios-Analco)

Para el año 1560 el crecimiento se direccionó hacia el sur, poniente y oriente en correspondencia al río, algunas circunstancias que frenaron su crecimiento hacia el norte fue el bloque del convento de Sta. María de Gracia y hacia el sur-oriente por los 
terrenos anegables en la orilla del río. Para el año 1600 la extensión territorial tuvo un crecimiento hacia el sur, norte y poniente en dependencia con el río San Juan de Dios y fue hasta el 1700 la extensión territorial se conurbo con los pueblos de indios de Analco y Mexicaltzingo. Una de las circunstancias que limito el crecimiento del territorio fue el bloque del convento Franciscano (modelo 1).

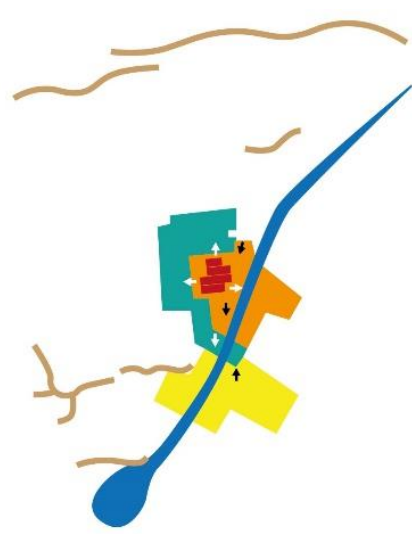

Modelo 1) Crecimiento GDL 1700. Elaboración propia. Fuente: Moreno 2001

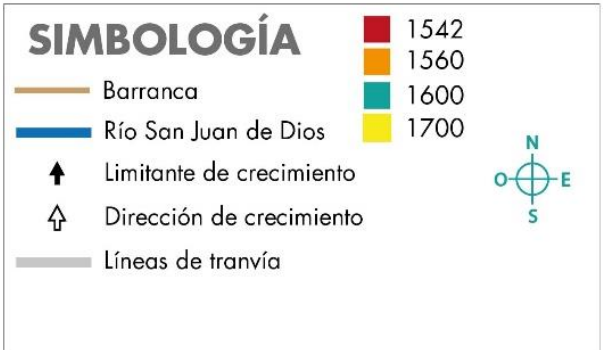

2.1.2. Guadalajara, periodo $1732-1741$ A lo largo de este periodo, después de la fundación definitiva en el Valle de Atemajac, Guadalajara queda consolidada como una ciudad de importancia para el gobierno español, su crecimiento estuvo principalmente marcado en orientación al poniente con disposición de las plazas en correspondencia con el norte y oriente de la Plaza mayor donde "la marca de adhesión del espacio construido a lo sagrado" (López, 2001: 51).

Las características principales de este periodo se muestran la tabla 2. 
En 1741 la tendencia de crecimiento se ve encauzada hacia la expansión de la ciudad en dirección al norte y poniente en concordancia con el río, algunos de los límites provisionales de freno del crecimiento fueron las barrancas en la calle Parroquia, así como el convento e iglesia del Carmen (Modelo 2).
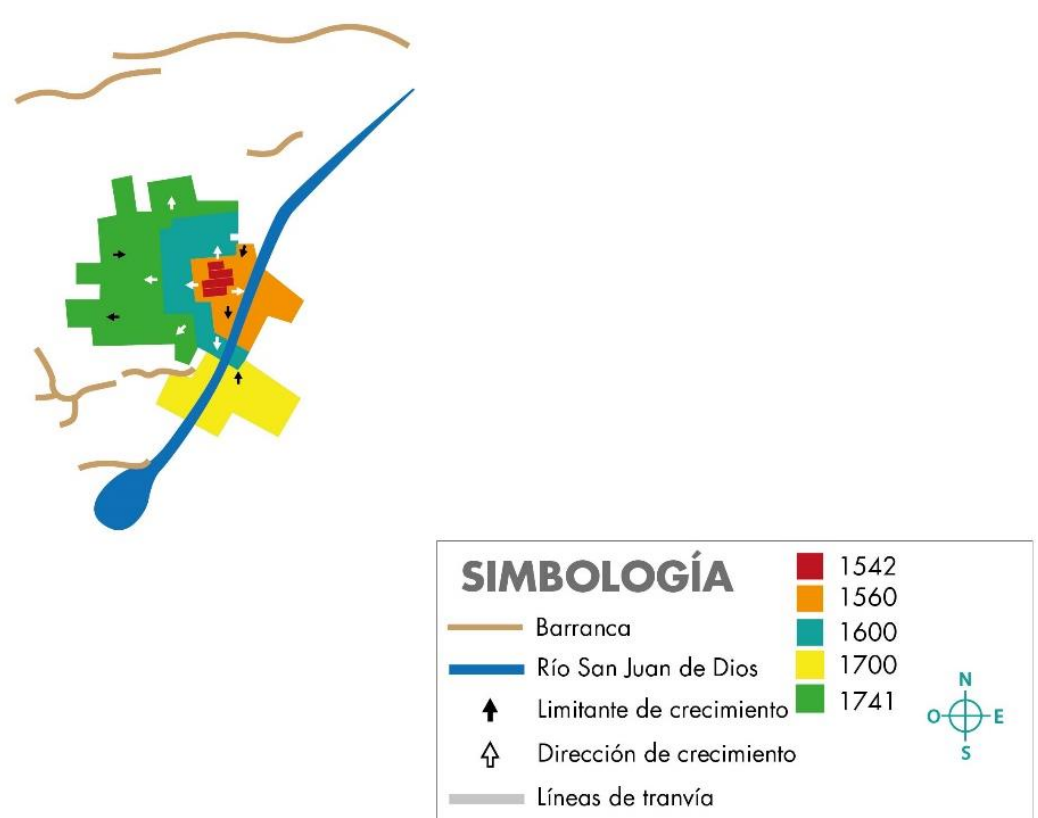

Modelo 2) Crecimiento GDL 1741. Elaboración propia. Fuente: Moreno 2001

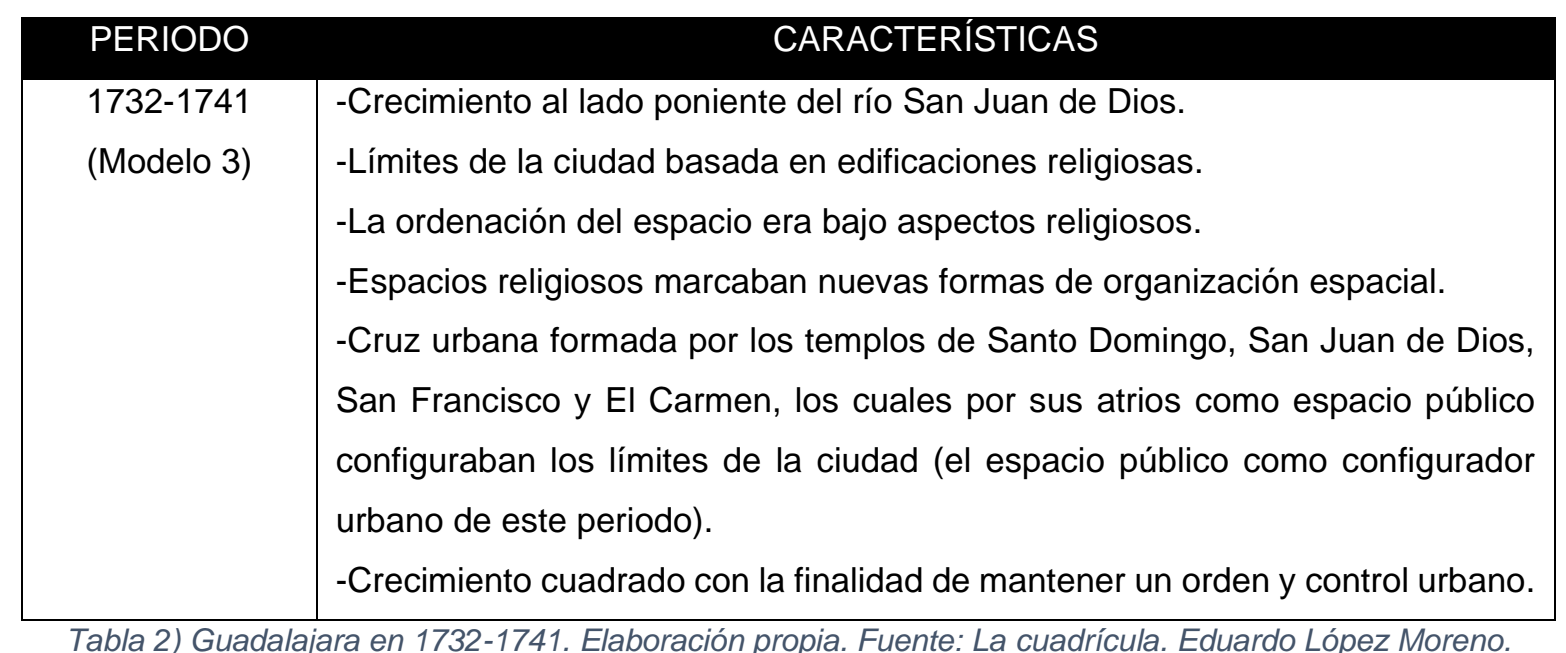




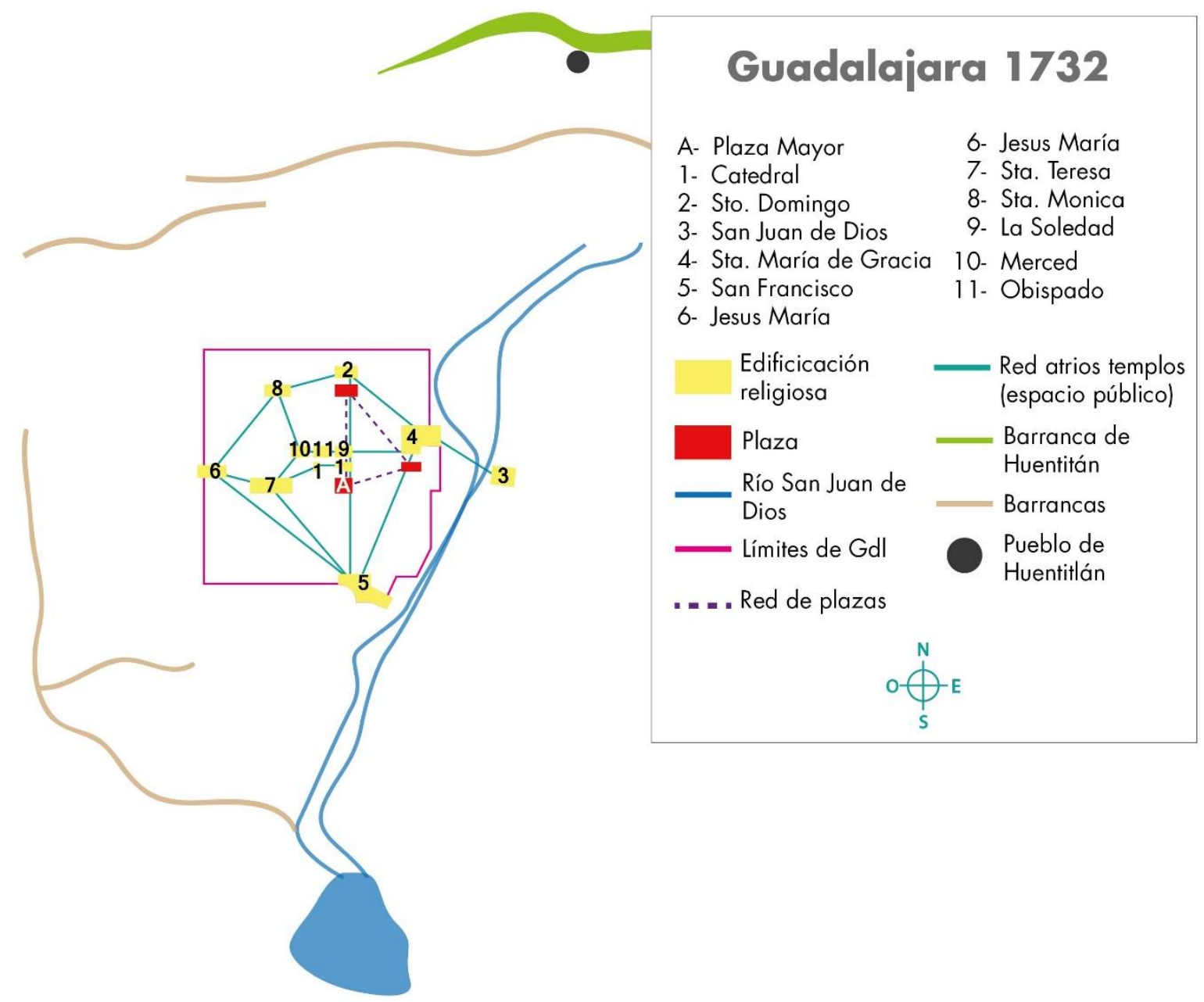

Modelo 3) Guadalajara en 1732. Elaboración propia. Fuente: La cuadrícula. Eduardo López Moreno.

2.1.3. Guadalajara, periodo $1741-1753$

En este periodo se rompe la forma de crecimiento cuadrado en gran medida por irregularidades en la traza debido a la discontinuidad de las manzanas al Sur del convento de San Francisco a causa de la topografía del suelo, lo que propicio un notorio crecimiento hacia el norte y poniente de la ciudad, siendo evidente que los términos de la urbe se veían aún marcados por el dominio eclesiástico, dado que la configuración y adaptación de las calles se concibió en dependencia con grandes edificios, especialmente de orden religioso, además se experimenta un rompimiento con la traza 
ortogonal en gran parte por la influencia del convento. Para el año de 1753 la ciudad contaba con 175 manzanas, 16 al Norte-Sur y 14 de oriente-poniente (López, 2001: 58).

\begin{tabular}{|l|l|}
\hline \multicolumn{1}{|c|}{ PERIODO } \\
\hline (Modelo 4) & CARACTERISTICAS \\
& $\begin{array}{l}\text {-Tiferenciación social. } \\
\text {-Densificación de los espacios libres existentes entre la ciudad y el río con } \\
\text { viviendas. } \\
\text {-La ciudad deja de ser representada con calles rectas y manzanas regulares } \\
\text { (la calle Degollado ubicada a un costado del convento de San Francisco } \\
\text { aparece por primera vez en diagonal en relación con la traza original. } \\
\text {-Debido a las características topográficas del terreno la ciudad va perdiendo la } \\
\text { traza ortogonal. } \\
\text {-Se mantenía una división parroquial de la ciudad. } \\
\text {-Las iglesias de Jesús María, Santa Mónica y del Pilar permitieron la } \\
\text { estructuración del espacio urbano hacia el Poniente, una vez más el espacio } \\
\text { público de los atrios configuraba la traza urbana de la ciudad. } \\
\text {-Disposición de las plazas en relación con el sur y norponiente de la Plaza } \\
\text { Mayor. }\end{array}$ \\
\hline Tabla 3) Guadalajara en 1741-1753. Elaboración propia. Fuente: La cuadrícula. Eduardo López Moreno 2001.
\end{tabular}

Es importante señalar que si bien la ciudad de indios disponía de espacios públicos abiertos al aire libre como el tianguis o plazas con diferentes vocaciones, para el encuentro, lo religioso, lo cívico, es durante la época de la Colonia que el espacio público de la ciudad se ve producido por la plaza fundacional al centro y en el interior de la ciudad a partir de los atrios (y los jardines que podían llegar a contener), los cuales se estructuraban y producían a partir de componentes físicos arquitectónicos como las iglesias, conventos y templos.

Las características de este periodo se muestran en la tabla 3. 


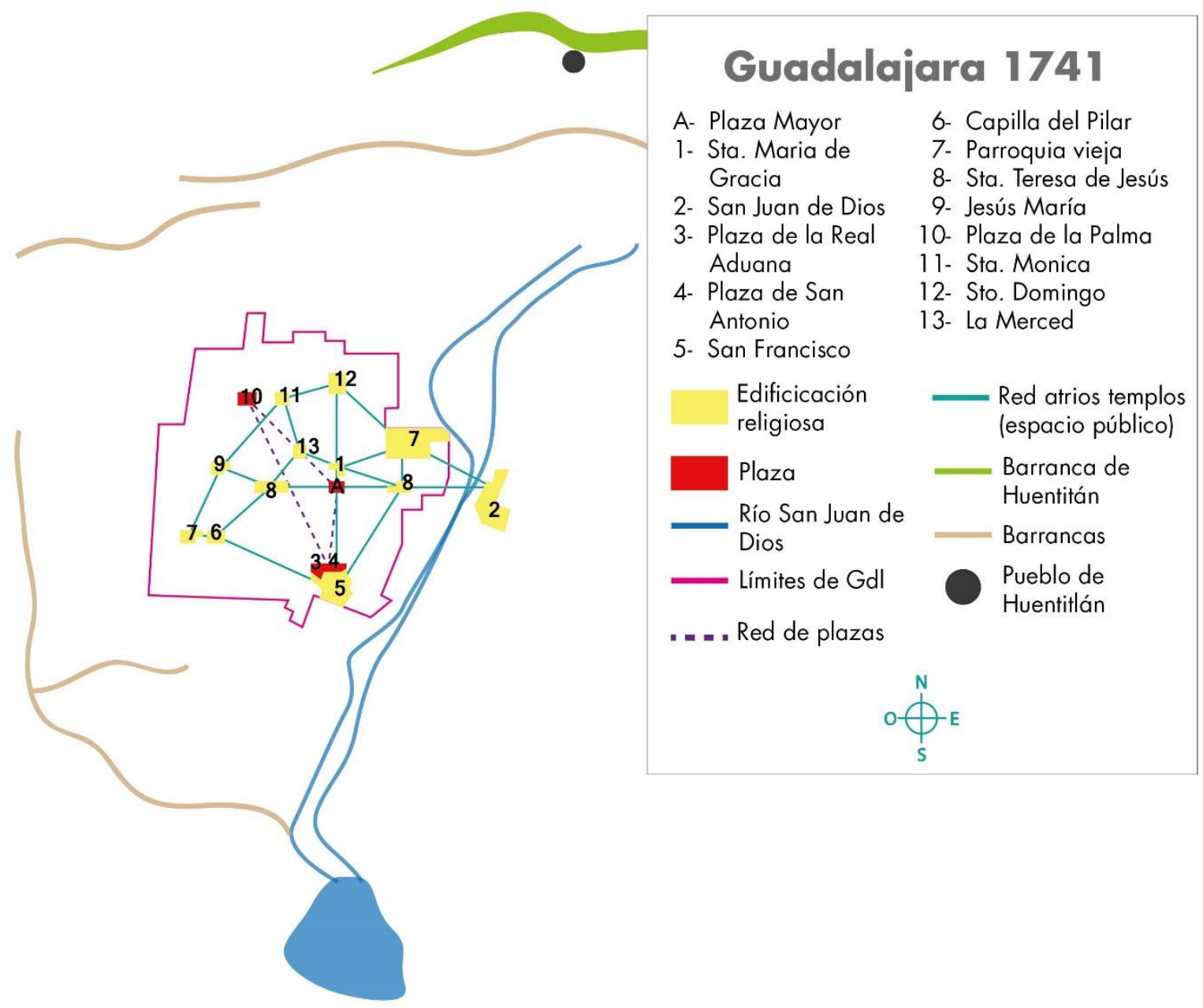

Modelo 4) Guadalajara en 1741. Fuente: La cuadrícula. Eduardo López Moreno (elaboración propia).

2.1.4. Guadalajara, periodo $1753-1800$

En el lapso de 1753 y 1800 la ciudad tenía 344 manzanas, 15 manzanas por el eje Oriente-Poniente y 25 en dirección Norte-Sur (López, 2001: 61) y en el año1792 se funda la Universidad de Guadalajara. Por otro lado, la barranca de Belén era un límite natural al Norte de la ciudad, San Juan de Dios fue el primer barrio y se encontraba al costado Oriente del Río San Juan de Dios, situación que conllevo a una pauta de nueva orientación de crecimiento de la ciudad hacia el este. 
En 1779 surgen "Las Cuadritas" por obra de Fray Antonio Alcalde (primer modelo de vivienda social) en el barrio del Santuario, lo que favorece al ensanche de la ciudad en dirección norte. El barrio de Santo Domingo se conformó alrededor del convento del mismo nombre, el cual formaba parte de uno de los cuatro brazos de la cruz urbana, también surge el barrio de Santa Mónica alrededor del edificio religioso con el mismo nombre.

A la par emerge el barrio del Pilar alrededor de la iglesia de Jesús María el cual era habitado por familias con recursos económicos altos. En un plano esquemático de 1800 aparecen por primera vez representados los principales barrios de San Juan de Dios, Mexicaltzingo, Analco, el Carmen y Santuario, estos barrios poseían una fisonomía articular debido a que en conjunto formaban un modelo socio espacial definido por una gradación de jerarquías sociales de centro periferia (López, 2011: 65), aparece también el barrio de la Estrella al costado poniente de la Alameda junto a un edificio religioso.

Es importante mencionar que el empedrado de calles seguía la lógica de comunicar los tres poderes (Ayuntamiento, privados, sociedad) y revalorizar ciertas actividades y lugares importantes de la ciudad (centralidad de las plazas) que partían de la iglesia hacia la periferia (López, 2011: 74), es decir, las calles eran los conectores para una buena accesibilidad a la red interna de espacios públicos que contenía la ciudad, plazas, atrios y jardines.

A continuación, se muestra la tabla 4 que enmarca las principales características de este periodo: 


\begin{tabular}{|c|c|}
\hline PERIODO & CARACTERISTICAS \\
\hline $\begin{array}{l}1753-1800 \\
\text { (Modelo 5) }\end{array}$ & 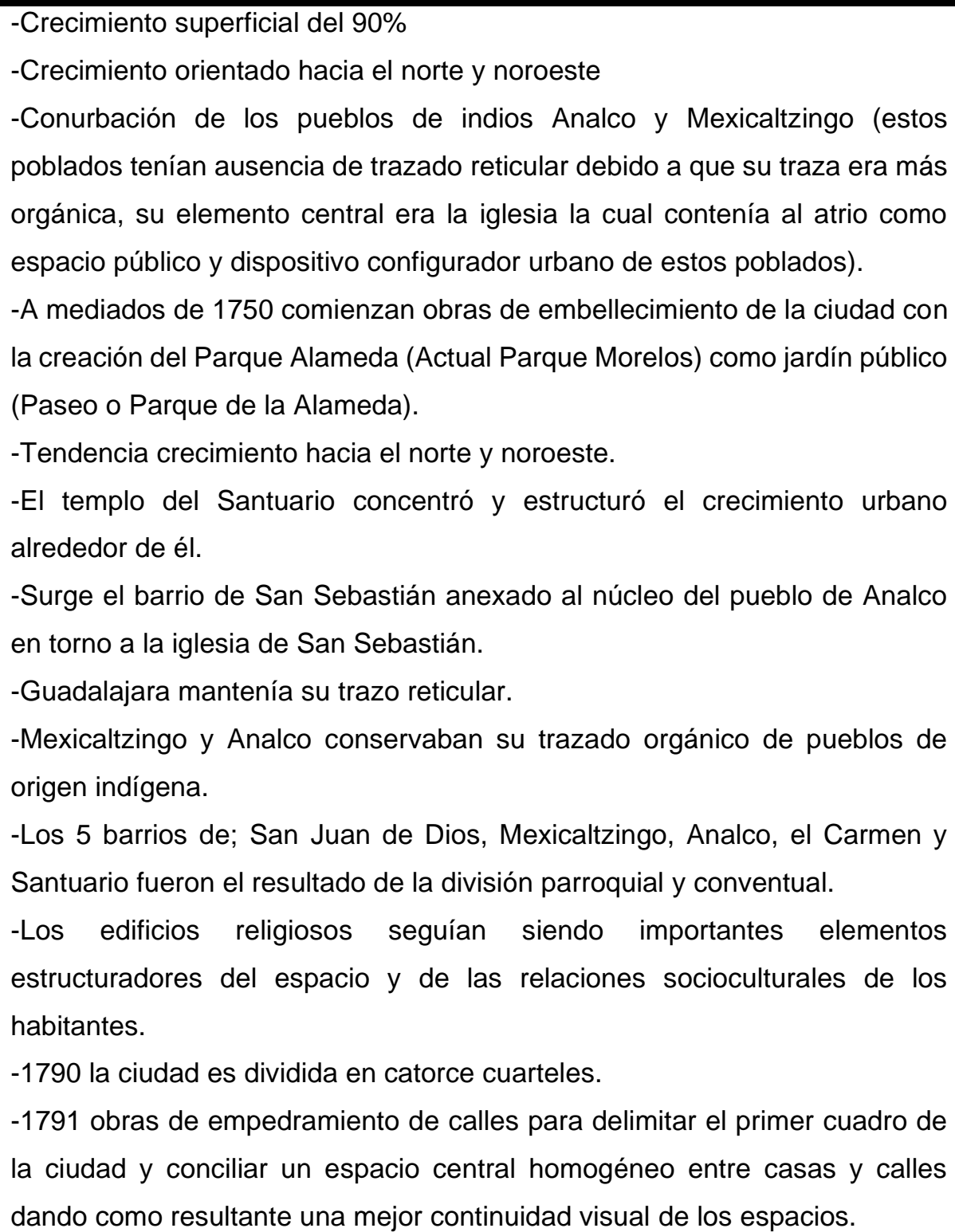 \\
\hline
\end{tabular}

Tabla 4) Guadalajara en 1753- 1800. Elaboración propia. Fuente: La cuadrícula. Eduardo López Moreno. 


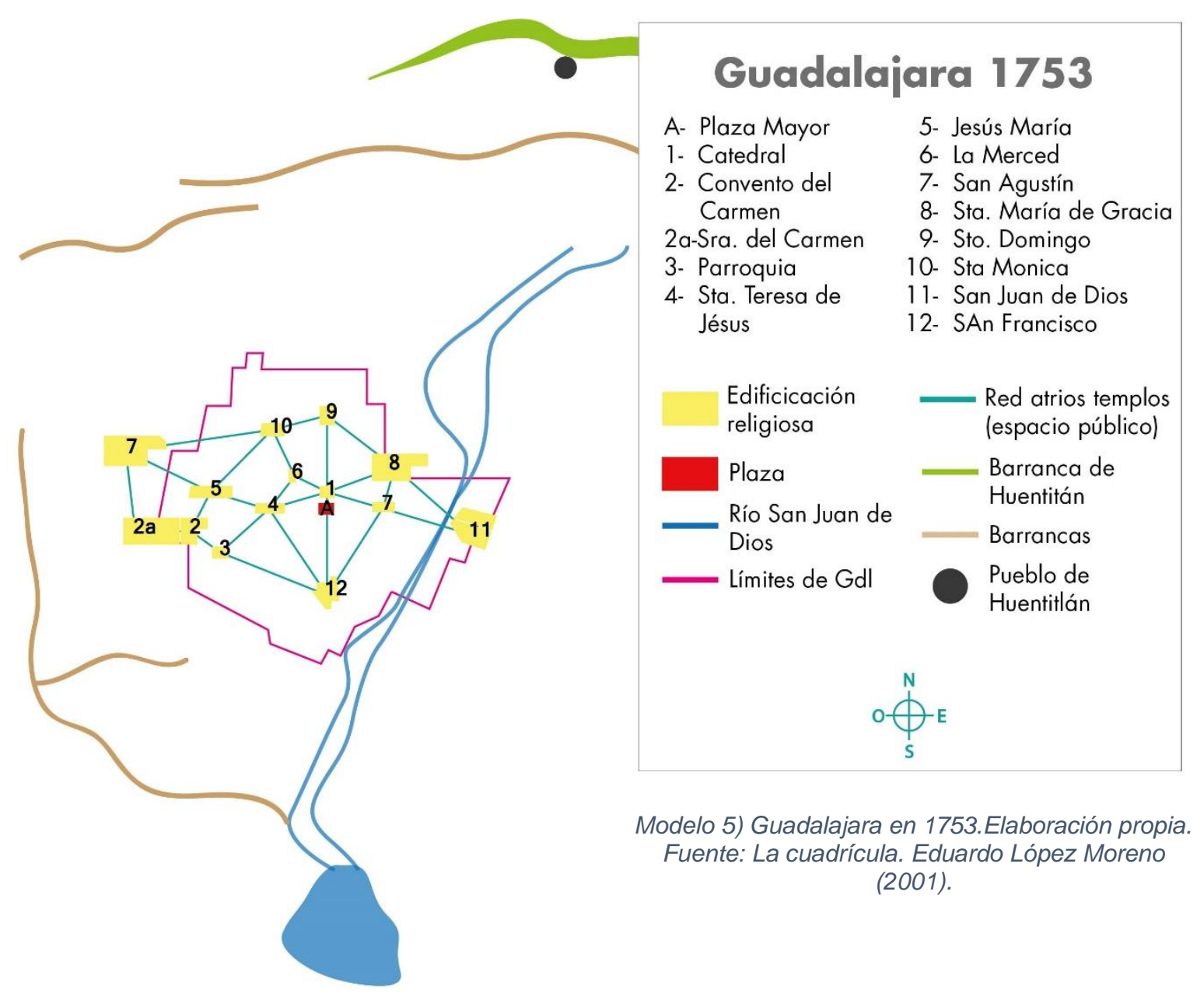

2.1.5. Guadalajara, periodo $1800-1850$

La ciudad mantiene un crecimiento orientado hacia el poniente en gran parte por la disponibilidad de agua y características de los terrenos. En este periodo la ciudad tenía bajos indicadores espaciales (espacios públicos para la ciudadanía o amplias avenidas para el tráfico) y el suelo periférico se disgrega a cuestiones especulativas, deja de ser el espacio desvalorizado para convertirse subsecuentemente en el punto donde se enfoca la demanda (López, 2011: 77-82).

Algunos de los terrenos residuales ubicados dentro de la ciudad son "recuperados" por los mismos habitantes, quienes los rehabilitaban y en ocasiones integraban en medida de lo posible a la trama reticular, constituyendo habitantes y municipalidad en 
“ordenadores del espacio" (López, 2001: 86) y fue hasta 1821 por medio de un Decreto se declaró a Mexicaltzingo y Analco como barrios de la ciudad.

Durante los años 1825 a 1850 se construye la penitenciaria en el lado poniente de la ciudad, está fue un núcleo que absorbió el crecimiento de la ciudad (los cementerios y penitenciaria también eran controladores de la expansión de la ciudad) y para el año 1842 Guadalajara ya contaba con 599 manzanas con una superficie estimada de 422 has a diferencia de 1850 donde tenía 759 manzanas y 553 has que conformaban la traza entera. Algunas de las características significativas se enlistan en la tabla 5.

\begin{tabular}{|c|c|}
\hline PERIODO & CARACTERISTICAS \\
\hline $\begin{array}{l}1800-1850 \\
\text { (Modelo 6) }\end{array}$ & $\begin{array}{l}\text {-Se desarrollan servicios municipales (aseo público, cuerpo de policía, } \\
\text { servicio de diligencia) } \\
\text {-La ciudad se extendió uniformemente en todas las direcciones. } \\
\text {-El Hospicio Cabañas oriento el crecimiento de la ciudad en dirección al } \\
\text { oriente. } \\
\text {-Las Garitas eran un punto de atracción y limitantes periféricos (barreras u } \\
\text { obstáculos) en los puntos de entrada de la ciudad. } \\
\text {-El modelo regulador parcelatorio continúa siendo las manzanas en damero. } \\
\text {-Después de la Independencia de } 1810 \text { empieza a ser más notorio los solares } \\
\text { con formas rectangulares en las periferias como posible consecuente de } \\
\text { afluencia de migrantes. } \\
\text {-El Río San Juan de Dios se mantenía como factor de ruptura o división del } \\
\text { modelo espacial de la ciudad. } \\
\text {-La mayoría de apertura de calles se hizo respetando la trama ortogonal. } \\
\text {-El río Arenal era la restricción natural de crecimiento de la ciudad en } \\
\text { dirección al sur, separaba la ciudad española y el barrio de Mexicaltzingo de } \\
\text { manera geográfica, motivo por el cual el crecimiento de la ciudad se orientó } \\
\text { hacia otras direcciones. } \\
\text { - } 1842 \text { la mancha urbana deja de presentar una forma regular. } \\
\text {-De } 1840 \text { a } 1850 \text { la ciudad creció hacia el norte por el aumento de la } \\
\text { población pobre en esa dirección debido al bajo coste de la tierra. } \\
\text {-1850 en dirección al norte la mancha urbana encuentra los límites naturales } \\
\text { de la barranca de Belén. }\end{array}$ \\
\hline
\end{tabular}

Tabla 5) Guadalajara en 1800-1850. Elaboración propia. Fuente: La cuadrícula. Eduardo López Moreno. 


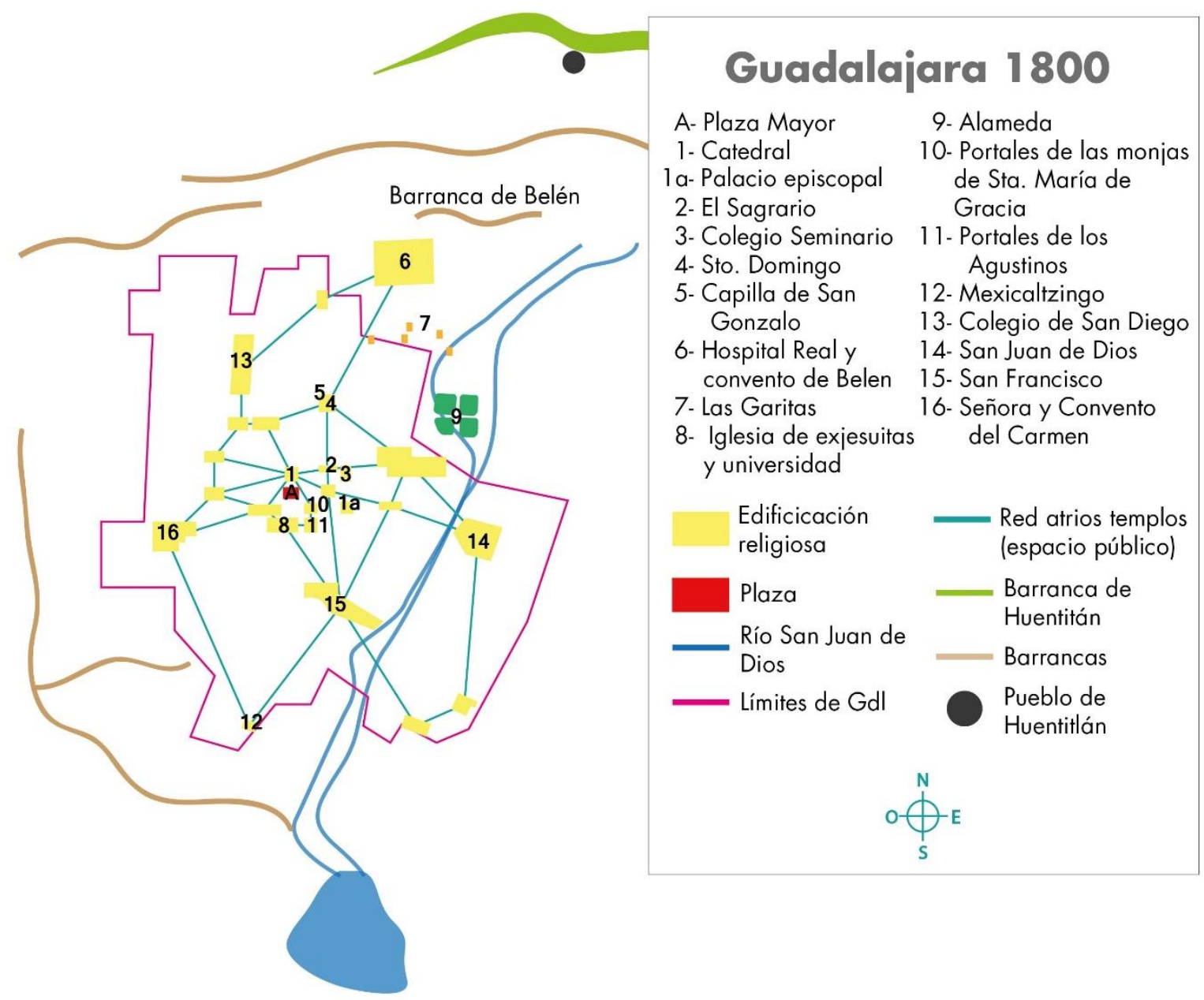

Modelo 6) Guadalajara en 1800. Elaboración propia. Fuente: La cuadrícula. Eduardo López Moreno.

Para 1800 la tendencia de crecimiento de la traza de la ciudad se orienta hacia el norte y oriente principalmente, uno de los factores que regularon su crecimiento fue el convento de San Juan de Dios, el hospital Real, Convento de Belén, Convento del Carmen y la tragedia de la familia Pareja en el Palacio Medrano, sobre la muerte de los hijos, puesto que la población consideraba la zona habitada por espíritus (modelo 7). 


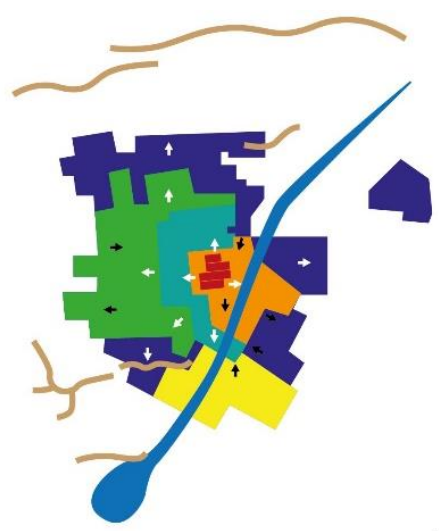

Modelo 7) Crecimiento GDL 1800. Elaboración propia. Fuente: Moreno 2001

2.1.6. Guadalajara, periodo 1850-1897 Leyes de Reforma.

Debido a la expropiación de terrenos se realizaron trabajos de apertura, rectificación y alineamiento de calles para mayor comodidad de peatones y una mejor comunicación de los barrios. Tal fue el caso de la calle o paseo de la Acequia (contigua al parque de la Alameda) era la salida al camino que comunicaba con Huentitán.

En el año1885 el barrio de Mexicaltzingo se conurba con el barrio de Mezquitán al norte, esta conurbación a su vez propicio el surgimiento de varias fábricas con orientación al noroeste, estas manufacturas se asentaron en terrenos fuera de Guadalajara, razón que altero su trama y da como resultante la aparición de nuevas discontinuidades en la traza urbana. En 1879 surge la construcción de tranvías suburbanos (Tranvías de Guadalajara S.A. y el gobierno del estado Mexicaltzingo) sin afectaciones a la traza urbana, la introducción del tranvía provocó un cambio en la tendencia direccional del crecimiento de la ciudad, causando que los terrenos libres a los lados de las vías se ocuparan. A lo largo del lapso de 1542 hasta las Leyes de Reformas en 1859, la ciudad se mantuvo ordenada y polivalente a las necesidades de la corona española con un enfoque de poder y control, en el que el espacio de las plazas, atrios de iglesias y 
parques, pero en mayor medida las plazas, servían como únicos articuladores sociales para la ciudadanía y como planteaba Lefebvre que si bien un espacio social contiene objetos diversos tanto sociales como naturales, pero que a su vez facilitan el intercambio de artículos e información (Lefebvre, 2013,134), estos espacios públicos abiertos al aire libre (plazas, atrios y parques) se convertían en sitios de espacios vividos por las experiencias individuales y colectivas de las personas.

Las características más destacables de este periodo se enlistan en la tabla 6.

\begin{tabular}{|l|l|}
\hline PERIODO & \multicolumn{1}{|c|}{ CARACTERISTICAS } \\
\hline (Modelo 8) & $\begin{array}{l}\text {-Modificación a la traza por las Leyes de Reforma y la ley de desamortización } \\
\text { de bienes en manos muertas. } \\
\text {-El trabajo de alineamiento de calles era con la intención de enmarcar un } \\
\text { proyecto de embellecimiento de la ciudad. } \\
\text {-1850 a } 1860 \text { la mancha urbana se extendió en dirección al este y oeste de } \\
\text { forma longitudinal. } \\
\text {-Acelerada densificación habitacional, lo que provoco formas de ocupación } \\
\text { colectiva (vecindades) y en masa de la periferia. } \\
\text {-El municipio dejo de ser el responsable directo del crecimiento de la ciudad, } \\
\text { cedió su papel de urbanizador a los nuevos propietarios urbanos y } \\
\text { promotores inmobiliarios. } \\
\text {-Se poblaron principalmente espacios residuales de la ciudad (periferias). } \\
\text {-La disponibilidad de terrenos al oriente y al poniente de la ciudad } \\
\text { favorecieron el crecimiento de la mancha urbana en esas direcciones. } \\
\text {-1888 Llega el Ferrocarril Central Mexicano, este transporte ocasionó una } \\
\text { distorsión en la trama por los asentamientos que se originaron a su alrededor. } \\
\text {-Los trabajos de lineamiento y ensanche de calles se llevaron a cabo } \\
\text { principalmente al norte de la ciudad en el barrio de Mezquitán y en la parte } \\
\text { sur de Mexicaltzingo, esto debido que al ser barrios antiguos con naturaleza } \\
\text { indígena (crecimiento orgánico), provocaron desajustes en la trama reticular, } \\
\text { motivo necesario para regularizar funcional y estéticamente las calles. }\end{array}$ \\
\hline
\end{tabular}

Tabla 6) Guadalajara en 1850-1896. Fuente: La cuadrícula. Eduardo López Moreno (elaboración propia).

Con la llegada de las Leyes de Reforma comenzó una serie de grandes cambios para la ciudad, dado que muchos de los bienes espaciales eclesiásticos pasarían a ser 
espacios utilizados para lo colectivo y lo social y se verían reflejados en nuevas y más amplias calles o en jardines o plazas comunes.

Para el año 1850 la ciudad tuvo una expansión en dirección de todos sus ejes (norte, sur, oriente y poniente en correlación con el río), una de las condiciones que restringieron su aumento fueron las barranquitas al noroeste de la ciudad y los ejidos destinados al pastado de ganados (modelo 9).

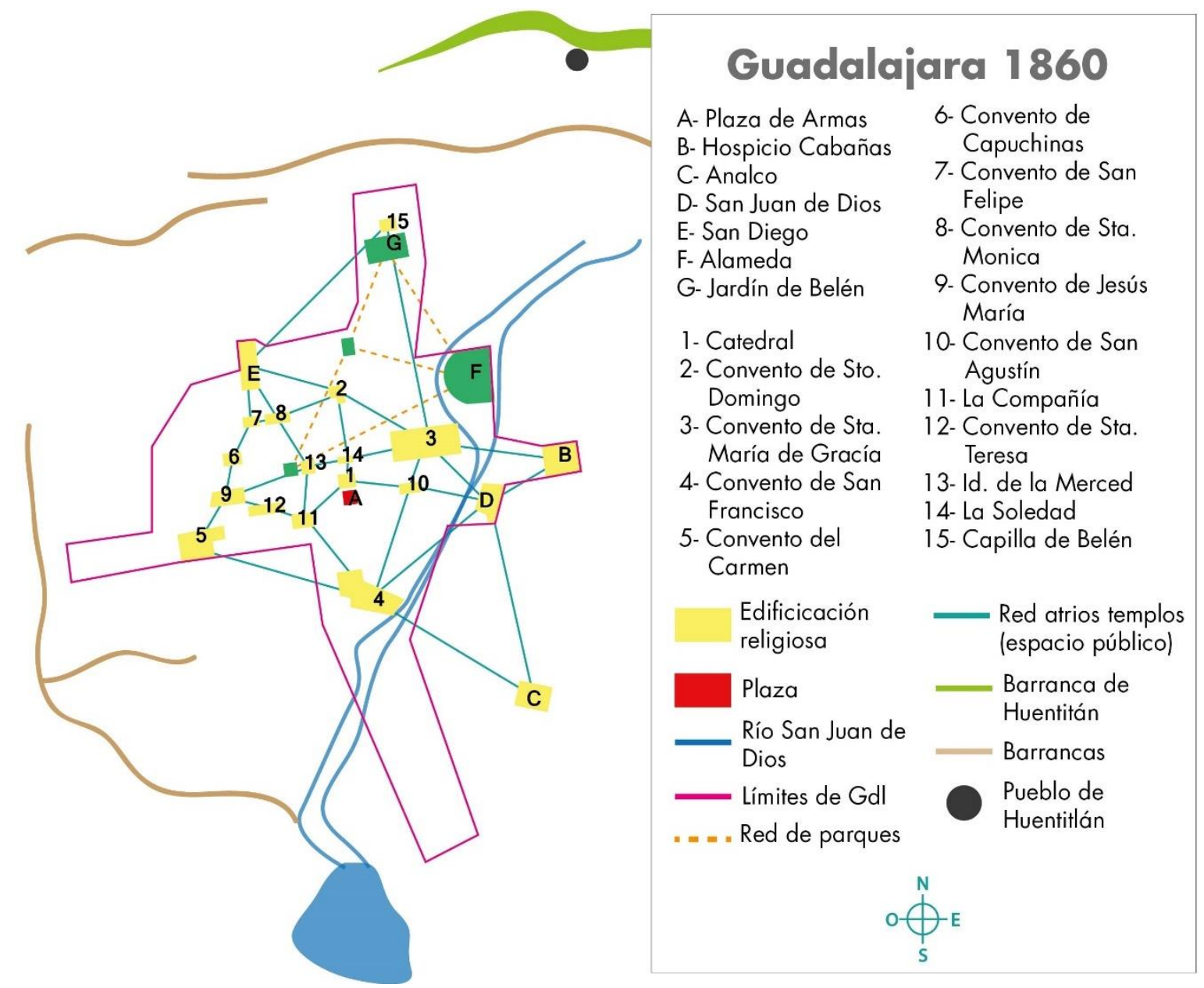

Modelo 8) Crecimiento GDL 1860. Elaboración propia. Fuente: Plano Guadalajara en 1860, archivo municipal 

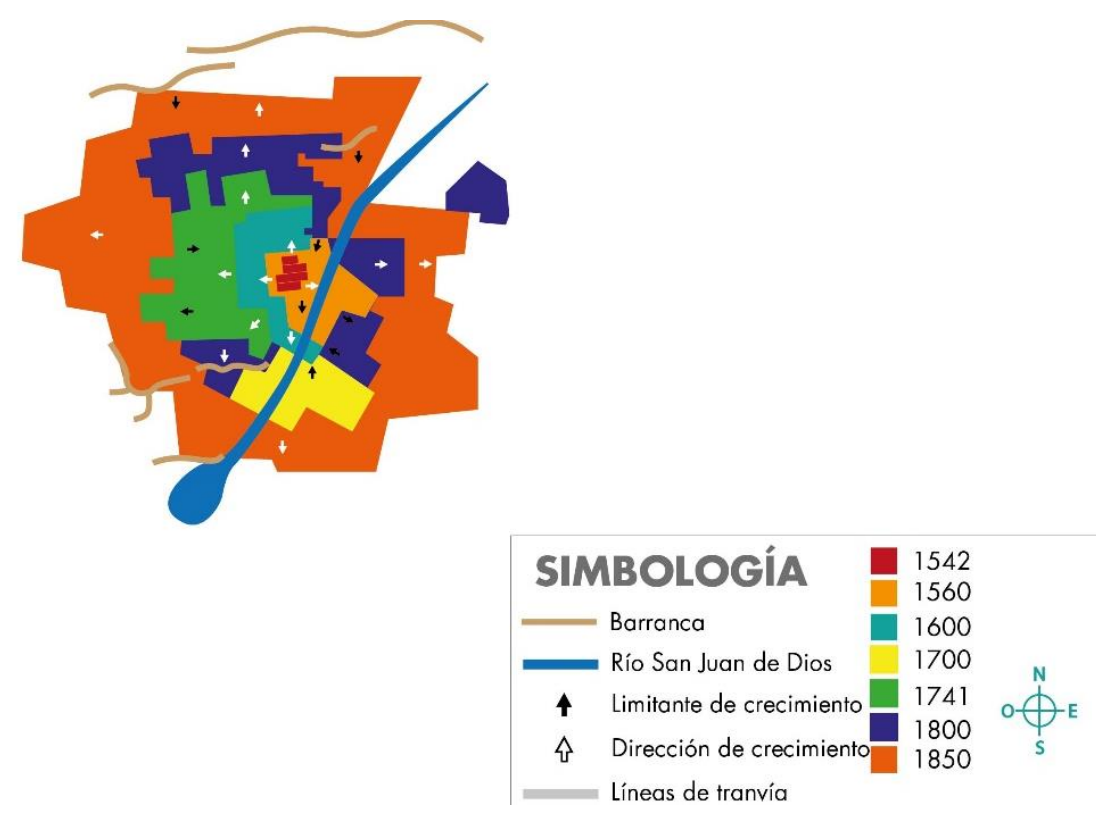

Modelo 9) Crecimiento GDL 1850. Elaboración propia. Fuente: Moreno 2001

\subsection{Aparición de las "Colonias" y entubamiento del río San Juan de Dios como primeros elementos modernizadores de la ciudad (1897-1947)}

Hacia finales del siglo XIX aparecen los primeros asentamientos planificados "las Colonias", las cuales romperán con la forma cuadrada de la ciudad al modificar el modelo concéntrico introduciendo las ideas de las colonias suburbanas derivadas de la ciudad jardín, provocando el aceleramiento del proceso de transformación de los bienes raíces (uso-valor).

El modelo urbano de las Colonias buscaba las mejoras urbanas de sus espacios con la conformación de Alamedas, ${ }^{8}$ a la par se da inicio al embovedamiento del río San Juan de Dios por iniciativa del Ayuntamiento de Guadalajara y Gobierno del Estado bajo las ideas higienistas del Porfiriato (se inició en 1897 y finalizó en 1910).

La ciudad comenzó un crecimiento notorio al poniente por estrategias especulativas de los propietarios de tranvías a causa de que varios de los terrenos ahí ubicados eran

\footnotetext{
${ }^{8}$ Las Alamedas eran un símbolo de poder en el Porfiriato. Fierro, J.M. (2016). Ernesto Fuchs. En Fierro, J. N. Ernesto Fuchs (pág 45). Guadalajara: Arquitónica.
} 
suyos, motivo por lo cual se comenzó a generar plusvalía en las nuevas colonias del poniente.

La colonia Francesa y Americana pretendían crear una zona residencial de carácter campestre para edificar chalets rodeados de jardines, huertos y amplios terrenos, el establecimiento de estas dos colonias fue un símbolo del progreso modernizador del Porfiriato. Dentro de estas nuevas Colonias se construye el bulevar Lafayette (hoy paseo Chapultepec) como parte de las ideas de la ciudad jardín que Fuchs replicó. Este bulevar surge de un proyecto vial de la avenida Lafayette que conectaba la parte alta (norte) con la parte baja de las colonias, esta avenida tenía grandes banquetas y espacios arbolados que ofrecía la posibilidad de paseo en su camellón central. Con la construcción del bulevar se remarca la importancia del espacio público como agente configurador del espacio urbano.

Con la aparición de las colonias se produjo un nuevo modelo socioespacial: familias acomodadas orientadas al poniente (occidente-oeste) de la ciudad y las familias de bajos ingresos como indígenas y migrantes se concentraron al oriente y norte, es decir, las Colonias intentaban separar orgánica y socialmente el espacio para crear uno homogéneo y aislado que respondía a una estrategia mercantil del incremento del valor del suelo en un lugar simbólicamente cerrado y por tal motivo reforzar la barrera social del poniente rico y el oriente pobre.

Ya en 1910 tras la finalización de los trabajos de embovedamiento del río San Juan de Dios se propició el surgimiento de espacios residuales, razón que favoreció el trazado de nuevas calles y manzanas con la finalidad de ocupar el espacio vacío y que ocasionó eventualmente que estos espacios no se ajustaran a la cuadrícula existente, dando lugar a vías en diagonal y manzanas en chuchilla.

Algunas de las características notables de este periodo se enlistan en la tabla 7. 
(Modelo 10) -Las formas de construcción de las colonias respondían a las tipologías europeas (villas y chalets).

-Con la llegada de las colonias surge el capital inmobiliario.

-En 1898 surge la primera colonia residencial en la ciudad "La colonia Francesa" planificada por el arquitecto Alemán Ernesto Fuchs. Esta colonia seguía las ideas de la ciudad Jardín de Ebenezer Howard y se ubicaba en el límite poniente de la ciudad a un costado de la escuela de Artes y oficios del espíritu Santo.

-La colonia Francesa fue la primera colonia higiénica de la República Mexicana, apoyaba las ideas de la "Revolución Sanitaria" emprendida por Haussman en París.

-Hacia 1899 aparece la colonia Americana a un costado de la Francesa. Esta fue también diseñada por Fuchs y presentó el primer rompimiento drástico con la cuadrícula, dado que el trazado de las calles era en diagonal noroestesuroeste (primera discontinuidad importante en la estructura morfológica de la ciudad).

-Las vías internas de las colonias eran de secciones más amplias que las del centro de la ciudad y con una franja de árboles a sus costados.

-Surge la colonia West End al poniente.

-La concepción de las Colonias fue bajo los estipulados de Modernidad que enfatizaba la higiene y mejor utilización del espacio, proyectando más parques que mejorarían la apariencia de la colonia y de las viviendas, dejando al frente un jardín de $5 \mathrm{mts}$.

-1905 se reglamenta el suelo urbano para establecer aspectos para el embellecimiento de la ciudad, alineamiento y prolongación de calles, pero con la intención de seguir con el trazado reticular, apertura de remates visuales en los conjuntos religiosos.

-Las Colonias buscaban instaurar un nuevo patrón de urbanización que rompiera con el orden urbano existente (concéntrico) al introducir las ideas de los suburbios que venían de las ideas de la ciudad jardín, en el que plantearon la revalorización del espacio físico y social del barrio al considerarlo obsoleto y perjudicial, por lo cual fue necesario salir del núcleo de la ciudad e instaurarse en terrenos de la periferia para la construcción de 


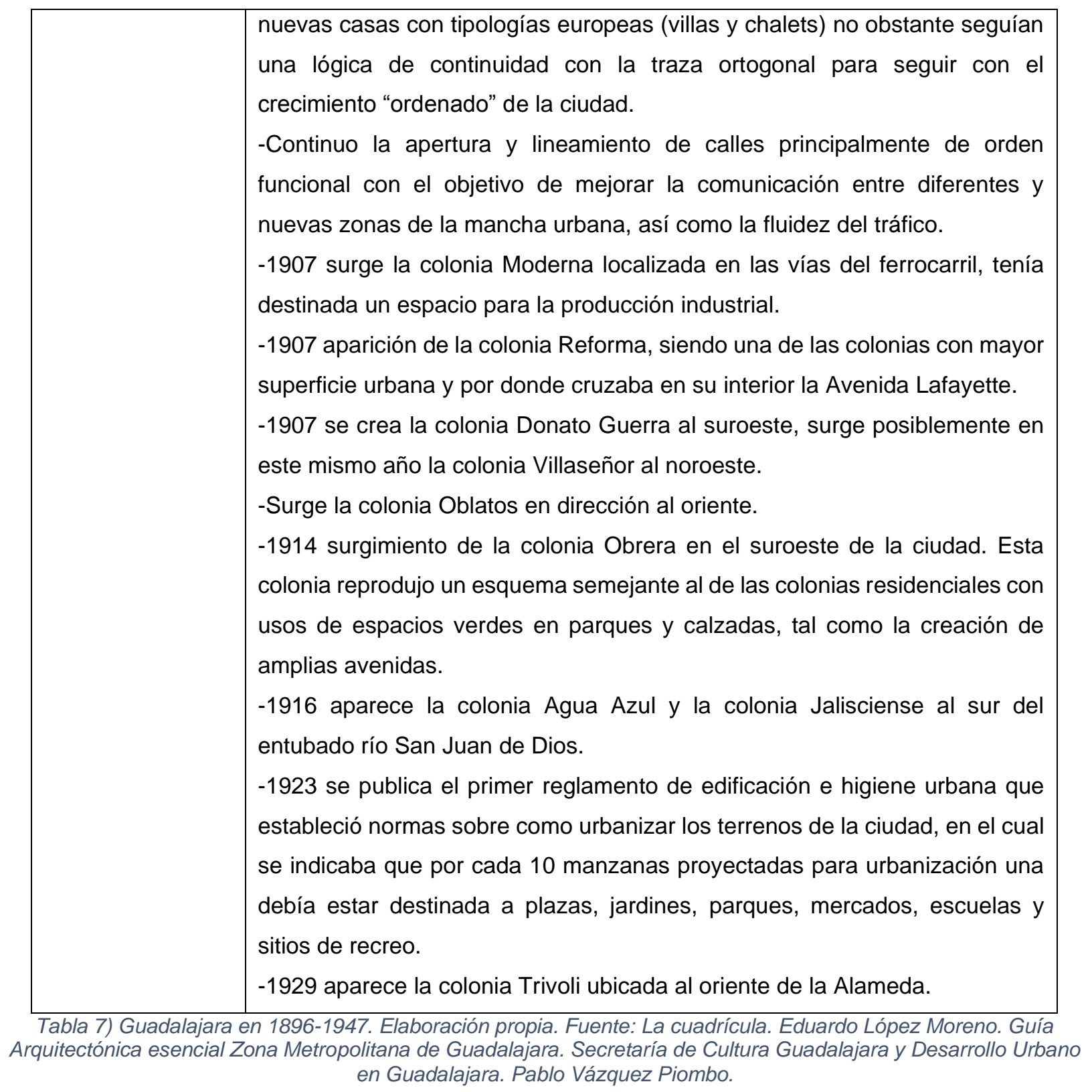




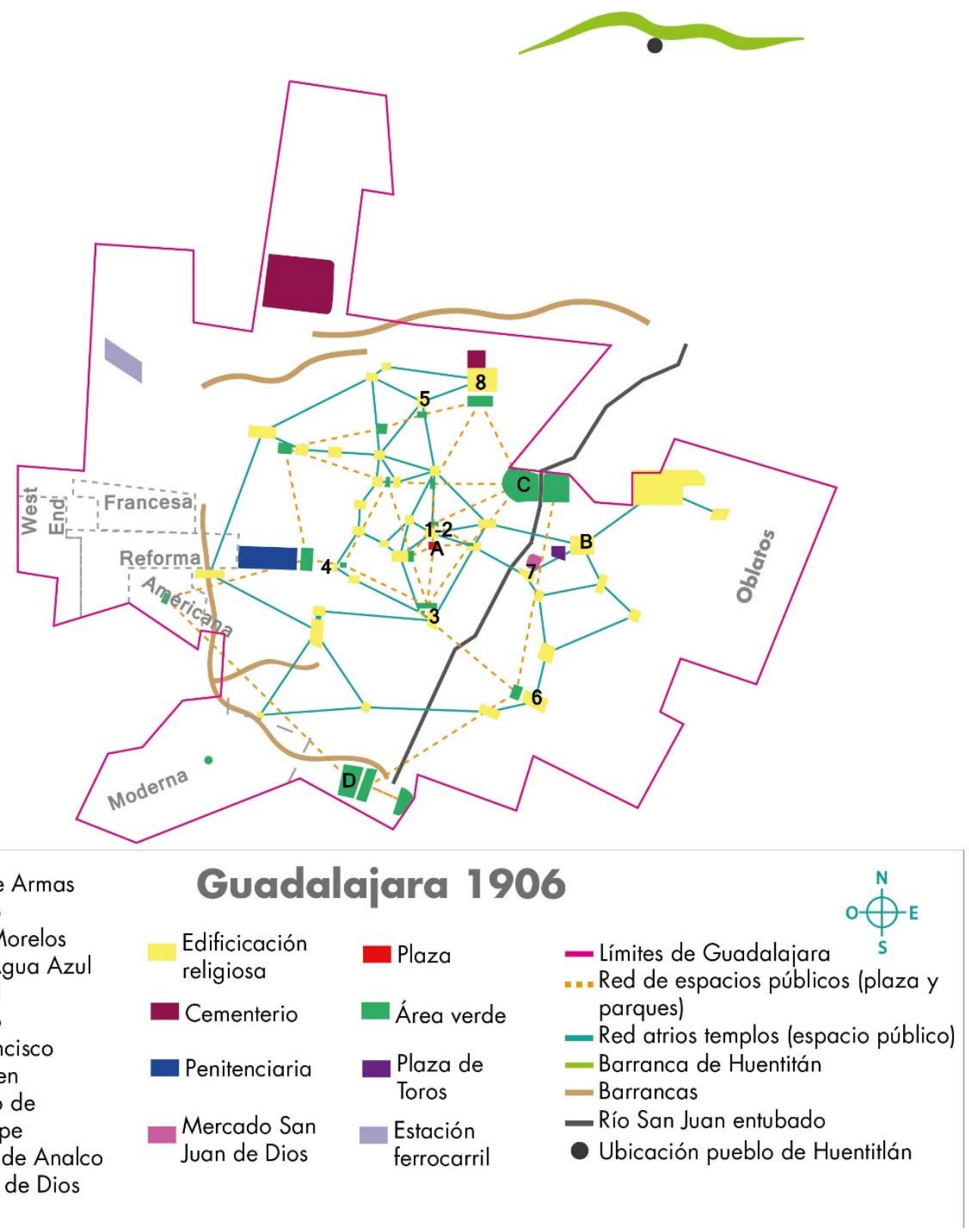

Modelo 10) Guadalajara en 1906. Elaboración propia. Fuente: mapoteca del archivo del estado de Jalisco, PL 7.3 190629

En cuanto al periodo del Porfiriato se llevaron a cabo diversas obras de modernización de la ciudad que se ven evidenciadas en los diversos jardines que se situaron en los distintos puntos de la ciudad. El entubamiento del río San Juan de Dios y la aparición de las Colonias trajo consigo cambios importantes para la Perla Tapatía, tal fue el caso de nuevas morfologías urbanas (ciudad jardín) y romper la barrera física de 
las dos Guadalajaras (la ciudad de los españoles y los indios). La saturación del tejido urbano de los años anteriores contribuyo al desarrollo urbano superficial de la ciudad hacia las zonas periféricas y como consecuente de esta acción se aseguró la continuidad y expansión del tejido urbano.

A lo largo de este periodo con las Leyes de Reforma y la aparición de las Colonias se observa una constante histórica del registro del ordenamiento del espacio a través del "espacio concebido y de prácticas materializadas" (Lefebvre y Soja) reflejadas en la producción de lo físico y tangible de los edificios y calles de la ciudad en contraposición del registro de relatos de las experiencias.

Durante 1906 la expansión territorial se da en dirección norte, oriente y sur poniente, esto debido a la influencia del tranvía en esa dirección (modelo 11).
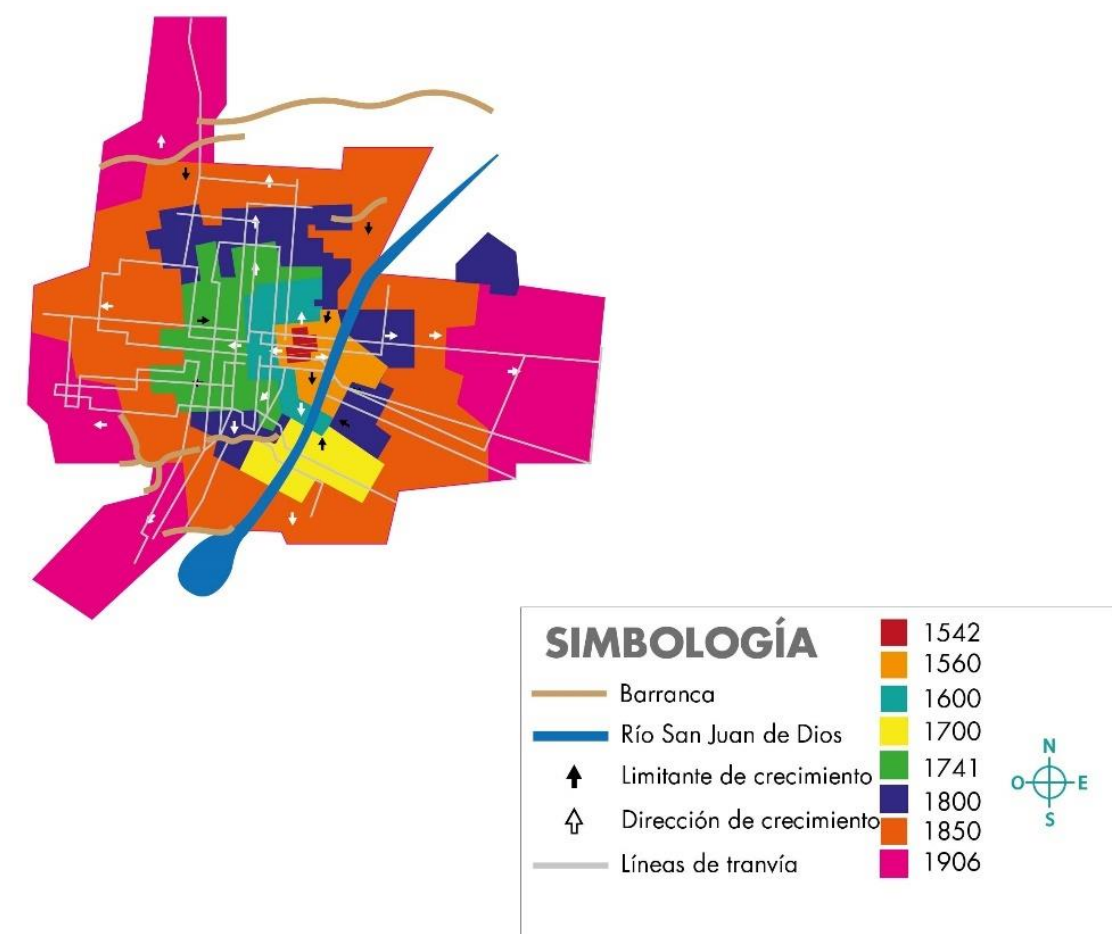

Modelo 11) Crecimiento GDL 1906. Elaboración propia. Fuente: Moreno 2001

Para 1920 la tendencia del crecimiento se da nuevamente en las 4 direcciones cardinales (norte, sur, oriente y poniente), algunos de los factores que restringieron su crecimiento fue la influencia del ferrocarril, la barranca de Belén como límite natural y la inauguración de la Av. Belisario Domínguez (modelo 12). 


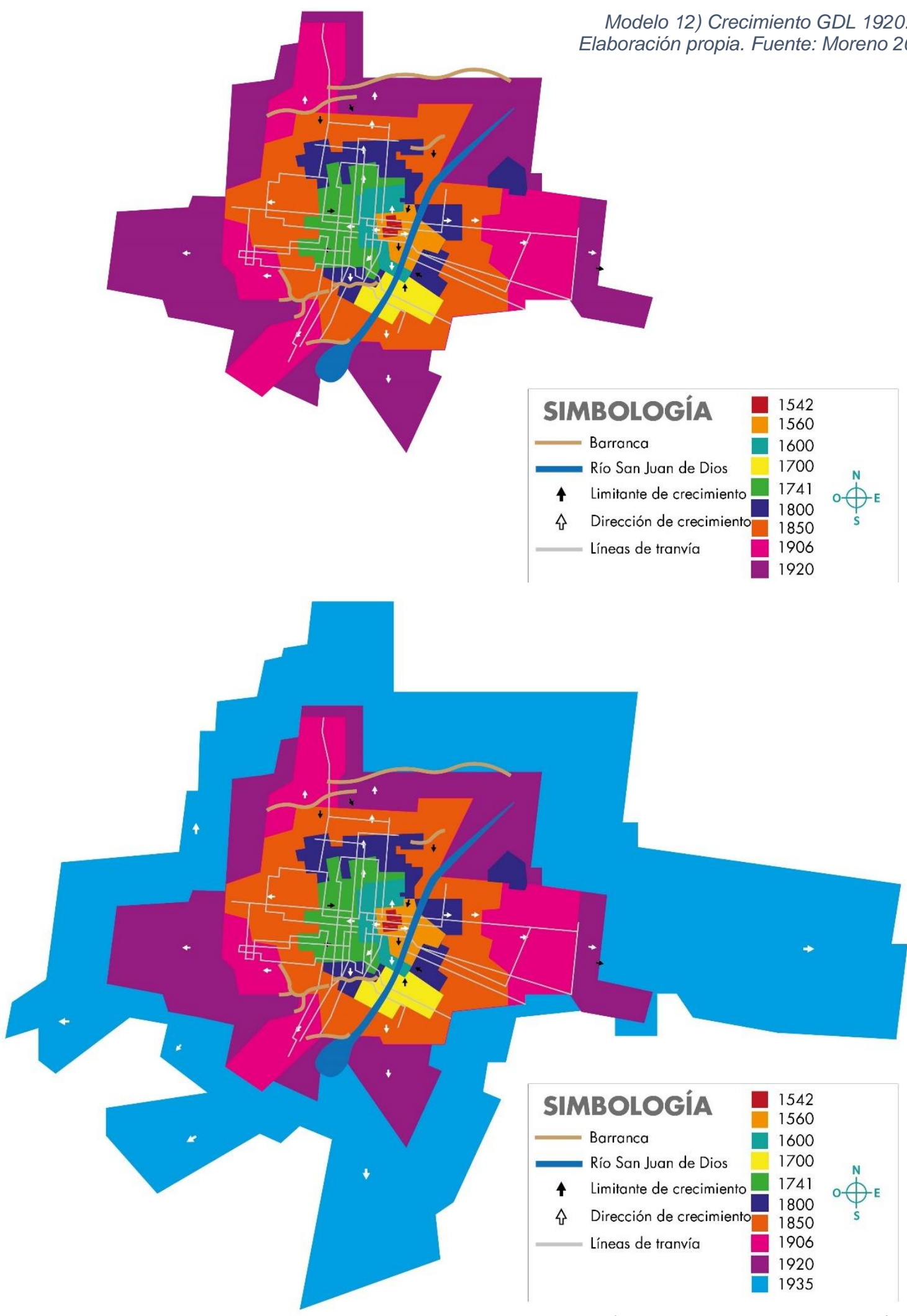

Modelo 13) Crecimiento GDL 1935. Elaboración propia. Fuente: Moreno 2001 
En el año 1935 la expansión se da hacia el poniente sur, sur y oriente (modelo 13).

\subsection{Guadalajara Moderna. De Cruz de Plazas y ensanches en la ciudad (1947-2000)}

En la gobernatura de José de Jesús Gonzáles Gallo, Guadalajara requiere de más espacios públicos, pues para esa época Guadalajara era una ciudad pequeña, pero con un uso creciente del automóvil que había saturado sus estrechas calles, provocando que la urbe se fuera quedando sin suficientes espacios de uso recreativo, en que los únicos espacios decentes y amplios para el disfrute público de la ciudad eran la plaza de Armas y el parque Morelos, motivo suficiente por el cual se le encarga al arquitecto Díaz Morales realizar un plan regulador para que la ciudad tenga un perfil más funcional y formal. Bajo esta idea de más espacios públicos Morales propone la construcción de la simbólica Cruz de Plazas: Plaza Guadalajara, Rotonda de los Jaliscienses Ilustres, Plaza de la Liberación y Plaza de Armas (plaza fundacional del virreinato).

De modo que de acuerdo con la premisa de modernización se da pauta a la iniciativa privada y del Gobierno local por demoler y alterar el centro histórico con la intención de modernizar a la ciudad con nuevos espacios públicos y edificaciones.

En los 70 autoridades intentan establecer planes de ordenamiento urbano para la ciudad, al igual que la incorporación del sistema de transporte colectivo subterráneo (SITREN) y un eje vial de norte a sur (Calzada del Federalismo) para desahogar la situación del tráfico de la ciudad, en el año 1973 se inician las obras para el eje vial y sistema de Transporte colectivo subterráneo, este sistema implico la demolición de varias fincas que dejaron una cicatriz y marca a la traza urbana al demoler propiedades con valor histórico, arquitectónico y cultural.

Estas intervenciones modernizadoras influyeron en la consolidación de Guadalajara como una ciudad abastecedora de servicios dentro de la región y por consiguiente un centro metropolitano. Al convertirse en un centro metropolitano la ciudad comenzó a expandirse de una manera descontrolada. 
En 1982 se inicia el proyecto de Plaza Tapatía ubicada entre el teatro Degollado y Hospicio Cabañas. Para su construcción se demolieron entre 9 y 13 manzanas que contaba con edificaciones históricas como la Plaza de Toros el Progreso.

Entre 1980-1890 se crea el Parque Natural Huentitán, un espacio de 16 has que buscaba proveer de espacios públicos a la zona norte de la ciudad y no fue hasta 1992 con las explosiones del colector intermedio de la ciudad al oriente de Analco lo que provocó una transformación del centro histórico del barrio de origen indígena y por tanto nuevamente una alteración de la traza urbana.

Si bien el espacio tiene una dimensión social, este periodo de "rayo" modernizador nos lleva a lo que sugiere Borja $(2000,28)$, que el espacio público tiene cualidades formales; es decir, una continuidad en el espacio urbano que le permite una facultad ordenadora por sus formas, diseño y la adaptabilidad de diversos usos a través del tiempo, en que estos espacios se han ido adaptando a los distintos usuarios y a los cambios generacionales de la ciudad, tal como menciona Lefebvre $(2013,142-143)$ "Los espacios sociales se interpretan y/o se yuxtaponen, debido a que no hay un solo espacio social, sino varios espacios sociales con una multiplicidad ilimitada"

Las características más destacadas de este periodo se observan en la tabla 8.

La Cruz de Plazas fue el primer paso de renovación urbana que culminaría en Plaza Tapatía con el objetivo de generar espacios públicos adecuados para la recreaciónesparcimiento de los tapatíos, tenía la intención de que esta cruz modificara la imagen urbana, la traza de la ciudad y dotar de una nueva belleza colonial tradicional. 
1947-2000 -1953 proyecto para modernizar la ciudad "Cruz de Plazas", para su construcción

(Modelo 14) se demolieron fincas como casas reales, el palacio Cañedo, el templo de la Soledad y su convento.

-La Cruz de Plazas hace referencia a un homenaje de la cruz urbana del virreinato (Santo Domingo, San Juan de Dios, San Francisco y El Carmen).

-1959 durante la administración de Juan Gil Preciado se decreta la Ley de Planeación y Urbanización del Estado que creó la Junta General de Planeación y Urbanización.

-Fue durante los 70 que comienzan a aparecer asentamientos ilegales e irregulares alrededor de los límites de la ciudad como proceso de desplazamiento y crecimiento urbano en relación con las nuevas colonias, conformando como consecuente un cinturón de miseria, es decir, lugares donde no se contempló la implementación de espacios públicos y de poco valor inmobiliario y con precariedad de servicios y equipamientos públicos.

-Se gestaron parques públicos como el del Refugio localizado frente a la iglesia del mismo nombre sobre la Czda. del Federalismo.

-Comienzan a surgir las primeras tipologías de vivienda cerrada dentro de murallas (fraccionamientos privados), donde el espacio público recreativo de los mismos se sesgaba al uso exclusivo de quienes vivían dentro de las "murallas". -1977 se instaura el Departamento de Planeación y Urbanización que pasa a ser una dependencia estatal.

-A finales de los años 70 se crea el parque Mirador Independencia en el extremo norte de la ciudad colindante a la Barranca de Huentitán.

-1982 se decreta el primer plan de ordenamiento de la zona conurbada de Guadalajara con programas y acciones para controlar el uso de suelo.

-La Plaza Tapatía buscó transformar la fisonomía y perspectiva urbana del centro y concebir al Hospicio Cabañas como un remate monumental.

-La construcción de la Cruz de Plazas y Plaza Tapatía pretendían configurar un recorrido peatonal dentro del primer cuadro histórico de la ciudad.

-En el año de 1884 la mancha urbana se extiende hasta el norte periférico de la ciudad, alcanzando y comenzando a absorber al poblado de Huentitán.

-Durante este periodo existió una marcada distinción entre centro y periferia, rompiendo con la traza homogénea de la ciudad.

Tabla 8) Guadalajara en 1947-2000. Elaboración propia. Fuente: Guadalajara y Desarrollo Urbano en Guadalajara. Pablo Vázquez Piombo. Guía Arquitectónica esencial Zona Metropolitana de Guadalajara. Secretaría de Cultura

Guadalajara. 


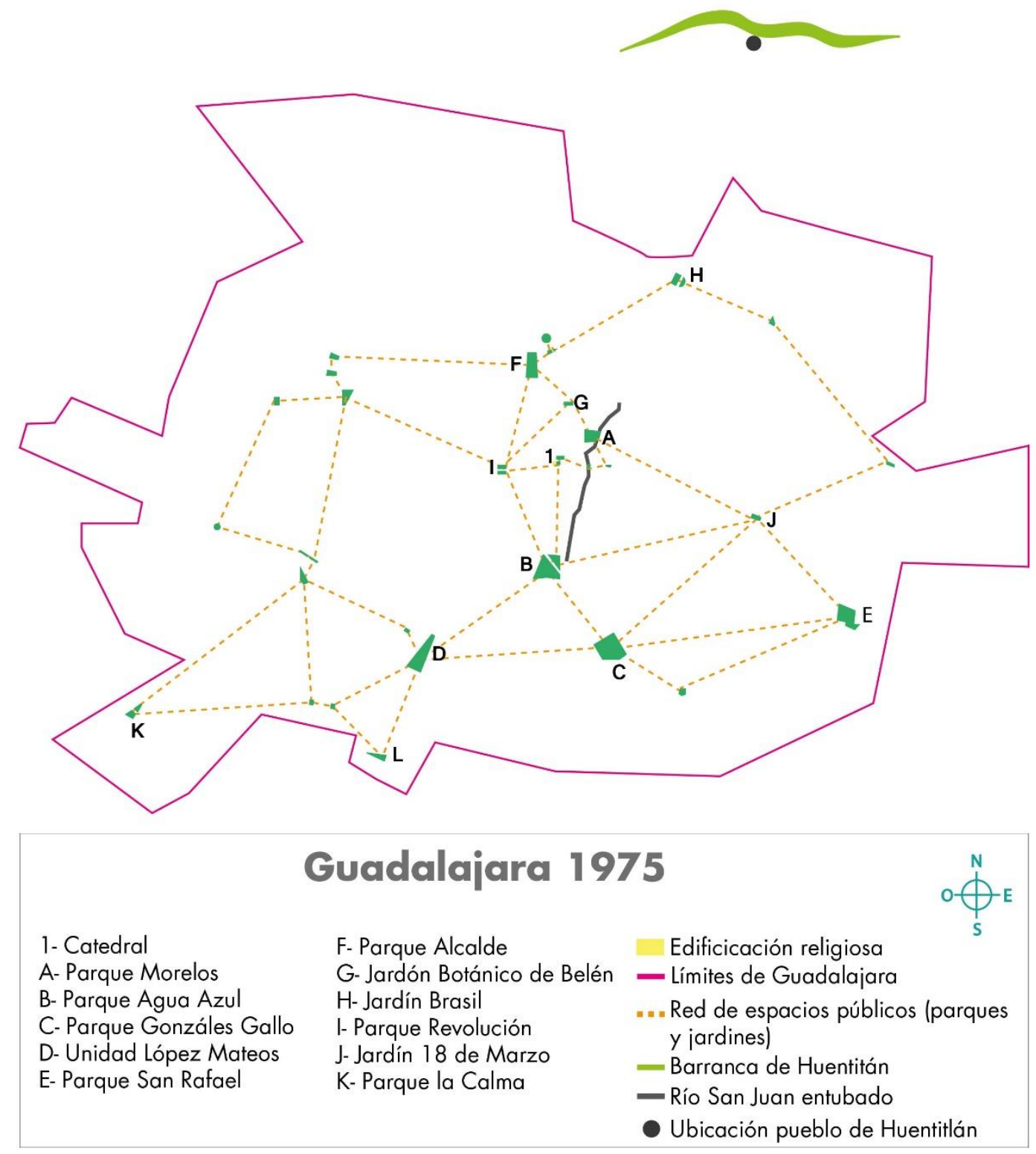

Modelo 14) Guadalajara en 1975. Elaboración propia. Fuente: mapoteca del archivo del municipal basado en un plano de la ciudad de Guadalajara 1975, 36gdlzm el cual solo señaliza parques.

Por otro lado, la producción del espacio público de la zona periférica norte de Guadalajara, Huentitán, colonia popular que se localiza al final de la Calzada Independencia al borde de la Barranca, se encuentra ubicado el primer gran espacio público abierto verde de este pintoresco barrio, el Parque Mirador Independencia. 
Siguiendo por la Calzada y situado a un costado del Zoológico está el segundo gran espacio público abierto verde de la colonia, el Parque Natural de Huentitán.

Si bien la colonia de Huentitán cuenta con otros pequeños parques vecinales, estas dos grandes extensiones de área verde representan el mayor porcentaje de espacio público para el barrio, en el que propios y visitantes de otras colonias se acercan para disfrutar no solo de los servicios ambientales que proporcionan estas áreas arboladas, sino para realizar actividades específicas, que por las características de los espacios no se pueden realizar en otros sitios de Huentitán o de la zona centro de la ciudad.

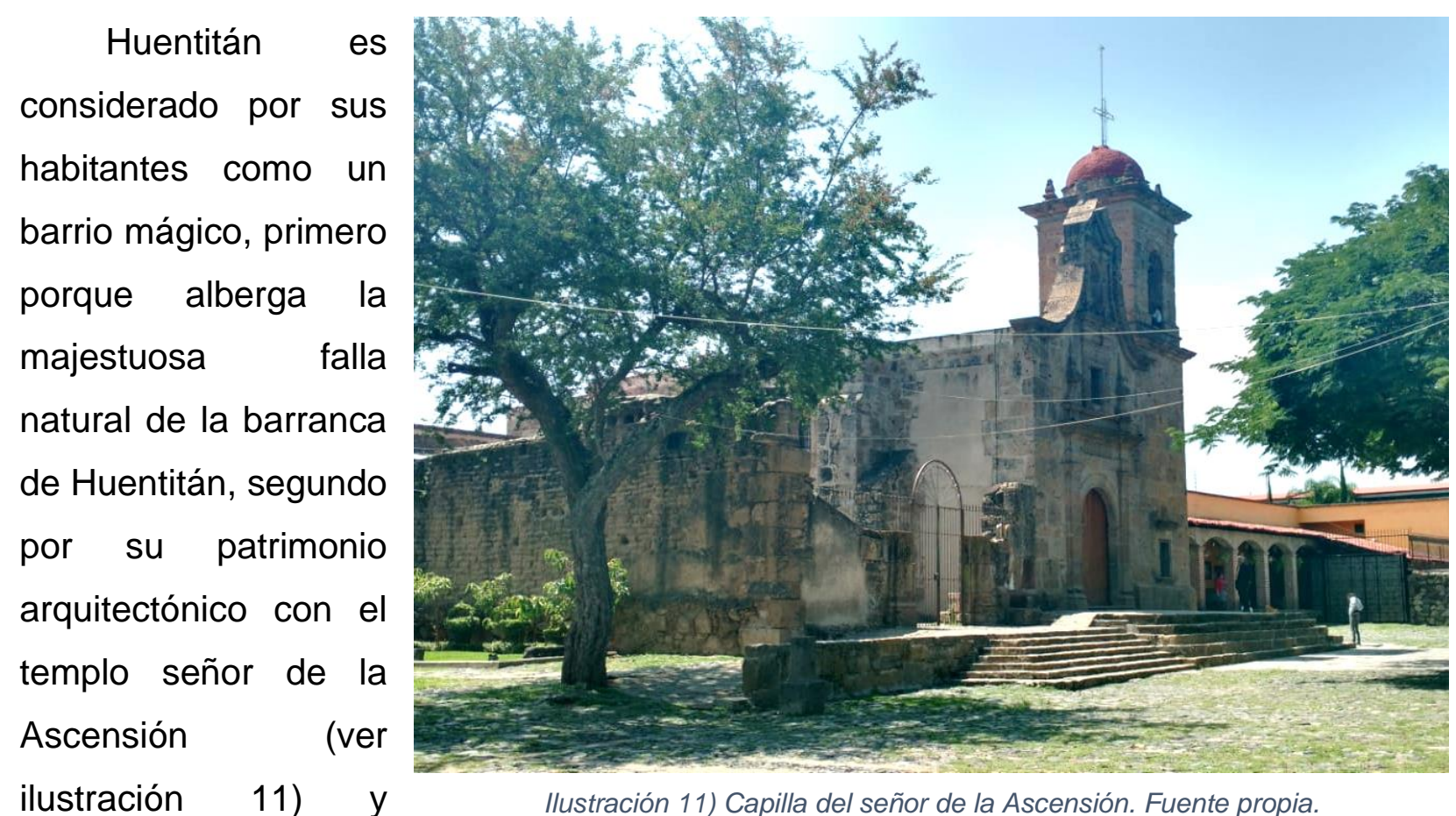

tercero por tener dos de los más grandes parques de la ciudad, Parque Mirador con unas vistas privilegiadas y el parque Natural de Huentitán al ser un pequeño bosque urbano dentro de la zona norte.

No existe un registro preciso de la conurbación de este poblado con Guadalajara, si bien la Facultad de Arquitectura de la Universidad de Guadalajara se fundó al pie de la Barranca en 1948 (UDG, 2019), su construcción no fue detonante para el crecimiento del barrio. En los años subsecuentes no hay registro de la extensión de Huentitán o de la ciudad misma hacia el norte, prueba de ello es un plano de la ciudad de 1975 en el que 
se observa que los límites de Guadalajara en dirección al norte era el anillo periférico (ver ilustración 12).

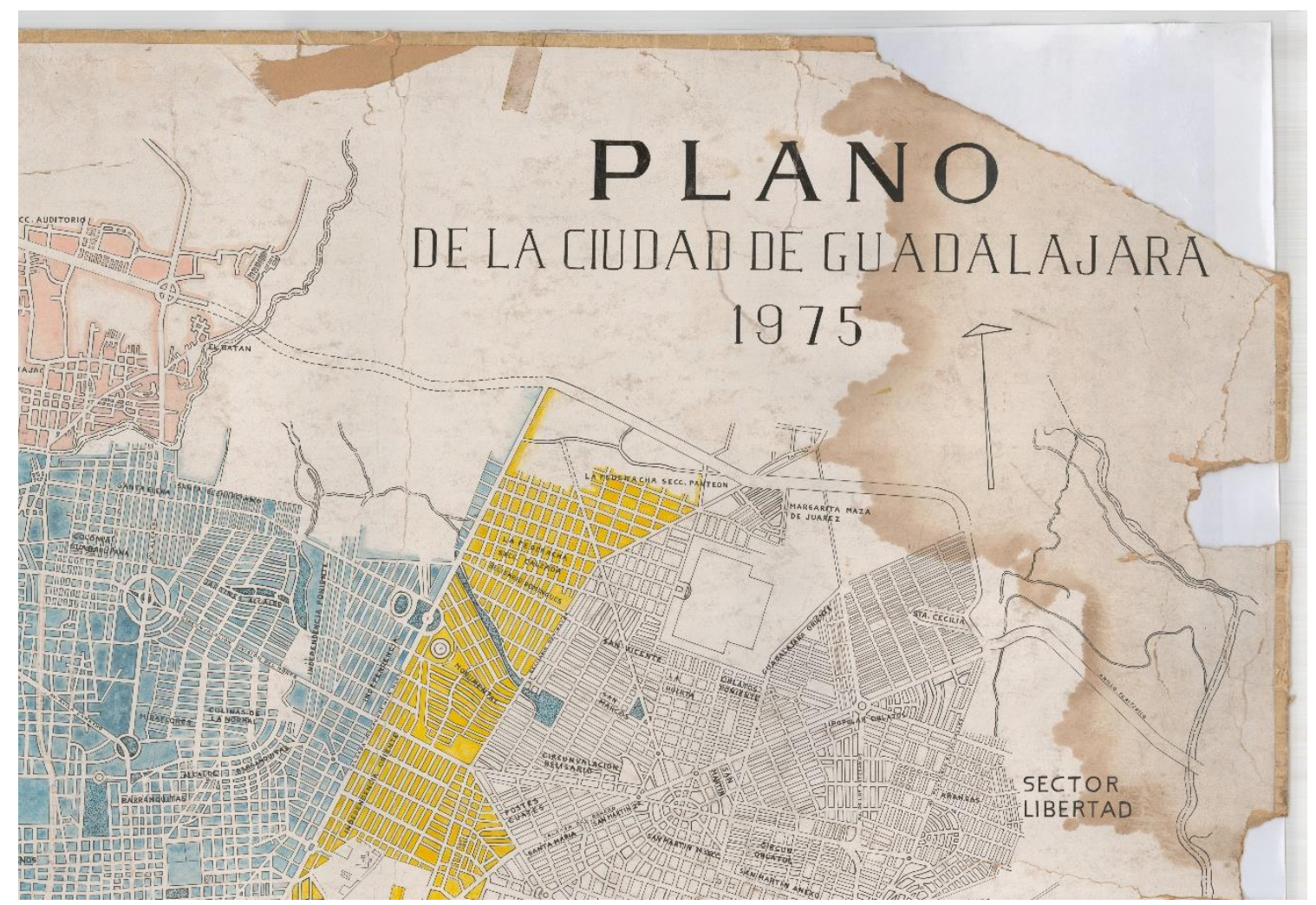

Ilustración 12) Fragmento del límite Guadalajara al norte con anillo periférico. Fuente: mapoteca del archivo del municipal basado en un plano de la ciudad de Guadalajara 1975, 36gdlzm

\subsection{Guadalajara contemporánea. Megaproyectos en la Perla Tapatía (2000-2018)}

Debido al aumento de la población y el crecimiento de la ciudad surgen propuestas de intervención urbanística que logren regenerar el tejido urbano con la reintegración de la población y producir nuevos espacios públicos y culturales por medio de proyectos impulsados por el gobierno y participación de capital privado para promover procesos de desarrollo financiero, cultural y turístico a la ciudad. A la vez se da la promoción y participación directa del estado en la orientación de recursos públicos y adecuación de instrumentos de planeación y gestión urbana. 


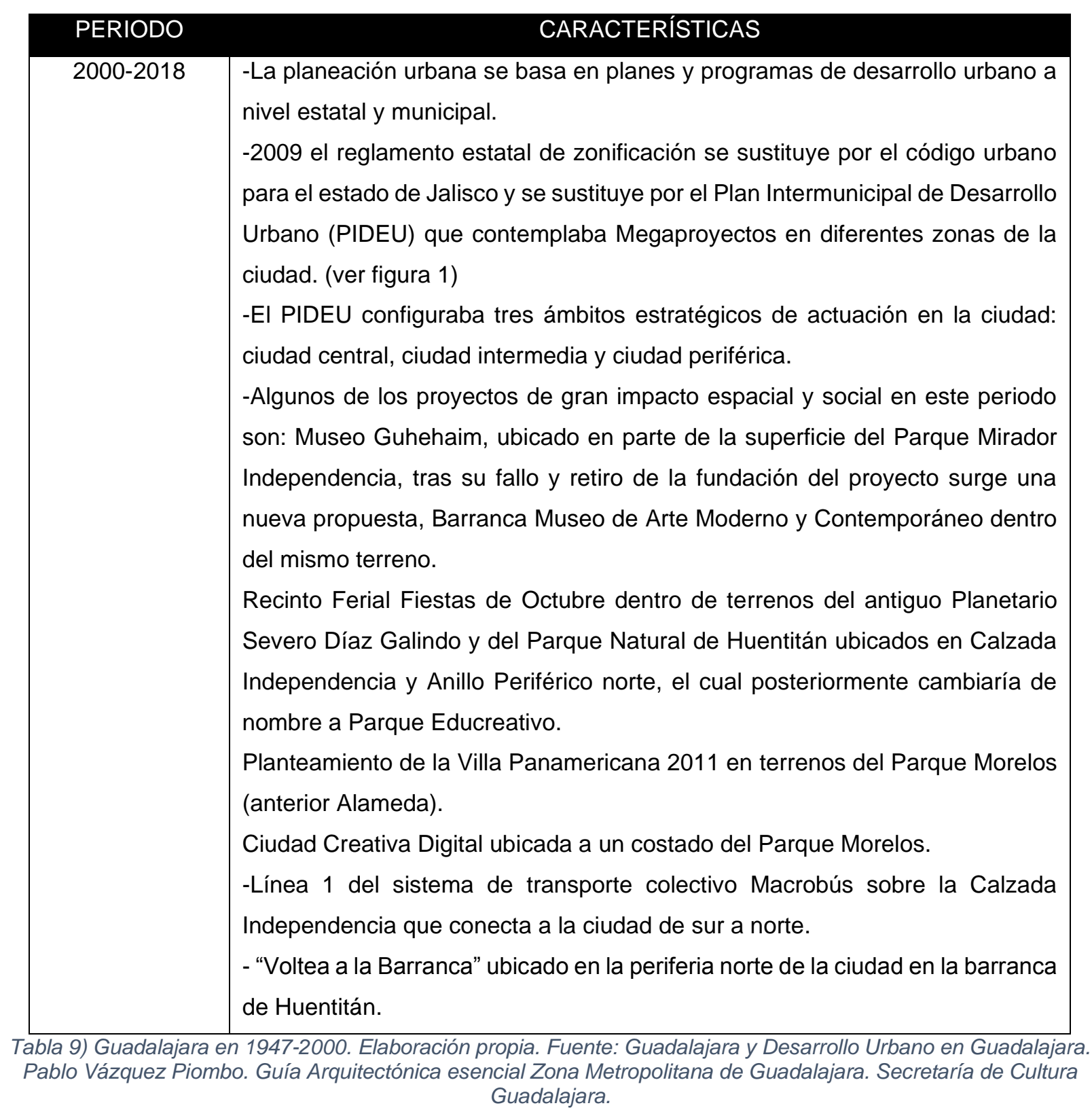

En este periodo y a partir el movimiento moderno en la ciudad se muestra una importancia y registro del espacio percibido y del espacio vivido de las experiencias que definen Lefebvre y Soja respectivamente y sin dejar de lado la concepción concebida y materializada del espacio desde la opinión de los expertos planificadores y arquitectos, ya que ello implica una mixtura, como describe Soja $(2000,40)$

"El espacio urbano, esencialmente reducido a un resultado o producto de la acción e intención social, es visto como algo a ser explicado. Solo de vez 
en cuando es reconocido como un proceso de construcción espacial ( $y$ social)"

En la tabla 9 se enlistan algunos de los hechos más relevantes de este periodo.

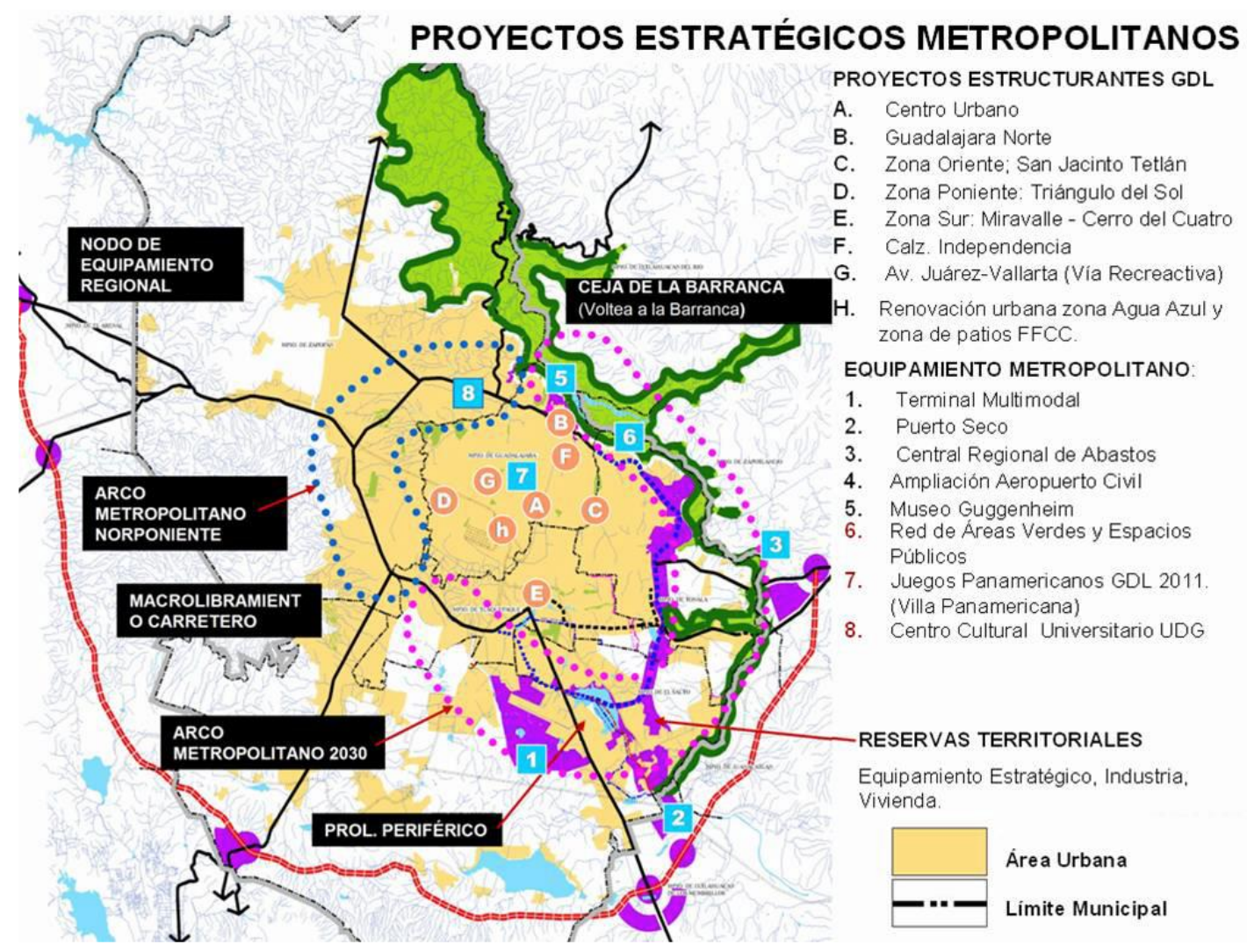

Figura 1) Proyectos estratégicos Metropolitanos contenidos dentro del PIDEU. Fuente: GRANDES PROYECTOS DE INTERVENCIÓN EN LA CIUDAD-METRÓPOLI:CGUADALAJARA, MÉXICO Y LOS RETOS EN LA PLANEACIÓN URBANA

En el nuevo siglo es evidente la necesidad de las autoridades de regular el orden urbano de la ciudad pero a su vez mantener a Guadalajara como una ciudad moderna y polo de atracción para inversionistas, dicha modernidad ha sido por medio de revalorizar mediante la especulación terrenos y espacios subutilizados de la ciudad con la finalidad de figurar como una urbe de vanguardia pero sacrificando sus áreas verdes y patrimonio histórico edificado, dando como resultante, no solo un déficit de masa verde, también discontinuidades marcadas en su traza que generan un rompimiento en su identidad histórica, alteraciones que dieron lugar a cambios de usos de suelo, segmentación de 
barrios tradicionales que cuentan con espacios patrimoniales y edificaciones que el nuevo trazado urbano transformó en áreas para actividades comerciales turísticas, institucionales, culturales así como una falta de sensibilidad en correlación al uso habitacional y de la población residente.

\section{Conclusiones capítulo 2}

Guadalajara tuvo series de transiciones, transformaciones y cambios urbanos a través de su historia; obras de embellecimiento de la ciudad con el Parque Alameda (1750) actual Parque Morelos, las Leyes de Reforma (1850) que permitieron la expropiación de terrenos en manos de la iglesia para la apertura de calles y construcción de nuevos espacios, entubamiento del Río San Juan de Dios (1897) que dio fin a la barrera física que separaba a las dos Guadalajaras (la ciudad de los españoles fundacional y la de los indios), las primeras urbanizaciones higiénicas de la ciudad con las "Colonias" (1898) barrios con influencias extranjeras en cuanto a trama y traza europea y americana, la proyección y construcción de la Cruz de plazas (1950), apertura del primer centro comercial "Plaza del Sol" (años 70) y crecimiento hacia las periferias. Este último fenómeno afecto a Huentitán, que de ser un pueblo se transformó en un barrio popular a las orillas de la ciudad con asentamientos regulares e irregulares, con extensiones de terreno baldíos que fungían como espacios de esparcimiento, o áreas verdes para el uso recreativo de los habitantes periféricos, quienes a su vez encontraban espacios de identidad, descanso y distracción óptimos en la centralidad de la ciudad (casco histórico), motivo por el cual ejidatarios de la zona deciden donar terrenos para uso comunitario y que posteriormente da como resultante la aparición de dos grandes parques en la colonia, Parque Mirador Independencia (1970) y Parque Natural de Huentitán.

La perla Tapatía es una ciudad de origen colonial fundada dentro de poblados indígenas, su crecimiento respondía a las Leyes de Indias, las cuales regulaban la morfología de crecimiento de las nuevas ciudades españolas dentro del nuevo continente, Guadalajara no fue la excepción y su forma de expansión del territorio virreinal 
estaba de alguna manera pre-diseñado, razón por la cual la Perla Tapatía tiene similitudes con otras ciudades coloniales en donde las calles se trazaban en una retícula que situaba al centro la Plaza de Armas y albergaba a su alrededor las autoridades religiosas y el Ayuntamiento.

Plaza de Armas desde las ordenanzas de las Leyes de Indias más allá de estar concebida físicamente como un espacio público, era percibida por su valor simbólico de núcleo ordenador para la ciudad, al ser centro de la ciudad desde ahí se desplegaba la traza y era precisamente desde la plaza donde se resguardaba y se decidían las acciones de expansión y dominio del territorio. La Plaza de Armas a partir de la perspectiva de Lefebvre tendría dos ejes, por un lado, era un espacio concebido por los expertos que planificaron las Leyes de Indias para la zonificación del reino de la Nueva España, y por otro lado un sitio de la realidad cotidiana donde el simbolismo de espacio público de poder para indios y españoles se hacía evidente al ser un punto de encuentro no solo social y de convivencia y a la par un referente de la acción política y religiosa.

La ciudad fue creciendo y extendiendo su territorio hasta alcanzar poblados de indios que posteriormente fueron domesticados y evangelizados. Algo que se debe destacar de esta forma de crecimiento y expansión del territorio colonial es que la Plaza de Armas era el espacio central principal y mayor de la ciudad, su producción correspondía desde el abordaje de Soja como espacio vivido al ser construido por los expertos de las leyes reguladoras de Indias, no obstante al analizar los diferentes mapas y convertirlos en modelos de crecimiento y expansión de la ciudad sobresale que la urbe regía su crecimiento y sus límites expansivos con relación a inmuebles religiosos, los cuales vendrían a fungir como espacios públicos de encuentro para la convivencia social y religiosa en los atrios de los templos o jardines de los mismos, y en que la producción del espacio público se desarrollaba en un sentido religioso abierto, puesto que para los franciscanos (ordenanza que tuvo presencia en Jalisco) era importante tener un espacio abierto al aire libre para que los indígenas se pudiesen reunir, esto debido a que los espacios públicos de encuentro y convivencia prehispánicos correspondían a sitios abiertos y sin murallas de libre acceso para los pobladores. Es con base en este patrón 
de crecimiento que se observa que desde la fundación de Guadalajara hasta aproximadamente los años 30 s el crecimiento y expansión de la ciudad era determinado por los espacios públicos (atrios o jardines) de edificaciones religiosas, no dejando de lado que durante el año de 1750 se marca la importancia de las áreas verdes como espacios públicos para la recreación y esparcimiento de la psique de los tapatíos con la construcción del primer gran parque público de la ciudad, La Alameda hoy Parque Morelos. Al analizar los diferentes modelos de estos periodos se observó la constante de limitar el territorio de la urbe por una iglesia o convento, que además, poseía una proximidad para poder acceder en poco tiempo de manera peatonal entre un espacio y otro, esto indica que no solamente el espacio público era un regulador y determinante de crecimiento, también era indicador que la producción de los espacios públicos se ligaba a una red de nodos de espacios conectados a un núcleo central que es la Plaza de Armas, espacio que abrigaba la edificación religiosa más importante de la ciudad, la Catedral.

No obstante, los espacios públicos fueran revalorizados y puestos en la punta de lanza y ojo del Ayuntamiento durante la gobernatura de Gonzáles Gallo, este gobernador consideraba la importancia de dotar de más espacios públicos abiertos a la ciudadanía, dando como consecuente el planteamiento y construcción de la Cruz de Plazas. La Cruz de Plazas tuvo su origen desde la planeación y ordenamiento del territorio, fue un espacio concebido por expertos y reconocidos arquitectos e ingenieros de la época para el disfrute y revalorización del centro histórico como el gran patio o sala de estar de la ciudad, que al igual que el Parque Morelos tuvo una proyección para su destino de uso de suelo y desarrollo, quedando en testimonio de su planificación los planos de diseño que se elaboraron para su realización.

Por otro lado, de Huentitán se cuenta con poco registro de su crecimiento y expansión en los archivos históricos, mapas o planos de la ciudad. Al tener un origen de poblado de indios su primer espacio público estaba ligado a un atrio de una capilla franciscana, no fue hasta 1948 al fundar la escuela de Arquitectura que este poblado comenzó a ser un poco más conocido, sin embargo, fue hasta los años 70 con la construcción del Parque Mirador Independencia que la presencia del primer gran espacio 
público verde de la ciudad reforzó la identidad y simbolismo del poblado ligado a su origen barranqueño, donde posteriormente al construir el zoológico de la ciudad se destina un amplio terreno a un costado para un segundo espacio público verde con el Parque Natural de Huentitán. 
"Las ciudades son un conjunto de muchas cosas: memorias, deseos, signos de un lenguaje; son lugares de trueque, como explican todos los libros de historia de la economía, pero estos trueques no lo son sólo de mercancías, son también trueques de palabras, de deseos, de recuerdos".

Italo Calvino

3.1 Producción y del espacio público en la zona Centro de Guadalajara Como se menciona en el capítulo anterior, Guadalajara es una ciudad que mantuvo un crecimiento lento y constante por lo menos hasta los años 70 , fue durante este periodo que la ciudad se anexa físicamente con los municipios de Zapopan y Tlaquepaque y comienza a albergar a grandes empresas que diversificaron la producción industrial (Cruz, 2012: 17-18), por consecuente la Perla Tapatía era una ciudad compacta que quería renovarse, donde la demanda de vivienda se veía creciente en su periferia y el uso del automóvil comenzó a ahogar e inundar las calles, motivo por el cual sus habitantes comenzaron a quedarse sin espacios recreativos y de esparcimiento necesarios para el disfrute y descanso necesarios para la psique humana.

La plaza fundacional se había perdido y los únicos grandes espacios públicos que tenía la ciudad era el Parque Morelos y la Plaza de Armas, por ello era necesario proveer de nuevos espacios a la ciudad, regresar la plaza fundacional, pero sobre todo y como objetivo principal, ofrecer espacios gratuitos para el descanso, contemplación y esparcimiento a las personas, como el arquitecto Ignacio Díaz Morales ${ }^{9}$ dijo al momento de plantear su proyecto de la Cruz de Plazas:

"Que los tapatíos tuvieran un asiento gratuito en el corazón de la ciudad, para que todo el pueblo pudiera sentarse en el gran patio de su casa grande" (Kasis, 2004: 60).

Tras el movimiento moderno, sus tendencias de urbanismo y el derribo de grandes fincas patrimoniales para dar paso a nuevos espacios públicos (parques, jardines y plazas) como parte de las obras de renovación de la ciudad, diferentes necesidades y

\footnotetext{
${ }^{9}$ Ignacio Díaz Morales fue un arquitecto tapatío, uno de los pilares fundacionales de la académica de arquitectura en Guadalajara.
} 
criterios fueron puestos sobre la mesa, ya que si bien Morales abandono el proyecto por motivos personales al querer conservar ciertas edificaciones por su patrimonio histórico y a sus enfrentamientos con el gobernador Gonzáles Gallo ${ }^{10}$ quien no quiso hacer adecuaciones al proyecto y mantenerlo en marcha contratando a otros arquitectos para poder terminar la propuesta.

Actualmente a pesar de la perdida irreversible de edificios históricos la Cruz de Plazas demuestra la funcionalidad que tiene al ser un espacio de encuentro tanto para locales y turistas que caminan, juegan, pasean, contemplan el paisaje urbano, toman fotos, pero sobre todo se hace vida pública que concibe que el corazón de la ciudad sea un espacio vivo, vibrante y latiente día con día.

Por otro lado el Parque Morelos, una Alameda que se convirtió en un gran parque urbano con la intención de ser un espacio para el descanso, esparcimiento y recreación, durante el siglo XIX ha pasado por remodelaciones para mejorar su imagen física y simbólica, ya que al encontrarse ubicado dentro de la zona de tolerancia en los límites del centro de la ciudad y con límite a la Av. Calzada Independencia la cual separa simbólicamente la ciudad, que pesé a tener características físicas que invitan a la contemplación, esparcimiento y recreación al contar con áreas verdes y mobiliario de juego y descanso, a este espacio se le ha relacionado como un punto de encuentro para prostitutas, como quien va a una pasarela y elige a una dama, razón por lo cual durante la administración del 2018 el gobierno del municipio decidió hacer una remodelación contundente de sus andadores, áreas verdes, mobiliario urbano (bancas, juegos, pergolados, luminarias) y la implementación de vigilancia que realiza recorridos dentro de las 5 hectáreas de superficie del parque. Dicha remodelación consistió en la implementación de $35 \mathrm{mil} \mathrm{m2} \mathrm{de} \mathrm{andadores} \mathrm{en} \mathrm{todo} \mathrm{el} \mathrm{parque,} 30$ mil m2 de jardinería, mobiliario urbano como bancas y botes de basura, así como la instalación de 174 luminarias de led para iluminar el parque y brindar mayor seguridad (Ramírez 2019).

\footnotetext{
${ }^{10}$ José de Jesús Gonzáles Gallo fue un político mexicano y gobernador del estado de Jalisco en el periodo de 1497 a 1953
} 
La regeneración aplicada al espacio fue una medida drástica por parte del municipio para librar el "secuestro" del parque y que volviera a ser de uso y disfrute pleno para los ciudadanos, recuperar su vocación de espacio público y que a su vez formará parte de las dinámicas de los demás espacios céntricos de la ciudad. Si bien la imagen urbana del espacio mejoro bastante el contexto del lugar, la intervención no fue suficiente para desplazar a sus usuarias principales, las cuales vagan y hacen uso de determinados espacios del parque, además de que el entorno exterior que rodea al Morelos (bares, casas de empeño en su mayoría) no ayudó a que dicha remodelación logrará al 100\% su objetivo.

3.1.1 Cruz de Plazas

Como parte de la metodología de esta investigación se usarán métodos cualitativos de la etnografía urbana por medio de recursos como; entrevistas, mapeos, recorridos, toma de fotografías, para explorar las dos zonas de estudio.

En los siguientes apartados correspondientes a los espacios centrales de la Cruz de Plazas y Parque Morelos, como ya se mencionó en el capítulo 1, solo se aplicarán las tablas de las variables de comodidad-imagen y conexiones-accesos debido a que se relacionan a características cualitativas de los espacios y a aspectos del entorno físico y visual.

Las tablas de variables de sociabilidad y usos- actividades no serán aplicadas debido a que como se señaló anteriormente ya se cuentan con investigaciones y análisis sobre los usos y actividades de estas plazas y parque-alameda, además de que estos espacios desde sus orígenes asumieron una vocación como lugares de encuentro y que al pasar de los años siguen teniendo esta misma concepción. Tampoco se aplicarán encuestas a los usuarios ya que como se ha mencionado estas áreas han sido bastante estudiadas, sin embargo, para entender el contexto general de las plazas y parque se hará una descripción de los usos y actividades que suceden desde la observación transitoria con la finalidad de contextualizar las dinámicas que realizan las personas en ellos. 


\section{Características generales}

Ubicada en el casco histórico de la ciudad, esta cruz simbólica y física es obra del arquitecto Ignacio Díaz Morales, se vio materializada durante la gobernatura de Jesús Gonzáles Gallo en 1947 como producto de sus ideas modernistas y bajo el requerimiento de mayores espacios públicos para la ciudad (González,2005: 28)

La cruz se conforma por el conjunto de cuatro plazas que rodean a la Catedral Metropolitana de Guadalajara: Plaza Liberación, Plaza de Armas, Rotonda de los Jaliscienses ilustres y plaza de Guadalajara o del Ayuntamiento (ver ilustración 13).
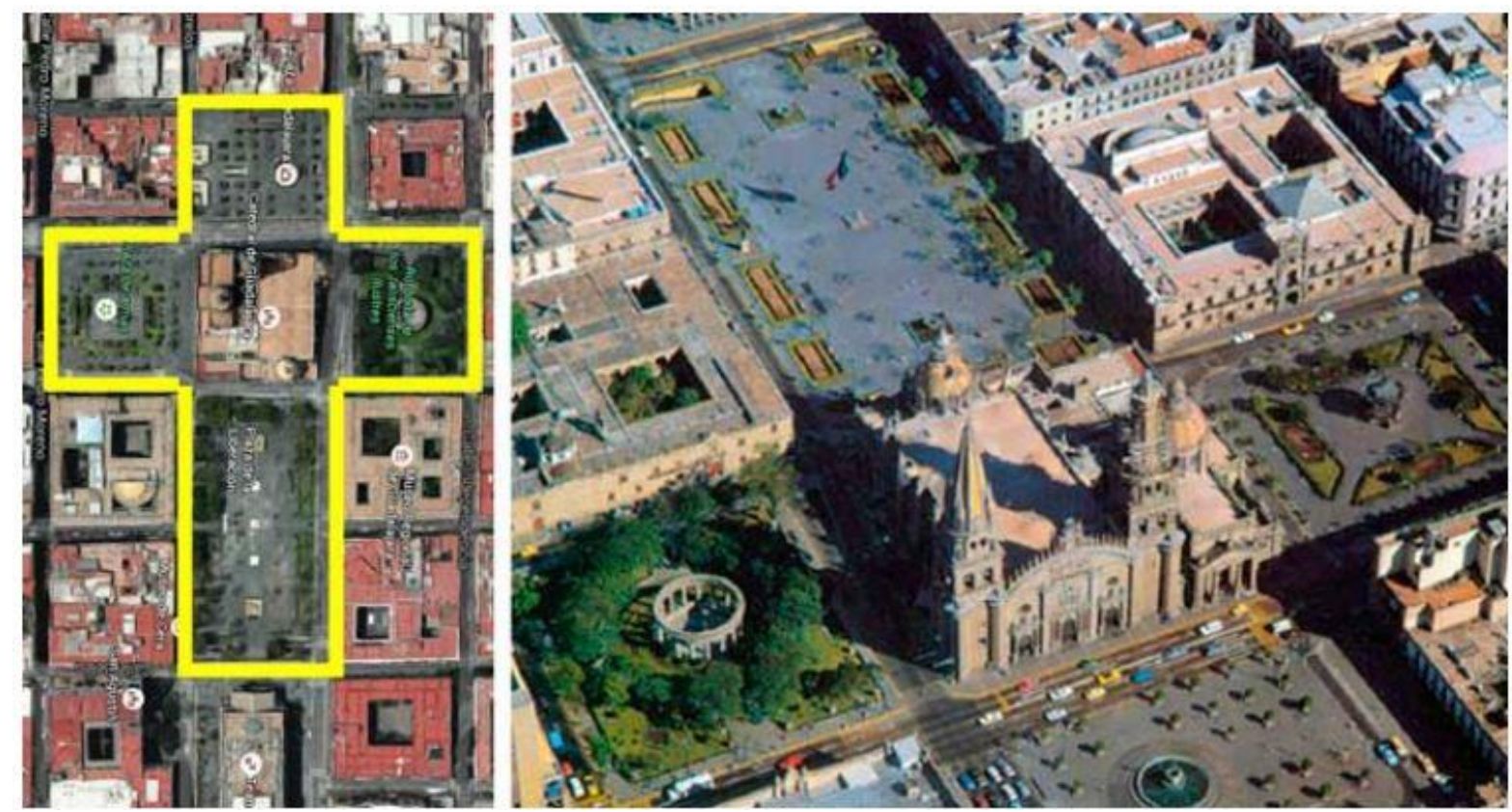

Ilustración 13) Cruz de Plazas. En la parte inferior Plaza Liberación, parte central derecha Plaza de Armas, parte superior Plaza Guadalajara y al centro a la derecha la Rotonda de los Jaliscienses Ilustres. Al centro la Catedral Metropolitana. Fuente: visitajalisco.com.mx 


\section{Características morfológicas y funcionales}

Esta cruz nace como un plano regulador para que la ciudad adquiera un perfil funcional y formal, si se tiene la oportunidad de observarla desde las alturas da la apariencia de una cruz latina que fue ajustada a la traza existente de cuadrícula (ver ilustración 15).

La Cruz de Plazas articula la configuración central del casco histórico, es un paseo rector y fundamental al conectar con importantes sitios de la ciudad como la Catedral, el Ayuntamiento, el museo Regional, el Teatro Degollado y también el Hospicio Cabañas por medio de Plaza Tapatía.

Cruz de Plazas no solo abre la perspectiva al centro histórico por los edificios antes mencionados, es también un símbolo que sirvió para dar entrada a la modernidad en la urbe.

\subsubsection{Plaza Liberación Características generales}

Popularmente esta plaza es conocida como "la de las dos copas" debido a dos fuentes que alberga en su interior. En un costado se puede apreciar una escultura de Miguel Hidalgo rompiendo las cadenas y que conmemora la abolición de la esclavitud, de ahí que esta plaza toma su nombre de "la Liberación" (Gonzáles; 2005: 34)

La plaza es obra del arquitecto Díaz Morales, para su construcción se demolieron dos manzanas con dos edificaciones de alto valor arquitectónico: casa Cañedo y una casa del siglo XVII (Gonzáles; 2005: 35). Fue terminada en 1953 y se encuentra ubicada entre la calle de Hidalgo, Degollado, Morelos y Liceo en medio del teatro Degollado y la Catedral.

Este espacio tiene una buena conectividad (ver tabla 10), ya que cercano a su perímetro se encuentran dos sistemas de transporte público masivo, el Macrobús y la línea 2 del tren ligero al estar ubicadas 2 estaciones cercanas a 5 minutos caminando aproximadamente, cuenta con una estación del sistema de bicicletas públicas Mibici y debajo de la plancha de la plaza se encuentra un estacionamiento público, por lo cual no 
solo se puede llegar caminando por medio del andador peatonal Morelos que viene desde Calzada Independencia, sino que se puede arribar en transporte público, bicicleta o coche privado.

\section{Características morfológicas y funcionales}

La plaza es una plancha con una superficie de 148 por 68 metros aproximadamente. Dentro de los elementos que contiene son áreas ajardinadas, arbolado, fuentes, asta de bandera, escultura y la marca Guadalajara Guadalajara (ver esquema 5)

Principalmente este espacio público tiene un carácter de estancia y esto es observable desde su imagen y comodidad (ver tabla 11) que se ve manifestada en el uso de sus bancas, la buena iluminación nocturna, el uso de sus fuentes como áreas de descanso o recreación, andadores que delimitan el área ajardinada en que las personas se sientan al borde de la cerca que separa este espacio verde de la plancha gris, ofreciendo un equilibrio entre lo abierto al aire libre y lo arbolado, entre el foro y el jardín. 


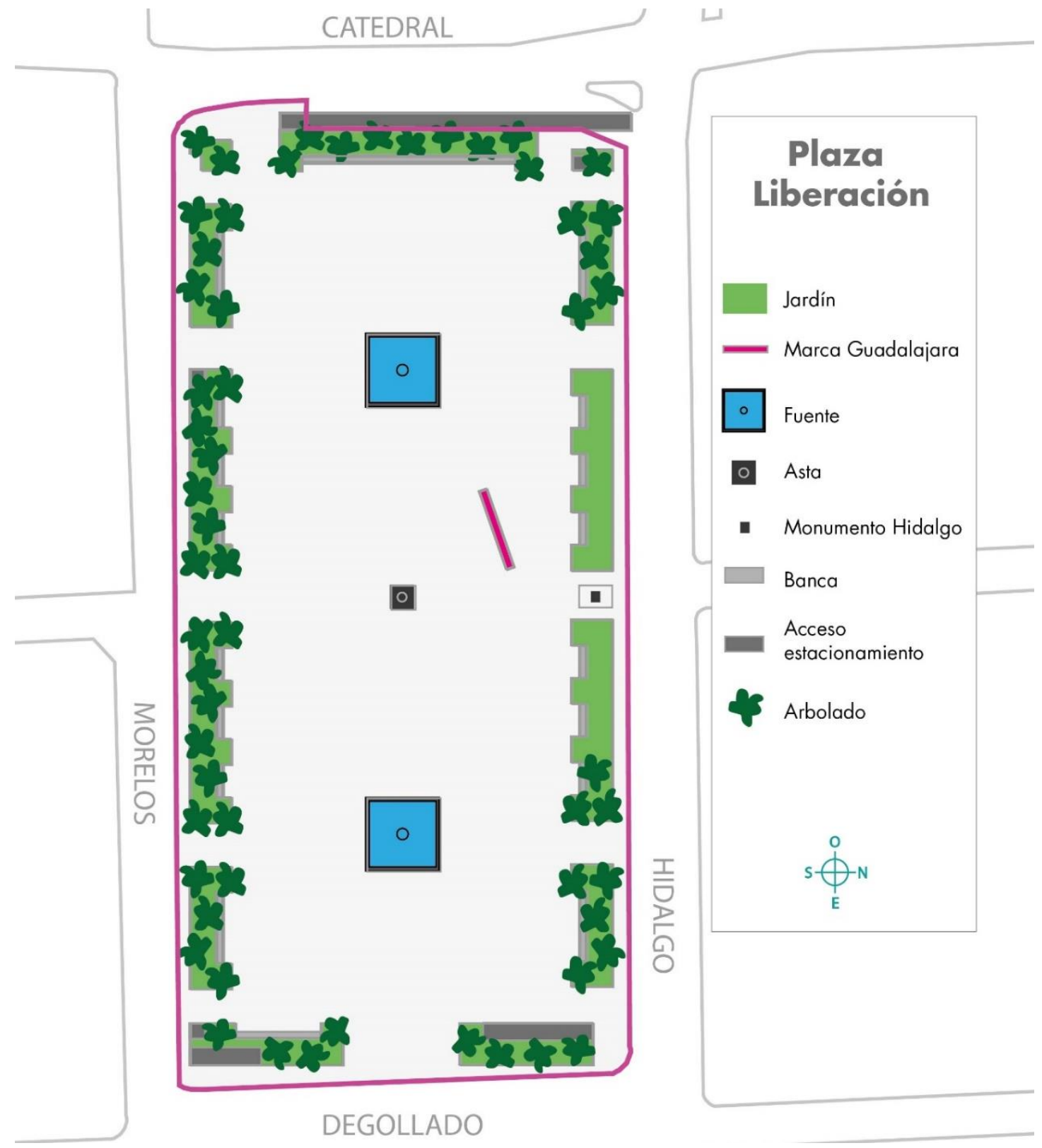

Esquema 5) Elementos físicos y morfológicos que conforman plaza Liberación 


\begin{tabular}{|c|c|c|c|c|c|c|c|}
\hline & \multicolumn{7}{|l|}{$\begin{array}{l}\text { Variable } \\
\text { ACCESOS Y } \\
\text { CONEXIONES }\end{array}$} \\
\hline & \multicolumn{7}{|l|}{ Indicador } \\
\hline Concepto & Parada bus & Parada tren & Parada BRT & $\begin{array}{l}\text { Bici } \\
\text { pública }\end{array}$ & Bici privada & Peatonal & Coche \\
\hline Tiene (si/no) & No & No & No & Sí & No & Sí & Sí \\
\hline No. De paradas & 0 & 0 & 0 & 1 & 0 & 4 & 1 \\
\hline Observaciones & & $\begin{array}{l}\text { La más } \\
\text { cercana es } \\
\text { Universidad } \\
5 \text { min } \\
\text { caminando }\end{array}$ & $\begin{array}{l}\text { La más } \\
\text { cercana es } \\
\text { San Juan de } \\
\text { Dios } 15 \text { min } \\
\text { Caminando }\end{array}$ & $\begin{array}{l}\text { Estación } \\
\text { de mibici } \\
\text { Gdl-032 }\end{array}$ & & $\begin{array}{l}\text { Rodeada } \\
\text { por aceras } \\
{ }^{\star} \text { Cruces } \\
\text { peatonales }\end{array}$ & $\begin{array}{l}\text { Estacionamiento } \\
\text { subterráneo } \\
{ }^{*} 4 \text { calles con flujo } \\
\text { vehicular }\end{array}$ \\
\hline
\end{tabular}

Tabla 10) Tabla de Variable: Accesos y conexiones de Plaza liberación. Elaboración propia

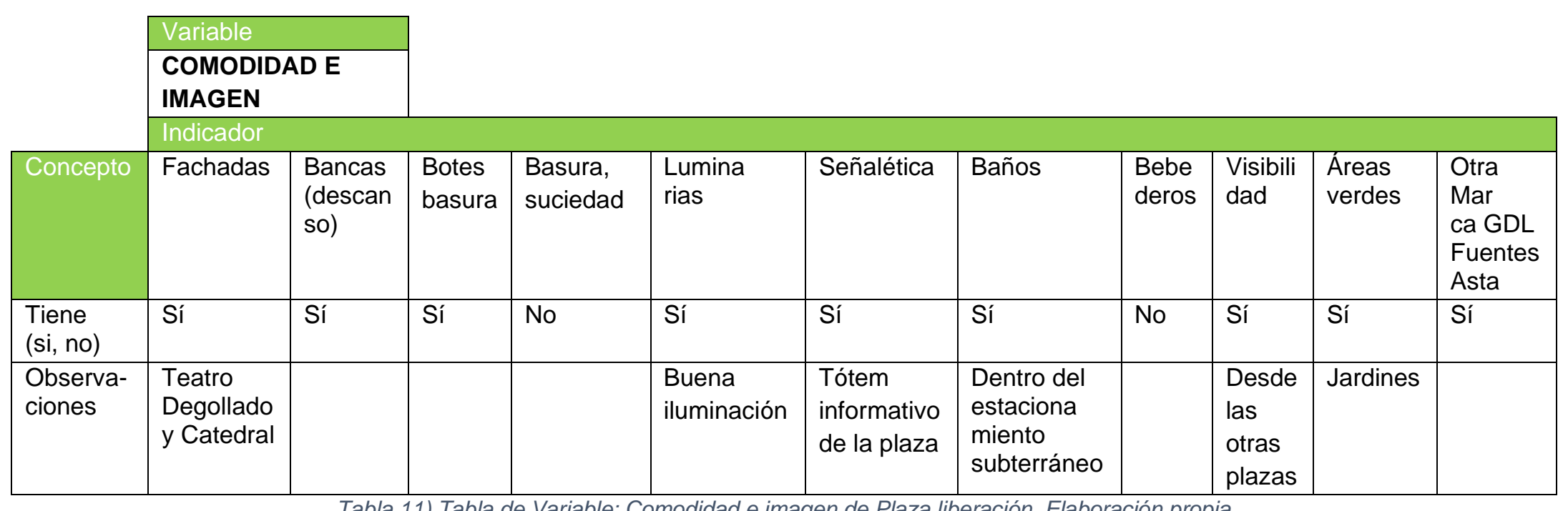




\section{Usos y actividades}

En la Liberación ocurren diferentes dinámicas de uso, desde las temáticas con instalaciones Navideñas, GDL luz durante el aniversario de la fundación de la ciudad, espacio de congregación masiva durante conciertos, festivales musicales, ferias de artesanías y las actividades cotidianas, turistas tomando fotos del entorno y edificios, personas contemplando el paisaje arquitectónico del Teatro Degollado y la Catedral, gente sentada en las bancas descansando bajo las copas de los árboles, congregación alrededor de las fuentes, sentadas descansando, niños jugando, personas congregadas en el asta de la bandera, boleadores cepillando zapatos y caminantes de paso que cruzan la plaza (ver diorama 1).

La noche es el periodo favorito de los paseantes, puesto que al ocultarse el sol todas las bancas y áreas donde no hay sombra se llenan de personas conversando, comiendo, niños que corren y juegan, gente que toma fotos de la iluminación de las fuentes o del teatro Degollado, esta plaza es todo un espectáculo y goce al anochecer, ya que de alguna manera es el "Zócalo" de la perla tapatía.
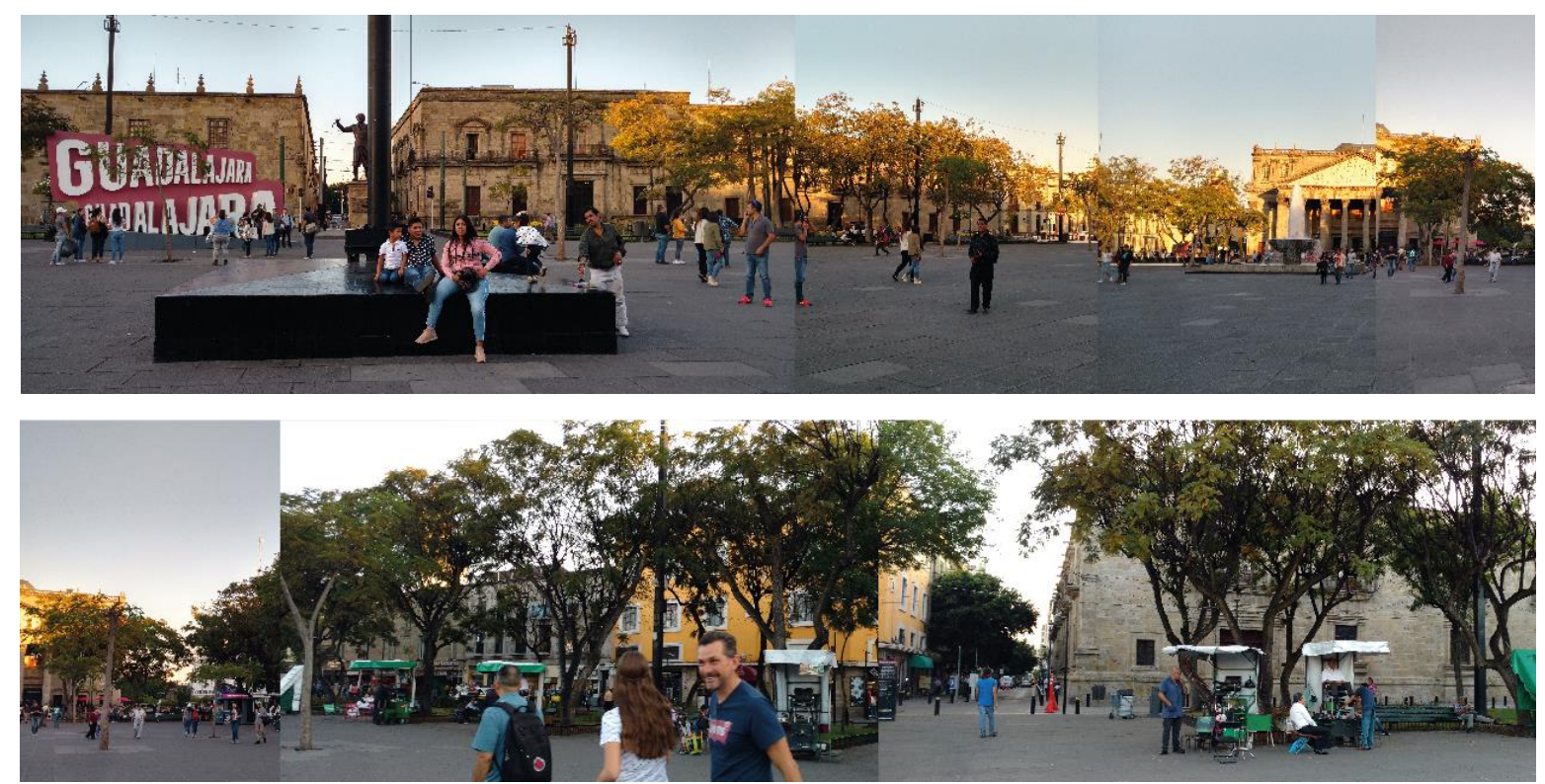


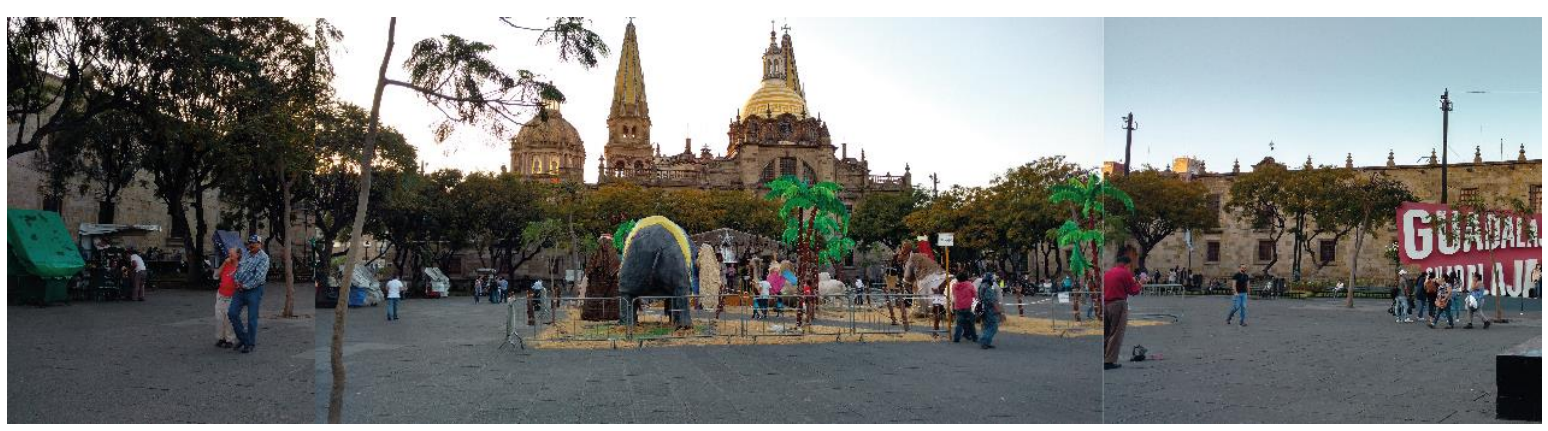

Diorama 1) Secuencia fotográfica de plaza Liberación en diciembre del 2018 por la tarde. Fuente propia

Esta plaza tiene movimiento y dinamismo durante todo el día, sin embargo, posee áreas de atracción para las personas (ver esquema 6), es decir, puntos de concentración donde la gente se reúne por diversos motivos. Las áreas de atracción de esta plaza se ligan con el mobiliario urbano por su utilidad física en relación con áreas de descanso (bancas debajo de la sombra del arbolado y borde de las fuentes y el asta de la bandera al atardecer) o a tomarse fotos con la marca Guadalajara o el agua luminosa de las fuentes.

Las áreas de atracción en este espacio no solo suceden dentro de la Liberación. Si no también en otros espacios alrededor de la plaza, como lo son los locales de comida/venta y museos que se encuentran por un costado en la calle Morelos, así como en la explanada frente al teatro Degollado donde las personas se reúnen a tomarse fotos o esperar a alguien.

En conclusión, las áreas de atracción de esta plaza son puntos de encuentro que las personas localizan más atractivos dentro del espacio para realizar diversas actividades y usos, en este caso relacionados con áreas de descanso, contemplación y sombra en el interior, al exterior de la plaza el atrayente de los espacios radica en servicios ofrecidos por los locales de negocios y la fachada monumental del Teatro Degollado como hito histórico cultural para la ciudad. El espacio público de esta plaza se ha producido principalmente por razones estéticas, embellecimiento y valor histórico para la zona de la ciudad, relacionándolo y conectándolo principalmente con otros espacios públicos de la zona centro que también poseen estas características físicas y simbólicas 
como sitios de atractivo turístico, historia e identidad de la ciudad y los cuales tienen poca o nula relación con los espacios periféricos.

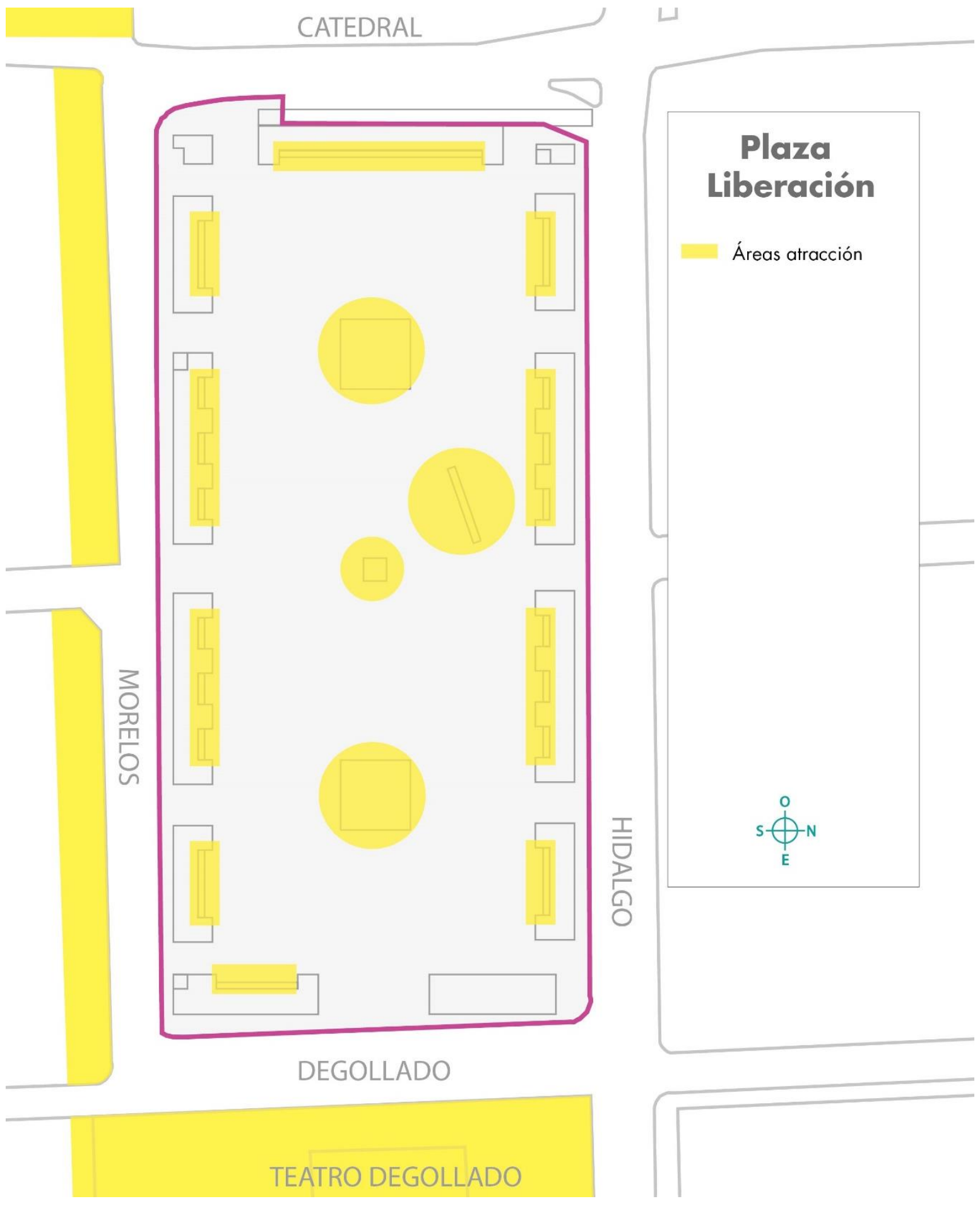

Esquema 6) Áreas de atracción en Plaza Liberación. Elaboración propia 


\subsubsection{Plaza de Armas Características generales}

Plaza de Armas es la plaza más antigua y que se preserva como vestigio de los primeros espacios públicos en la ciudad. Ha sufrido diversas intervenciones a través de los años, no obstante, la remodelación que se conoce y se conserva actualmente es la realizada durante el año 1954.

Se encuentra ubicada a un costado derecho de la Catedral Metropolitana entre las calles de Pedro Moreno entre Av. Alcalde y Liceo.

Durante las obras de la línea 3 la plaza sufrió una remodelación y restauración de su quiosco y jardines, e incluso el cambio de lozas del suelo como resultado de dichas obras.

Para llegar a la plaza sus conexiones y accesos principales (ver tabla 12) son los peatonales, puesto que se encuentra conectada al nuevo Paseo Alcalde (antigua calle vehicular Av. Alcalde) y con el andador de Pedro Moreno.

Cercana a ella se ubican dos estaciones de sistemas de transporte público masivo, Macrobús a 15 minutos caminando aproximadamente y 5 minutos caminando del tren ligero. No cuenta con estacionamiento, pero una calle con flujo vehicular pasa por uno de sus costados (calle Ramón Corona)

\section{Características morfológicas y funcionales}

De planta cuadrada con un quiosco en el centro de estilo Art Noveau (Gonzáles; 2005: 53) emergen 4 pasillos que conforman 4 sendos de jardinería con árboles. Distribuidos en los espacios internos y externos del área ajardinada están emplazadas una serie de bancas que hacen juego con las luminarias que alumbran por la noche la plaza (ver esquema 7). 
El quiosco es un referente a la música, puesto que las columnas que lo conforman destacan esculturas de carácter femenino que sostienen elementos alusivos a la música.

La función principal de este espacio es la de estancia y contemplación, algo importante de indicar es que cuenta con una buena imagen y comodidad para los caminantes debido a que, desde cualquier punto, el espectador puede observar la obra de herrería del quiosco. Aunado a ello, la visibilidad del espacio en general es buena, ya que es observable desde plaza liberación, Paseo Alcalde y Plaza de los Laureles o Guadalajara (ver tabla 13).

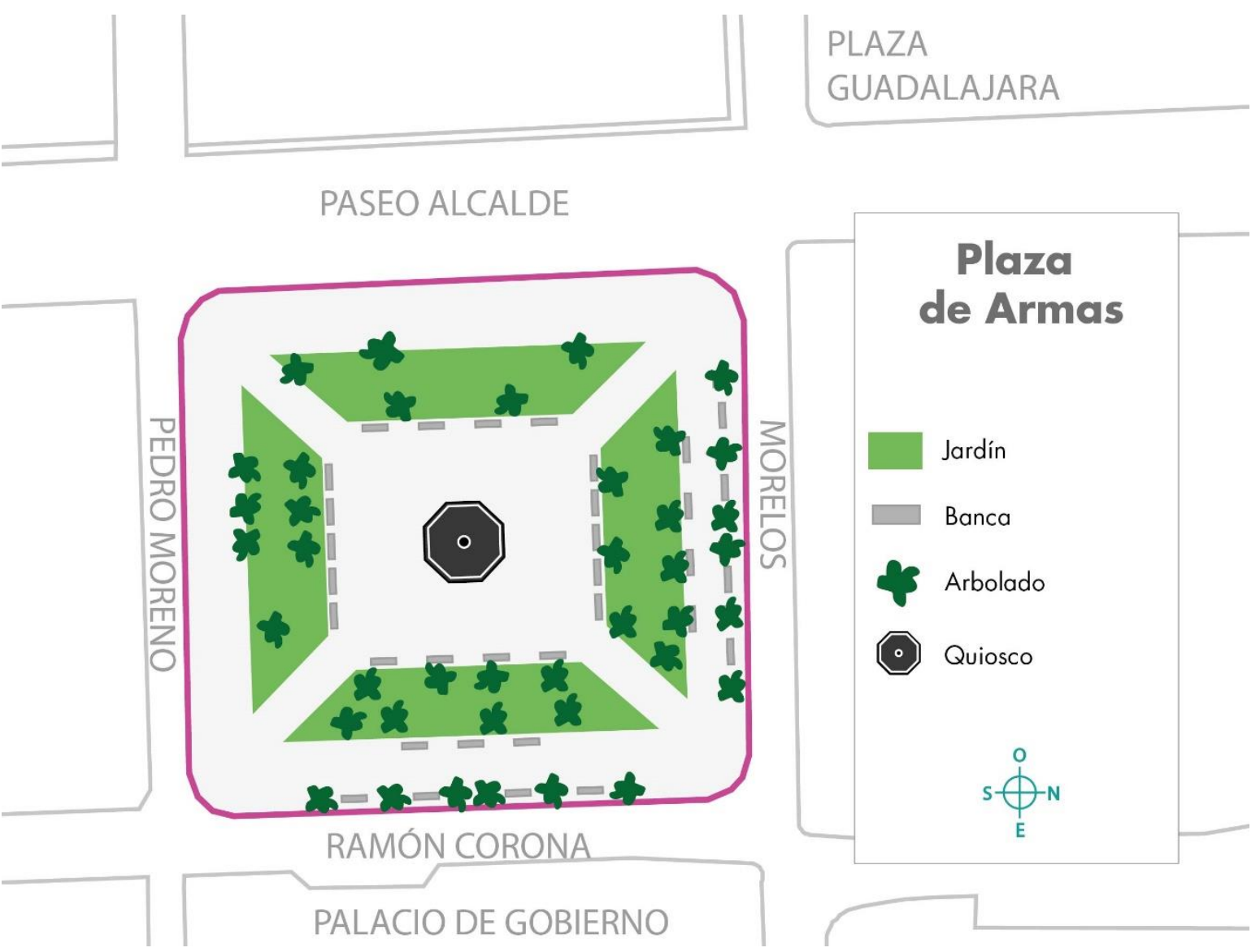

Esquema 7) Elementos físicos y morfología que conforma plaza de Armas. Elaboración propia. 


\begin{tabular}{|c|c|c|c|c|c|c|c|}
\hline & \multicolumn{7}{|l|}{\begin{tabular}{|l|} 
Variable \\
ACCESOS Y \\
CONEXIONES
\end{tabular}} \\
\hline & & & & & & & \\
\hline Concepto & Parada bus & Parada tren & Parada BRT & $\begin{array}{l}\text { Bici } \\
\text { pública }\end{array}$ & Bici privada & Peatonal & Coche \\
\hline Tiene (si/no) & No & No & No & No & No & Sí & No \\
\hline No. De paradas & 0 & 0 & 0 & 0 & 0 & 2 & 0 \\
\hline Observaciones & & $\begin{array}{l}\text { La más } \\
\text { cercana es } \\
\text { Universidad } \\
5 \text { min } \\
\text { caminando }\end{array}$ & $\begin{array}{l}\text { La más } \\
\text { cercana es } \\
\text { San Juan de } \\
\text { Dios } 15 \text { min } \\
\text { caminando }\end{array}$ & $\begin{array}{l}\text { La más } \\
\text { cercana es } \\
\text { la estación } \\
\text { Gdl-032 } \\
\text { de mibici } \\
5 \text { min } \\
\text { caminando }\end{array}$ & $\begin{array}{l}\text { No tiene } \\
\text { ciclopuertos }\end{array}$ & $\begin{array}{l}\text { Acera } \\
\text { Frontal, } \\
\text { andador } \\
\text { peatonal y } \\
\text { acceso } \\
\text { paseo } \\
\text { Alcalde }\end{array}$ & $\begin{array}{l}\text { Calle } \\
\text { *2 calles con flujo } \\
\text { vehicular }\end{array}$ \\
\hline
\end{tabular}

Tabla 12) Tabla de Variable: Accesos y conexiones de Plaza de armas. Elaboración propia

\begin{tabular}{|c|c|c|c|c|c|c|c|c|c|c|c|}
\hline & \multirow{2}{*}{$\begin{array}{l}\text { Variable } \\
\text { COMODIDAD } \\
\text { E IMAGEN }\end{array}$} & & & & & & & & & & \\
\hline & & & & & & & & & & & \\
\hline & \multicolumn{11}{|l|}{ Indicador } \\
\hline Concepto & $\begin{array}{l}\text { Facha } \\
\text { das }\end{array}$ & $\begin{array}{l}\text { Bancas } \\
\text { (descan } \\
\text { so) }\end{array}$ & $\begin{array}{l}\text { Botes } \\
\text { basura }\end{array}$ & $\begin{array}{l}\text { Basura, } \\
\text { suciedad }\end{array}$ & $\begin{array}{l}\text { Lumina } \\
\text { rias }\end{array}$ & $\begin{array}{l}\text { Seña } \\
\text { lética }\end{array}$ & Baños & $\begin{array}{l}\text { Bebe } \\
\text { deros }\end{array}$ & $\begin{array}{l}\text { Visibili } \\
\text { dad }\end{array}$ & $\begin{array}{l}\text { Áreas } \\
\text { verdes }\end{array}$ & $\begin{array}{l}\text { Otra } \\
\text { Quiosco }\end{array}$ \\
\hline $\begin{array}{l}\text { Tiene } \\
\text { (si, no) }\end{array}$ & Sí & Sí & Sí & No & Sí & Sí & No & No & Sí & Sí & Sí \\
\hline $\begin{array}{l}\text { Observa- } \\
\text { ciones }\end{array}$ & $\begin{array}{l}\text { Catedral y } \\
\text { Palacio de } \\
\text { Gobierno }\end{array}$ & & & & & $\begin{array}{l}\text { Tótem } \\
\text { Infor } \\
\text { mativo } \\
\text { de la } \\
\text { plaza }\end{array}$ & & & $\begin{array}{l}\text { Desde } \\
\text { paseo } \\
\text { Alcalde, } \\
\text { plaza } \\
\text { Liberación } \\
\text { y Gdl }\end{array}$ & Jardines & \\
\hline
\end{tabular}

Tabla 13) Tabla de Variable: comodidad e imagen de Plaza de armas. Elaboración propia 


\section{Usos y actividades}

En el día es un espacio de paso y de atractivo turístico por el quiosco, debido a la falta de sombra por ser un espacio abierto al aire libre solo es posible sentarse en las bancas que son cubiertas por alguna de las copas de los árboles o en los puntos donde la fachada lateral de Catedral genera sombra (ver diorama 2).
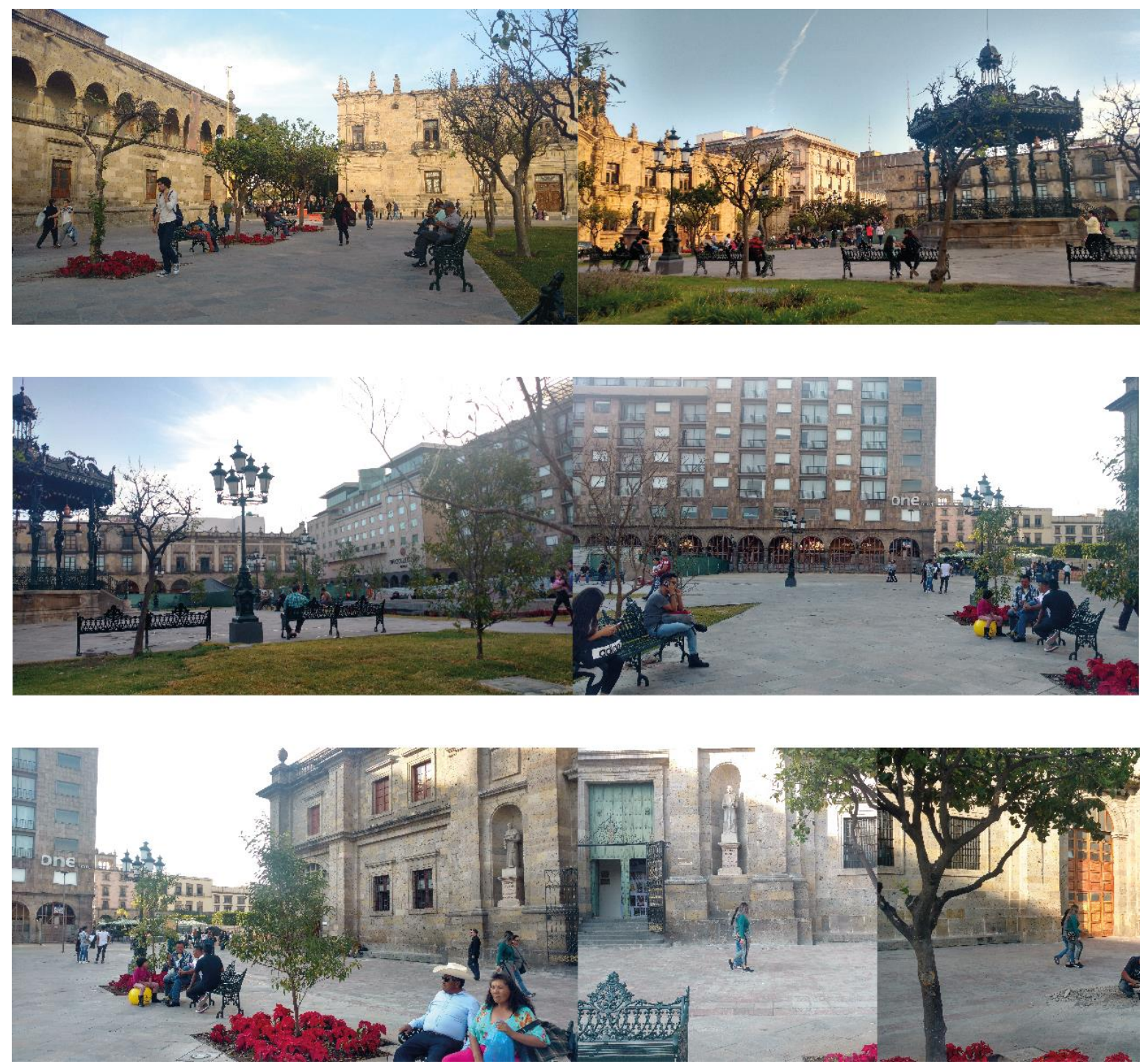

Diorama 2) Secuencia fotográfica de plaza de Armas aun con obras de remodelación. Febrero 2019. Fuente propia

Sin embargo, por las noches este espacio se transforma y se llena de vida por las personas que se sientan en las bancas a descansar, conversar, comer algún aperitivo, 
que observan y admiran la luz de ambientación de las farolas o el quiosco, y si se tiene mucha suerte, se puede ser testigo de la orquesta típica del estado de Jalisco que dinamiza sonoramente el espacio para tapatíos, turistas, curiosos y extraños.

Por su parte, el lugar predilecto de los niños es el quiosco, debido a que es un elemento interactivo para ellos en el que pueden subir y bajar las escaleras y jugar en la superficie interna.

En fiestas patrias esta plaza es sede del grito de Independencia, ese día los tapatíos se congregan para la celebración de la noche mexicana, el gobernador sale al balcón de Palacio de Gobierno y hace sonar las campanas.

Plaza de Armas a su vez es sitio de encuentro para la concentración de mítines o marchas sociales, ya que, al tener situado a Palacio de Gobierno en uno de sus laterales, el pueblo se reúne para exigir sus derechos o reclamar la atención del gobernador ante ciertas situaciones.

Esta plaza cuenta con puntos de atracción para las personas (ver esquema 8), estos se encuentran localizados en el quiosco y las bancas que rodean de forma interna el jardín las bancas que dan de frente a Palacio de Gobierno por la calle de Ramón Corona. Cercano a la plaza otras áreas de seducción son el paseo Alcalde que conecta con Plaza Guadalajara, la Rotonda y el andador Morelos que enlaza con Plaza Liberación y la Catedral por uno de sus laterales.

Los puntos de atracción de esta plaza están relacionados con el área de sombra durante el día y por la noche en relación con el atractivo del quiosco y las áreas peatonales que enlazan con otros atractivos del centro histórico, es decir, están atados principalmente al mojón central por las presentaciones y ensayos de la banda de música del estado o por el simple hecho de ser un hito por su diseño y elementos que lo forman, así como la disposición de las bancas alrededor de este elemento de la plaza y las bancas que dan de frente a Palacio de Gobierno, un edificio histórico representativo de poder de la ciudad donde cada 15 de Septiembre el gobernador da el grito de Independencia y la plaza se abarrota de gente. Por otro lado, el andador Morelos que se encuentra a un 
costado de la Catedral es un espacio llamativo para las personas debido a que la vialidad es peatonal y se conecta con un andador peatonal mayor que es Paseo Alcalde, el cual recorre desde Av. Revolución hasta la calle Garibaldi y posee áreas de descanso, jardineras, fuentes, luminarias y una ciclovía, tal motivo que sus características lo convierten en un espacio atractivo para los usuarios.

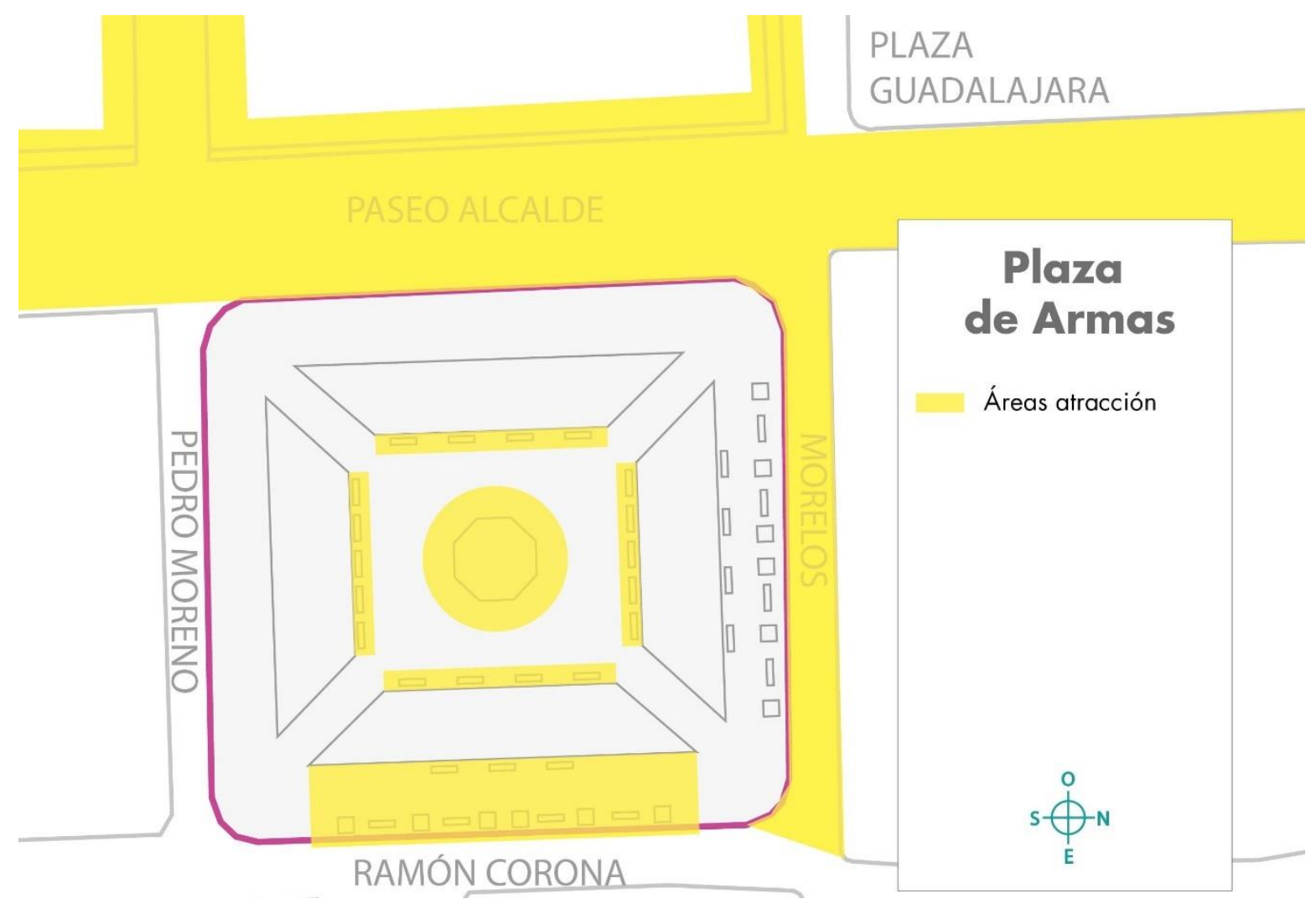

Esquema 8) Áreas de atracción en Plaza de Armas. Elaboración propia

\subsubsection{Rotonda de Jaliscienses ilustres \\ Características generales}

Tal como la Plaza Liberación esta plaza se realizó durante el sexenio del Gobernador Gonzáles Gallo. Está situada donde antiguamente se encontraba el Santuario de la Soledad y el Seminario del Señor San José (Gonzáles; 2005: 33). El proyecto fue ejecutado por el arquitecto Vicente Mendiola, ya que Díaz Morales abandono el proyecto, 
pero fue el ingeniero Miguel Aldana Mijares quien se hizo cargo de la obra en 1952, razón por lo que el proyecto se terminó y entregó durante la gobernatura de Agustín Yáñez.

Este espacio es una combinación entre monumento y jardín, fue erigido con la intención de honrar y conmemorar los restos de Jaliscienses sobresalientes en la historia de Jalisco.

Se encuentra localizada a un lado de la fachada norte de la Catedral y de la cara oriente del Palacio Municipal y frente al Museo Regional. Su ubicación exacta es entre las calles de Liceo, Hidalgo, Paseo Alcalde e Independencia. Existen distintos accesos y conexiones para abordar el lugar (ver tabla 14), la conexión principal para arribar a este espacio es por el corredor peatonal Paseo Alcalde, pero también se puede acceder en el sistema de transporte público Masivo Macrobús desde la estación San Juan de Dios que se encuentra a 15 minutos caminando, la estación del Tren Ligero Plaza Universidad a 5 minutos caminando o desde el camión del Tapatío-tour al tener su parada en la Rotonda sobre la calle de Hidalgo.

\section{Características morfológicas y funcionales}

La característica principal de este espacio es la rotonda que contiene en su centro un gran anillo de piedra sostenido por 17 columnas dentro de un área ajardinada como elemento dominante del espacio (un monumento general), esta rotonda contiene 98 gavetas y 3 tumbas. Alrededor del elemento dominante se despliegan 4 senderos que dan forma a 4 áreas de jardín con frondosos árboles, estos jardines en su parte exterior están rodeados por una serie de esculturas de jaliscienses ilustres (ver esquema 9) entre los que destacan, el arquitecto Luis Barragán Morfín, el ingeniero Matute Remus, Ignacio L. Vallarta, por mencionar algunos.

La plaza posee vistas privilegiadas en cuanto a paisaje arquitectónico, porque es el patio de entrada al edificio del Seminario Mayor actual Museo Regional y por la perspectiva que tiene de la fachada norte de la Catedral Metropolitana. 
En cuanto a la imagen y comodidad para los paseantes y usuarios del espacio es buena, debido a que cuenta con mobiliario de descanso (bancas) iluminación nocturna, tótem informativo, vista del patrimonio edificado con las fachadas de Catedral y Museo Regional y buena visibilidad desde plaza de la Liberación y Plaza Guadalajara (ver tabla 15.)

$$
\text { L }
$$

\section{PALACIO MUNICIPAL}

\section{PASEO ALCALDE}

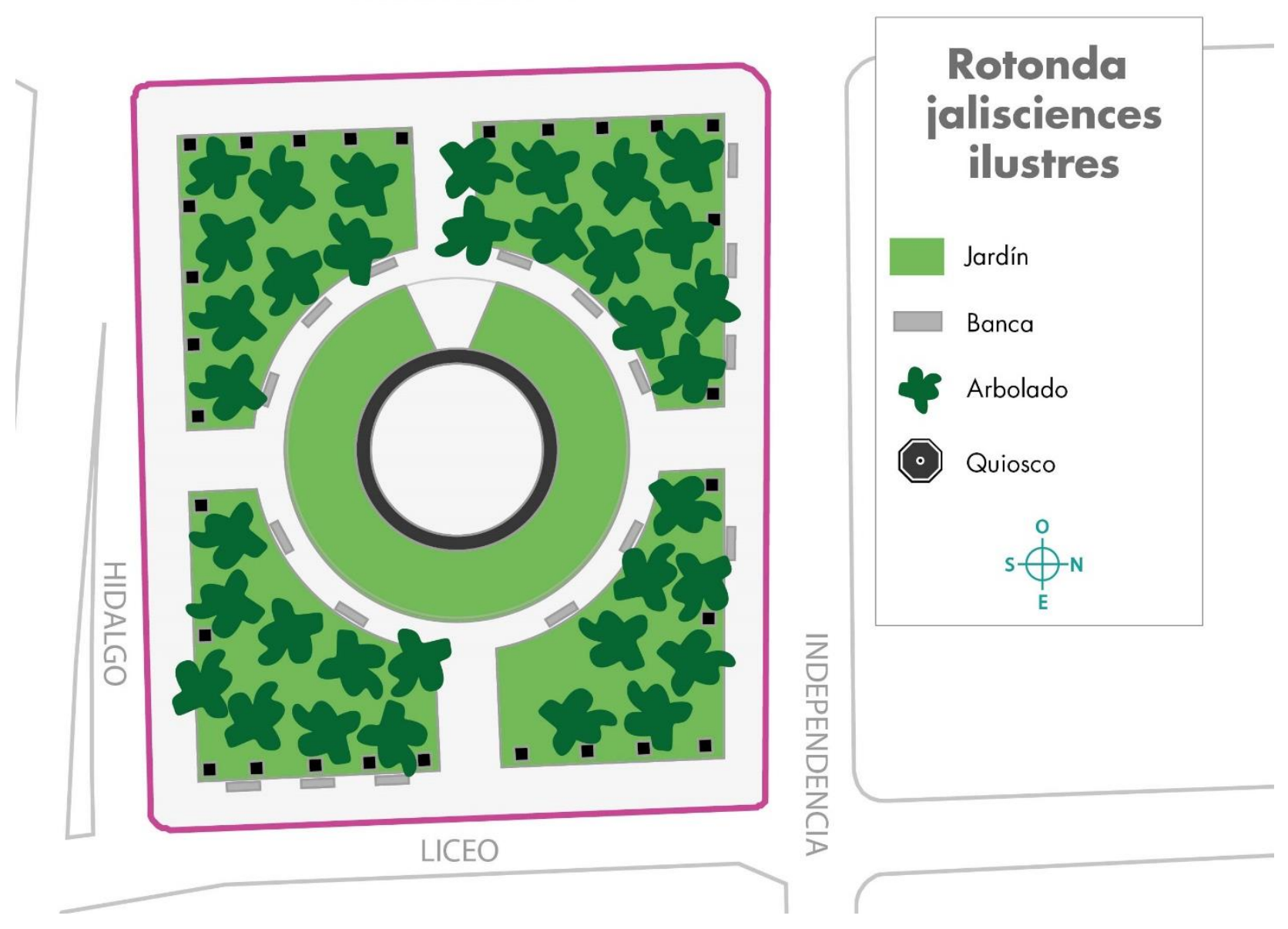

Esquema 9) Elementos físicos y morfología que conforma Rotonda de los Jaliscienses Ilustres. Elaboración propia. 


\begin{tabular}{|c|c|c|c|c|c|c|c|}
\hline & \multicolumn{7}{|l|}{$\begin{array}{l}\text { Variable } \\
\text { ACCESOS Y } \\
\text { CONEXIONES }\end{array}$} \\
\hline & Indicador & & & & & & \\
\hline Concepto & Parada bus & Parada tren & Parada BRT & $\begin{array}{l}\text { Bici } \\
\text { pública }\end{array}$ & Bici privada & Peatonal & Coche \\
\hline Tiene (si/no) & Sí & No & No & No & No & Sí & No \\
\hline No. De paradas & 0 & 0 & 0 & 0 & 0 & 4 & 0 \\
\hline Observaciones & Tapatío Tour & $\begin{array}{l}\text { Más cercana } \\
\text { Universidad } \\
5 \text { min } \\
\text { caminando }\end{array}$ & $\begin{array}{l}\text { Más } \\
\text { cercana San } \\
\text { Juan de } \\
\text { Dios } 15 \text { min } \\
\text { caminando }\end{array}$ & $\begin{array}{l}\text { Más } \\
\text { cercana } \\
\text { estación } \\
\text { Gdl-032 } \\
\text { de mibici } \\
5 \text { min } \\
\text { caminando }\end{array}$ & $\begin{array}{l}\text { No tiene } \\
\text { ciclopuertos }\end{array}$ & $\begin{array}{l}\text { Aceras } \\
\text { frontales y } \\
\text { laterales. } \\
\text { Acceso } \\
\text { paseo } \\
\text { Alcalde }\end{array}$ & $\begin{array}{l}\text { Calle } \\
\text { *3 calles con flujo } \\
\text { vehicular }\end{array}$ \\
\hline
\end{tabular}

\begin{tabular}{|c|c|c|c|c|c|c|c|c|c|c|c|}
\hline & \multicolumn{2}{|l|}{ Variable } & & & & & & & & & \\
\hline & \multicolumn{2}{|c|}{$\begin{array}{l}\text { COMODIDAD E } \\
\text { IMAGEN }\end{array}$} & & & & & & & & & \\
\hline & \multicolumn{11}{|c|}{ Indicador } \\
\hline Concept & Fachadas & $\begin{array}{l}\text { Bancas } \\
\text { (descanso } \\
\text { ) }\end{array}$ & $\begin{array}{l}\text { Botes } \\
\text { basura }\end{array}$ & $\begin{array}{l}\text { Basura, } \\
\text { sucieda } \\
\text { d }\end{array}$ & $\begin{array}{l}\text { Lumina } \\
\text { rias }\end{array}$ & $\begin{array}{l}\text { Seña } \\
\text { lética }\end{array}$ & Baños & $\begin{array}{l}\text { Bebe } \\
\text { deros }\end{array}$ & Visibilidad & $\begin{array}{l}\text { Áreas } \\
\text { verdes }\end{array}$ & $\begin{array}{l}\text { Otra } \\
\text { Monumento } \\
\mathrm{s} \\
\text { Estatuas }\end{array}$ \\
\hline $\begin{array}{l}\text { Tiene } \\
(\mathrm{si}, \mathrm{no})\end{array}$ & Sí & Sí & Sí & No & Sí & Sí & No & No & Sí & Sí & Sí \\
\hline $\begin{array}{l}\text { Observa- } \\
\text { ciones }\end{array}$ & $\begin{array}{l}\text { Catedral, } \\
\text { Palacio } \\
\text { Municipal } \\
\text { y Museo } \\
\text { Regional }\end{array}$ & & & & & $\begin{array}{l}\text { Toten } \\
\text { informati } \\
\text { vo de la } \\
\text { plaza }\end{array}$ & & & $\begin{array}{l}\text { Alcalde, } \\
\text { plaza } \\
\text { Liberació } \\
\mathrm{n} \text { y } \\
\text { Guadalaja } \\
\text { ra }\end{array}$ & $\begin{array}{l}\text { Jardin } \\
\text { es }\end{array}$ & Homenaje \\
\hline
\end{tabular}

Tabla 15) Tabla de Variable: comodidad e imagen Rotonda de los Jaliscienses Ilustres. Elaboración propia 


\section{Usos y actividades}

La plaza de la Rotonda quizás es la que menos flujo de personas tiene de las otras 3 plazas que integran la cruz cuyo centro es Catedral. Sin embargo, es visita obligada a todo turista para hacer una foto a la Rotonda tanto de día, pero especialmente de noche por su iluminación ambiental.

A la luz de día se pueden observar personas sentadas en las bancas alrededor de la Rotonda y algún despistado recostado en los jardines, el uso principal de este espacio es el de contemplación de la monumentalidad del anillo de piedra que se encuentra protegido por una cerca de metal. (ver diorama 3).
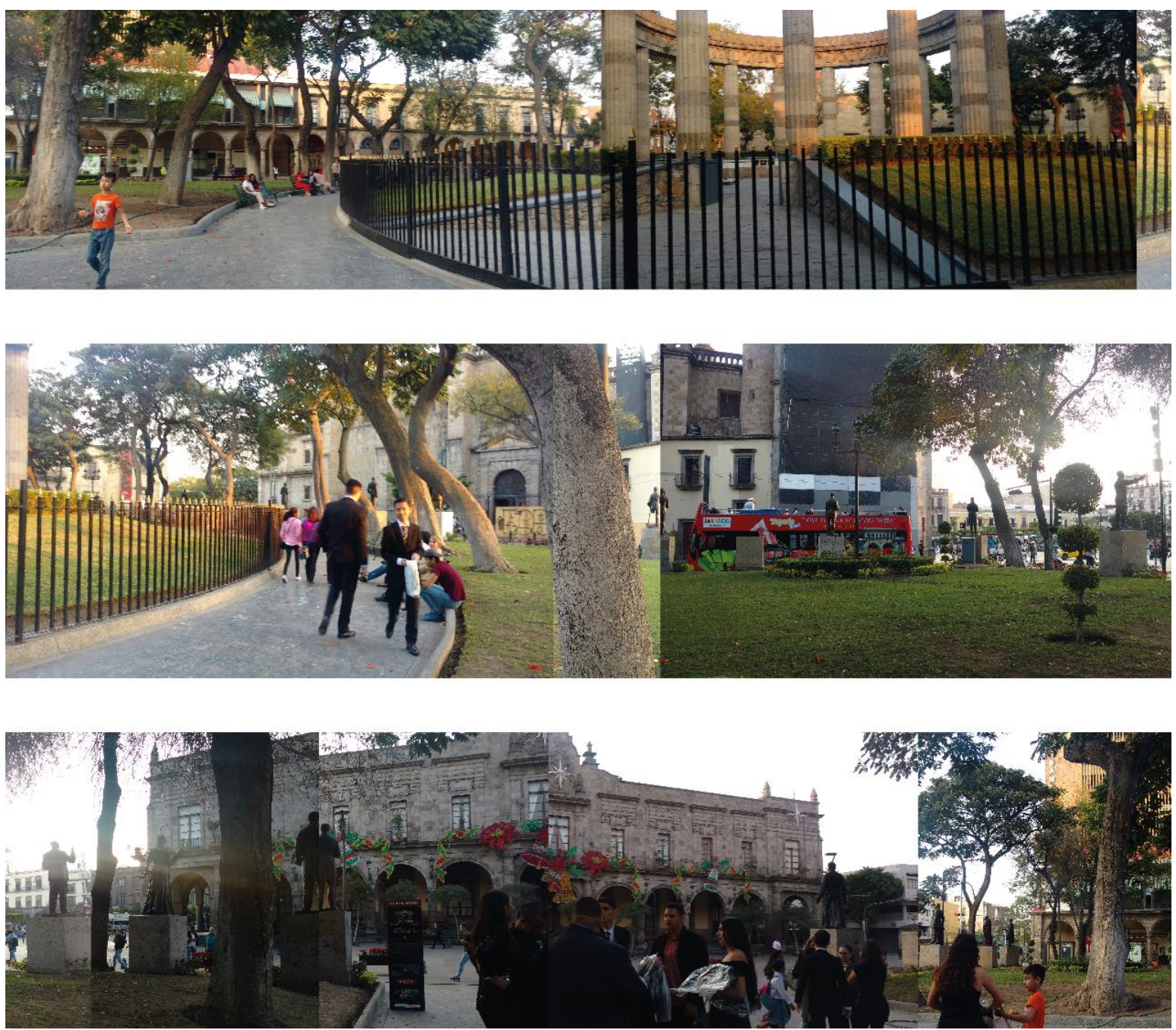

Diorama 3) Secuencia fotográfica Rotonda de los Jaliscienses Ilustres diciembre del 2018 por la tarde. Fuente propia 
Se observan también quinceañeras en sesiones fotográficas, así como recién egresados de Universidad haciendo la foto del recuerdo de generación.

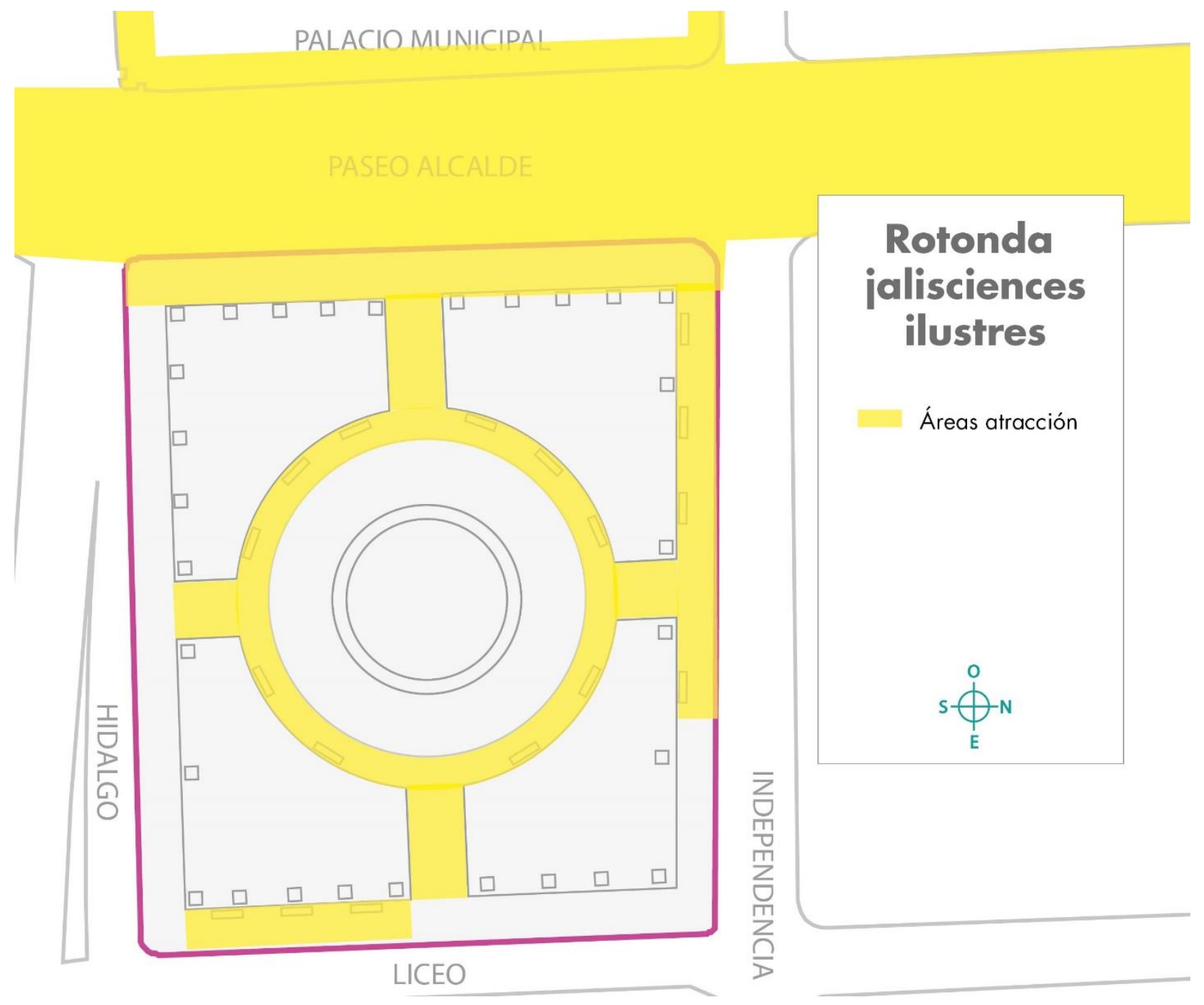

Esquema 10) Áreas de atracción Rotonda de los Jaliscienses llustres. Elaboración propia

Al igual que las otras plazas tiene áreas de atracción (ver esquema 10), la principal es alrededor del anillo, los 4 pasillos que llevan al interior del círculo y el adyacente por la calle Independencia, esto debido a que en estas zonas se encuentran ubicadas bancas con la mejor sombra de la copa de los árboles. Otro punto importante de atracción es paseo Alcalde, ya que desde que la calle se volvió un paseo peatonal, permite un gran 
flujo de personas que caminan sobre la calle para llegar y conectarse con otros espacios claves del centro histórico. En conclusión, estas áreas de atractivo para las personas se relacionan con su función de descanso, contemplación y sombra del arbolado, además de la conexión y flujo peatonal de Paseo Alcalde que conecta con otras plazas y lugares de utilidad de la zona centro de la ciudad.

\subsubsection{Plaza Guadalajara Características generales}

Se le conocía como Plaza de los Laureles y fue nombrada así por motivo del aniversario 450 de la fundación de la ciudad. Para la construcción de esta plaza se destruyeron varios inmuebles con importante valor histórico, el cine Lux y el Palacio de los Cañedo (Gonzáles; 2005: 29).

La plaza esta frente a la fachada principal de Catedral y de Paseo Alcalde y por un costado la fachada principal de Palacio Municipal. Se encuentra entre las calles de Hidalgo, Av. Alcalde, Morelos y Pedro Loza.

Una de las características principales de este espacio es ser un sitio turístico, debido a que en esta plaza parten recorridos a otros municipios de Jalisco (Chapala, Ajijic, Tlaquepaque, Tonalá, Tequila) además de estar localizadas las calandrias y el tranvía turístico.

Sus conexiones y accesos (ver tabla 16) es principalmente peatonal por el andador Morelos, Pedro Loza y el paseo Alcalde que como ya se ha mencionado previamente, conecta de manera articulada diversos espacios de la ciudad y con 3 de las 4 plazas de la cruz tapatía. Las estaciones más cercanas del sistema de transporte público masivo son la estación del tren plaza Universidad a 5 minutos y la estación de San Juan de Dios de Macrobús a 15 minutos caminando, asimismo cuenta con un área con ciclopuertos.

\section{Características morfológicas y funcionales}

Este espacio se conforma por una explanada que se halla frente a Catedral, como dice García Oropeza (1978) en su guía informal de Guadalajara: 
"La plaza de los Laureles viene a darle a Catedral el atrio que la historia le fue quitado. Una gran fuente sostiene allí el escudo de armas de la ciudad que se corona con la múltiple cruz de Jerusalén. La plaza, oficialmente llamada del Ayuntamiento, le da a la gran masa catedralicia aire y perspectiva"

Los elementos que forman parte de la plaza y que le dan perspectiva al entorno son una serie de jardineras que rodean una fuente que se localiza en el centro en lo alto de una escalinata circular (ver esquema 11) y un pasaje subterráneo.

En cuanto a su imagen y comodidad (ver tabla 17) el espacio conserva una buena visibilidad desde Plaza de Armas, la Rotonda y la fachada de Catedral y Palacio Municipal.

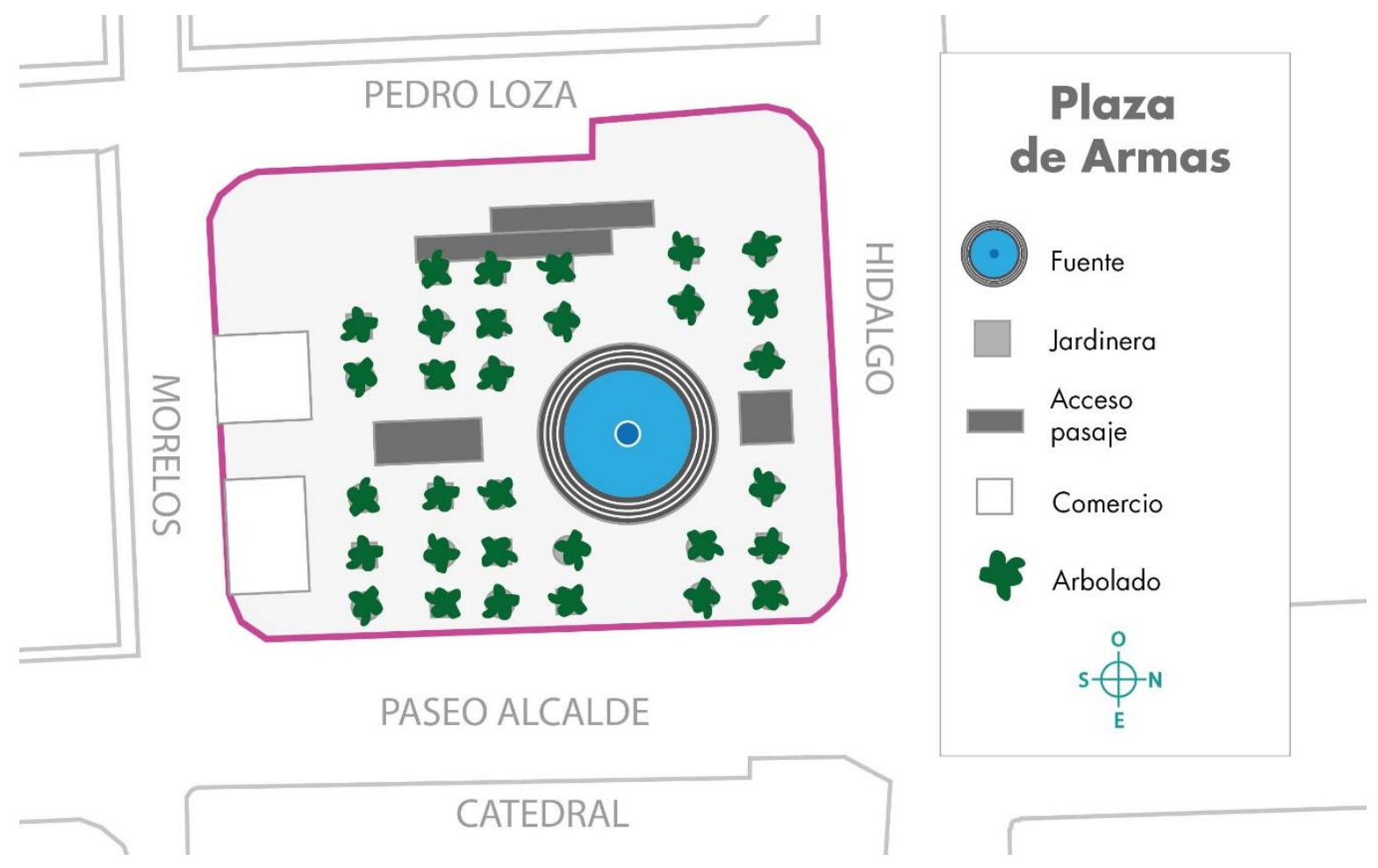

Esquema 11) Elementos físicos y morfología que conforma Plaza Guadalajara. Elaboración propia. 


\begin{tabular}{|c|c|c|c|c|c|c|c|}
\hline & \multicolumn{7}{|l|}{$\begin{array}{l}\text { Variable } \\
\text { ACCESOS Y } \\
\text { CONEXIONES }\end{array}$} \\
\hline & \multicolumn{7}{|l|}{ Indicador } \\
\hline Concepto & Parada bus & Parada tren & Parada BRT & Bici pública & $\begin{array}{l}\text { Bici } \\
\text { privada }\end{array}$ & Peatonal & Coche \\
\hline Tiene (si/no) & Sí & No & No & No & Sí & Sí & No \\
\hline No. De paradas & Tequila Tour & 0 & 0 & 0 & 1 & 4 & 0 \\
\hline Observaciones & Tapatío Tour & $\begin{array}{l}\text { Más cercana } \\
\text { es } \\
\text { Universidad } \\
5 \text { min } \\
\text { caminando }\end{array}$ & $\begin{array}{l}\text { Más } \\
\text { cercana San } \\
\text { Juan de } \\
\text { Dios } 15 \text { min } \\
\text { caminando }\end{array}$ & $\begin{array}{l}\text { Más } \\
\text { cercana } \\
\text { estación } \\
\text { Gdl-032 de } \\
\text { Mibici } 5 \text { min } \\
\text { caminando }\end{array}$ & $\begin{array}{l}\text { Tiene una } \\
\text { estación } \\
\text { de } \\
\text { ciclopuerto } \\
\text { s }\end{array}$ & $\begin{array}{l}\text { Dos andadores } \\
\text { peatonales, } \\
\text { acera lateral y } \\
\text { Paseo Alcalde }\end{array}$ & $\begin{array}{l}\text { Calle } \\
\text { *1 calle con } \\
\text { flujo vehicular }\end{array}$ \\
\hline
\end{tabular}

Tabla 16) Tabla de Variable: Accesos y conexiones de Plaza Guadalajara. Elaboración propia

\begin{tabular}{|c|c|c|c|c|c|c|c|c|c|c|c|}
\hline & \multirow{2}{*}{\multicolumn{11}{|c|}{$\begin{array}{l}\text { Variable } \\
\text { COMODIDA } \\
\text { D E IMAGEN } \\
\text { Indicador }\end{array}$}} \\
\hline & & & & & & & & & & & \\
\hline Concept & $\begin{array}{l}\text { Facha } \\
\text { das }\end{array}$ & $\begin{array}{l}\text { Bancas } \\
\text { (desca } \\
\text { n } \\
\text { so) }\end{array}$ & $\begin{array}{l}\text { Botes } \\
\text { basur } \\
\text { a }\end{array}$ & $\begin{array}{l}\text { Basura, } \\
\text { sucieda } \\
\text { d }\end{array}$ & $\begin{array}{l}\text { Lumin } \\
\text { a } \\
\text { rias }\end{array}$ & $\begin{array}{l}\text { Seña } \\
\text { lética }\end{array}$ & Baños & $\begin{array}{l}\text { Bebe } \\
\text { dero } \\
\mathrm{s}\end{array}$ & $\begin{array}{l}\text { Visibili } \\
\text { dad }\end{array}$ & $\begin{array}{l}\text { Áreas } \\
\text { verdes }\end{array}$ & $\begin{array}{l}\text { Otra } \\
\text { Fuente } \\
\text { Calandria } \\
\text { s }\end{array}$ \\
\hline $\begin{array}{l}\text { Tiene } \\
\text { (si, no) }\end{array}$ & Sí & Sí & Sí & No & Sí & Sí & Sí & No & Sí & No & Sí \\
\hline $\begin{array}{l}\text { Observa- } \\
\text { ciones }\end{array}$ & $\begin{array}{l}\text { Catedral y } \\
\text { Palacio de } \\
\text { Gobierno }\end{array}$ & & & & & $\begin{array}{l}\text { Toten } \\
\text { informativ } \\
\text { o de la } \\
\text { plaza }\end{array}$ & $\begin{array}{l}\text { Dentro del } \\
\text { pasaje } \\
\text { subterráne } \\
\text { o }\end{array}$ & & $\begin{array}{l}\text { Desde } \\
\text { paseo } \\
\text { Alcalde, } \\
\text { Rotond } \\
\text { a y } \\
\text { Plaza } \\
\text { de } \\
\text { Armas }\end{array}$ & $\begin{array}{l}\text { Jardinera } \\
\text { s con } \\
\text { árboles }\end{array}$ & \\
\hline
\end{tabular}




\section{Usos y actividades}

El carácter principal de este espacio es el de estancia y contemplación, dado que al estar situada de frente a la fachada de Catedral y tener jardineras con arbolado que brindan sombra, se puede observar gente descansando, admirando a la Catedral e incluso a grupos de señores que se reúnen a jugar ajedrez (ver diorama 4).
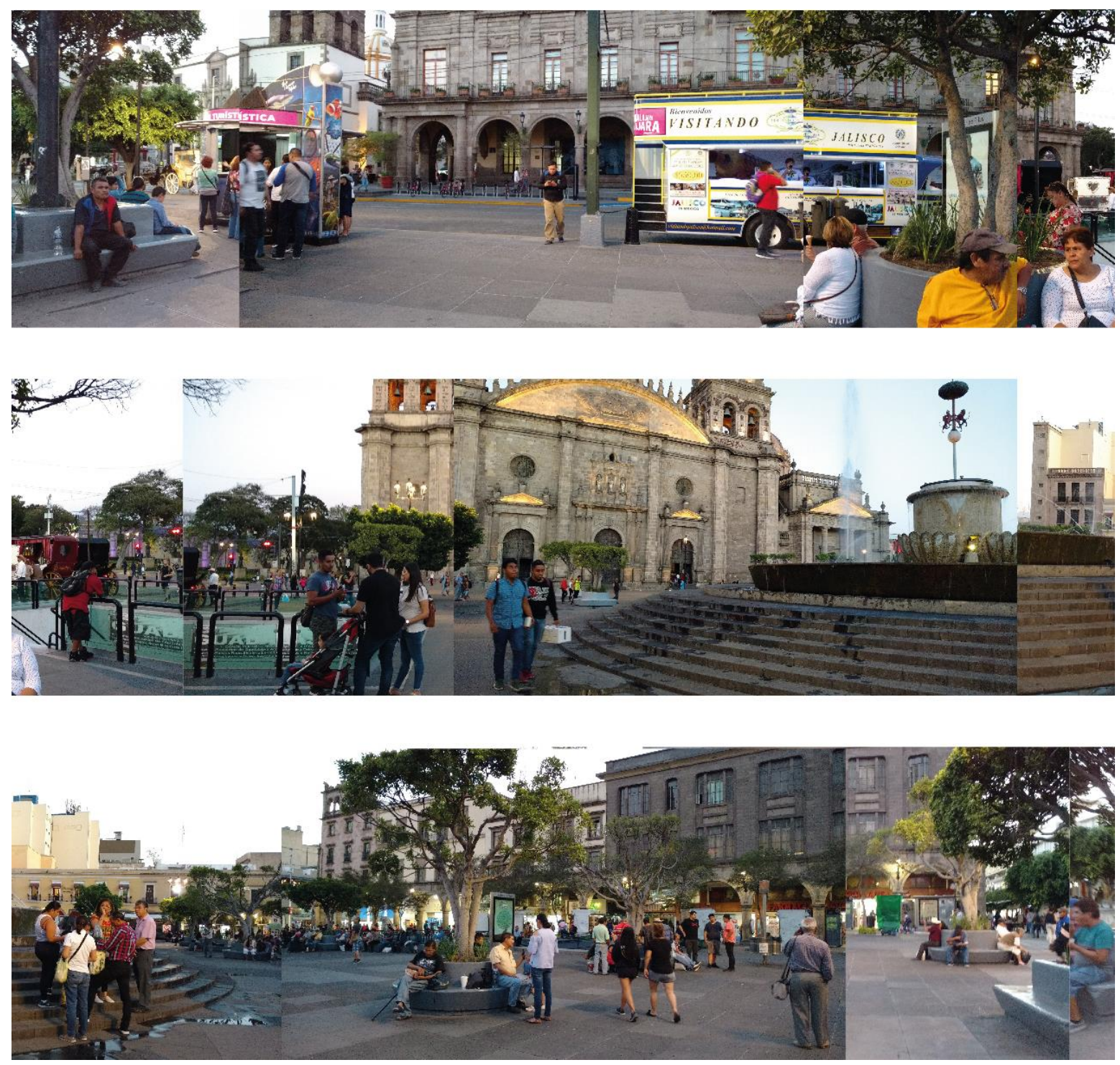

Diorama 4) Secuencia fotográfica Plaza Guadalajara Enero del 2019 por la tarde. Fuente propia 
Los niños que juegan alrededor de la fuente es otra actividad característica del espacio, e incluso los fines de semana se puede escuchar algún predicador mezclado con el bullicio de la multitud.

La plaza no es solo un lugar vibrante por los tapatíos que la visitan, es en paralelo un espacio de gran afluencia turística que busca ver la monumental fachada de la Catedral, por lo que se puede ver a un gran número de personas tomando fotos de recuerdo.

La vida del espacio durante el día es una mezcla entre lugar de transición y de permanencia, por la tarde al bajar el sol se puede observar un mayor número de usuarios apropiándose de los espacios de las jardineras y gradería de la fuente para sentarse, conversar, compartir o tomar alguna foto.

Como todo espacio tiene sus áreas de atracción (ver esquema 12), el principal es la zona de la fuente y jardineras, como se menciona, gran parte de la actividad pública sucede en estos espacios, puesto que tienen de escenario principal la monumental fachada del recinto religioso e identitario de la ciudad (Catedral).

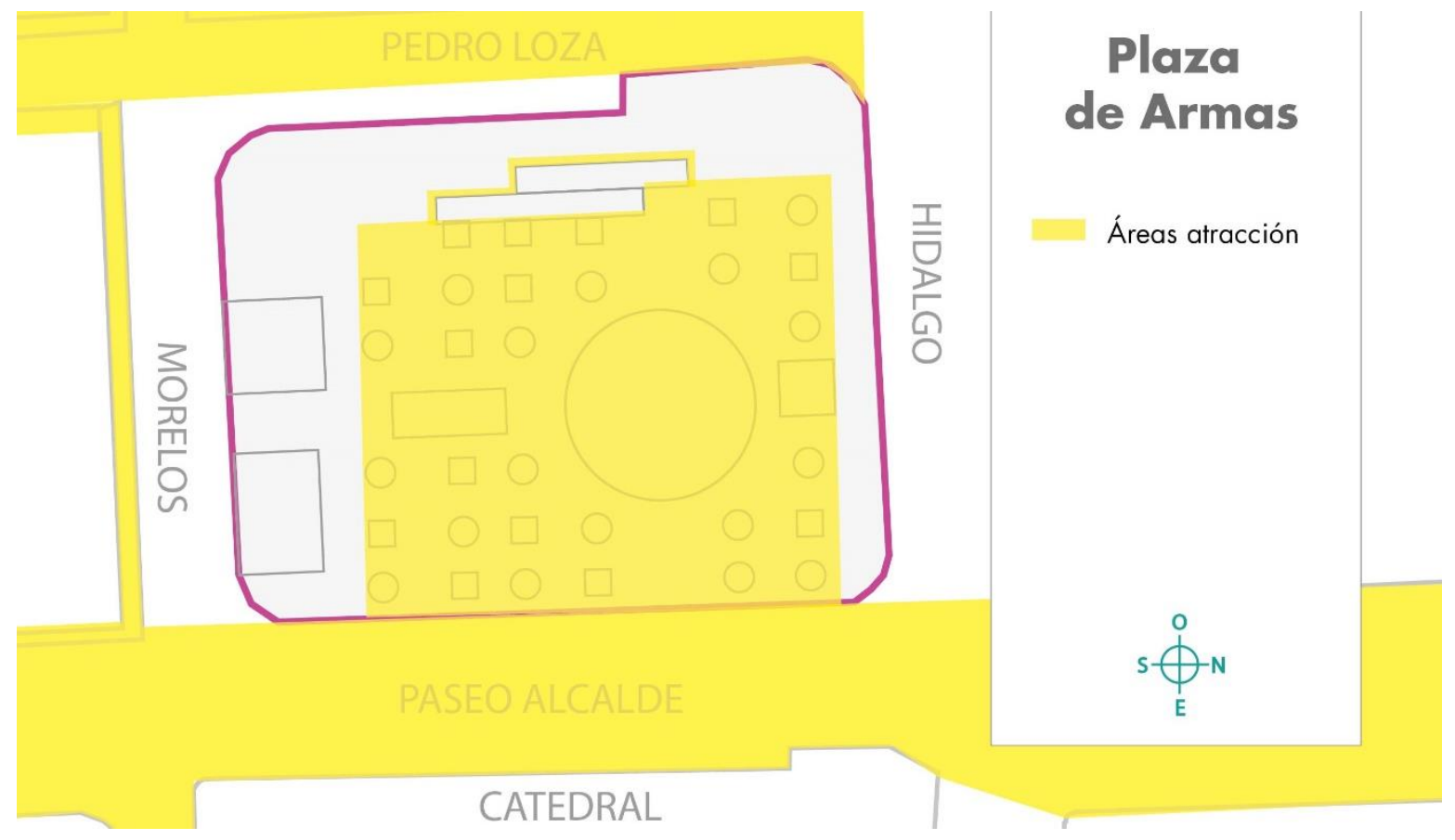

Esquema 12) Áreas de atracción Plaza Guadalajara. Elaboración propia 
Otro punto de atracción se localiza alrededor de la plaza, en los portales, donde la gente camina y se detiene en las tiendas o establecimientos de helado y comida (restaurantes y cafeterías). Agregando, otro espacio que no pasa desapercibido por la gente es paseo Alcalde, que como se ha analizado con anterioridad es un espacio con gran afluencia peatonal al conectar con tres de las plazas de Cruz de Plazas, es decir, estos puntos de atracción se relacionan principalmente con la posibilidad de las personas a ocupar y poder caminar los espacios en los andadores peatonales y a las zonas de descanso y contemplación de las bancas que tienen la vista de la majestuosa Catedral y sus representativas torres.

\subsection{2-Parque Morelos Características generales}

En época de la colonia el parque era un bosque pegado al Río San Juan de Dios, al terminar la Revolución mexicana el nuevo gobierno restructuro el espacio para volverlo menos inseguro y transformarlo en una Alameda, el primer parque de la ciudad (Gonzáles; 2005: 56).

Posteriormente se le cambió el nombre a parque Morelos por el gran Monumento que alberga de este importante personaje de la Independencia, dicho monumento colocado en el centro del parque da paso a la Calzada de los insurgentes en la cual se encuentran bustos homenajeando a los héroes de la Revolución.

Los accesos y conexiones a este parque (ver tabla 18) son principalmente por tres vías, la más simple es desde la estación de Macrobús Morelos que está justo de frente al parque, la segunda es por el andador peatonal que conecta al parque desde plaza tapatía y que cruza por ciudad creativa digital, el tercero es a través del sistema de bicicleta pública Mibici, al contar con dos estaciones distribuidas en el perímetro. 


\section{Características morfológicas y funcionales}

Este parque está constituido (ver esquema 13) en su interior por dos caminamientos circulares del que se despliegan desde el centro al exterior ramificaciones de andadores, en el centro de frente a calzada Independencia se localiza el acceso principal, un gran paseo peatonal que enlaza la banqueta exterior con el interior del parque.

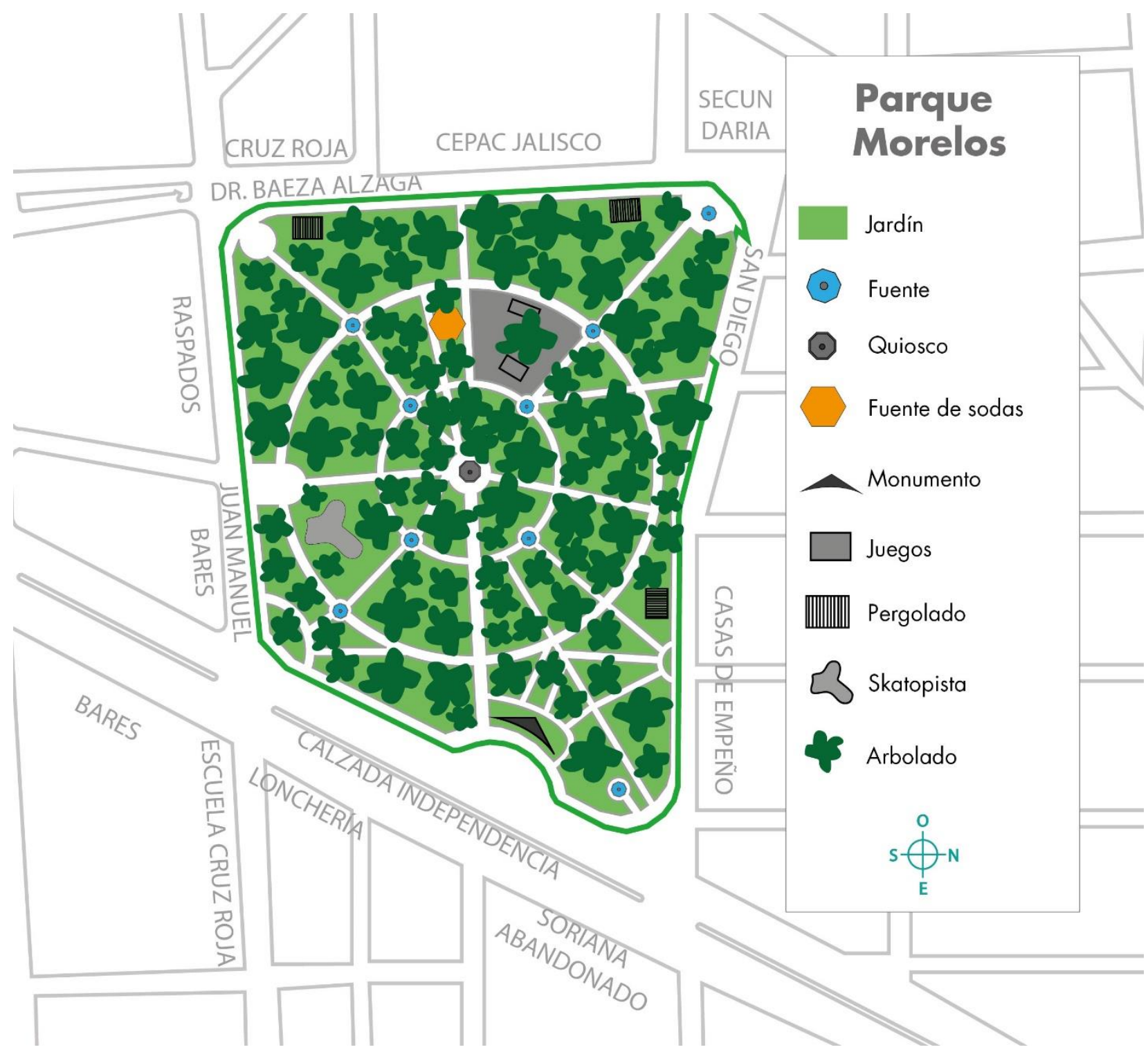

Esquema 13) Elementos físicos y morfología que conforma Parque Morelos. Elaboración propia. 
Al centro emplazado un pequeño quiosco rodeado de bancas, del que se despliegan andadores hacia todas las direcciones del parque.

Algo característico en la composición del espacio son los pequeños nodos que conectan a los andadores peatonales, ahí se localizan fuentes sitiadas por jardines y bancas.

Al fondo del parque en la sección poniente se ubica el área de juegos conformada por unas esculturas con formas de animales y un playground con columpios y pasamanos, a un costado de esta zona se localiza también una pequeña explanada cubierta por un paraboloide ${ }^{11}$.

El espacio se encuentra enmarcado por la banqueta exterior, que en el área poniente se adhiere con un andador peatonal que a su vez enlaza con Ciudad Creativa Digital y con Plaza Tapatía ${ }^{12}$

La imagen y comodidad (ver tabla 19) de este espacio alberga bancas y áreas para el descanso, baños para los usuarios, áreas recreativas y lúdicas, señalética informativa, luminarias, un skatepark, grandes árboles (vestigios de su origen boscoso) y buena visibilidad desde la Calzada Independencia, no obstante, a pesar de alojar elementos urbanos que facilitan su funcionalidad, al encontrarse ubicado en el límite de la zona de tolerancia, en automático adquiere una mala imagen para los tapatíos, que como ya se mencionó, el que se encuentre segregado en los límites de la Av. Calzada Independencia influye su percepción negativa con esta separación simbólica que representa la Guadalajara de los ricos y los pobres.

\footnotetext{
${ }^{11}$ Este diseño paraboloide es creación del arquitecto tapatío Alejandro Zohn, responsable de diseñar también el mercado Libertad (mercado San Juan de Dios)

12 Plaza Tapatía es la antesala para llegar a la explanada del museo Cabañas, antiguo Hospicio Cabañas, uno de los edificios emblemáticos de la ciudad.
} 


\begin{tabular}{|c|c|c|c|c|c|c|c|}
\hline & \multicolumn{7}{|l|}{$\begin{array}{l}\text { Variable } \\
\text { ACCESOS Y } \\
\text { CONEXIONES }\end{array}$} \\
\hline & \multicolumn{7}{|l|}{ Indicador } \\
\hline Concepto & Parada bus & Parada tren & Parada BRT & $\begin{array}{l}\text { Bici } \\
\text { pública }\end{array}$ & Bici privada & Peatonal & Coche \\
\hline Tiene (si/no) & Sí & No & Sí & Sí & Sí & Sí & Sí \\
\hline No. De paradas & & 0 & 1 & 2 & 1 & 4 & 80 \\
\hline Observaciones & & $\begin{array}{l}\text { La más } \\
\text { cercana es } \\
\text { San Juan de } \\
\text { Dios } 10 \text { min } \\
\text { caminando }\end{array}$ & $\begin{array}{l}\text { Estación } \\
\text { Morelos }\end{array}$ & $\begin{array}{l}\text { Estación } \\
\text { de mibici } \\
\text { Gdl-005 }\end{array}$ & $\begin{array}{l}\text { Tiene una } \\
\text { estación de } \\
\text { ciclopuertos }\end{array}$ & $\begin{array}{l}1 \text { andador } \\
\text { peatonal, } 1 \\
\text { acera frontal y } \\
2 \text { aceras } \\
\text { laterales }\end{array}$ & $\begin{array}{l}\text { Cajones de } \\
\text { estacionamiento } \\
\text { laterales }\end{array}$ \\
\hline
\end{tabular}

Tabla 18) Tabla de Variable: Accesos y conexiones de Parque Morelos. Elaboración propia

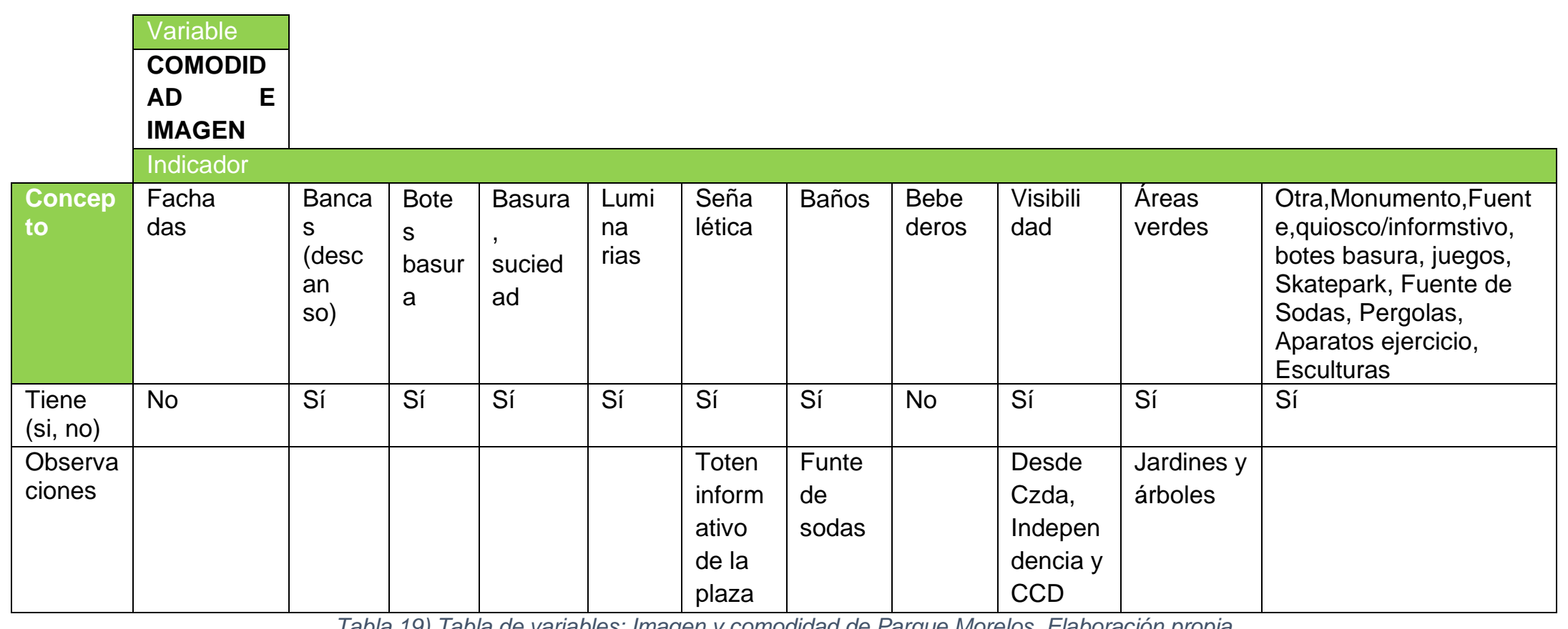

Tabla 19) Tabla de variables: Imagen y comodidad de Parque Morelos. Elaboración propia 


\section{Usos y actividades}

Popular, multitudinario el parque Morelos es anfitrión de la feria del cartón ${ }^{13}$ durante el mes de noviembre, preámbulo para dar continuidad al mercado navideño, siendo los dos últimos meses del año con mayor afluencia y actividad pública que va a observar y comprar adornos para sus altares, árboles y nacimientos.

El parque tiene un skatepark, pero se encuentra en el abandono y desaprovechado, sin uso al fondo, por otro lado en el área de esculturas juegos y mobiliario infantil es que se identifica la mayor vida pública (ver diorama 5), este espacio es el más vibrante de todo el parque al concentrar al mayor número de usuarios atraídos por los juegos y la fuente de sodas que ofrece venta de los ya tradicionales raspados y que además la explanada techada de la fuente sirve de pista de baile para un grupo que práctica danzón tres días a la semana.

De vez en cuando hay ciertos festivales culturales en la ciudad, el quiosco del Parque sirve como escenario, pero en lo cotidiano permanece vacío sin actividad alguna más que el acompañamiento de las personas que se sientan en las bancas que lo circundan.

Algunos vecinos cercanos llevan a sus perros a pasear, puesto que es el parque más cercano del casco histórico y que además limita con colonias de origen popular como el Retiro.

Los vendedores de papas y dulces se hacen presentes, así como elementos de la policía y paramédicos que realizan paseos en bicicleta y caminando.

A diferencia de la Cruz de Plazas en la que se observa una gran mixtura de diferentes tipos de usuarios (hombre, mujeres, jóvenes, niños, ancianos), en este parque se puede observar durante la mayor parte del año (exceptuando noviembre y diciembre

\footnotetext{
${ }^{13}$ Durante 9 décadas la feria del cartón ya es una tradición anual del día de muertos durante el mes de noviembre, Durante esta feria se encuentran diversos artículos elaborados de cartón, mascaras, muñecas, juguetes entre otros. Obtenido de: https://guadalajara.gob.mx/tags/parque-morelos
} 
por las ferias del cartón y navideña) que los usuarios predominantes son masculinos entre 40 y 60 años y mujeres entre los 30 a 50 años que brindan servicios sexuales.
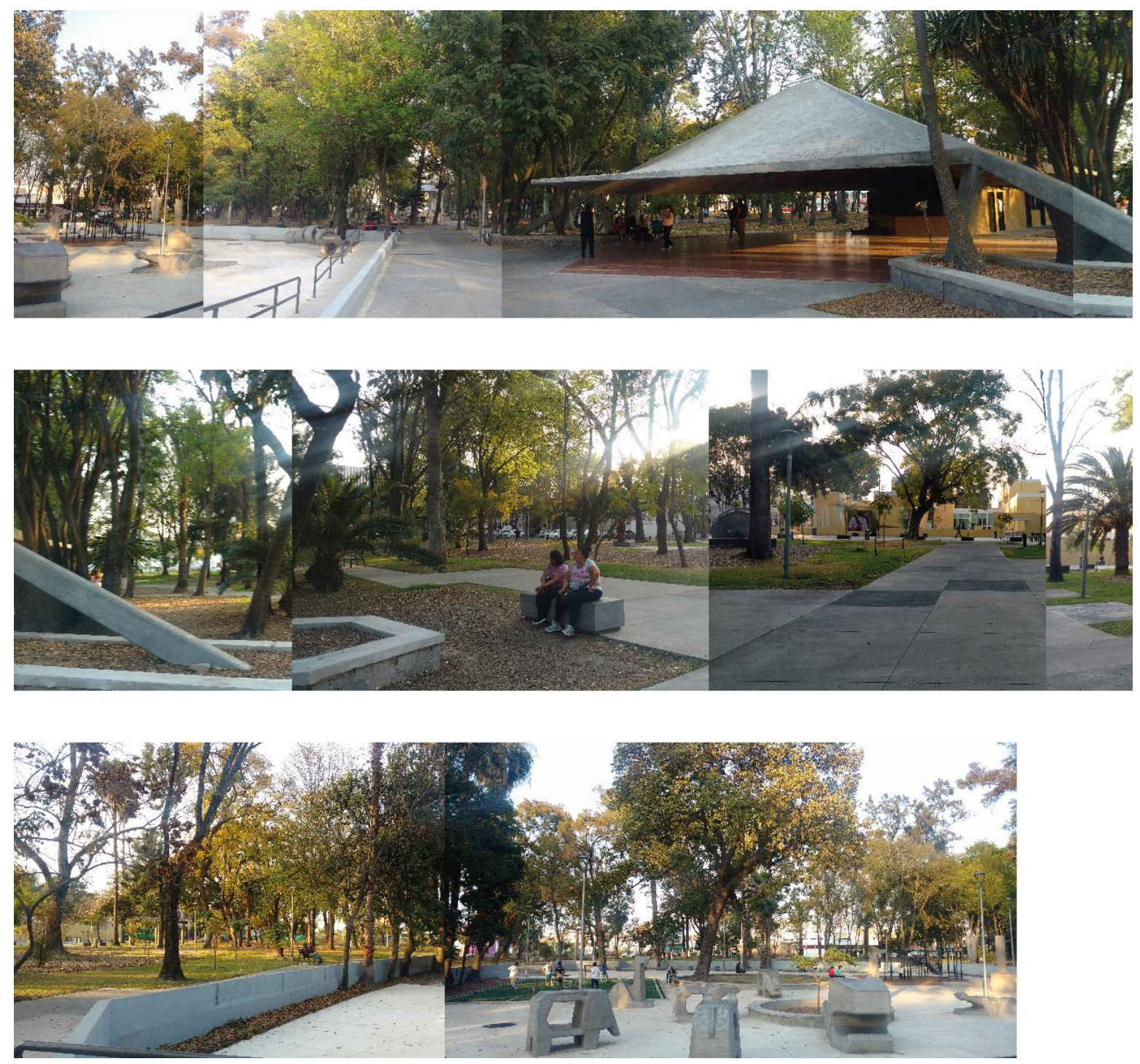

Diorama 5) Secuencia fotográfica Parque Morelos Enero del 2019 por la tarde. Fuente propia. 


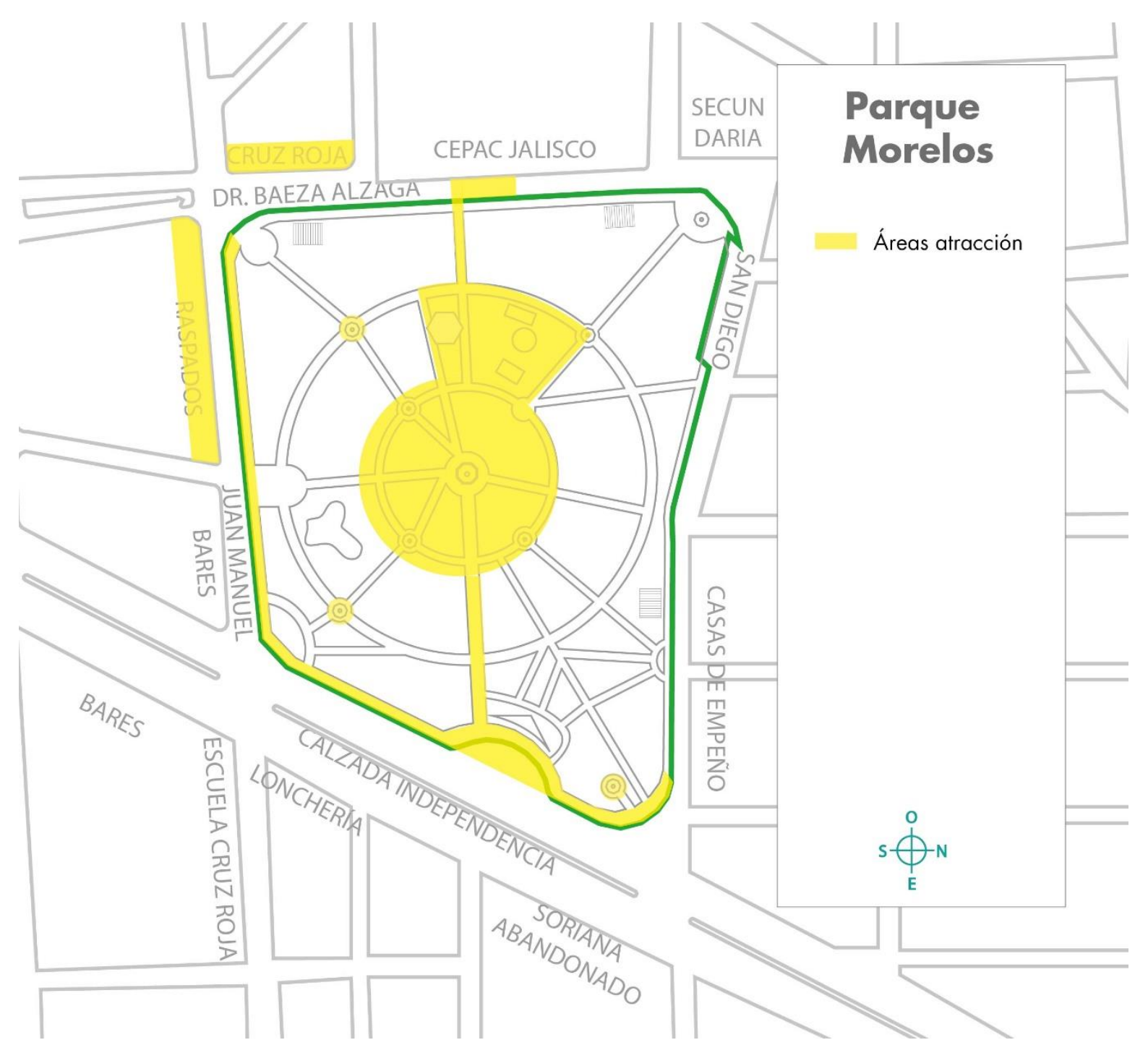

Esquema 14) Áreas de atracción Parque Morelos. Elaboración propia.

Lo anterior no indica que otros usuarios no usen el espacio, esto es observable en los puntos de atracción (esquema 14) del parque, la mayor concentración de un espectro más amplio de usuarios se da en el centro alrededor del quiosco, la zona de juegos y la explanada techada (fuente de sodas). Se observa también que la banqueta frontal y lateral izquierda de frente al monumento a Morelos hay un flujo constante de usuarios al ser aceras que conectan con la Calzada Independencia, al Macrobús y los establecimientos de raspados que se localizan en el perímetro. En conclusión, la mayor 
área de atractivo para las personas reside en los espacios de la acera que colindan con Czda. Independencia al ser un borde por su nivel tan pronunciado en proporción a la vialidad y con la calle de Juan Manuel en la que se encuentran ubicados los locales de los tradicionales raspados del Parque, por otra parte al centro, alrededor del quiosco, el área de juegos y fuente de sodas el atractivo reside en que estas áreas están conectadas unas con otras y posee elementos de descanso, contemplación y fuentes, además de que una arteria central "paseo" cruza de extremo a extremo el parque conectando estos espacios, en donde al fondo se halla la entrada del CEPAC (Centro Educativo para Altas Capacidades) y a un costado la Cruz Roja. Estos dos últimos por su vocación de centro educativo y servicios de salud son espacios en que las personas se agrupan, ya sea para recoger a sus hijos o esperar a alguien que recibe atención médica.

\subsection{Producción del espacio público en la zona periférica del norte de Guadalajara}

Huentitán es un barrio que colinda con la Barranca en los límites de la periferia norte de la ciudad. Esta colonia popular tiene sus orígenes en un pueblo de indios que con los años la mancha urbana absorbió hasta convertirlo en parte de la urbe.

Además de ser sede del Centro Universitario de Arte Arquitectura y Diseño (CUAAD), Huentitán tiene dos extensiones de espacios públicos verdes significativas para la urbe, el Parque Mirador Independencia y el Parque Natural de Huentitán. Ambos espacios han estado en la mira para intervenirlos con proyectos de asociaciones públicoprivadas (APP), es decir un esquema de proyecto viable económicamente en el que participa el sector público (gobierno) y el sector privado para el desarrollo y expansión de infraestructura pública en diversos ámbitos.

En el caso del Parque Mirador fue el Museo Guggenheim después Museo Barranca y en el Parque Natural de Huentitán la nueva sede del Recinto Ferial Fiestas de Octubre posterior Parque Educreativo, en el primero el resultante del proyecto fue la tala de arbolado del parque y un socavón que segrega el uso de casi la mitad del espacio dentro de un tapial de seguridad, en el Parque Natural el poder ciudadano se hizo presente en 
una lucha mediática de casi 5 años en la que al final el parque se dejó para el uso y disfrute de la colectividad.

Para efecto de esta investigación en los siguientes apartados correspondientes al Parque Mirador Independencia y al Parque Natural de Huentitán, como ya se señaló en el capítulo 1, se emplearán métodos cualitativos a través del empleo de las 4 tablas de variables por medio de un conteo realizado en distintos horarios y días, de lunes a domingo por la mañana y la tarde, además de la aplicación de encuestas, siendo el tamaño de la muestra; 50 para el Parque Mirador Independencia y 50 para el Parque Natural de Huentitán. Estas encuestas serán realizadas a individuos mayores de 15 años por la razón que ya se había señalado en el apartado 1.3.1 (Propuesta de variables e indicadores a aplicar en los espacios públicos de las zonas de estudio), los cuales se verán plasmados a manera de gráficos para representar los resultados de la información obtenida. En estos apartados siguientes el análisis y estudio será más exhaustivo, puesto, que no se cuenta con investigaciones que aborden a fondo y detalle estos dos espacios de la zona norte de la ciudad.

\subsubsection{Parque Mirador Independencia Características generales}

Este parque es uno de los más famosos de la ciudad por su espectacular vista de la Barranca desde sus miradores que se encuentran a más de 500 metros de altura, se localiza en el extremo norte de la Calzada Independencia y tiene una extensión aproximada de 7 has (Rodríguez, 2018).

Este espacio pertenece a la red de bosques urbanos ${ }^{14}$ de Guadalajara. La red está conformada por 11 parques ${ }^{15}$, que además de contribuir a un aire más limpio para la

\footnotetext{
${ }^{14}$ La Red de Bosques Urbanos es la instancia encargada de vigilar y mantener en buen estado las 160 hectáreas de bosque urbano que existen dentro de Guadalajara. Obtenido de https://ismaeldeltoro.mx/blog/la-red-de-bosquesurbanos-de-guadalajara

${ }^{15}$ Los parques que conforman la red de bosques urbanos de Guadalajara son: Bosque Los Colomos, Parque natural Huentitán, Mirador Independencia, Parque Agua Azul, Parque González Gallo, Parque Morelos, Parque Alcalde, Parque Ávila Camacho, Parque Liberación, Puerta a la Barranca, Arboledas del Sur. Obtenido de
} 
ciudad, forman parte del patrimonio arquitectónico de Guadalajara, como es el caso del Mirador que fue construido en la segunda mitad del siglo XX en 1965, en el que el conjunto del mobiliario remata en un anfiteatro diseñado por el arquitecto Aldo Helio Córdova Fermani (Arenal 2016).

El parque tiene el propósito e intención de ser un espacio contemplativo para observar y disfrutar las vistas que ofrece la Barranca durante todo el año. Además de los Miradores cuenta con un restaurante, áreas de juegos, terrazas y un foro al aire libre (ver ilustración 14).

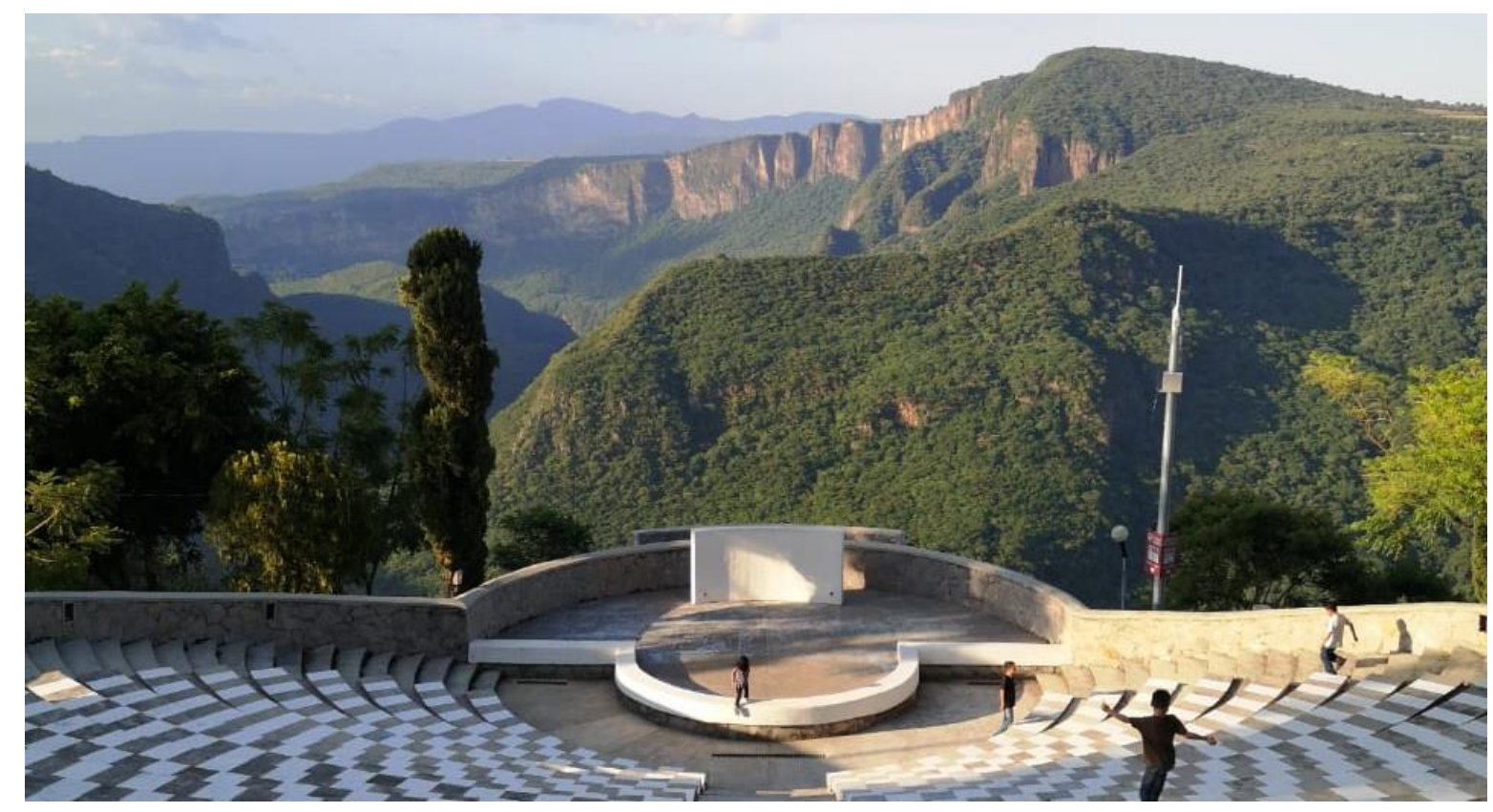

Ilustración 14) Foro del Parque Mirador, al fondo la Barranca de Huentitán. Fuente propia.

En 2007 el gobierno de Guadalajara donó a la Asociación Guadalajara Capital Cultural un pedazo del predio para la construcción de un museo Guggenheim, sin embargo, en 2009 la fundación Solomon R. Guggenheim anuncio su retiro y abandono del proyecto (Partida, 2009: 7). Al tener la donación del terreno por parte del gobierno de Guadalajara se proyectó una nueva propuesta de museo que fue responsable que en 2011 se viera reducida la masa arbórea y espacio de uso para la construcción de

https://www.informador.mx/jalisco/Ayuntamiento-tapatio-presenta-Red-de-Bosques-Urbanos-de-Guadalajara20171128-0097.html 
"Barranca, museo de arte moderno y contemporáneo" proyectado por el gobierno estatal y el ayuntamiento de Guadalajara, para lo cual se talaron alrededor de 182 árboles (García, 2011), cercenando casi la mitad de la superficie verde total del parque. De las obras del museo solo se realizó la excavación para la cimentación, pero el proyecto quedo parado por falta de dinero, lo que ocasiono que el espacio quedase inutilizable del uso público, pero a su vez segregado por un tapial de seguridad. (ver ilustración 15).

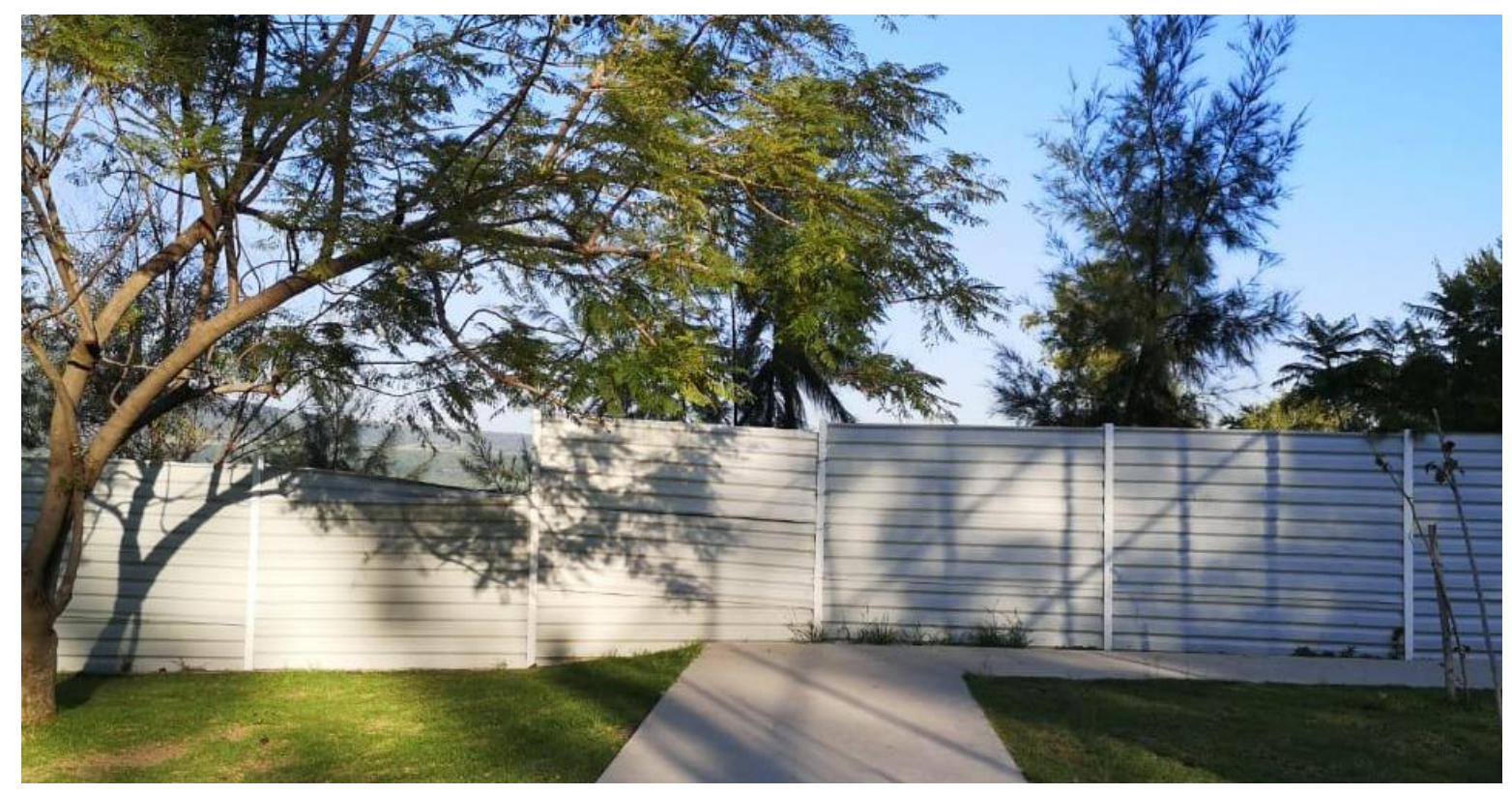

Ilustración 15) Tapial divisorio de obras del museo parque Mirador. Fuente propia

Este sitio fue la primera área verde de la zona norte en ser reconocida como parque público, al ser un espacio público abierto al aire libre tiene una amplia gama de usuarios de distintos rangos de edades (ver gráfico 1 y 2 ). 


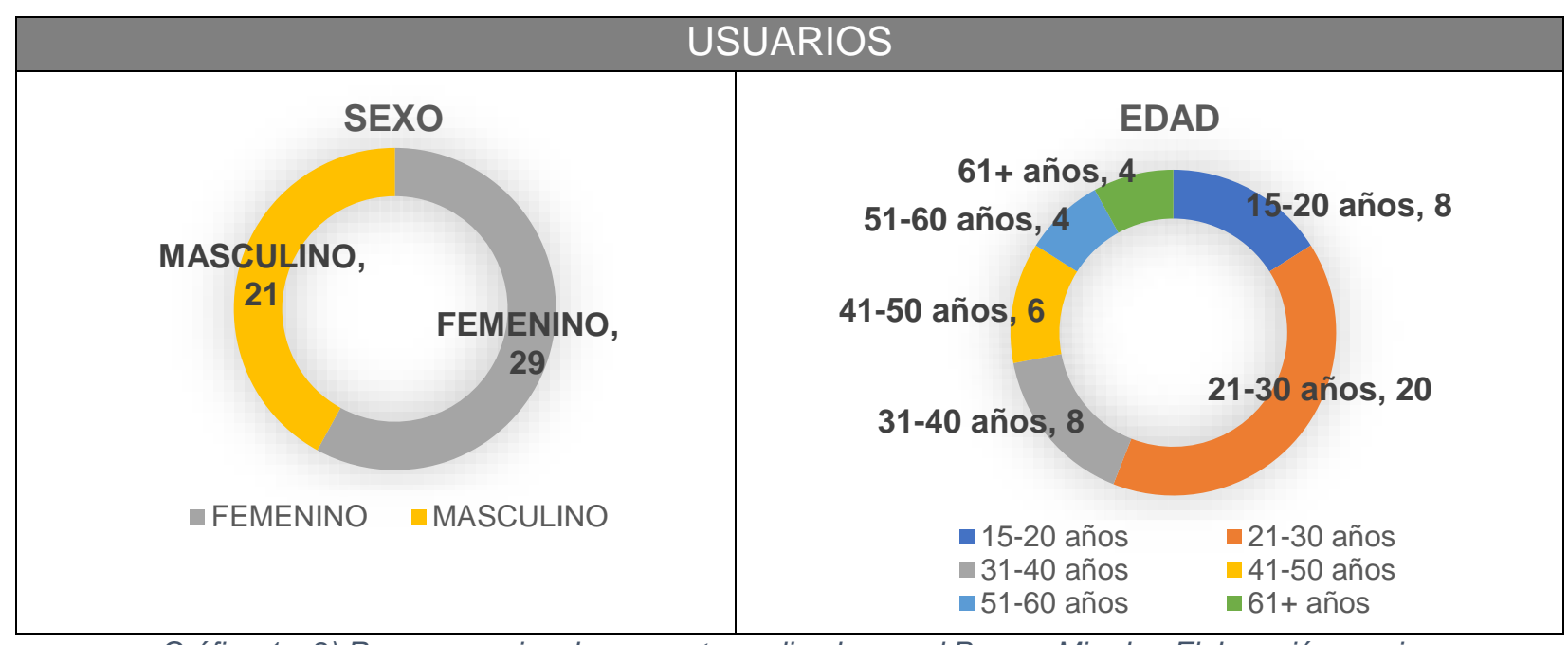

Gráfico 1 y 2) Rango usuarios de encuestas aplicadas en el Parque Mirador. Elaboración propia

El parque cuenta únicamente con un acceso principal que funciona de acceso peatonal y vehicular. Al encontrarse en la orilla de la ciudad, sus accesos y conexiones (ver tabla 20) se ven limitados, una de las vías de entrada principal es por vehículo privado, pues cuenta con un amplio estacionamiento, otra manera sencilla de llegar es por medio del sistema de transporte público masivo Macrobús en su última estación Mirador que está ubicada a una cuadra de distancia del acceso principal o incluso caminando por todo el camellón de Calzada Independencia.

Al tener una buena conexión de transporte público y estacionamiento amplio gran parte de los usuarios vienen de otros barrios de la ciudad, seguido de barrios vecinos y del mismo barrio, donde su punto de origen es principalmente su casa, ya sea en Macrobús, coche privado o caminando, tomando en cuenta que una parte significativa de usuarios indirectos son estudiantes del $\operatorname{CUAAD}^{16}$ que dejan sus vehículos dentro del estacionamiento, los usuarios directos son más representativos los fines de semana. (ver gráfico $3,4,5)$.

De acuerdo con la percepción de los usuarios con relación a las conexiones y accesos internos existe una muy buena sensación de caminabilidad (ver gráfico 6) entre los jardines, pasillos y caminamientos, exceptuando para quienes usan sillas de ruedas,

\footnotetext{
${ }^{16}$ Siglas del Centro Universitario de Arte Arquitectura y Diseño de la Universidad de Guadalajara.
} 
ya que, por sus características topográficas para acceder a los miradores a pie de barranca, se tienen que bajar escaleras. Referente a la accesibilidad con el espacio también se percibe como muy buena y buena en general porque se puede llegar en transporte público y el ingreso al parque es gratuito (ver gráfico 7)

La percepción que existe en cuanto al enlace con otros espacios es positiva, por la condicionante de que el Macrobús conecta con la zona centro en 30 minutos. Para entender lo anterior los usuarios encuestados perciben que el parque se conecta de manera rápida con Plaza Independencia y el Parque Natural de Huentitán (ver gráfico 8 y 9$)$.

Su imagen y comodidad es buena, cuenta con 7 indicadores positivos contra 4 negativos de un total de 11 (ver tabla 21), tiene bancas y áreas de descanso ajardinadas, luminarias, áreas de juegos, cancha, terrazas para picnic y un foro al aire libre por mencionar algunos.

\begin{tabular}{|c|c|c|c|c|c|c|c|}
\hline & \multicolumn{2}{|c|}{$\begin{array}{l}\text { ACCESOS Y } \\
\text { CONEXIONES }\end{array}$} & & & & & \\
\hline & \multicolumn{7}{|c|}{ Indicador } \\
\hline Concepto & $\begin{array}{l}\text { Parada } \\
\text { bus }\end{array}$ & $\begin{array}{l}\text { Parada } \\
\text { tren }\end{array}$ & $\begin{array}{l}\text { Parada } \\
\text { BRT }\end{array}$ & $\begin{array}{l}\text { Bici } \\
\text { pública }\end{array}$ & Bici privada & Peatonal & Coche \\
\hline Tiene (si/no) & No & No & Sí & No & No & Sí & Sí \\
\hline $\begin{array}{l}\text { No. De } \\
\text { paradas }\end{array}$ & 0 & 0 & 1 & 0 & 0 & 1 & 1 \\
\hline Observaciones & & & $\begin{array}{l}\text { Macrobús } \\
\text { Estación } \\
\text { Mirador }\end{array}$ & & $\begin{array}{l}\text { No cuenta } \\
\text { con } \\
\text { ciclopuertos }\end{array}$ & $\begin{array}{l}\text { Acera } \\
\text { lateral }\end{array}$ & Estacionamiento \\
\hline
\end{tabular}

Tabla 20) Tabla de Variable: Accesos y conexiones de Parque Mirador. Elaboración propia

Muy satisfactoria perciben su experiencia las personas en el espacio, a su vez consideran que los elementos que le dan primordialmente identidad al parque son su vegetación (áreas verdes) y las actividades sociales que se realizan,seguido de la arquitectura. La limpieza en general se percibe como muy buena/buena y el confort del 
parque como muy bueno mayoritariamente. En cuanto a la percepción de seguridad los usuarios la consideran muy buena (ver gráfico 10, 11, 12, 13 y 14).

Algo a destacar de acuerdo con los resultados es que la gente siente un sentido de apropiación del espacio (se ve reflejado en que es mínima la basura que se observa tirada) y perciben una conexión en relación con aspectos sociales principalmente y seguida por aspectos urbanos (la arquitectura, diseño el equipamiento y mobiliario, los elementos que conforman lo tangible del espacio) (ver gráfico 15 y 16). 


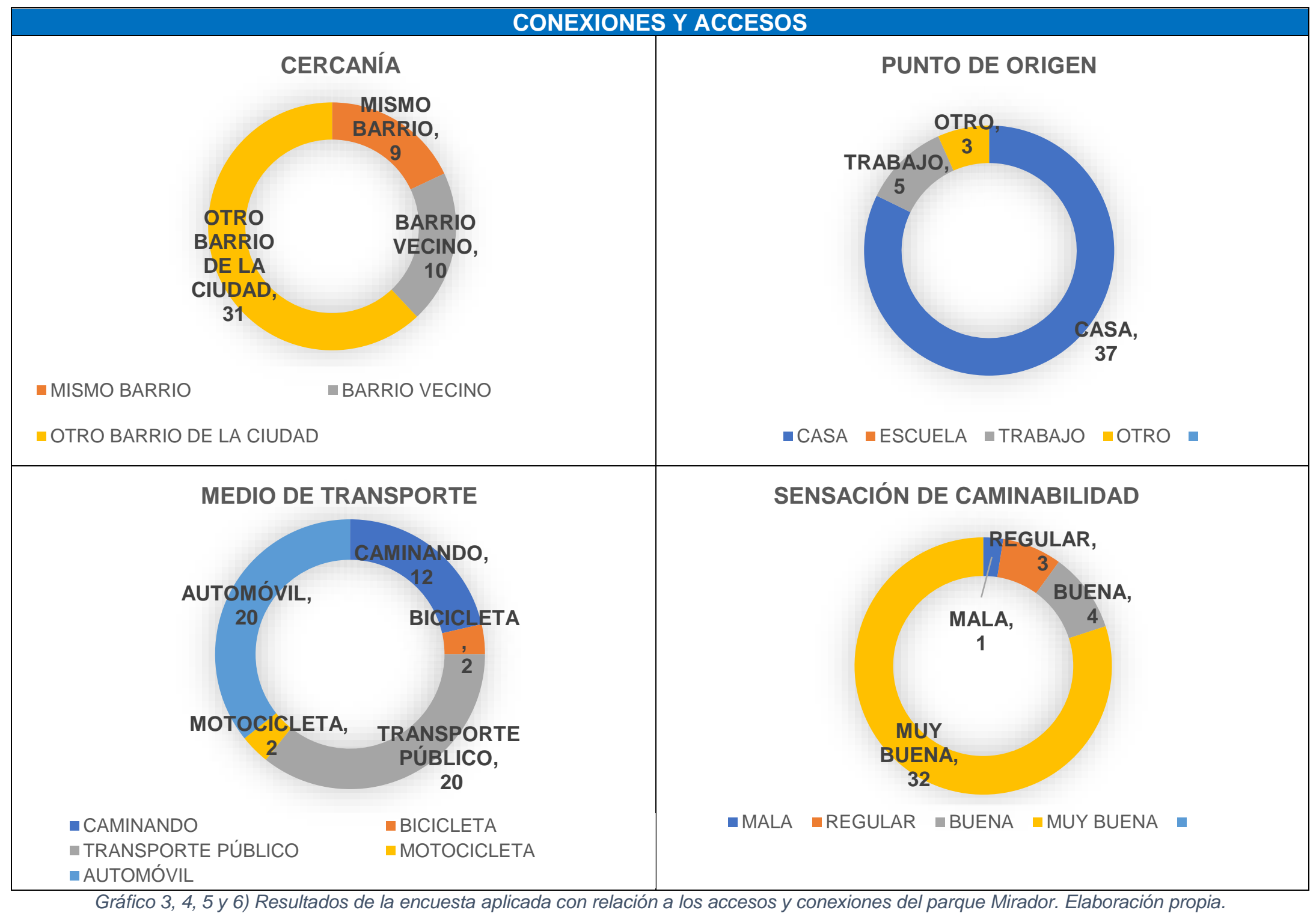




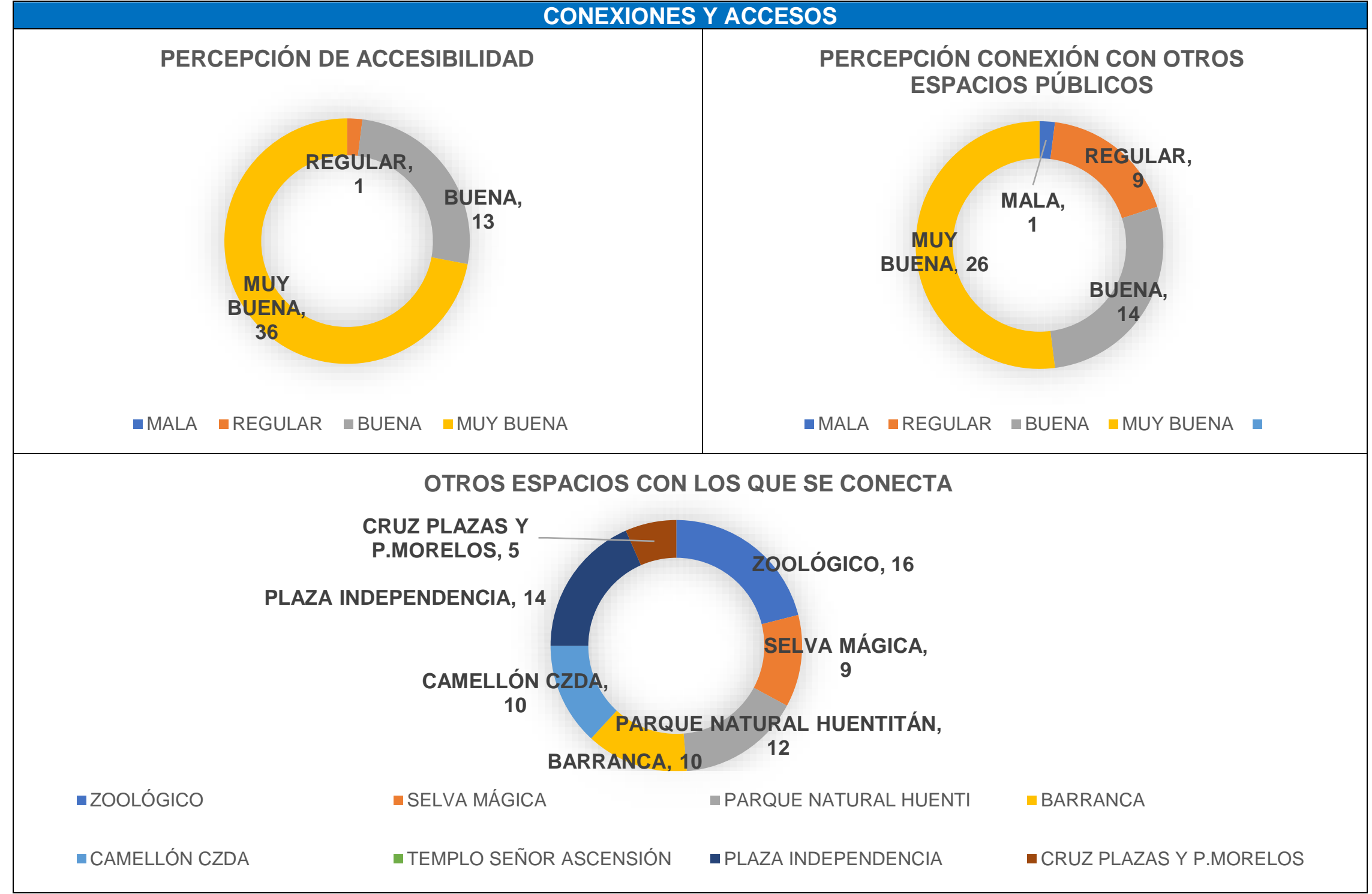

Gráfico 7,8 Y 9) Resultados de la encuesta aplicada con relación a los accesos y conexiones del parque Mirador. Elaboración propia. 


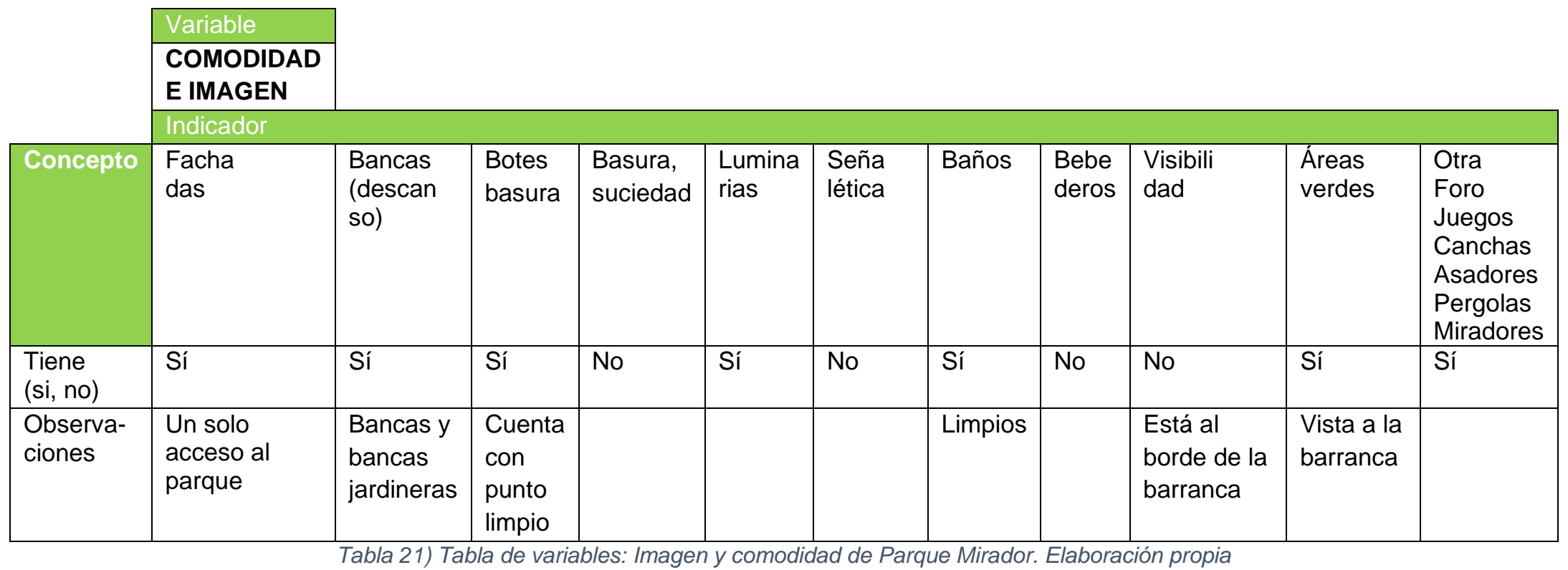




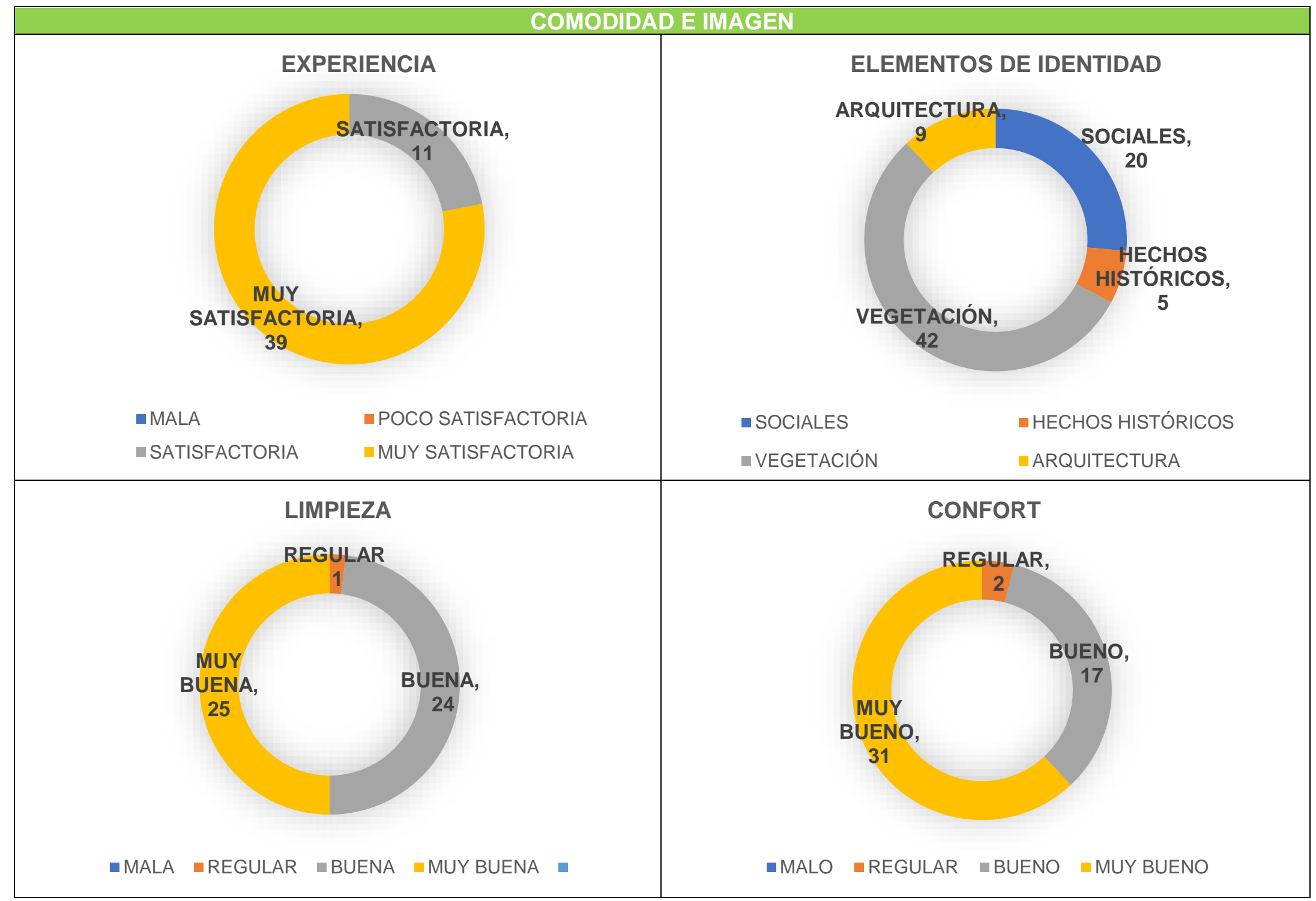

Gráfico 10,11, 12 y 13) Resultados de la encuesta aplicada con relación a la imagen y comodidad del parque Mirador. Elaboración propia. 


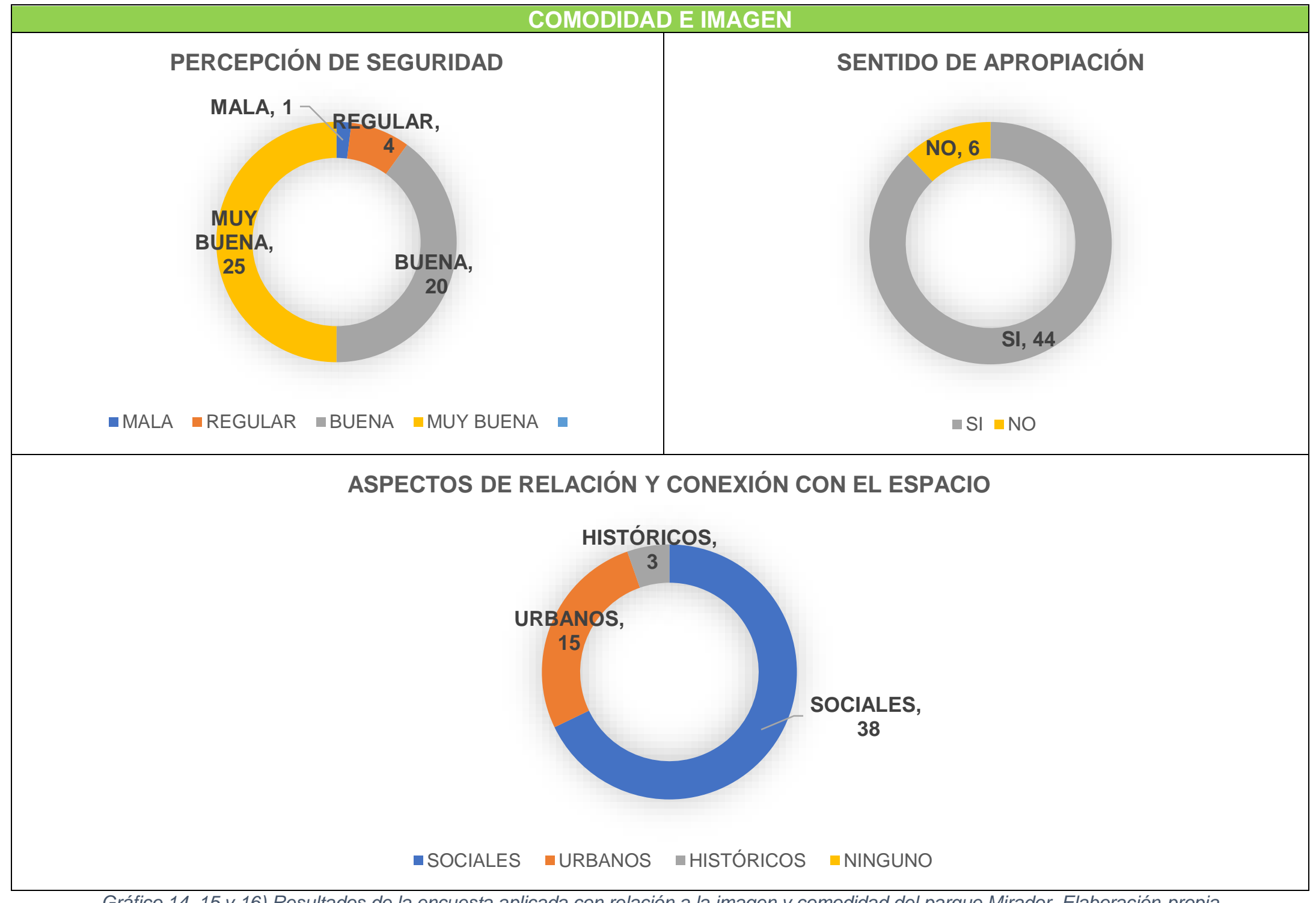

Gráfico 14, 15 y 16) Resultados de la encuesta aplicada con relación a la imagen y comodidad del parque Mirador. Elaboración propia 
En cuanto a la sociabilidad del espacio el mayor rango de personas interactuando se observó entre semana después de las 17 horas y especialmente el fin de semana, domingo, por la tarde (ver ilustración 16 y tabla 22, 23, 24, 25, 26 y 27).

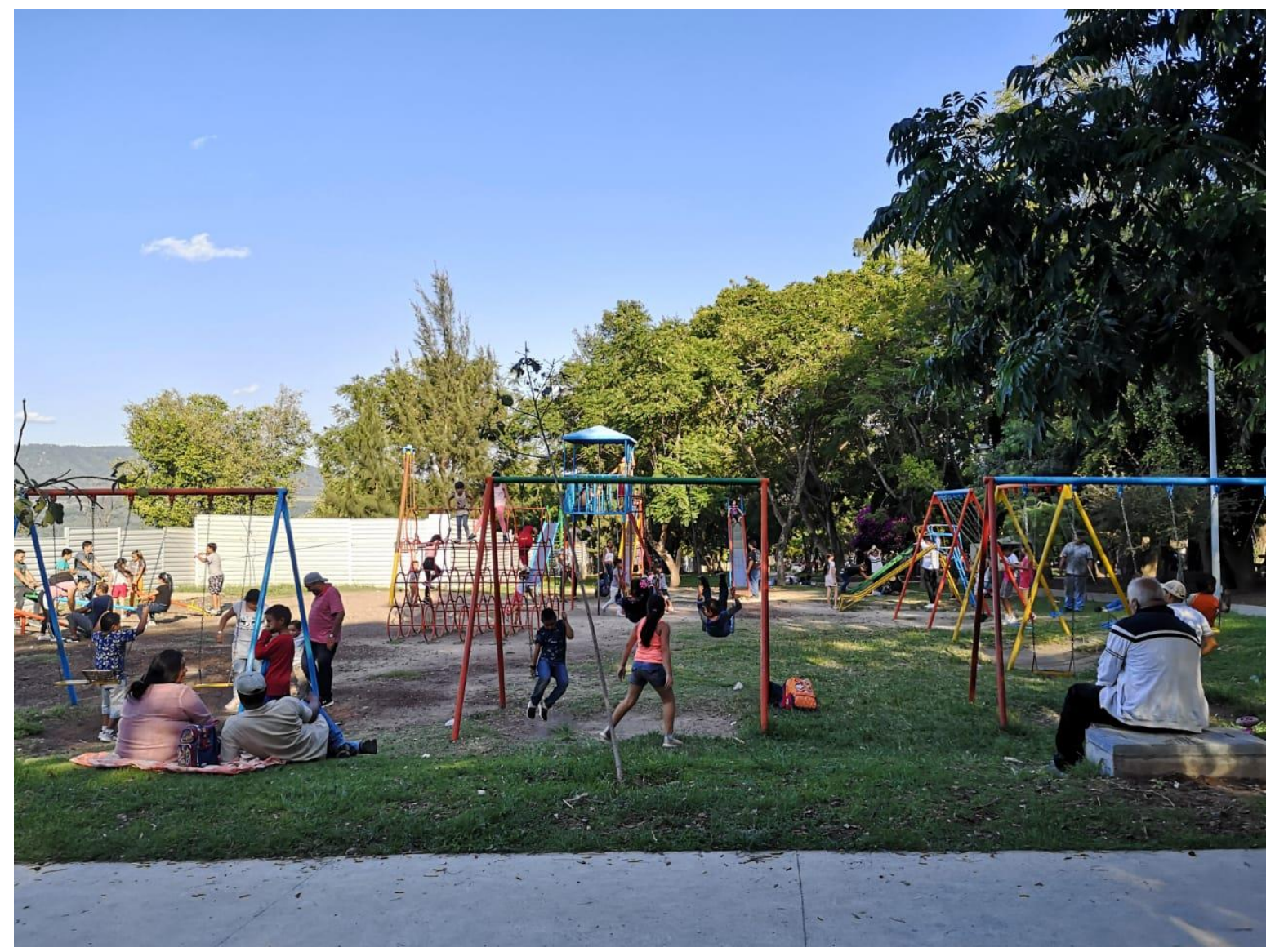

Ilustración 16) domingo por la tarde en el Parque Mirador. Fuente propia.

La frecuencia de visita por parte de los usuarios es mayormente semanal y el tiempo de estancia es entre 30 y 2 horas cuando lo visitan. Usualmente quienes frecuentan el sitio lo hacen acompañados y prefieren interactuar con amigos, quienes acuden al parque son principalmente personas que no pertenecen a ningún grupo, pero también hay presencia de usuarios que corresponden a algún colectivo que realiza actividades dentro del espacio (ver gráfico 17, 18, 19, 20 y 21). 


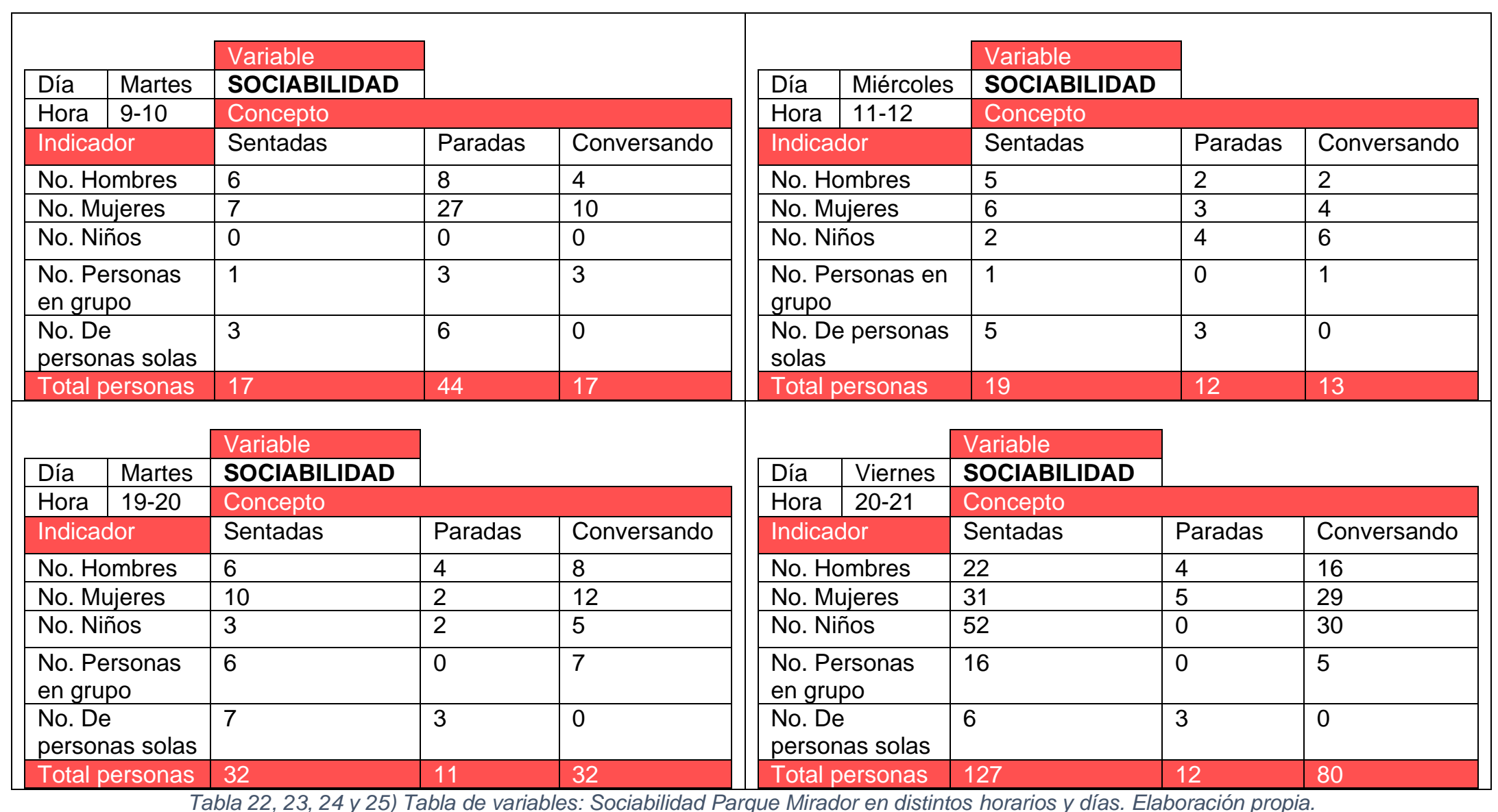




\begin{tabular}{|c|c|c|c|c|c|c|c|c|c|}
\hline & & \multirow{2}{*}{\multicolumn{3}{|c|}{$\begin{array}{l}\text { Variable } \\
\text { SOCIABILIDAD }\end{array}$}} & \multicolumn{3}{|r|}{$\sqrt{\text { Variable }}$} & & \\
\hline Día & Sábado & & & & Día & Sábado & \multicolumn{3}{|l|}{ SOCIABILIDAD } \\
\hline Hora & $11-12$ & \multicolumn{3}{|l|}{ Concepto } & Hora & $19-20$ & \multicolumn{3}{|l|}{ Concepto } \\
\hline \multicolumn{2}{|c|}{ Indicador } & Sentadas & Paradas & Conversando & \multicolumn{2}{|c|}{ Indicador } & Sentadas & Paradas & Conversando \\
\hline \multicolumn{2}{|c|}{ No. Hombres } & 15 & 11 & 14 & \multicolumn{2}{|c|}{ No. Hombres } & 11 & 9 & 2 \\
\hline \multicolumn{2}{|c|}{ No. Mujeres } & 19 & 9 & 17 & \multicolumn{2}{|c|}{ No. Mujeres } & 9 & 4 & 3 \\
\hline \multicolumn{2}{|c|}{ No. Niños } & 8 & 8 & 13 & \multicolumn{2}{|c|}{ No. Niños } & 3 & 3 & 1 \\
\hline \multicolumn{2}{|c|}{$\begin{array}{l}\text { No. Personas } \\
\text { en grupo }\end{array}$} & 5 & 1 & 6 & \multicolumn{2}{|c|}{$\begin{array}{l}\text { No. Personas } \\
\text { en grupo }\end{array}$} & 7 & 2 & 6 \\
\hline \multicolumn{2}{|c|}{$\begin{array}{l}\text { No. De } \\
\text { personas solas }\end{array}$} & 9 & 3 & 0 & \multicolumn{2}{|c|}{$\begin{array}{l}\text { No. De } \\
\text { personas solas }\end{array}$} & 3 & 0 & 0 \\
\hline \multicolumn{2}{|c|}{ Total personas } & 56 & 32 & 50 & \multicolumn{2}{|c|}{ Total personas } & 33 & 18 & 12 \\
\hline
\end{tabular}

Tabla 26 y 27) Tabla de variables: Sociabilidad Parque Mirador en distintos horarios y días. Elaboración propia.

\begin{tabular}{|c|c|}
\hline & AD \\
\hline 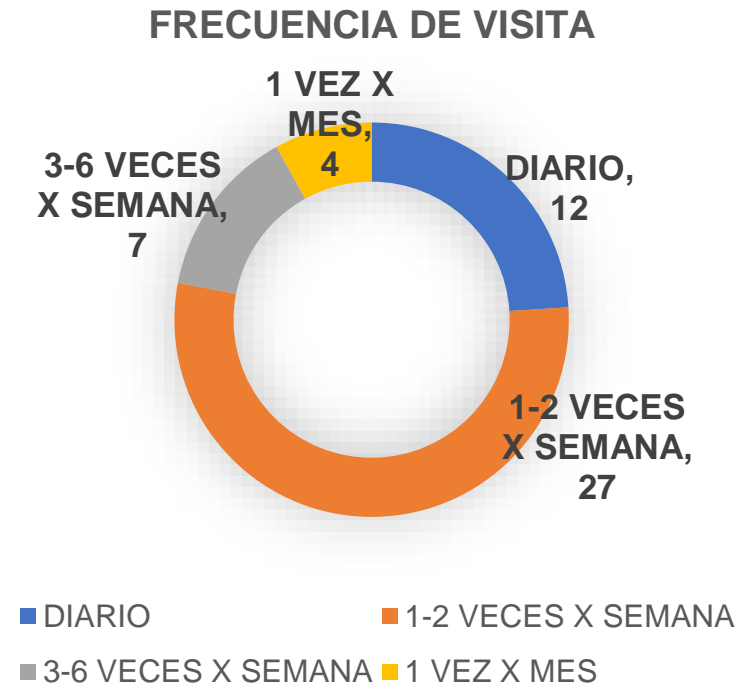 & 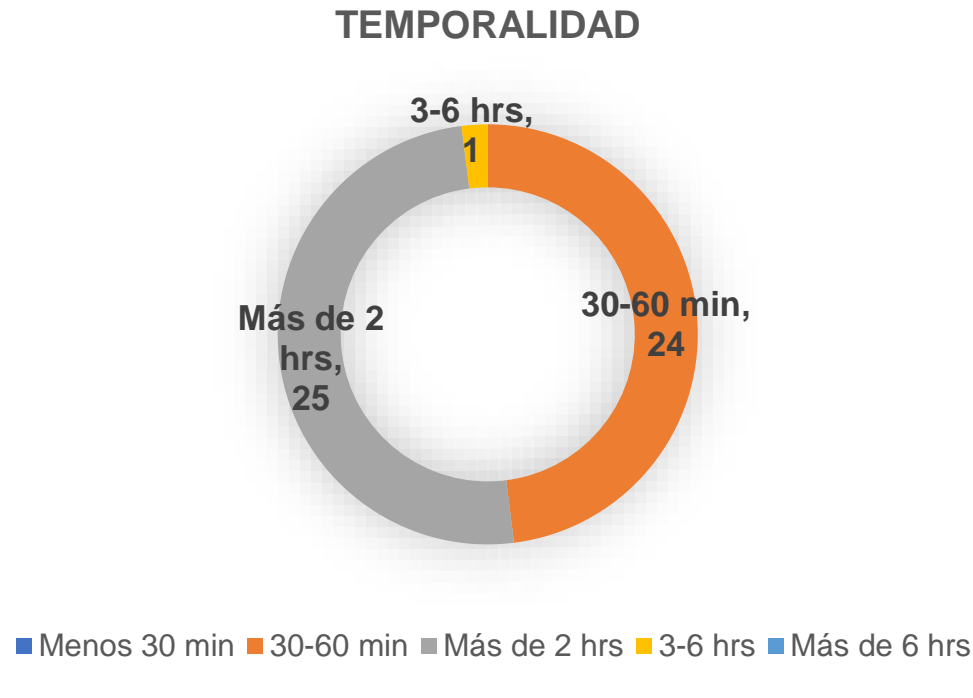 \\
\hline
\end{tabular}

Gráfico 17 y 18) Resultados de la encuesta aplicada con relación a la imagen y comodidad del parque Mirador. Elaboración propia 


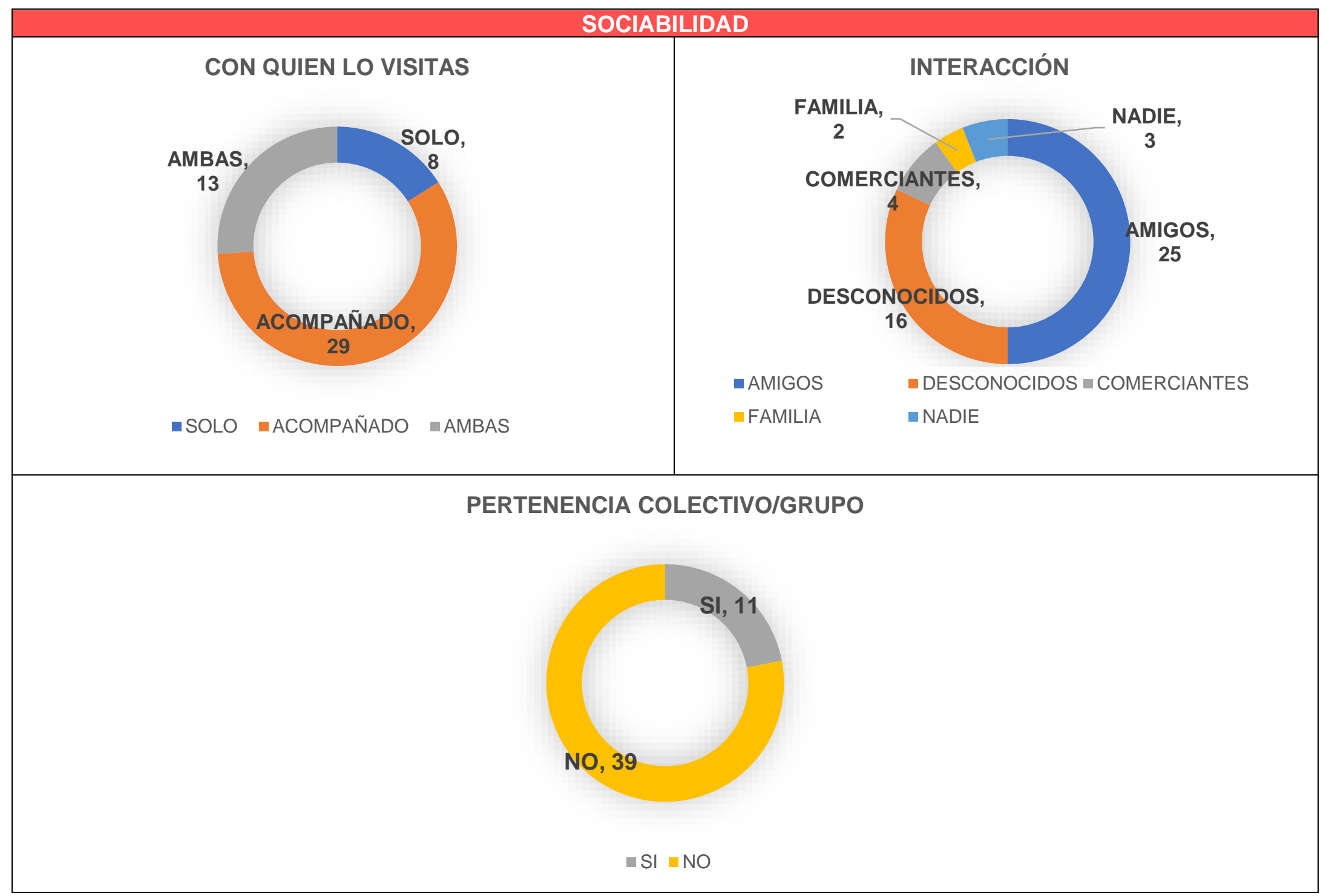

Gráfico 19, 20 y 21) Resultados de la encuesta aplicada con relación a la imagen y comodidad del parque Mirador. Elaboración propia 


\section{Características morfológicas y funcionales}

El espacio tiene una forma semi cuadrada, en su parte interna casi en el corazón del parque se encuentra la excavación del fallido museo cercada por un tapial de protección para los usuarios, al costado izquierdo a un lado del CUAAD ${ }^{17}$ está ubicada una explanada con un jardín y monumento a Hidalgo (de ahí su nombre de Mirador Independencia), al costado derecho se sitúa una cancha de usos múltiples y zona de juegos, más al fondo jardines con unas cuantas terrazas, al final de las terrazas un caminamiento que conecta circundante a los miradores y a todo el parque rodeando la obra del museo. De la explanada principal de Hidalgo se despliega un corredor que enlaza con una segunda plancha de concreto, amplia, extensa con un primer mirador que muestra la vista del foro y la barranca, a un costado derecho ubicado frente a la obra negra el restaurante del parque con unas vistas espectaculares. Bajando por unas escaleras se conecta al foro, bajando un poco más se llega a los miradores que son el límite del parque con la barranca (ver esquema 15).

\section{Usos y actividades}

Niños corriendo, personas acostadas en los jardines, jóvenes jugando futbol, personas contemplando la vista, reuniones familiares, fiestas infantiles son algunas de las actividades que se ven dentro del Mirador (ver diorama 6), sin embargo, las acciones que se observa realizan con mayor frecuencia los usuarios son; ejercicio, caminar y contemplar el paisaje (ver tabla $28,29,30,31,32$ y 33 ), aunque bien, dependiendo del horario y el día son las actividades que se puede ver se ejecutan con mayor frecuencia.

Como ya se describió el parque tiene un foro al aire libre, en él se realizan proyecciones de cine al aire libre una vez a la semana y de vez en cuando una o

\footnotetext{
${ }^{17}$ CUAAD son las siglas para el Centro Universitario de Arte Arquitectura y Diseño
} 
dos veces al año el espacio es sede de obras de teatro o presentaciones musicales (ver ilustración 17).

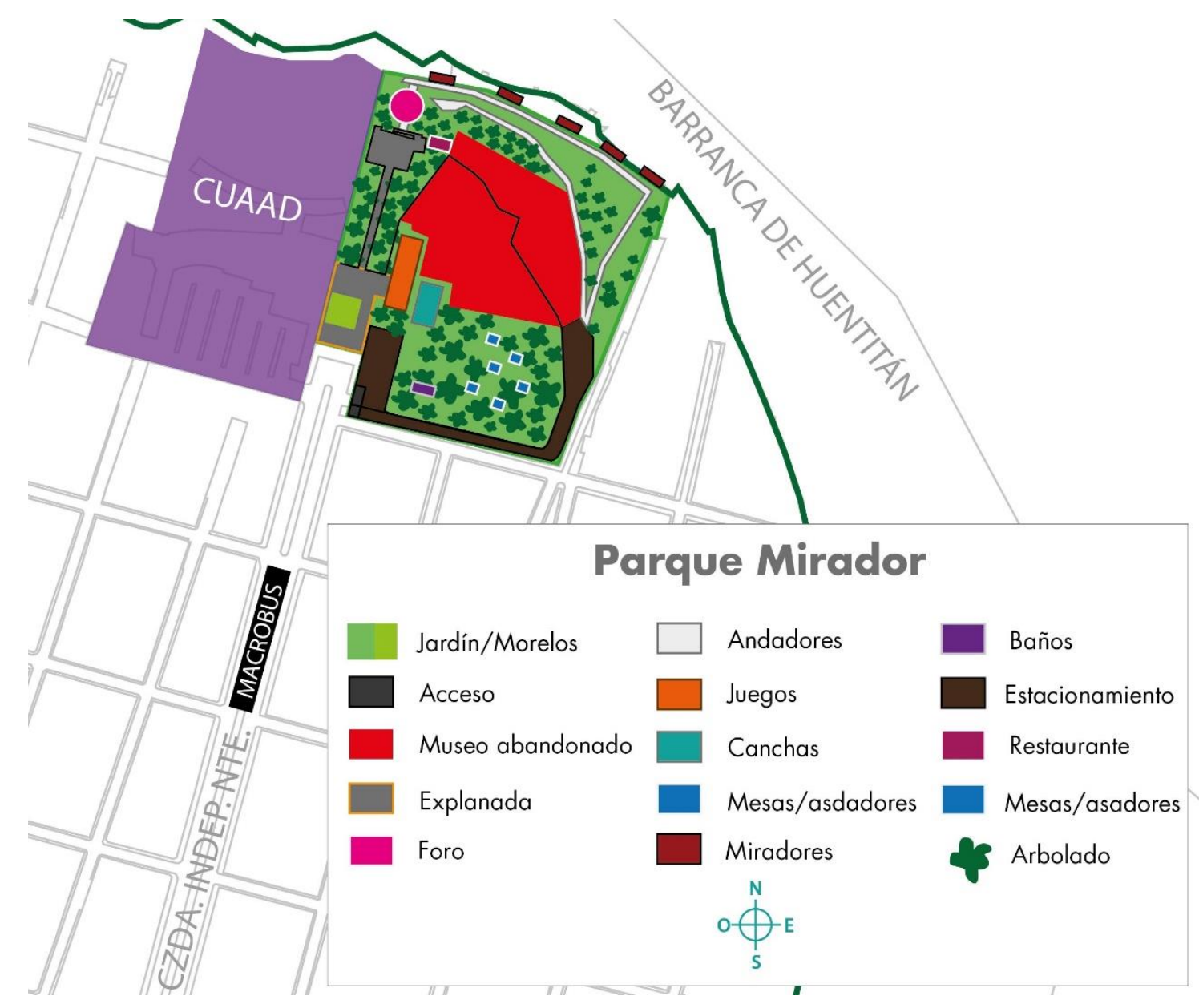

Esquema 15) Elementos físicos y morfología que conforma Parque Mirador. Elaboración propia.

Otro de los usos y actividades que aportan los usuarios al Mirador son las clases de karate para los más pequeños y las clases de yoga en compañía de las vistas de acantilados y peñascos de la barranca.

De acuerdo a la encuesta realizada los usuarios perciben su visita al parque como satisfactoria y señalan que las actividades y usos que hacen dentro de este espacio son principalmente de descanso, convivencia y recreación (ver gráfico 22 y 23) acotando que el motivo de su visita es principalmente porque les gusta el parque, por la cercanía y las actividades sociales que desempeñan así como la 
mayor parte de los encuestados señaló que las acciones a las que mayor asisten son las relacionadas con eventos sociales (ver gráfico 24 y 25).
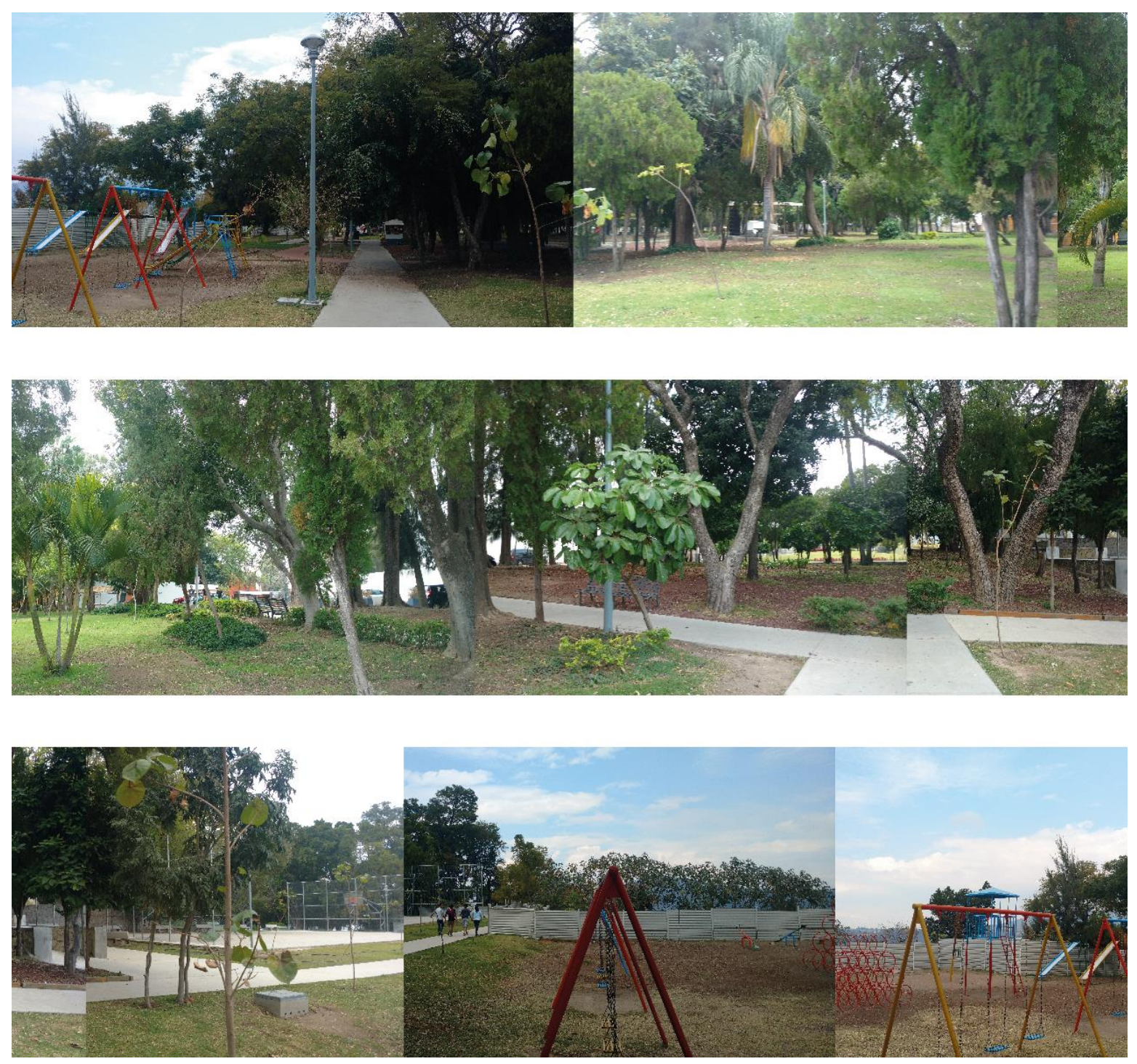

Diorama 6) Secuencia fotográfica Parque Mirador Enero del 2019 por la mañana. Fuente propia. 


\begin{tabular}{|c|c|c|c|c|c|c|c|c|c|c|c|}
\hline & \multirow{2}{*}{\multicolumn{3}{|c|}{ Variable }} & & & & & & & \\
\hline & & & & & & & & & & & \\
\hline Día & Lunes & \multicolumn{3}{|c|}{ USOS Y ACTIVIDADES } & & & & & & & \\
\hline Hora & $10-11$ & \multicolumn{10}{|c|}{ Concepto } \\
\hline \multicolumn{2}{|c|}{ Indicador } & Ejercicio & Caminando & $\begin{array}{l}\text { Jugan } \\
\text { do }\end{array}$ & Contemplación & $\begin{array}{l}\text { Tomar } \\
\text { fotos }\end{array}$ & $\begin{array}{l}\text { Pasear } \\
\text { mascota }\end{array}$ & Leyendo & Comiendo & Venta & $\begin{array}{l}\text { Otra/ } \\
\text { especificar }\end{array}$ \\
\hline \multicolumn{2}{|c|}{ No. Hombres } & 4 & 10 & 0 & 5 & 0 & 0 & 1 & 0 & 0 & 0 \\
\hline \multicolumn{2}{|c|}{ No. Mujeres } & 6 & 12 & 0 & 5 & 0 & 0 & 0 & 2 & 0 & 0 \\
\hline \multicolumn{2}{|c|}{ No. Niños } & 0 & 0 & 5 & 0 & 0 & 0 & 0 & 2 & 0 & 0 \\
\hline \multicolumn{2}{|c|}{$\begin{array}{l}\text { No. } \\
\text { Personas en } \\
\text { grupo }\end{array}$} & 0 & 0 & 0 & 0 & 0 & 0 & 0 & 0 & 0 & 0 \\
\hline \multicolumn{2}{|c|}{$\begin{array}{l}\text { No. De } \\
\text { personas } \\
\text { solas }\end{array}$} & 5 & 17 & 0 & 2 & 0 & 0 & 0 & 0 & 0 & 0 \\
\hline \multicolumn{2}{|c|}{$\begin{array}{l}\text { Total } \\
\text { personas }\end{array}$} & 15 & 39 & 5 & 12 & 0 & 0 & 1 & 4 & 0 & 0 \\
\hline
\end{tabular}

\begin{tabular}{|c|c|c|c|c|c|c|c|c|c|c|c|}
\hline & & & & & & & & \\
\hline & & \multirow{2}{*}{\multicolumn{3}{|c|}{$\begin{array}{l}\text { Variable } \\
\text { USOS Y ACTIVIDADES }\end{array}$}} & & & & & & & \\
\hline Día & Martes & & & & & & & & & & \\
\hline Hora & $9-10$ & \multicolumn{10}{|c|}{ Concepto } \\
\hline \multicolumn{2}{|c|}{ Indicador } & Ejercicio & Caminando & $\begin{array}{l}\text { Jugan } \\
\text { do }\end{array}$ & Contemplación & $\begin{array}{l}\text { Tomar } \\
\text { fotos }\end{array}$ & $\begin{array}{l}\text { Pasear } \\
\text { mascota }\end{array}$ & Leyendo & Comiendo & Venta & $\begin{array}{l}\text { Otra/ } \\
\text { especificar }\end{array}$ \\
\hline \multicolumn{2}{|c|}{ No. Hombres } & 3 & 4 & 0 & 2 & 0 & 0 & 0 & 0 & 0 & 0 \\
\hline \multicolumn{2}{|c|}{ No. Mujeres } & 9 & 3 & 0 & 3 & 0 & 2 & 0 & 0 & 0 & 0 \\
\hline \multicolumn{2}{|c|}{ No. Niños } & 0 & 0 & 0 & 0 & 0 & 0 & 0 & 0 & 0 & 0 \\
\hline \multicolumn{2}{|c|}{$\begin{array}{l}\text { No. Personas } \\
\text { en grupo }\end{array}$} & 1 & 0 & 0 & 0 & 1 & 0 & 0 & 0 & 0 & 0 \\
\hline \multicolumn{2}{|c|}{$\begin{array}{l}\text { No. De } \\
\text { personas } \\
\text { solas }\end{array}$} & 4 & 5 & 0 & 3 & 0 & 0 & 0 & 0 & 0 & 0 \\
\hline \multicolumn{2}{|c|}{$\begin{array}{l}\text { Total } \\
\text { personas }\end{array}$} & 17 & 12 & 0 & 8 & 1 & 2 & 0 & 0 & 0 & 0 \\
\hline
\end{tabular}




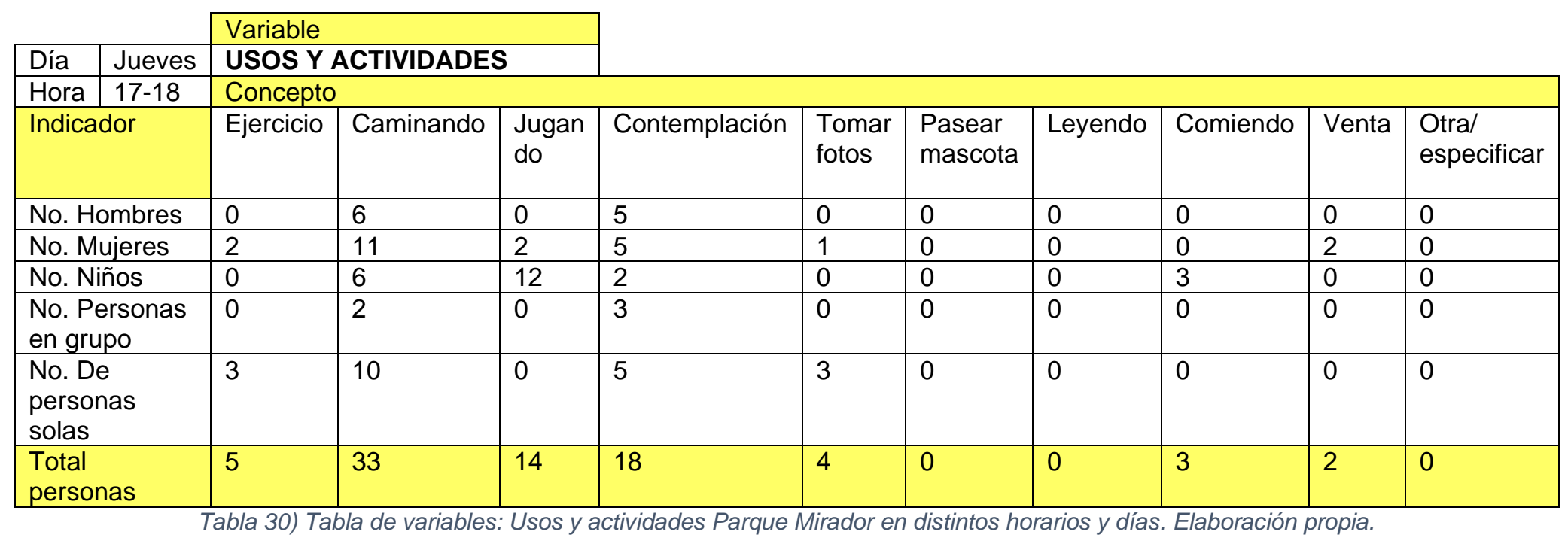

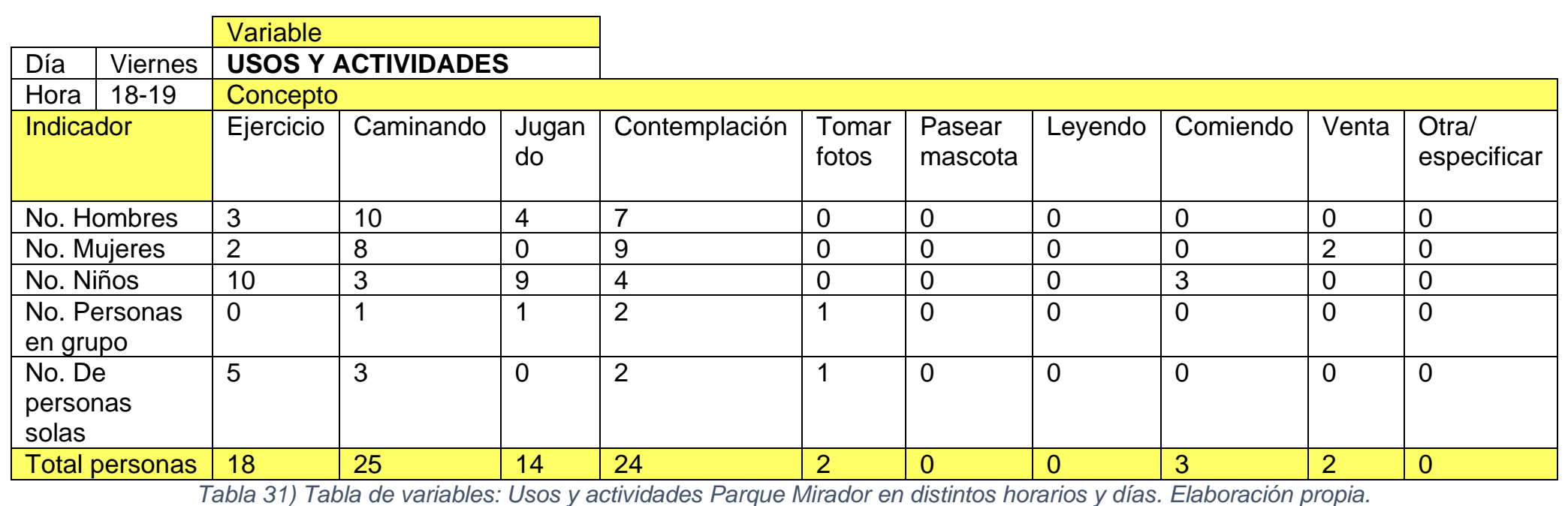




\begin{tabular}{|c|c|c|c|c|c|c|c|c|c|c|c|}
\hline & \multirow{2}{*}{\multicolumn{3}{|c|}{ Variable }} & & & & & & & \\
\hline & & & & & & & & & & & \\
\hline Día & Sábado & \multicolumn{3}{|c|}{ USOS Y ACTIVIDADES } & & & & & & & \\
\hline Hora & $9-10$ & \multicolumn{10}{|c|}{ Concepto } \\
\hline \multicolumn{2}{|c|}{ Indicador } & Ejercicio & Caminando & $\begin{array}{l}\text { Jugan } \\
\text { do }\end{array}$ & Contemplación & $\begin{array}{l}\text { Tomar } \\
\text { fotos }\end{array}$ & $\begin{array}{l}\text { Pasear } \\
\text { mascota }\end{array}$ & Leyendo & Comiendo & Venta & $\begin{array}{l}\text { Otra/ } \\
\text { especificar }\end{array}$ \\
\hline \multicolumn{2}{|c|}{ No. Hombres } & 3 & 2 & 0 & 4 & 0 & 1 & 0 & 0 & 0 & 0 \\
\hline \multicolumn{2}{|c|}{ No. Mujeres } & 9 & 3 & 0 & 6 & 2 & 1 & 0 & 0 & 0 & 0 \\
\hline \multicolumn{2}{|c|}{ No. Niños } & 0 & 0 & 0 & 0 & 0 & 0 & 0 & 10 & 0 & 0 \\
\hline \multicolumn{2}{|c|}{$\begin{array}{l}\text { No. Personas } \\
\text { en grupo }\end{array}$} & 3 & 0 & 0 & 2 & 1 & 0 & 0 & 0 & 0 & 0 \\
\hline \multicolumn{2}{|c|}{$\begin{array}{l}\text { No. De } \\
\text { personas } \\
\text { solas }\end{array}$} & 5 & 5 & 0 & 3 & 3 & 2 & 0 & 0 & 0 & 0 \\
\hline \multicolumn{2}{|c|}{ Total personas } & 20 & 8 & 0 & 15 & 6 & 4 & 0 & 10 & 0 & 0 \\
\hline
\end{tabular}

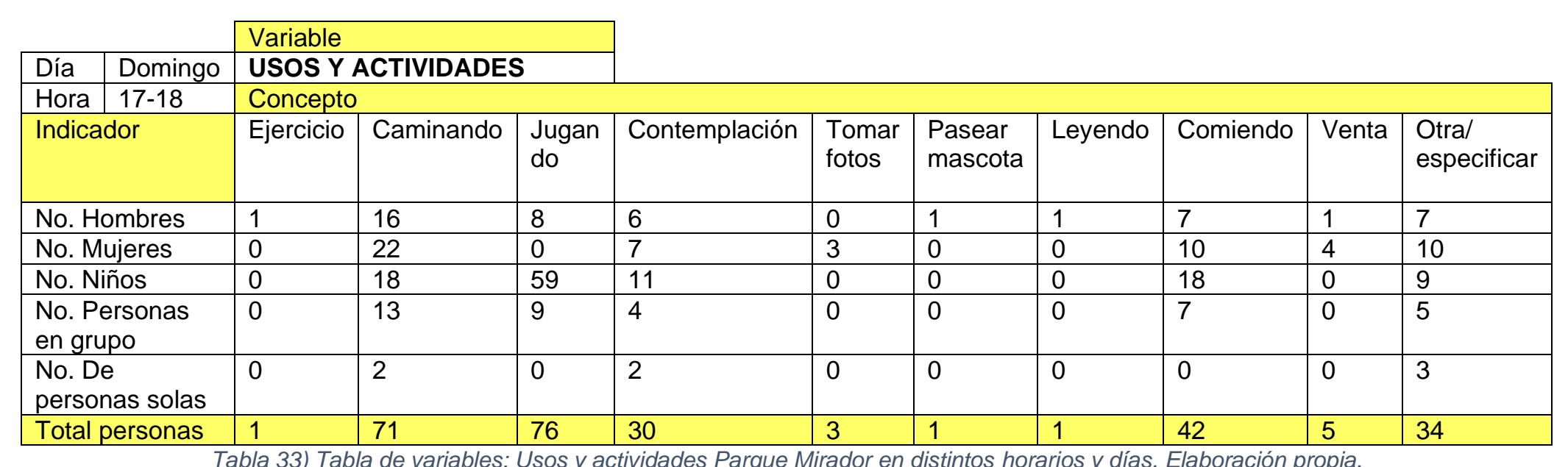




\section{USOS Y ACTIVIDADES}

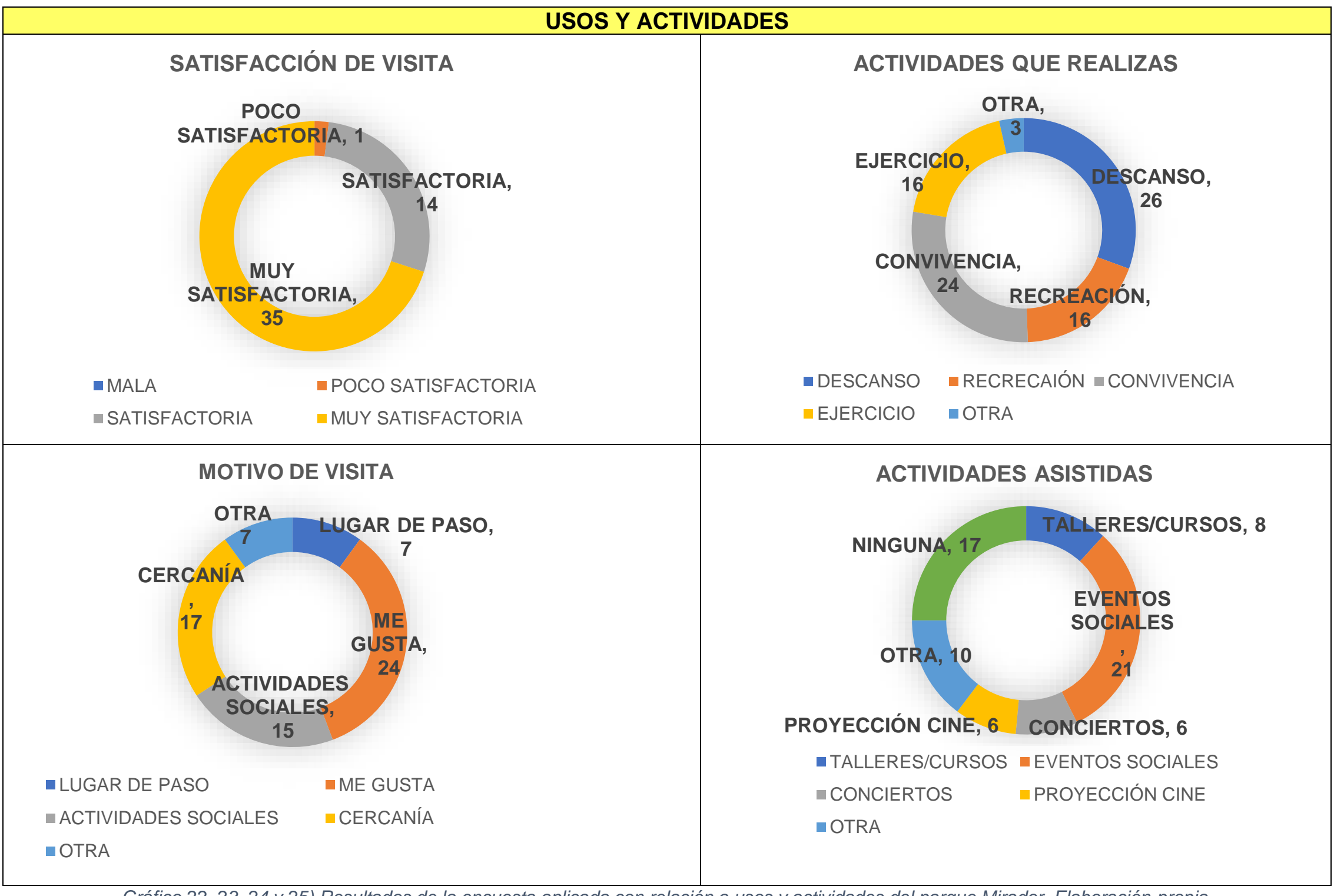

Gráfico 22, 23, 24 y 25) Resultados de la encuesta aplicada con relación a usos y actividades del parque Mirador. Elaboración propia. 


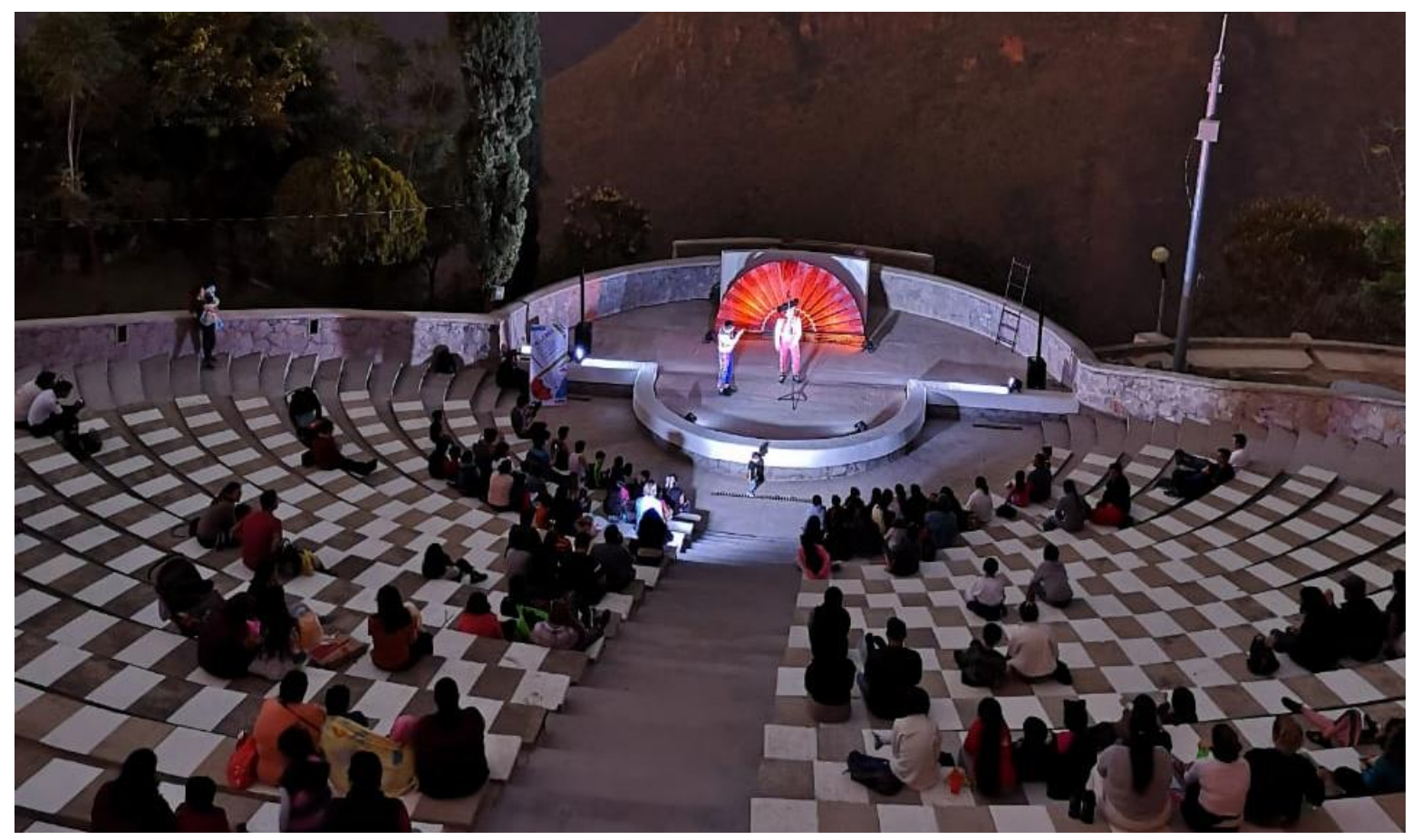

Ilustración 17) Función de circo en el Foro del Parque Mirador. Fuente propia.

El Mirador como todo espacio tiene áreas de atracción para las personas (ver esquema 16), la mayor carga de actividades y concentración de estas se efectúan en el área de juegos y cancha, el pasillo que conecta con la explanada superior, la explanada misma, el restaurante, el foro y la serie de miradores a pie de la barranca. Durante los fines de semana hay concentración de usos y actividades dentro de la zona de terrazas, entre semana (mayor número de horas y días) el rango de atracción es constante y notorio en las áreas antes descritas, ya que son los puntos más atractivos para padres con niños o jóvenes buscando espacios para el esparcimiento (juegos y cancha) y las más cercanas al acceso principal, puesto que de ahí se puede acceder de manera sencilla, práctica y directa hacia los miradores (superior y pie de barranca) y el restaurante con su privilegiada vista. Por su parte en el perímetro exterior la concentración de personas sucede principalmente por la acera que conecta a CUAAD, sobre ella se ubican papelerías, centros de impresión, locales de comida y bebidas, un Oxxo y un 7eleven, lo cual resulta atractivo para los jóvenes universitarios que son quienes transitan, ocupan y consumen tiempo en este punto por los servicios que se ofrecen. 


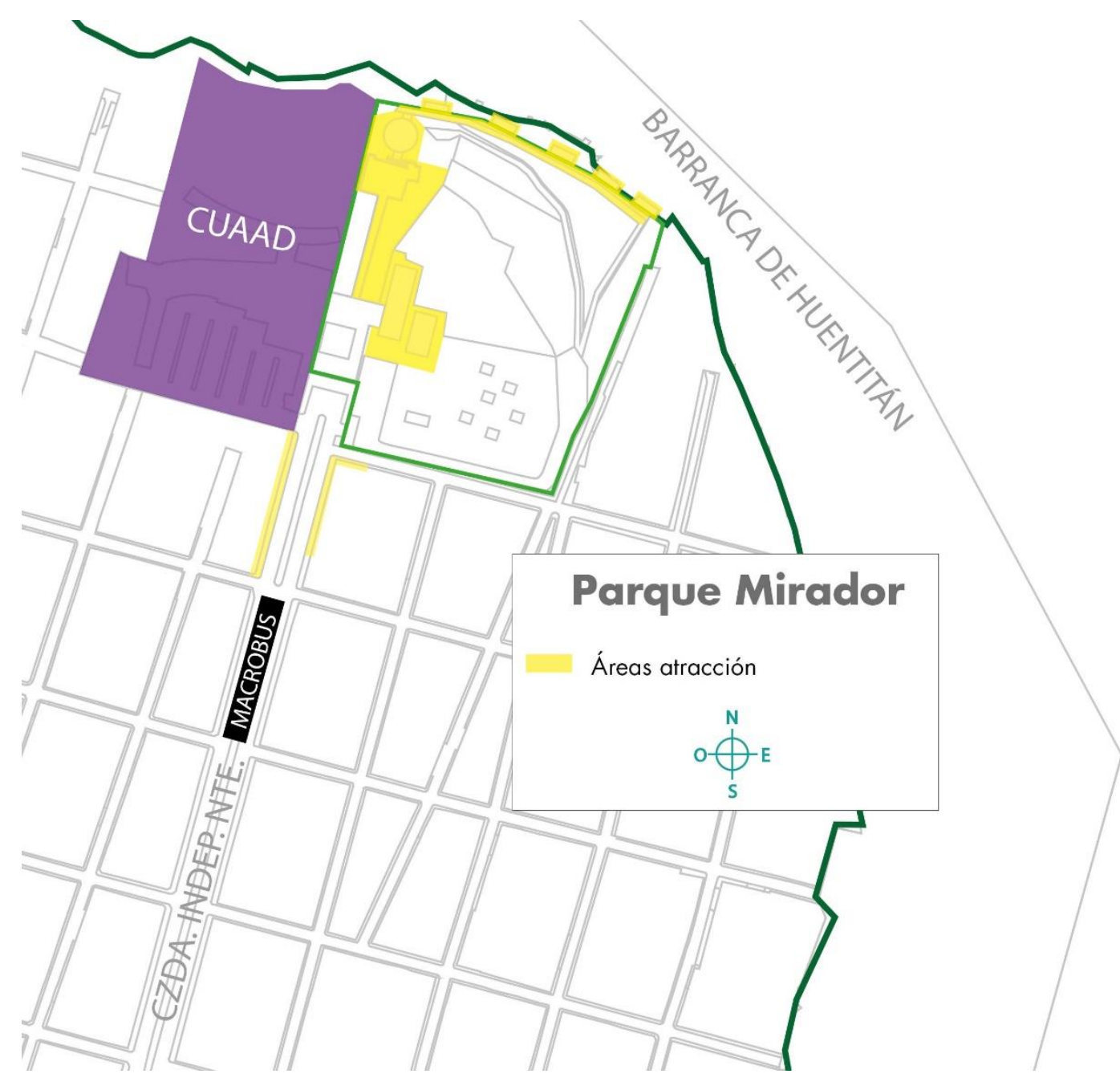

Esquema 16) Áreas de atracción Parque Mirador. Elaboración propia

\subsection{2-Parque Natural de Huentitán Características generales}

El Parque Natural de Huentitán es uno de los espacios públicos abiertos al aire libre importantes dentro de la zona norte de Guadalajara al tener una amplia extensión territorial verde. Al igual que el Mirador pertenece a la Red de bosques urbanos de Guadalajara y forma parte de las áreas verdes aledañas a la barranca. Este parque popularmente es conocido como Parques y Jardines debido a que dentro de él en administraciones pasadas albergaba las oficinas de dicha dependencia. Tiene una 
extensión aproximada de 13.3 hectáreas y se encuentra localizado a un costado del predio de Zoológico Guadalajara.

Una de las características principales del espacio es la de ser un sitio ecológicodeportivo (ver ilustración 18), tal como lo describe la página del Gobierno de Guadalajara (2018), puesto que invita a los visitantes al bienestar físico y a la relajación, dispone de asadores, juegos infantiles, ejercitadores, canchas deportivas, módulos de baños, pabellón de adultos, módulos de mesas y bancas.

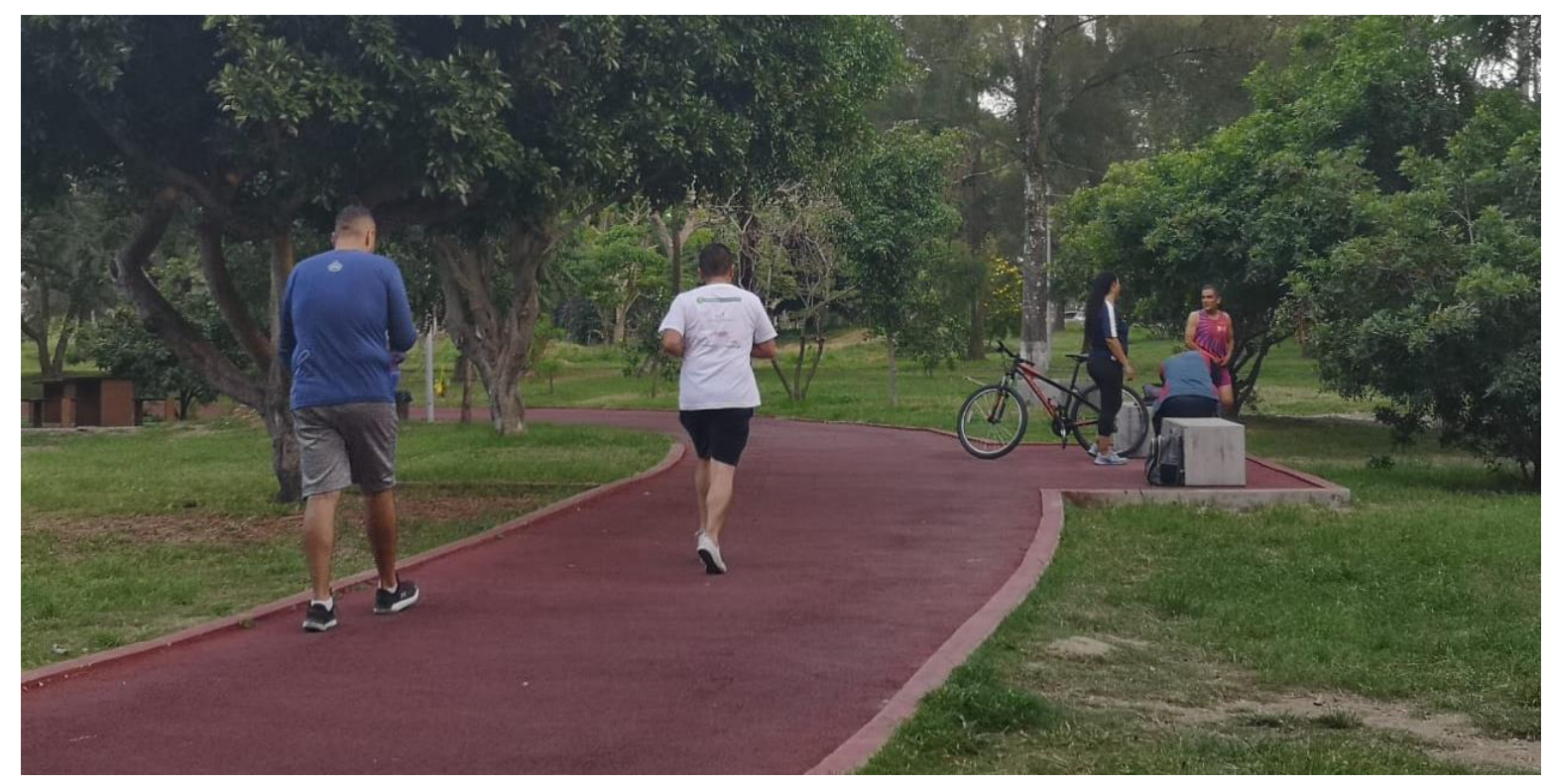

Ilustración 18) Pista de tartán en interior del Parque Natural Huentitán. Fuente propia.

En 2012 el Ayuntamiento de Guadalajara entrego un pedazo de predio del parque (240 mil 189 metros cuadrados) a la Asociación Civil EXTRA A.C. para que desarrollara el Vivero Metropolitano (EL INFORMADOR, 2012). Se talaron árboles y se aplanó el terreno para la instalación del vivero, pero el proyecto no se consolidó y no se operó, lo que ocasionó que la infraestructura instalada quedara como un elefante blanco que privaba una parte del uso del espacio del parque para los usuarios.

Con el paso del tiempo el parque fue quedando en el abandono por parte de las autoridades quienes dejaron de dar mantenimiento a las áreas verdes, arbolado y mobiliario, por lo que poco a poco el estado del espacio fue deteriorándose. 
A pesar del abandono físico los usuarios y vecinos seguían haciendo uso del espacio, sin embargo, fue hasta 2014 tras la publicación y difusión de la aprobación del Cabildo del Ayuntamiento de Guadalajara el cambio de sede de las Fiestas de Octubre a un espacio que marcaba la venta del predio donde se localizaba el Planetario Severo Díaz Galindo, las antiguas oficinas de la dirección de Parques y Jardines y un polígono del Parque Natural de Huentitán (EL INFORMADOR, 2014). Después de la noticia, los vecinos alarmados por perder su parque se organizaron de manera colectiva en diferentes frentes o grupos vecinales para defender y apropiarse con mayor arraigo del parque, haciendo uso de la vía legal (amparos), la vía mediática (manifestaciones, ruedas de prensa) y la apropiación del espacio por medio de acciones de rehabilitación (reforestaciones, riego y poda del arbolado, pinta de mobiliario entre otros) y la realización de eventos deportivos masivos como carreras.

Tras el arduo trabajo, diálogo con las autoridades y la presión de diferentes colectivos y asociaciones de vecinos por preservar las áreas existentes del Parque, durante la administración del presidente municipal Enrique Alfaro, en el 2017 se dio inicio a obras de renovación de la primera sección del parque (6 has); plantación de 530 árboles e intervención de distintas áreas (asadores, mesas de picnic, pista, jardineras, explanadas, acceso, etc.) En la actualidad el parque cuenta con personal de limpieza, vigilancia y paramédico (Villaseñor, 2018)

Con el cambio de administración y el nuevo Ayuntamiento, en agosto del 2019 el presidente Municipal Ismael del Toro anunció que el proyecto que contemplaba las Fiestas de Octubre dentro de un predio de la Zona Barranca de Huentitán (Parque Natural) quedaba descartado y que las sedes de las fiestas serían en el municipio de Tlaquepaque (MILENIO, 2019) por lo que se intervendría y renovaría la segunda sección del parque.

El Parque Natural se localiza en la esquina de Calzada Independencia y Paseo de Zoológico a una cuadra de Periférico Norte, a la par está emplazado a un costado del Zoológico Guadalajara y Selva Mágica. Fue el segundo espacio público al aire libre 
otorgado a la comunidad para su uso público (el primero fue el Mirador) y posee una extensa escala de usuarios de distintas edades (ver gráfico 26 y 27 ).

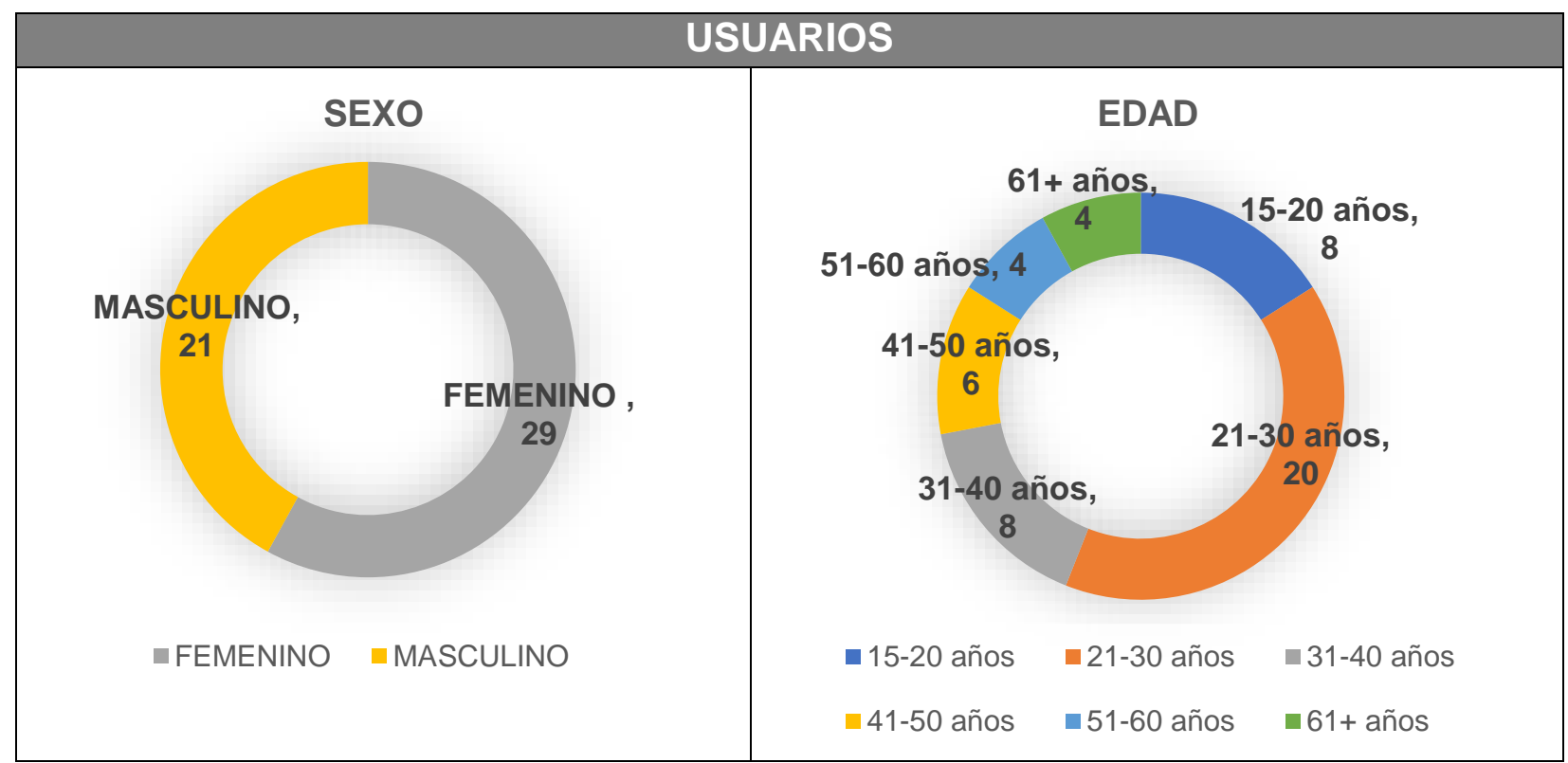

Gráfico 26 y 27) Rango usuarios de encuestas aplicadas en el Parque Natural de Huentitán. Elaboración propia.

En lo que respecta a los accesos y conexiones (ver tabla 34) tiene dos entradas principales, una sobre Calzada Independencia y otra sobre Paseo del Zoológico. El espacio no cuenta con estacionamiento propio, así que es necesario estacionarse en la vía pública o llegar en el sistema de transporte público Macrobús, puesto que se encuentra en medio de dos estaciones, Zoológico e Independencia Norte, a no más de 3 minutos caminando.

\begin{tabular}{|c|c|c|c|c|c|c|c|}
\hline & \multirow{2}{*}{\multicolumn{7}{|c|}{$\begin{array}{l}\text { Variable } \\
\text { ACCESOS Y } \\
\text { CONEXIONES } \\
\text { Indicador }\end{array}$}} \\
\hline & & & & & & & \\
\hline Concepto & Parada bus & $\begin{array}{l}\text { Parada } \\
\text { tren }\end{array}$ & $\begin{array}{l}\text { Parada } \\
\text { BRT }\end{array}$ & $\begin{array}{l}\text { Bici } \\
\text { pública }\end{array}$ & Bici privada & Peatonal & Coche \\
\hline Tiene (si/no) & No & No & Sí & No & Sí & Sí & No \\
\hline $\begin{array}{l}\text { No. De } \\
\text { paradas }\end{array}$ & 0 & 0 & 1 & 0 & 6 & 2 & 0 \\
\hline Observaciones & & & $\begin{array}{l}\text { Macrobús } \\
\text { Estación } \\
\text { Zoológico }\end{array}$ & & Ciclopuertos & $\begin{array}{l}\text { Acera } \\
\text { Frontal y } \\
\text { lateral }\end{array}$ & \\
\hline
\end{tabular}

Tabla 34) Tabla de Variable: Accesos y conexiones del Parque Natural de Huentitán. Elaboración propia. 


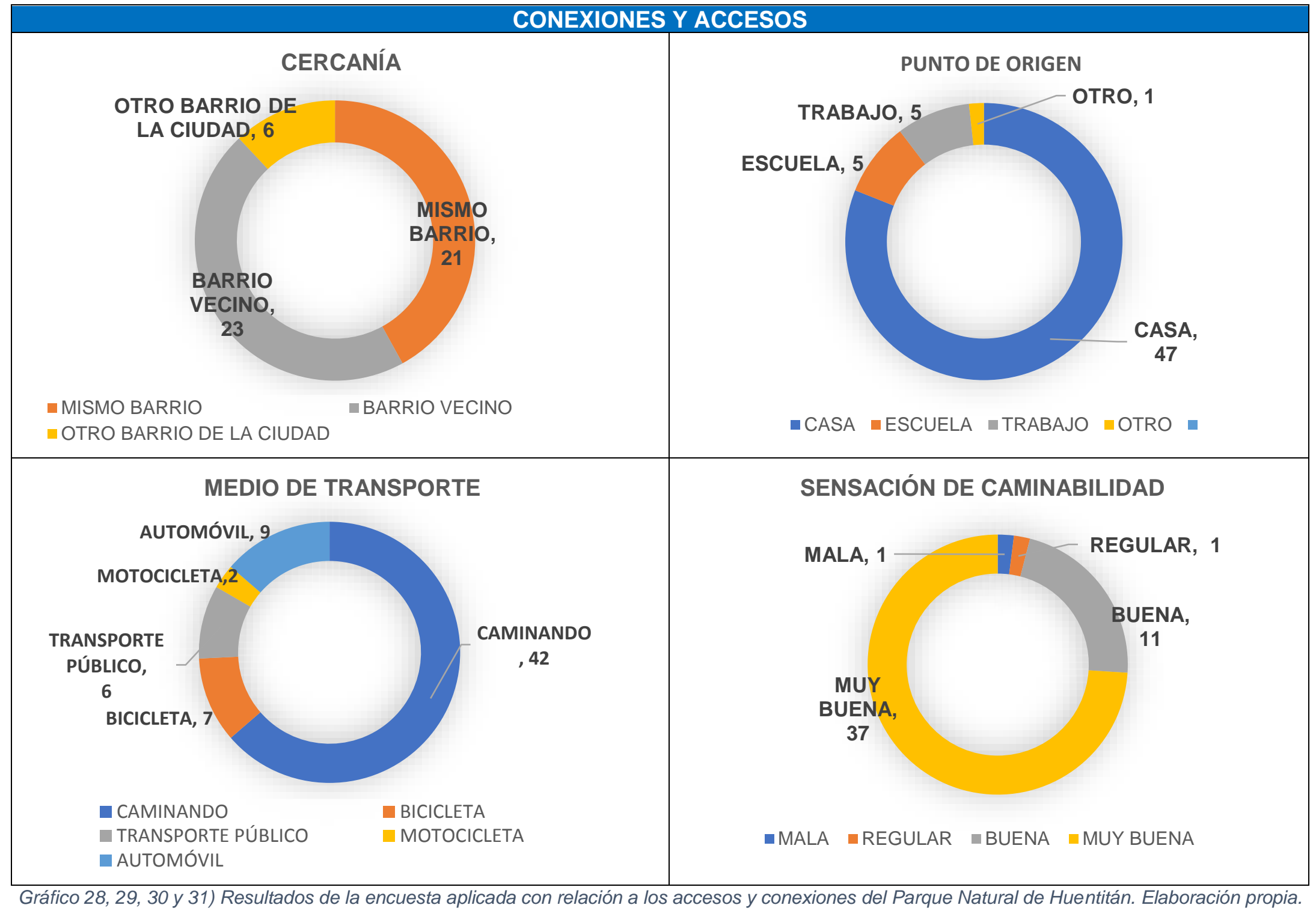




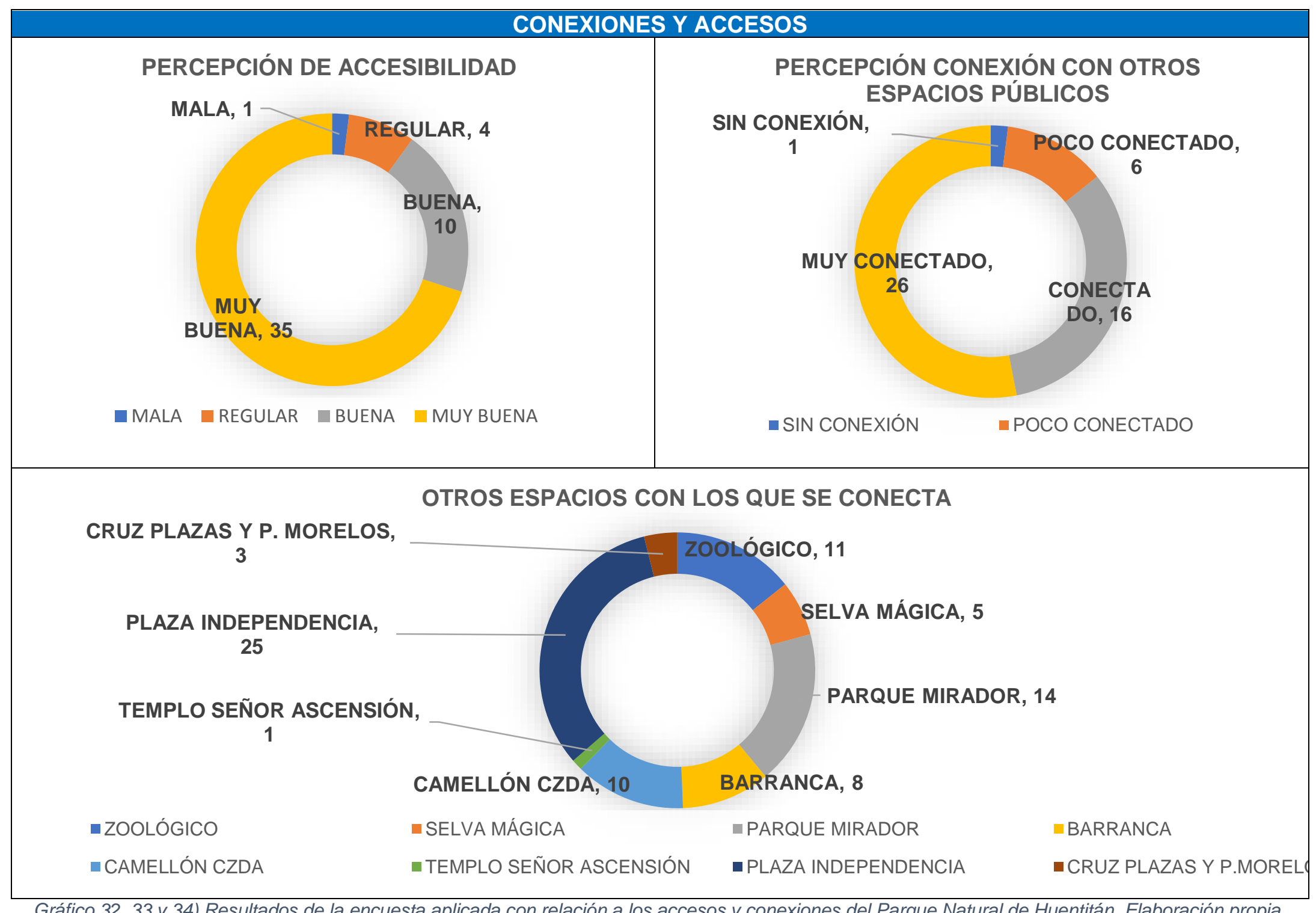


Al encontrarse ubicado muy cerca de Periférico este parque está en un punto medio tanto para personas del mismo barrio como para colonias aledañas quienes en su mayoría visitan el parque caminando debido a su cercanía y en que frecuentemente el punto de partida es su casa (ver gráfico 28, 29 y 30). La mayor parte de los usuarios encuestados llega al parque caminando y tienen una percepción de caminabilidad muy buena, respecto a accesibilidad también se considera muy buena, puesto que se encuentra sobre Calzada Independencia y cerca a Anillo Periférico, además de que conecta con un sistema de transporte público masivo (ver gráfico 31, 32 y 33).

Los usuarios también perciben que el parque está conectado a otros espacios públicos, tales como Plaza Independencia, Parque Mirador, Zoológico y la Barranca (ver gráfico 34) debido a que son los más cercanos y se puede llegar a ellos caminando o en bicicleta.

La imagen y comodidad del espacio se percibe como buena, cuenta con 10 de los 11 indicadores propuestos en las tablas de variables (ver tabla 35).

Referente a la experiencia de las personas en el Parque Natural se considera muy satisfactoria, también creen que el elemento principal que le da identidad al espacio es la vegetación (áreas verdes) seguido de los sociales como las actividades que realizan y finalmente de la arquitectura que tiene el parque (pabellón, plazoleta, accesos). En cuanto a la limpieza la califica entre muy buena y buena de acuerdo con su percepción y el confort que proporciona. El espacio es muy bueno por el mobiliario, equipamiento y vegetación (ver gráfico 35, 36, 37 y 38). En cuanto a la percepción de seguridad los usuarios la consideran muy buena, esto debido a que desde diciembre de 2017 el parque cuenta con elementos de vigilancia y paramédicos (ver gráfico 39).

En cuanto al sentido de apropiación y pertenencia las personas se identifican con el parque, viéndose reflejado en el cuidado que prestan a los espacios. A dos años de la renovación, no hay casi basura, las mesas de picnic están en buen estado y los baños están limpios, a la par sienten una relación de conexión al parque 
en lo referente a los aspectos sociales como las relaciones afectivas, experiencias, sentimientos y actividades que realizan, seguido de los aspectos urbanos como la nueva arquitectura monumental de los accesos, el equipamiento y mobiliario (ver gráfico 40 y 41).

La sociabilidad del espacio (personas interactuando) sucede durante todo el día, pero se intensifica y es más evidente por las tardes después de las 17 horas (ver ilustración 19) que es cuando el sol ha bajado. Esta sociabilidad es más observable y obvia el domingo por las tardes (ver tabla $36,37,38,39,40$ y 41 )

Las personas suelen tener una frecuencia de visita principalmente de 1 a 2 veces por semana y el tiempo de permanencia ronda entre los 30 minutos y más de 2 horas, su visita y estancia suele ser en compañía, asimismo prefieren interactuar con amigos y son muy pocos quienes participan en alguna asociación, colectivo 0 grupo (ver gráfico 42, 43, 44, 45 y 46).

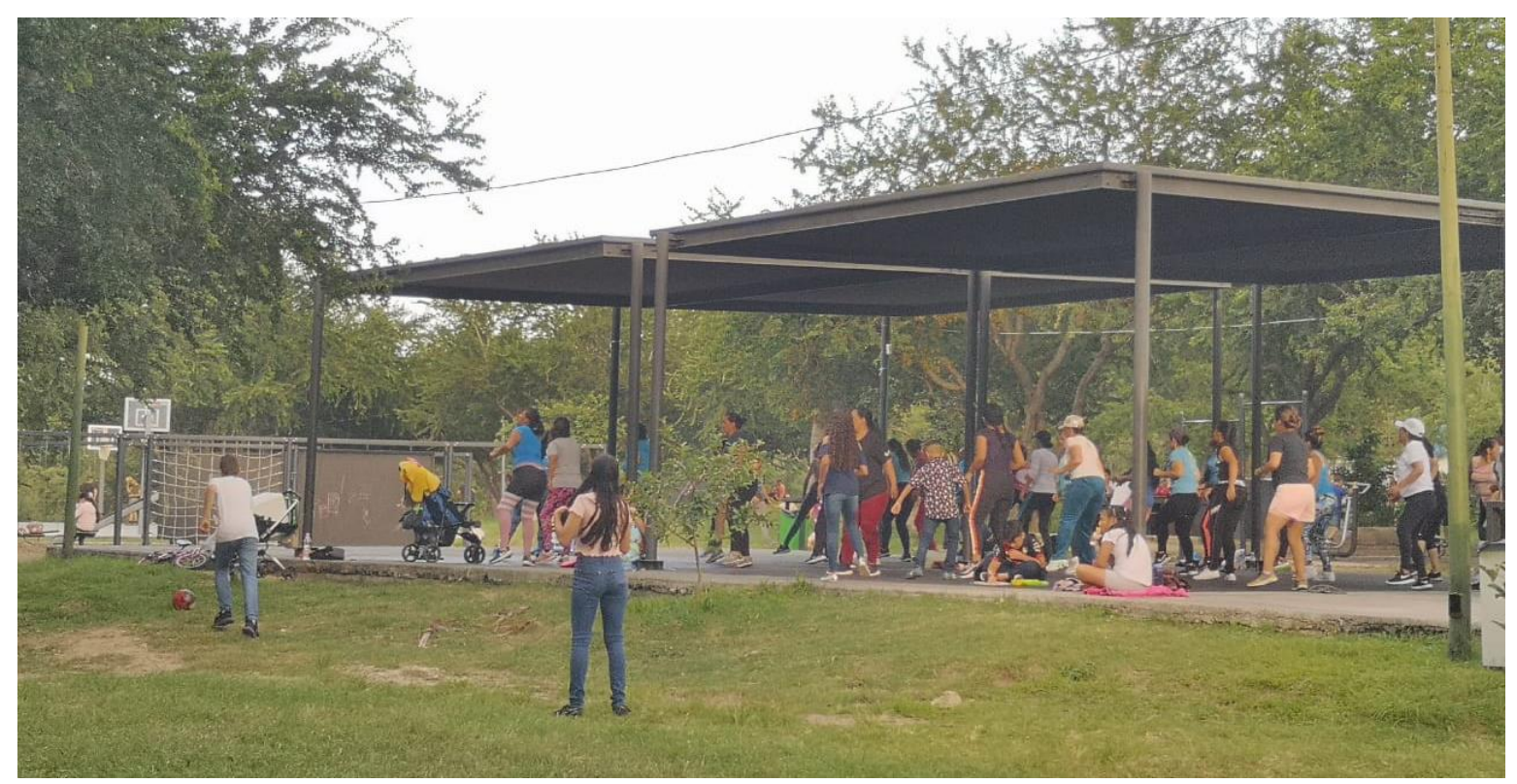

Ilustración 19) Clase de activación física en el pergolado del Parque Natural un lunes a las 18 horas. Fuente Propia. 


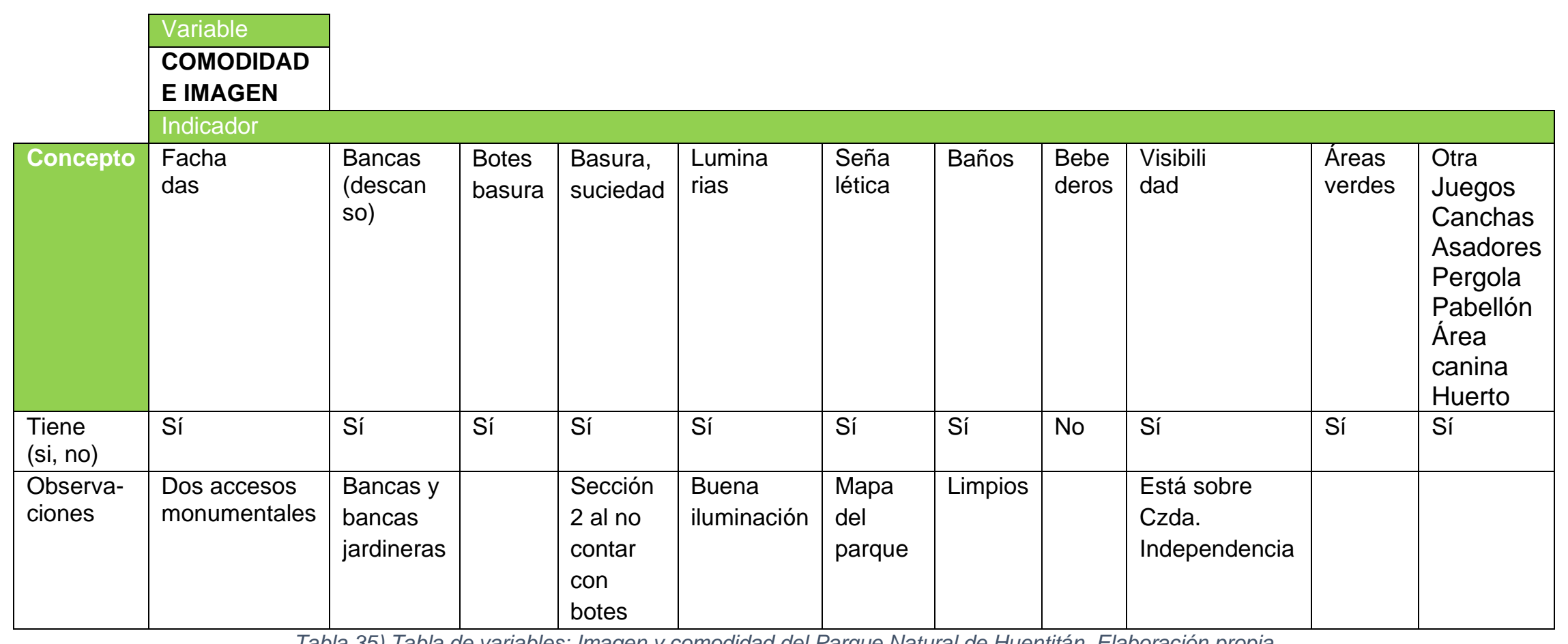

Tabla 35) Tabla de variables: Imagen y comodidad del Parque Natural de Huentitán. Elaboración propia 


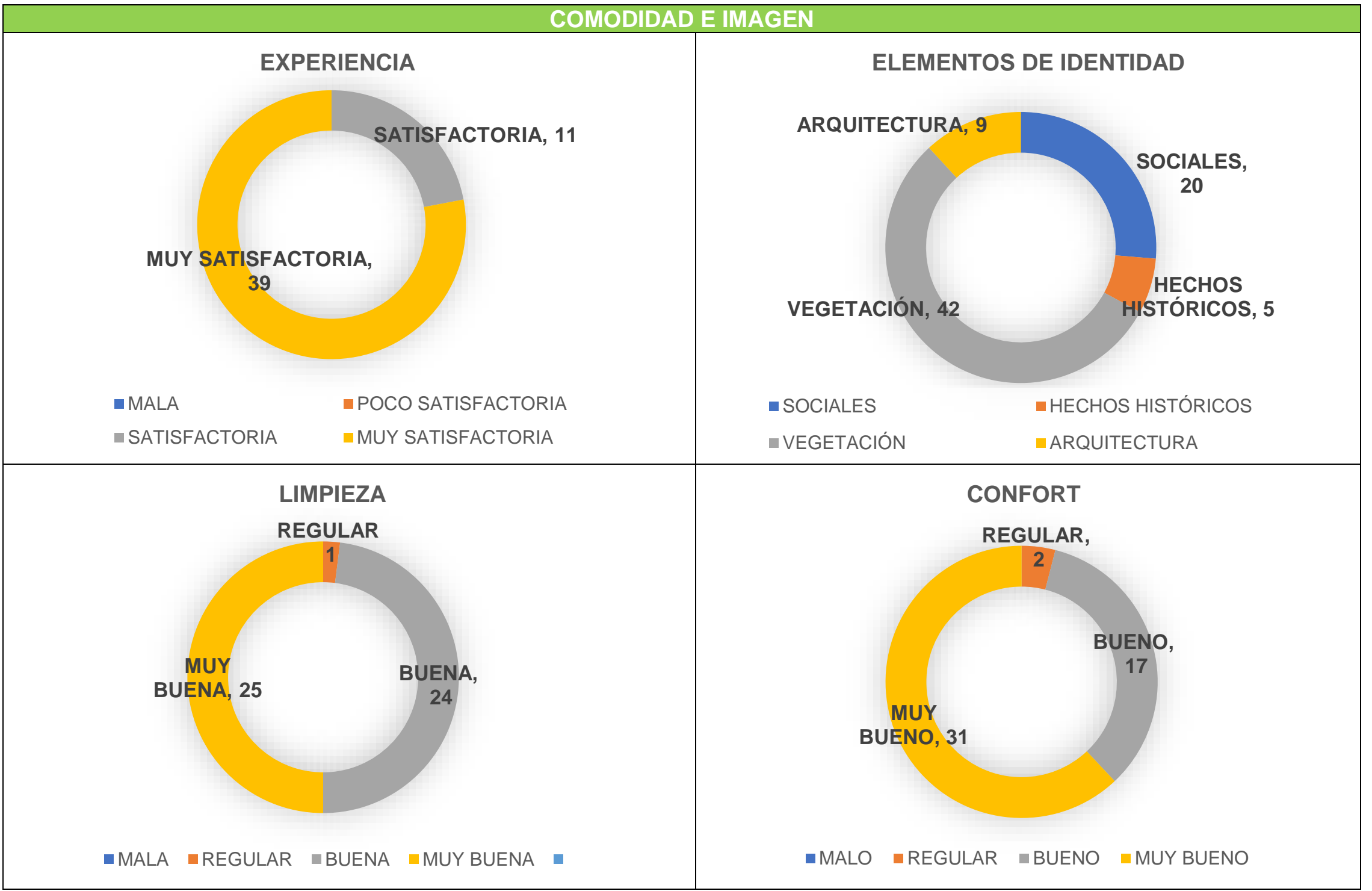

Gráfico 35, 36, 37 y 38) Resultados de la encuesta aplicada con relación a la imagen y comodidad del Parque Natural de Huentitán. Elaboración propia. 


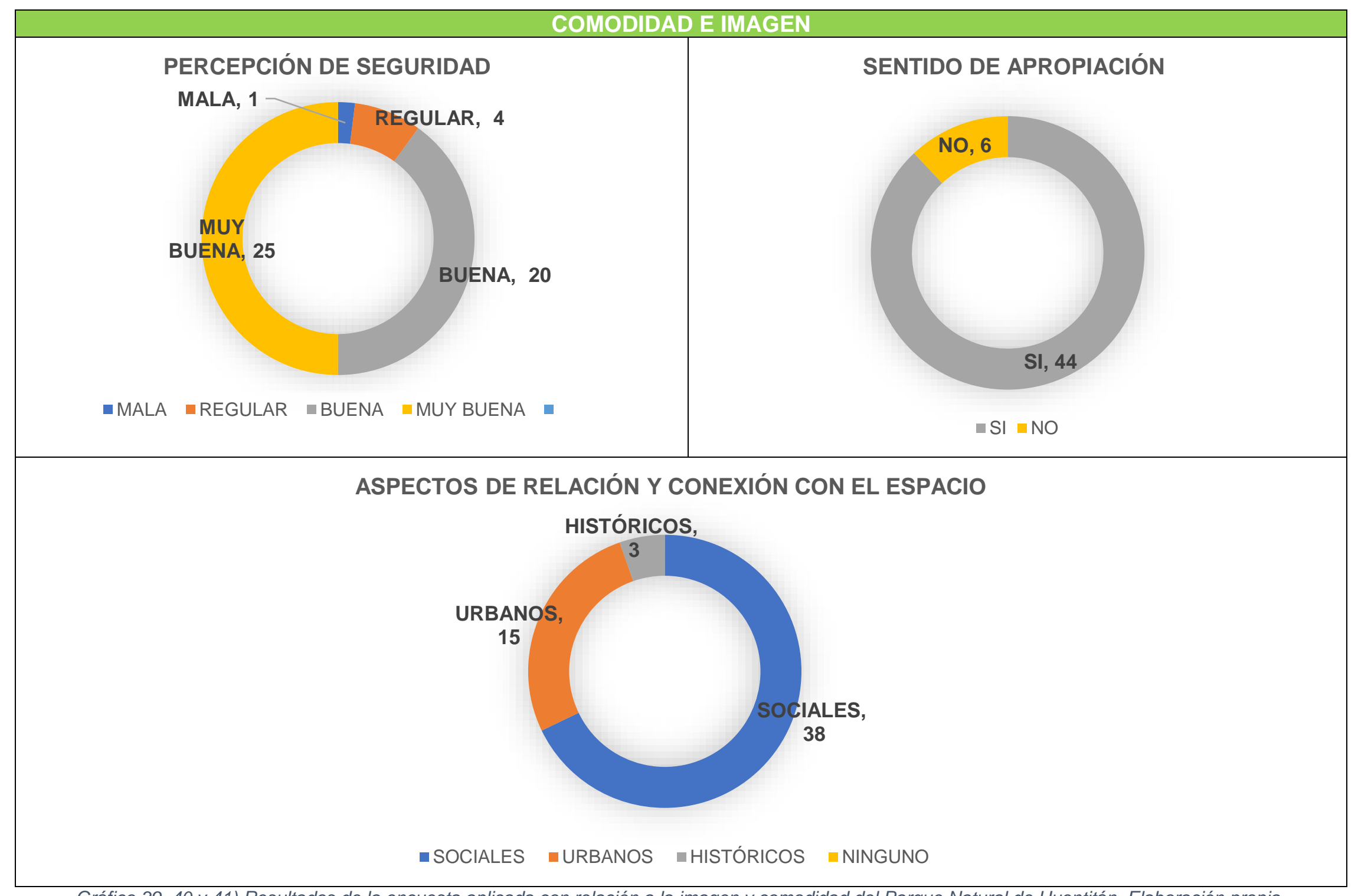

Gráfico 39, 40 y 41) Resultados de la encuesta aplicada con relación a la imagen y comodidad del Parque Natural de Huentitán. Elaboración propia. 


\begin{tabular}{|c|c|c|c|c|c|c|c|c|c|}
\hline & & \multicolumn{3}{|l|}{\begin{tabular}{|l|} 
Variable \\
\end{tabular}} & \multicolumn{3}{|r|}{ Variable } & & \\
\hline Día & Martes & \multicolumn{3}{|l|}{ SOCIABILIDAD } & Día & Miércoles & \multicolumn{3}{|l|}{ SOCIABILIDAD } \\
\hline Hora & $9-10$ & \multicolumn{3}{|l|}{ Concepto } & Hora & $11-12$ & \multicolumn{3}{|l|}{ Concepto } \\
\hline \multicolumn{2}{|c|}{ Indicador } & Sentadas & Paradas & Conversando & \multicolumn{2}{|c|}{ Indicador } & \multicolumn{3}{|l|}{ Sentadas } \\
\hline \multicolumn{2}{|c|}{ No. Hombres } & 6 & 8 & 4 & \multicolumn{2}{|c|}{ No. Hombres } & 5 & 2 & 2 \\
\hline \multicolumn{2}{|c|}{ No. Mujeres } & 7 & 27 & 10 & \multicolumn{2}{|c|}{ No. Mujeres } & 6 & 3 & 4 \\
\hline \multicolumn{2}{|c|}{ No. Niños } & 0 & 0 & 0 & \multicolumn{2}{|c|}{ No. Niños } & 2 & 4 & 6 \\
\hline \multicolumn{2}{|c|}{$\begin{array}{l}\text { No. Personas } \\
\text { en grupo }\end{array}$} & 1 & 3 & 3 & \multicolumn{2}{|c|}{$\begin{array}{l}\text { No. Personas en } \\
\text { grupo }\end{array}$} & 1 & 0 & 1 \\
\hline \multicolumn{2}{|c|}{$\begin{array}{l}\text { No. De } \\
\text { personas solas }\end{array}$} & 3 & 6 & 0 & \multicolumn{2}{|c|}{$\begin{array}{l}\text { No. De personas } \\
\text { solas }\end{array}$} & 5 & 3 & 0 \\
\hline \multicolumn{2}{|c|}{ Total personas } & 17 & 44 & 17 & \multicolumn{2}{|c|}{ Total personas } & 19 & 12 & 13 \\
\hline \multirow{2}{*}{\multicolumn{5}{|c|}{ Variable }} & \multicolumn{5}{|c|}{ Variable } \\
\hline Día & & & & SOCIABILIDAD & Día & Viernes & \multicolumn{3}{|l|}{ SOCIABILIDAD } \\
\hline Hora & $19-20$ & \multicolumn{3}{|l|}{ Concepto } & Hora & $20-21$ & \multicolumn{3}{|l|}{ Concepto } \\
\hline \multicolumn{2}{|c|}{ Indicador } & Sentadas & Paradas & Conversando & \multicolumn{2}{|c|}{ Indicador } & Sentadas & Paradas & Conversando \\
\hline \multicolumn{2}{|c|}{ No. Hombres } & 6 & 4 & 8 & \multirow{2}{*}{\multicolumn{2}{|c|}{ No. Hombres }} & 22 & 4 & 16 \\
\hline \multicolumn{2}{|c|}{ No. Mujeres } & 10 & 2 & 12 & & & 31 & 5 & 29 \\
\hline \multicolumn{2}{|c|}{ No. Niños } & 3 & 2 & 5 & No. 1 & ños & 52 & 0 & 30 \\
\hline $\begin{array}{l}\text { No. P } \\
\text { en grt }\end{array}$ & $\begin{array}{l}\text { rsonas } \\
\text { po }\end{array}$ & 6 & 0 & 7 & $\begin{array}{l}\text { No. F } \\
\text { en gr }\end{array}$ & $\begin{array}{l}\text { rsonas } \\
\text { po }\end{array}$ & 16 & 0 & 5 \\
\hline $\begin{array}{l}\text { No. D } \\
\text { perso }\end{array}$ & as solas & 7 & 3 & 0 & $\begin{array}{l}\text { No. [ } \\
\text { persc }\end{array}$ & las solas & 6 & 3 & 0 \\
\hline Total & ersonas & 32 & 11 & 32 & Total & ersonas & 127 & 12 & 80 \\
\hline
\end{tabular}




\begin{tabular}{|c|c|c|c|c|c|c|c|c|c|}
\hline & & \multirow{2}{*}{\multicolumn{3}{|c|}{$\begin{array}{l}\text { Variable } \\
\text { SOCIABILIDAD }\end{array}$}} & \multicolumn{3}{|r|}{ Variable } & & \\
\hline Día & Sábado & & & & Día & Domingo & SOCIABILIDAD & & \\
\hline Hora & $11-12$ & \multicolumn{3}{|l|}{ Concepto } & Hora & $17-16$ & \multicolumn{3}{|l|}{ Concepto } \\
\hline \multicolumn{2}{|c|}{ Indicador } & Sentadas & Paradas & Conversando & \multicolumn{2}{|c|}{ Indicador } & Sentadas & Paradas & Conversando \\
\hline \multicolumn{2}{|c|}{ No. Hombres } & 15 & 11 & 14 & \multicolumn{2}{|c|}{ No. Hombres } & 21 & 12 & 19 \\
\hline \multicolumn{2}{|c|}{ No. Mujeres } & 19 & 9 & 17 & \multicolumn{2}{|c|}{ No. Mujeres } & 29 & 10 & 21 \\
\hline \multicolumn{2}{|c|}{ No. Niños } & 8 & 8 & 13 & \multicolumn{2}{|c|}{ No. Niños } & 10 & 8 & 33 \\
\hline \multicolumn{2}{|c|}{$\begin{array}{l}\text { No. Personas } \\
\text { en grupo }\end{array}$} & 5 & 1 & 6 & \multicolumn{2}{|c|}{$\begin{array}{l}\text { No. Personas en } \\
\text { grupo }\end{array}$} & 8 & 2 & 6 \\
\hline \multicolumn{2}{|c|}{$\begin{array}{l}\text { No. De } \\
\text { personas solas }\end{array}$} & 9 & 3 & 0 & \multicolumn{2}{|c|}{$\begin{array}{l}\text { No. De personas } \\
\text { solas }\end{array}$} & 6 & 0 & 0 \\
\hline \multicolumn{2}{|c|}{ Total personas } & 56 & 32 & 50 & \multicolumn{2}{|c|}{ Total personas } & 74 & 32 & 79 \\
\hline
\end{tabular}

Tabla 40 y 41) Tabla de variables: Sociabilidad Parque Natural de Huentitán en distintos horarios y días. Elaboración propia.

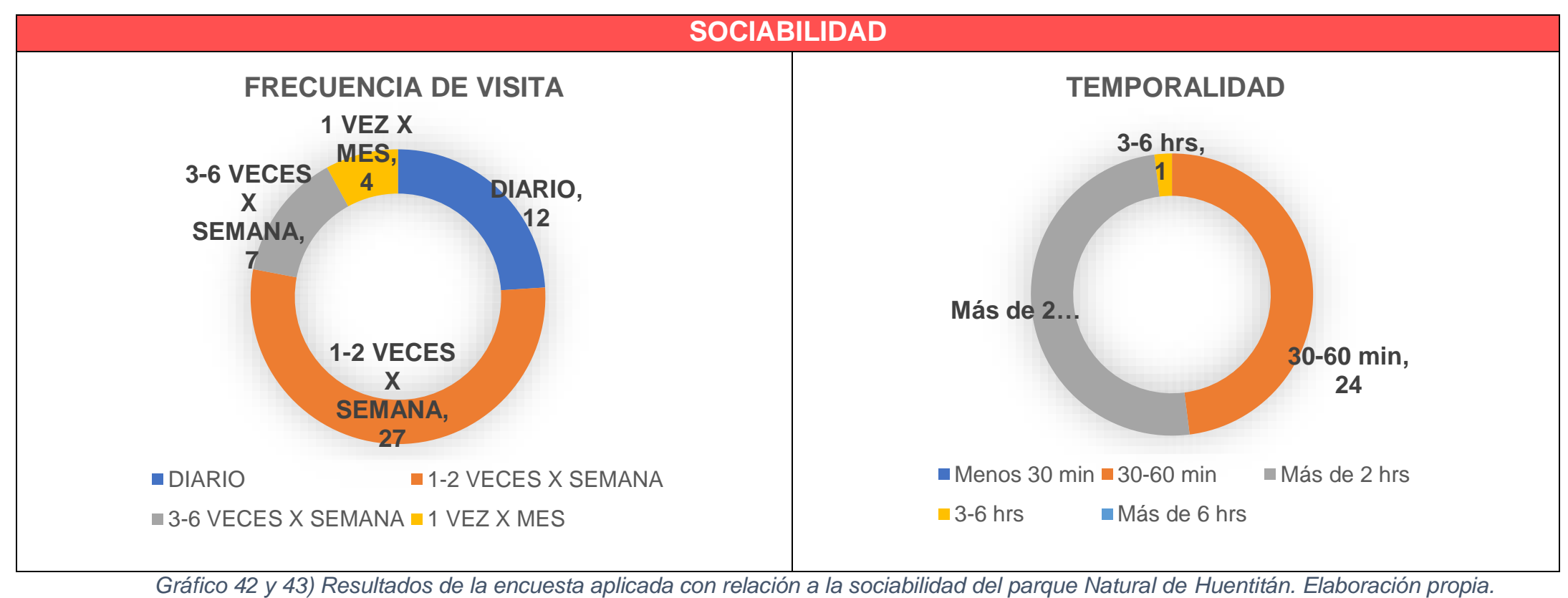

Gráfico 42 y 43) Resultados de la encuesta aplicada con relación a la sociabilidad del parque Natural de Huentitán. Elaboración propia. 


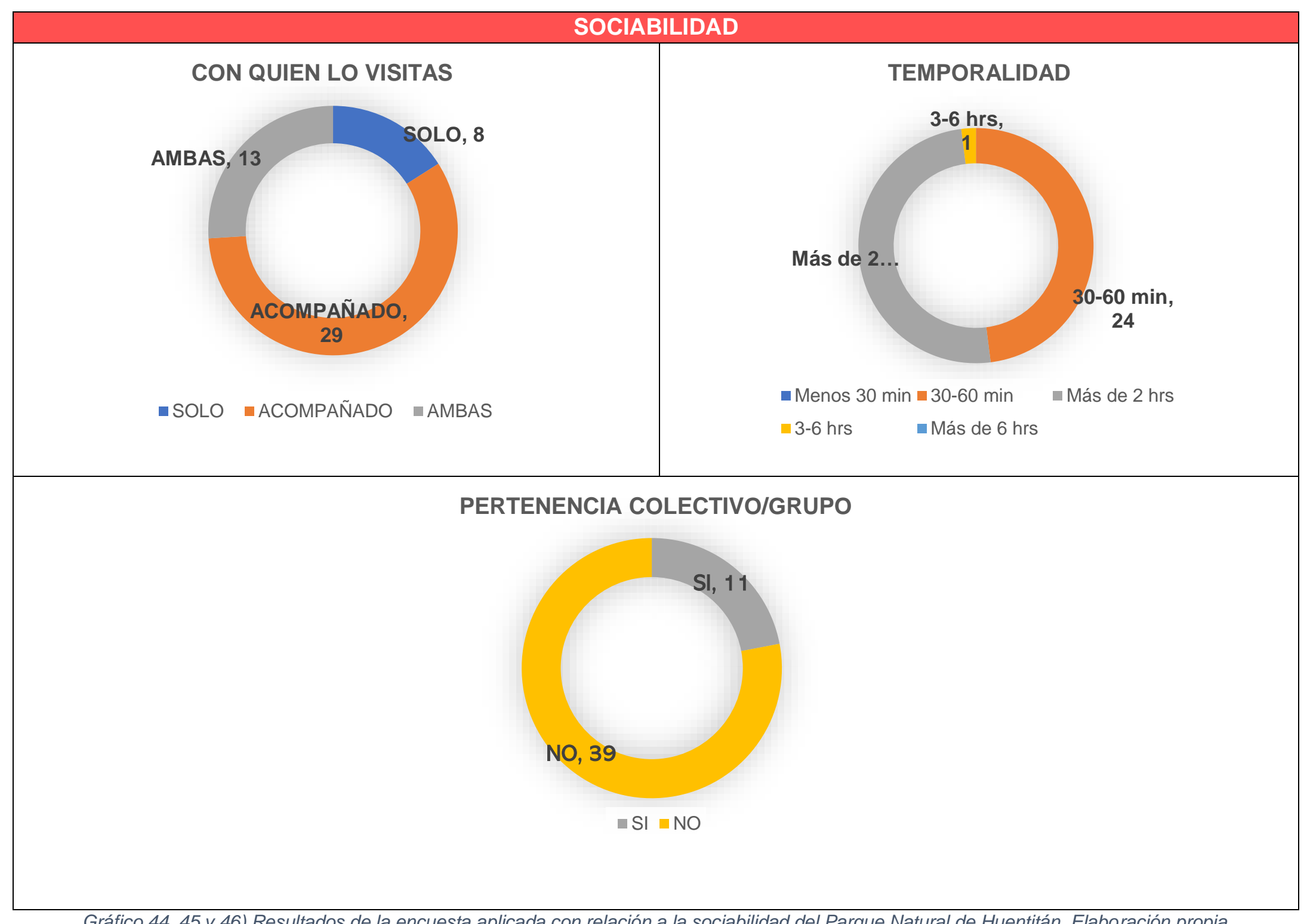

Gráfico 44, 45 y 46) Resultados de la encuesta aplicada con relación a la sociabilidad del Parque Natural de Huentitán. Elaboración propia. 


\section{Características morfológicas y funcionales}

Este espacio de casi 14 has tiene una forma orgánica, pero con un lateral más geométrico que delimita con el Zoológico y Selva Mágica, mientras que el lado orgánico y continuo adapta su forma por una vialidad elíptica que es Paseo del Zoológico.

Los dos accesos al parque son monumentales, dos paredes de piedra en vertical se encuentran cara a cara, dotando de una sensación de grandeza y misterio al interior, cruzando los accesos se choca con una primera explanada pequeña con señalética de mapa del parque y ciclopuertos. Se continúa el paso peatonal marcado por un caminamiento que enlaza con una plazoleta (explanada) que alberga unos baños, bancas y fuentes. A la plazoleta se liga a otros andadores y senderos internos del parque que articulan a otros espacios de interés para los visitantes; en el costado norte se ubica un Pabellón multiusos, área canina, unos baños y área de juego, en el centro del parque a un lateral de la explanada se localiza una cancha multiusos, un área de juegos, área de gimnasio urbano, un pergolado multiusos y mesas de picnic con asadores. Al fondo oriente, en la segunda sección del parque están las antiguas oficinas de parques y jardines, una tercera área de juegos, una cancha de voleibol, una cancha multiusos, unos baños que no están en funcionamiento y un huerto comunitario (producto de la apropiación y auto construcción por parte de vecinos y usuarios). Un segundo huerto, pero escondido entre la maleza y de índole privado se encuentra casi a un costado de Paseo del Zoológico (ver esquema 17).

El mobiliario y equipamiento de la segunda sección del parque luce descuidado y abandonado debido a que por años no se ha intervenido más allá de los vestigios de la mano de obra vecinal; algunas bancas pintadas y cajetes en los árboles.

Una pista de tartán, para lo corredores, rodea el perímetro de la primera sección y conecta con los antiguos caminos de la sección dos que envuelve la parte interna del espacio, conectando y haciendo remate visual con el antiguo y primer acceso del parque, unas fuentes y explanadas que ofrecían la bienvenida cuando se inauguró por primera ocasión. 
Todo el parque tiene árboles, sin embargo, en la zona norte donde se localizaba el antiguo vivero se percibe la falta de sombra, ya que los árboles plantados aún no crecen lo suficiente.

La iluminación natural de día es buena gracias a la distribución de los árboles y las podas constantes que realizan los de mantenimiento en ambas secciones, por las noches la sección uno tiene una mejor iluminación porque tiene luminarias nuevas y modernas distribuidas y bien orientadas, la sección dos en cambio tiene poca iluminación debido a las luminarias viejas que no funcionan o están fundidas.

\section{Usos y actividades}

El uso del espacio es marcado y delimitado por cada sección del parque. En la sección uno se observa una vida y uso más vibrante de las personas, puesto que cuenta con mobiliario y equipamiento nuevo atractivo para los usuarios, sin embargo, la sección dos aún mantiene su estructura física inicial de un espacio menos intervenido y más natural que lo convierte en más atrayente para algunos usuarios.

Personas realizando ejercicio de manera independiente o el equipo de atletismo "Las tortugas" hacen uso de la pista de Tartán (también utilizan los caminamientos de la sección dos), clases de zumba y yoga en el pergolado y pabellón, talleres de malabares, funciones de cine al aire libre en la plazoleta central, fiestas de cumpleaños, personas acostadas en los jardines, niños scouts haciendo acciones de limpieza o reuniones, jóvenes jugando en las canchas y ejercitándose en la zona de gimnasio, personas paseando a sus perros o corriendo, actividades de avistamiento de aves y algunas carreras son las actividades y usos que dan las personas al parque (ver diorama 7) 


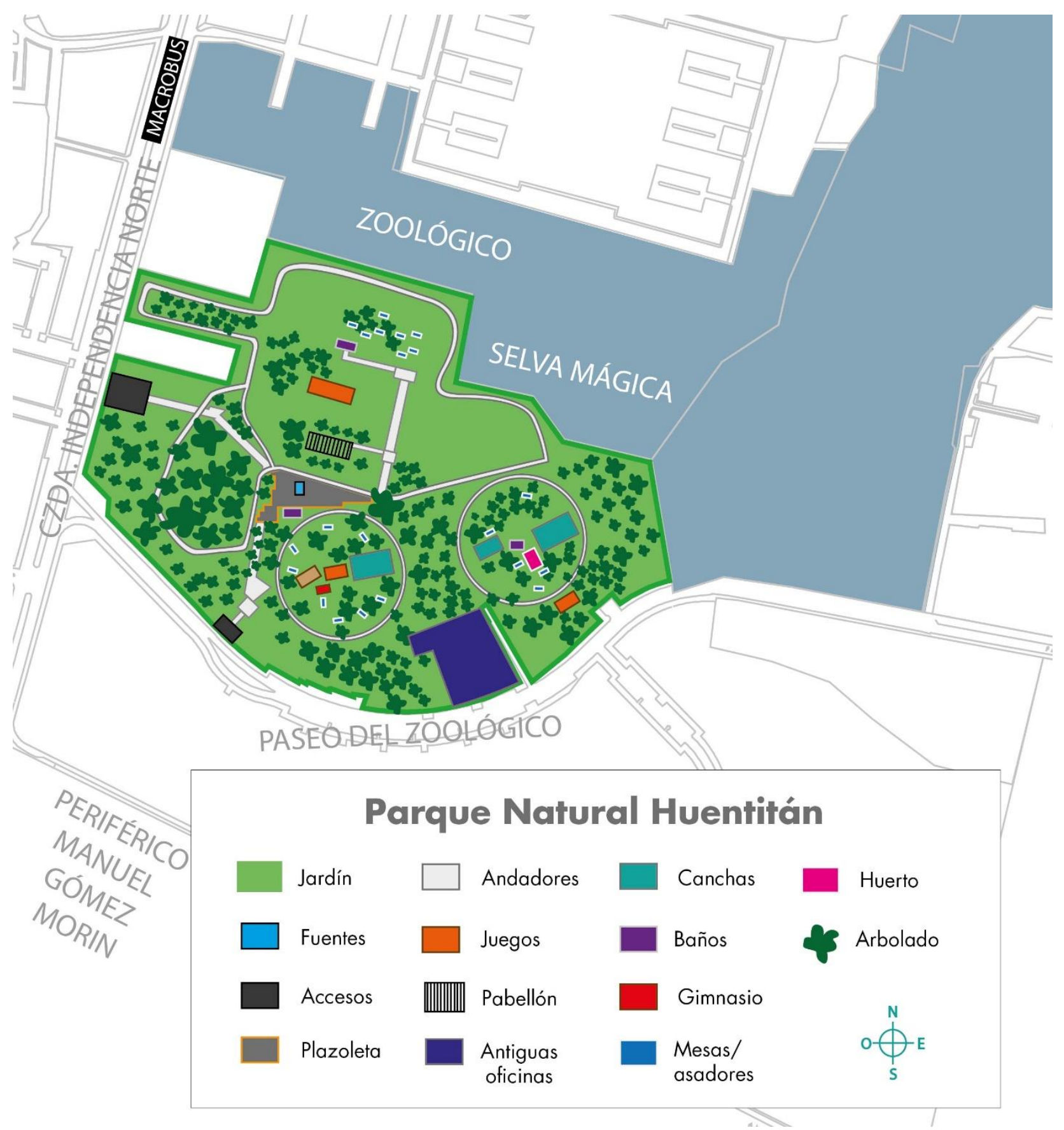

Esquema 17) Elementos físicos y morfología que conforma Parque Natural de Huentitán. Elaboración propia.

De acuerdo con la observación y tablas de variables las actividades que se realizan con mayor frecuencia son; ejercitarse, caminar, contemplación, jugar, personas 
paseando a su mascota y comer (ver tablas $42,43,44,45,46$ y 47 ) aunque dependiendo el horario y día es cuando son más observables ciertas acciones.

Todos los miércoles al anochecer hay función de cine al aire libre en la zona de la plazoleta central, en el que niños, jóvenes y adultos asisten y se apropian del espacio.

El pabellón que se localiza al lado norte del parque cada miércoles y jueves por la mañana alberga clases de yoga, sus usuarias principalmente mujeres se apoderan del lugar a través de movimientos corpóreos. El pergolado central es otro espacio que de lunes a viernes por la mañana y tarde tiene una ocupación por las clases de activación física ${ }^{18}$ que ofrece COMUDE de forma gratuita.

El huerto comunitario tiene una permanencia de dos años en el espacio e inicio como un proyecto de resistencia y ocupación en protesta a las fiestas de octubre. La convivencia, medio ambiente, el procomún y agroecología son algunos de los valores y prácticas que se ponen en ejecución (ver ilustración 20).

Referente a los resultados de la encuesta realizada, los usuarios perciben su visita como muy satisfactoria y las dos actividades recurrentes que realizan son las relacionadas con el ejercicio, descanso y convivencia (ver gráfico 47 y 48 ). El motivo de visita se vincula a que les gusta el parque y la cercanía a su punto de origen, así como la mayor parte respondió que a las actividades que suelen acudir más son las relacionadas con eventos sociales y talleres/cursos (ver gráfico 49 y 50 ).

Este parque también tiene áreas de atracción (ver esquema 18), la concentración de personas se observa en el centro en la sección uno que es donde se realizó la renovación, las personas se reúnen en un pedazo ajardinado que colinda con la vialidad de Paseo de Zoológico, en las mesas de picnic, la cancha, el pergolado, área de juegos, pista circular, la explanada y un poco más hacia el norte en el pabellón donde se hace yoga. El perímetro en el que se encuentra la pista de tartán también tiene una gran afluencia de usuarios. En la sección dos los puntos de atracción se relacionan con las

\footnotetext{
${ }^{18}$ Las clases de activación física fueron gestionadas por la asociación vecinal Huentitán Vive A.C.
} 
acciones que realizan en el área del huerto comunitario, la cancha multiusos y las mesas de picnic y asadores contiguas a estas áreas.

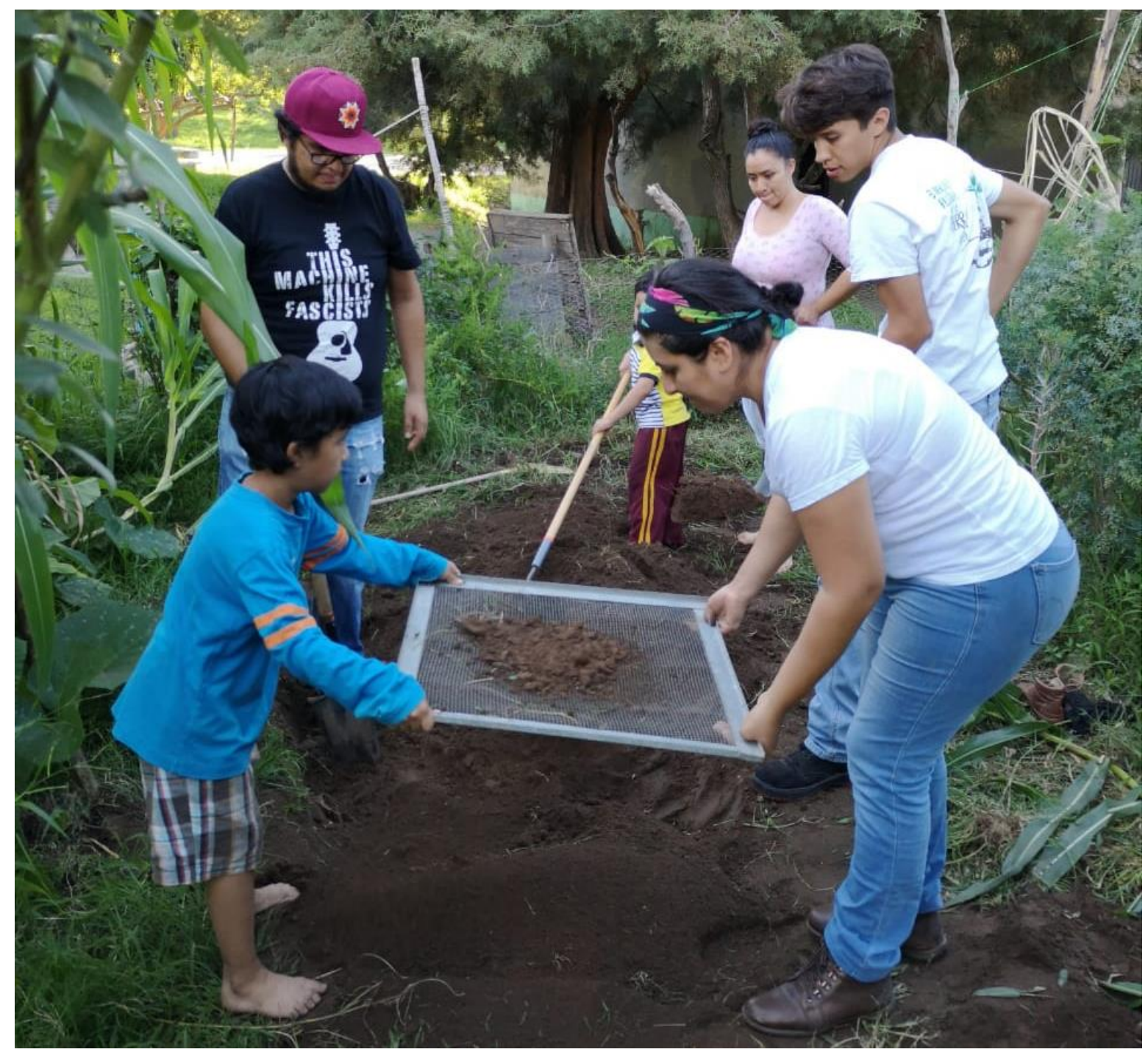

Ilustración 20) Huerteros del Huerto comunitario Tlacuache en la construcción de una cama biointensiva. Fuente propia

Existe una dinámica muy interesante de la concentración de personas entre la sección uno y dos, durante toda la semana de lunes a viernes la sección uno es ocupada con distintas actividades durante el día por usuarios más locales y cercanos al parque, se relaciona esta atracción al nuevo mobiliario y equipamiento más próximos a los accesos y por tener una topografía menos accidentada, mientras que la sección dos posee su mayor afluencia y atracción de usuarios los fines de semana, especialmente los 
domingos que es cuando el parque tiene su punto más alto de visitas tanto de locales como de otras partes de la ciudad, entre semana son menos las personas que lo recorren, esto se relaciona a que la oferta de equipamiento y mobiliario es menos y lo existente necesita mantenimiento para un mejor uso además de que los caminamientos y áreas ajardinadas tienen una topografía más accidentada y natural.

En el perímetro exterior al parque la atracción se da en las aceras que colindan con los accesos al Zoológico, esto debido a que se localizan y ubican puestos de venta de productos y comida, principalmente fines de semana. Las modalidades que generan este flujo en el parte posterior exterior del parque están ligados a un fin comercial porque estas aceras son espacios de transito que confluyen con la entrada principal del Zoológico, por lo que se vuelven atractivas para poder adquirir productos de consumo ya sea para entrar al Zoológico o para consumirlos dentro del Parque Natural.
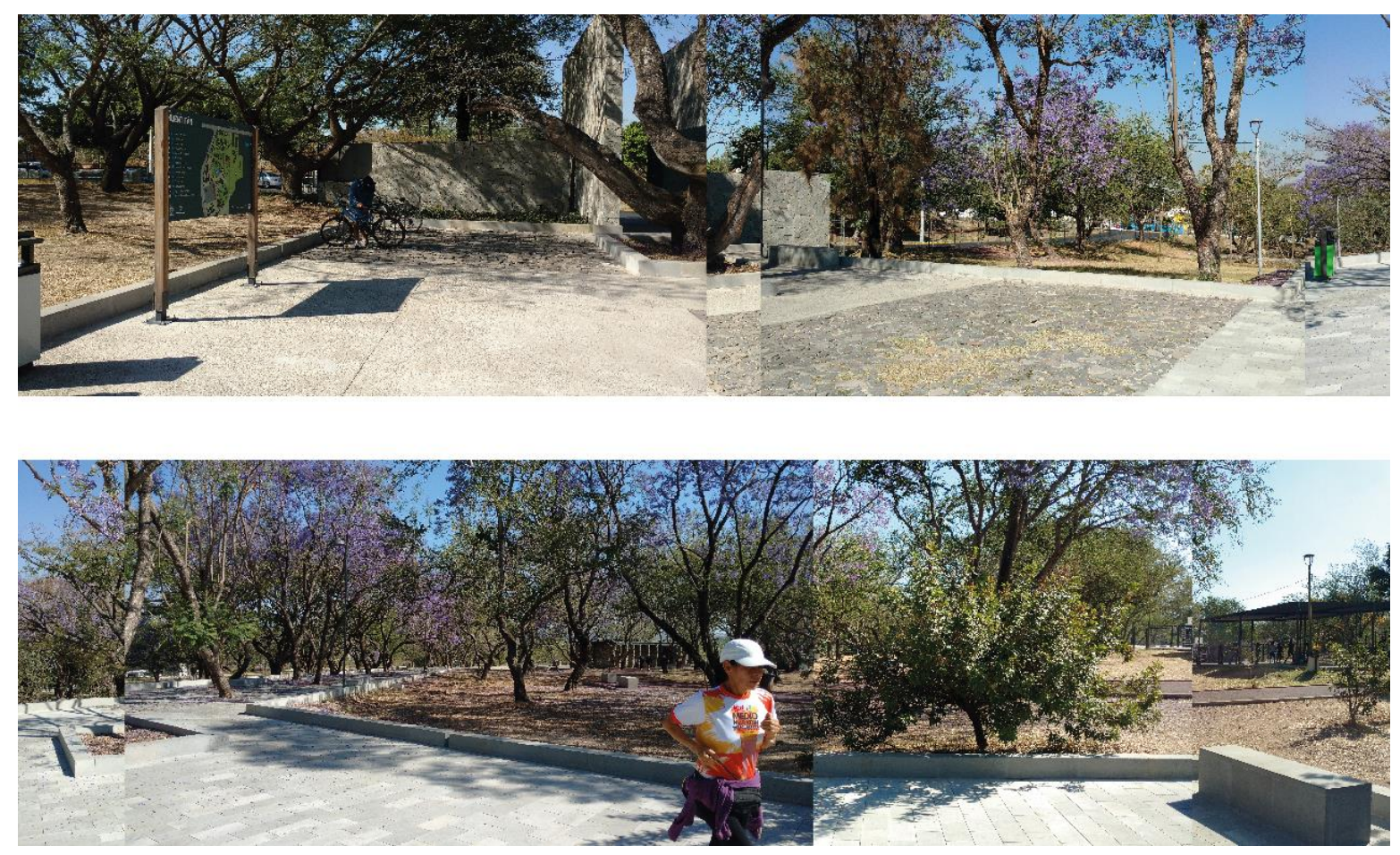

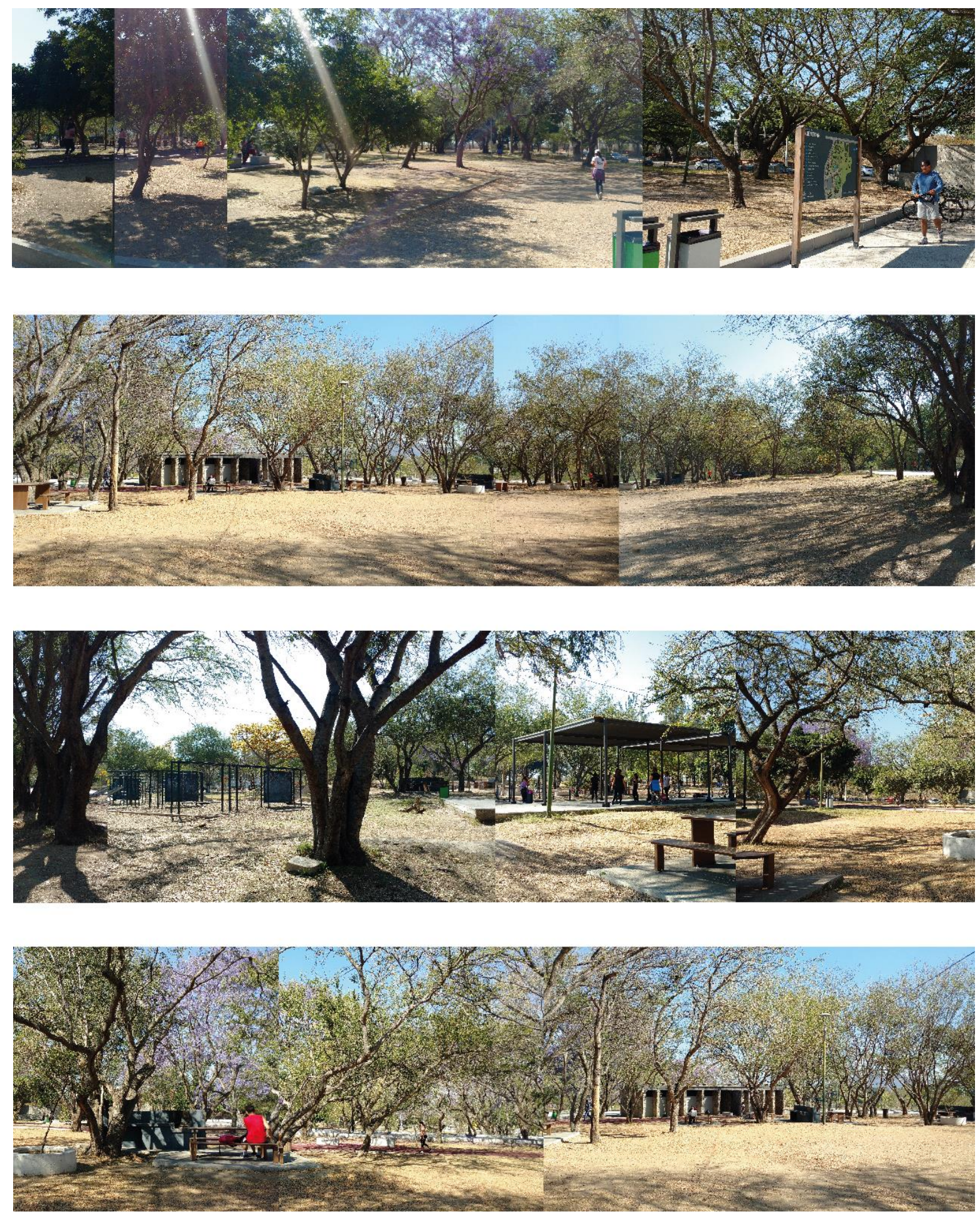

Diorama 7) Secuencia fotográfica Parque Natural de Huentitán Enero del 2019 por la mañana. Fuente propia. 


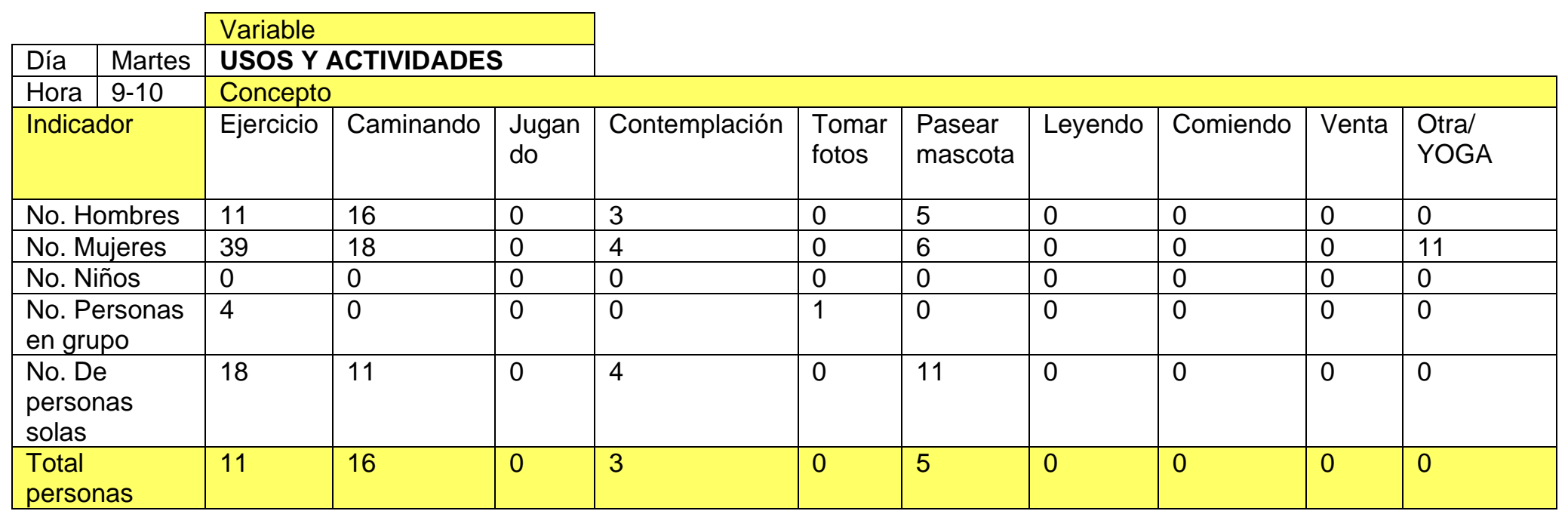

Tabla 42) Tabla de variables: Usos y actividades Parque Natural de Huentitán en distintos horarios y días. Elaboración propia.

\begin{tabular}{|c|c|c|c|c|c|c|c|c|c|c|c|}
\hline & \multirow{2}{*}{\multicolumn{3}{|c|}{ Variable }} & & & & & & & \\
\hline & & & & & & & & & & & \\
\hline Día & Miércoles & \multicolumn{3}{|c|}{ USOS Y ACTIVIDADES } & & & & & & & \\
\hline Hora & $11-12$ & \multicolumn{10}{|c|}{ Concepto } \\
\hline \multicolumn{2}{|c|}{ Indicador } & Ejercicio & Caminando & $\begin{array}{l}\text { Jugan } \\
\text { do }\end{array}$ & Contemplación & $\begin{array}{l}\text { Tomar } \\
\text { fotos }\end{array}$ & $\begin{array}{l}\text { Pasear } \\
\text { mascota }\end{array}$ & Leyendo & Comiendo & Venta & $\begin{array}{l}\text { Otra/ } \\
\text { especificar }\end{array}$ \\
\hline \multicolumn{2}{|c|}{ No. Hombres } & 4 & 8 & 0 & 7 & 0 & 3 & 0 & 0 & 0 & 0 \\
\hline \multicolumn{2}{|c|}{ No. Mujeres } & 3 & 9 & 0 & 6 & 0 & 2 & 0 & 0 & 0 & 0 \\
\hline \multicolumn{2}{|c|}{ No. Niños } & 0 & 4 & 4 & 0 & 0 & 0 & 0 & 0 & 0 & 0 \\
\hline \multicolumn{2}{|c|}{$\begin{array}{l}\text { No. Personas en } \\
\text { grupo }\end{array}$} & 0 & 2 & 0 & 3 & 0 & 0 & 0 & 2 & 0 & 0 \\
\hline \multicolumn{2}{|c|}{$\begin{array}{l}\text { No. De personas } \\
\text { solas }\end{array}$} & 7 & 5 & 0 & 7 & 0 & 5 & 0 & 0 & 0 & 0 \\
\hline \multicolumn{2}{|c|}{ Total personas } & 14 & 28 & 4 & 23 & 0 & 8 & 0 & 2 & 0 & 0 \\
\hline
\end{tabular}

Tabla 43) Tabla de variables: Usos y actividades Parque Natural de Huentitán en distintos horarios y días. Elaboración propia. 


\begin{tabular}{|c|c|c|c|c|c|c|c|c|c|c|c|}
\hline & \multicolumn{3}{|c|}{ Variable } & & & & & & & \\
\hline Día & Martes & \multicolumn{10}{|c|}{ USOS Y ACTIVIDADES } \\
\hline Hora & $19-20$ & \multicolumn{10}{|c|}{ Concepto } \\
\hline \multicolumn{2}{|c|}{ Indicador } & Ejercicio & Caminando & $\begin{array}{l}\text { Jugan } \\
\text { do }\end{array}$ & Contemplación & $\begin{array}{l}\text { Tomar } \\
\text { fotos }\end{array}$ & $\begin{array}{l}\text { Pasear } \\
\text { mascota }\end{array}$ & Leyendo & Comiendo & Venta & $\begin{array}{l}\text { Otra/ } \\
\text { HUERTO }\end{array}$ \\
\hline \multicolumn{2}{|c|}{ No. Hombres } & 17 & 16 & 9 & 6 & 1 & 4 & 0 & 0 & 0 & 2 \\
\hline \multicolumn{2}{|c|}{ No. Mujeres } & 45 & 11 & 4 & 7 & 0 & 10 & 1 & 0 & 1 & 1 \\
\hline \multicolumn{2}{|c|}{ No. Niños } & 7 & 6 & 13 & 0 & 0 & 0 & 0 & 0 & 0 & 2 \\
\hline \multicolumn{2}{|c|}{$\begin{array}{l}\text { No. Personas } \\
\text { en grupo }\end{array}$} & 4 & 3 & 2 & 0 & 0 & 1 & 0 & 2 & 0 & 0 \\
\hline \multicolumn{2}{|c|}{$\begin{array}{l}\text { No. De } \\
\text { personas } \\
\text { solas } \\
\end{array}$} & 16 & 4 & 0 & 7 & 0 & 8 & 0 & 0 & 0 & 0 \\
\hline \multicolumn{2}{|c|}{$\begin{array}{l}\text { Total } \\
\text { personas }\end{array}$} & 89 & 40 & 28 & 20 & 1 & 23 & 1 & 2 & 1 & 5 \\
\hline
\end{tabular}

Tabla 44) Tabla de variables: Usos y actividades Parque Natural de Huentitán en distintos horarios y días. Elaboración propia.

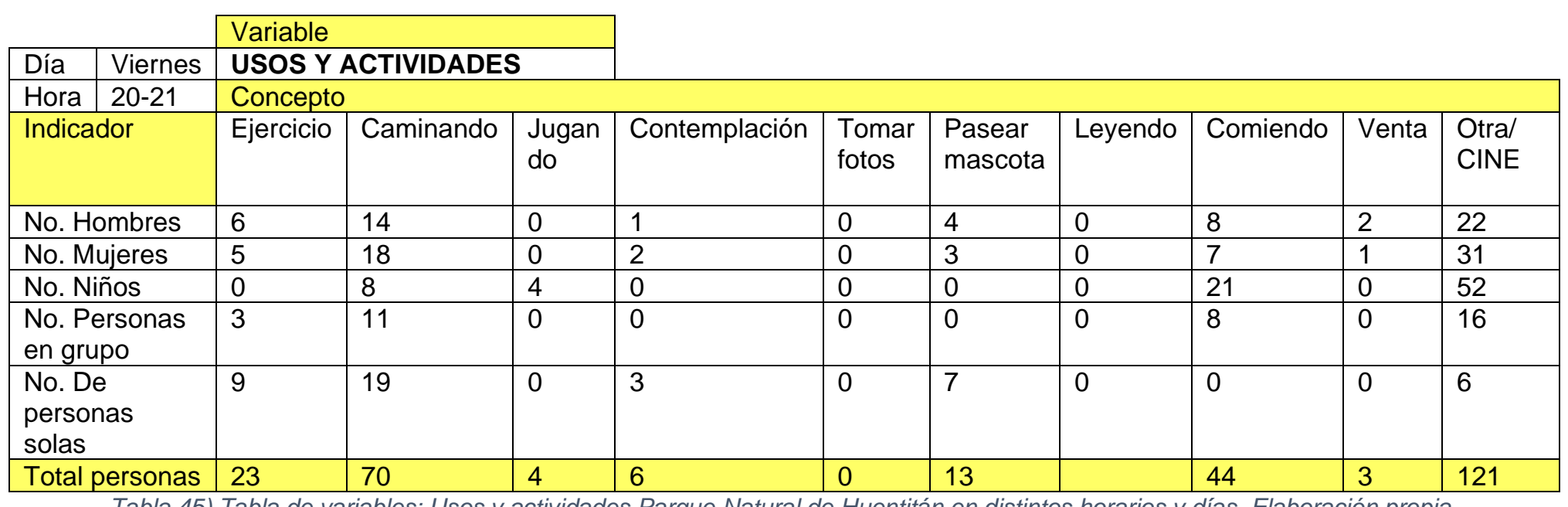

Tabla 45) Tabla de variables: Usos y actividades Parque Natural de Huentitán en distintos horarios y días. Elaboración propia. 


\begin{tabular}{|c|c|c|c|c|c|c|c|c|c|c|c|}
\hline & & Variable & & & & & & & & & \\
\hline Día & Sábado & USOS Y & CTIVIDADES & & & & & & & & \\
\hline Hora & $11-12$ & Concepto & & & & & & & & & \\
\hline Indice & & Ejercicio & Caminando & $\begin{array}{l}\text { Jugan } \\
\text { do }\end{array}$ & Contemplación & $\begin{array}{l}\text { Tomar } \\
\text { fotos }\end{array}$ & $\begin{array}{l}\text { Pasear } \\
\text { mascota }\end{array}$ & Leyendo & Comiendo & Venta & $\begin{array}{l}\text { Otra/ } \\
\text { HUERTO }\end{array}$ \\
\hline$\overline{\text { No. } \mathrm{H}}$ & mbres & 12 & 12 & 8 & 8 & 0 & 4 & 0 & 0 & 0 & 6 \\
\hline No. N & jeres & 8 & 20 & 3 & 6 & 0 & 6 & 0 & 0 & 0 & 4 \\
\hline No. N & & 0 & 10 & 16 & 5 & 0 & 1 & 0 & 0 & 0 & 4 \\
\hline $\begin{array}{l}\text { No. P } \\
\text { en gr }\end{array}$ & $\begin{array}{l}\text { rsonas } \\
\text { bo }\end{array}$ & 0 & 3 & 2 & 3 & 0 & 0 & 0 & 2 & 0 & 1 \\
\hline $\begin{array}{l}\text { No. D } \\
\text { perso } \\
\text { solas }\end{array}$ & & 8 & 5 & 0 & 4 & 0 & 7 & 0 & 0 & 0 & 0 \\
\hline Total & ersonas & 28 & 50 & 28 & 26 & 0 & 18 & 0 & 2 & 0 & 15 \\
\hline
\end{tabular}

Tabla 46) Tabla de variables: Usos y actividades Parque Natural de Huentitán en distintos horarios y días. Elaboración propia.

\begin{tabular}{|c|c|c|c|c|c|c|c|c|c|c|c|}
\hline & & Variable & & & & & & & & & \\
\hline Día & Domingo & USOS Y & ACTIVIDADE & & & & & & & & \\
\hline Hora & $17-18$ & Concepto & & & & & & & & & \\
\hline Indic & & Ejercicio & Caminando & $\begin{array}{l}\text { Jugan } \\
\text { do }\end{array}$ & Contemplación & $\begin{array}{l}\text { Tomar } \\
\text { fotos }\end{array}$ & $\begin{array}{l}\text { Pasear } \\
\text { mascota }\end{array}$ & Leyendo & Comiendo & Venta & $\begin{array}{l}\text { Otra/ } \\
\text { ACOSTADOS }\end{array}$ \\
\hline No. $\mathrm{H}$ & mbres & 9 & 25 & 11 & 7 & 0 & 5 & 2 & 0 & 0 & 2 \\
\hline No. $\mathrm{N}$ & jjeres & 6 & 31 & 6 & 10 & 2 & 6 & 0 & 0 & 0 & 2 \\
\hline No. 1 & ños & 0 & 28 & 21 & 3 & 0 & 0 & 0 & 8 & 0 & 0 \\
\hline $\begin{array}{l}\text { No. } \\
\text { en gr }\end{array}$ & $\begin{array}{l}\text { isonas } \\
\text { po }\end{array}$ & 1 & 12 & 9 & 11 & 2 & 0 & 0 & 9 & 0 & 0 \\
\hline $\begin{array}{l}\text { No. L } \\
\text { persc }\end{array}$ & as solas & 3 & 6 & 0 & 8 & 0 & 3 & 0 & 0 & 0 & 1 \\
\hline Total & ersonas & 19 & 102 & 47 & 39 & 4 & 14 & 2 & 17 & 0 & 5 \\
\hline
\end{tabular}

Tabla 47) Tabla de variables: Usos y actividades Parque Natural de Huentitán en distintos horarios y días. Elaboración propia. 


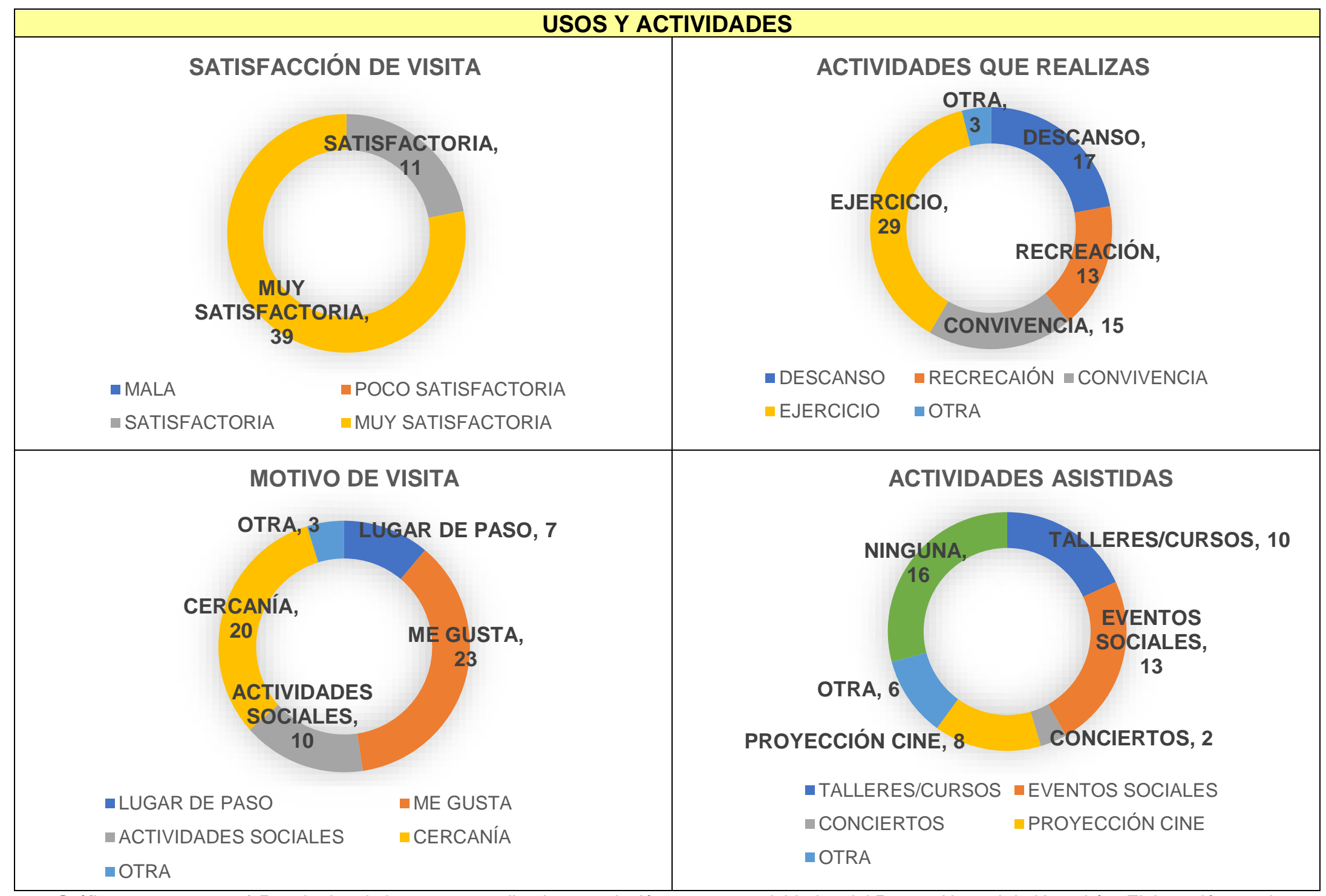

Gráfico 47, 48, 49 y 50) Resultados de la encuesta aplicada con relación a usos y actividades del Parque Natural de Huentitán. Elaboración propia 


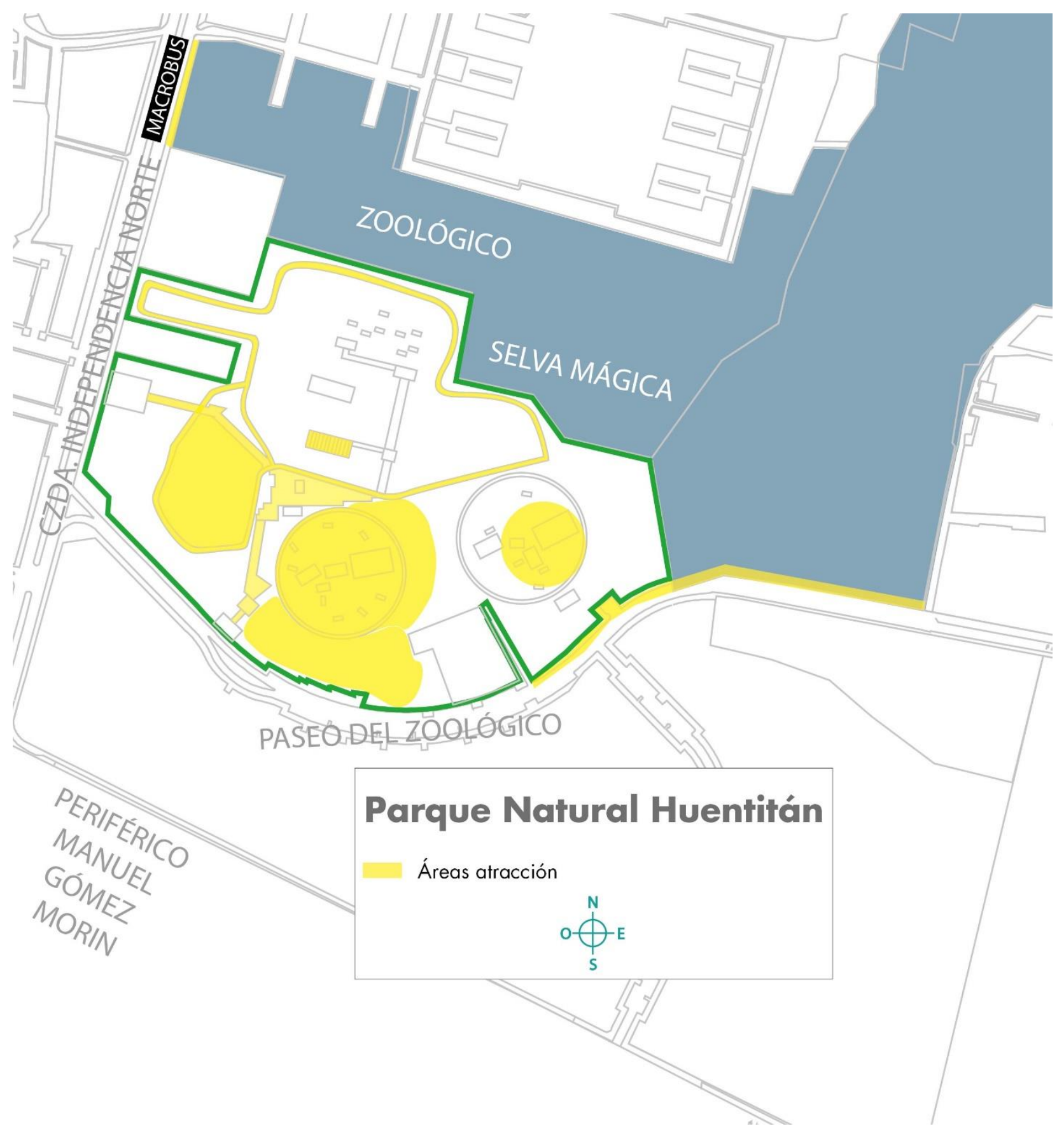

Esquema 18) Áreas de atracción Parque Natural de Huentitán. Elaboración propia. 


\section{Conclusiones capítulo 3}

De acuerdo con las características generales, morfológicas funcionales, usos y actividades de los espacios públicos centrales y periféricos de Huentitán que se estudiaron y analizaron, se perciben las dos vertientes en las que se basa esta investigación:

a) el espacio concebido, construido y vivido al que hacen referencia Lefebvre y Soja se refleja en la historia de la ciudad (capitulo 2) y el crecimiento de esta a partir de sus espacios públicos, ya que dichos espacios fueron planificados y proyectados por distintos urbanistas, arquitectos e ingenieros de acuerdo con las necesidades de cada periodo histórico.

b) la identificación de los usos, actividades, características y cualidades de los espacios analizados en las dos zonas de estudio nos permite reconocer el espacio percibido, al que hace referencia Lefebvre, y el espacio de las practicas materializadas que plantea Soja, lo cual refiere identidad y apropiación por parte de la ciudadanía.

Como analizamos en este capítulo tanto los espacios públicos centrales y periféricos de Guadalajara tienen características morfológicas y de usos distintos, es notable el valor edificado que confiere de identidad a los espacios públicos del centro, ya que al encontrarse dentro del primer cuadro del casco histórico la esencia de la historia de la ciudad fundacional prevalece en ellos, proyectando esta característica al devolverle el valor de espacios de fundación durante el movimiento moderno, pero no dejando aparte su valor simbólico que se relaciona más a aspectos históricos de valorización de espacio de encuentro histórico (la plaza y Alameda).

Por su parte los espacios públicos de la periferia norte tienen un valor más acorde con un "espacio social" como lo define Lefebvre en la producción del espacio, un producto de la sociedad, en el que cada espacio es una abstracción donde convergen diversos elementos y procesos de las relaciones sociales: 
"El espacio social contiene objetos muy diversos, tanto naturales como sociales, incluyendo redes y ramificaciones que facilitan el intercambio de artículos e informaciones[...] Esos "objetos" no son únicamente cosas, sino también relaciones." (Lefebvre, 2013: 134)

Es decir, todas las sociedades producen su propio espacio, a través de este espacio es que se produce el espacio físico y simbólico porque confluyen los elementos construidos y las relaciones simbólicas y afectivas, al momento de unificar estas dos partes es que el espacio social se convierte un lugar de acuerdo a las ideas de De Certeau (2000), un lugar de relaciones individuales y colectivas, una coexistencia de estas relaciones con la espacialidad de sus elementos que dotan de un sentido propio a los lugares.

Siguiendo esta premisa es que los espacios públicos periféricos de esta investigación, Parque Natural de Huentitán y Mirador son sitios que aportan un alto valor de espacio social a la ciudad, ya que más allá de sus elementos construidos (lo físico y arquitectónico) la ciudadanía produce a estos espacios a partir del valor simbólico de sus áreas verdes que se asocian al bienestar y disfrute de actividades de ocio, recreativas, convivencia y deportivas, y que al hallarse cercanas al gran cinturón verde de la Barranca de Huentitán, por ello estos sitios deberían ser considerados como espacios nodos e integradores de una red de espacios públicos de la ciudad de Guadalajara, velar por su protección ambiental, social y conectividad con otros espacios y el fácil acceso para los tapatíos.

Como lo define Göbel en su libro Aprendizaje social en espacios públicos (2019; 38), el espacio no es únicamente un recipiente tridimensional, sino que también es un entorno que permite que la acción social suceda

Las formas de producción del espacio público en la zona central y periférica de Guadalajara después de los años 30 corresponden a un "urbanismo tradicional" es decir, seguía ideas modernistas y de la industrialización donde la ciudad crecía a gran escala, con planeación centralizada y expansión por razones especulativas 
y monetarias con la construcción de fraccionamientos que en muchas ocasiones no se adecuan a las necesidades reales de las personas, alejados de los centros de trabajo y por tanto de espacios públicos de calidad o en que los espacios públicos existentes se planea cambiar su uso de suelo, entendiendo al uso de suelo como la actividad permitida para un predio, dicho de otra forma, el vocacionamiento del predio, y por consecuente modificar su uso de suelo público a uno privado o público privado, segregando o limitando su libre acceso y uso a las personas.

Para entender mejor estos procesos se elaboró una tabla de hallazgos y similitudes entre los espacios de las zonas de estudio de esta investigación (ver tabla 48).

\begin{tabular}{|c|c|c|c|}
\hline \multicolumn{4}{|c|}{$\begin{array}{c}\text { CASOS DE ESTUDIO: ESPACIOS ABIERTOS AL AIRE LIBRE DE LA ZONA } \\
\text { CENTRO Y PERIFERIA NORTE DE GUADALAJARA }\end{array}$} \\
\hline Bases teóricas & $\begin{array}{l}\text { Caso de } \\
\text { estudio }\end{array}$ & Hallazgo & Similitud \\
\hline \multirow[t]{2}{*}{$\begin{array}{l}\text { Espacio } \\
\text { concebido } \\
\text { (expertos) } \\
\text { Lefebvre }\end{array}$} & $\begin{array}{l}\text { Cruz de Plazas } \\
\text { y Parque } \\
\text { Morelos }\end{array}$ & $\begin{array}{l}\text { Existe registro en los } \\
\text { archivos históricos } \\
\text { de su planificación a } \\
\text { través de la historia. } \\
\text { Espacios con valor } \\
\text { de ordenamiento y } \\
\text { control para la ciudad } \\
\text { pensados como } \\
\text { espacios para el } \\
\text { encuentro } \\
\text { ciudadano. }\end{array}$ & \multirow{2}{*}{$\begin{array}{l}\text { Se han ejecutado } \\
\text { proyectos para la } \\
\text { remodelación e } \\
\text { intervención para } \\
\text { la mejora y } \\
\text { optimización de } \\
\text { uso para los } \\
\text { usuarios. } \\
\text { Ambas áreas son } \\
\text { contempladas en } \\
\text { la actualización de } \\
\text { los planes } \\
\text { parciales. } \\
\text { En el caso del } \\
\text { Parque Morelos y } \\
\text { parques de } \\
\text { Huentitán } \\
\text { espacios creados } \\
\text { como lugares para } \\
\text { el esparcimiento y } \\
\text { disfrute colectivo } \\
\text { ciudadano. }\end{array}$} \\
\hline & $\begin{array}{l}\text { Parque Natural } \\
\text { de Huentitán y } \\
\text { Parque Mirador }\end{array}$ & $\begin{array}{l}\text { No existe un registro } \\
\text { claro y preciso en los } \\
\text { archivos de su } \\
\text { diseño. } \\
\text { Realización de } \\
\text { reuniones y mesas } \\
\text { de trabajo con } \\
\text { vecinos y usuarios } \\
\text { para presentar los } \\
\text { proyectos de } \\
\text { intervención. } \\
\text { Consulta pública y } \\
\text { mesas de trabajo } \\
\text { para la actualización }\end{array}$ & \\
\hline
\end{tabular}




\begin{tabular}{|c|c|c|c|}
\hline & & $\begin{array}{l}\text { de los planes } \\
\text { parciales los cuales } \\
\text { proyectan } \\
\text { megaproyectos en } \\
\text { estos espacios. }\end{array}$ & \\
\hline \multirow[t]{2}{*}{$\begin{array}{l}\text { Espacio percibido } \\
\text { (experiencias } \\
\text { materiales) } \\
\text { Lefebvre }\end{array}$} & $\begin{array}{l}\text { Cruz de Plazas } \\
\text { y Parque } \\
\text { Morelos }\end{array}$ & $\begin{array}{l}\text { Espacio con fuerte } \\
\text { carga simbólica } \\
\text { social e histórica por } \\
\text { ser parte del núcleo } \\
\text { central del casco } \\
\text { histórico de la } \\
\text { ciudad. } \\
\text { Espacio abierto que } \\
\text { permite la interacción } \\
\text { con los elementos y } \\
\text { edificaciones que los } \\
\text { envuelven. } \\
\text { Parque Morelos con } \\
\text { una imagen urbana } \\
\text { deteriorada por } \\
\text { localizarse en los } \\
\text { límites del cinturón } \\
\text { de tolerancia de la } \\
\text { zona centro. }\end{array}$ & \multirow[t]{2}{*}{$\begin{array}{l}\text { Espacios de libre } \\
\text { acceso para la } \\
\text { ciudadanía. } \\
\text { Convergen en } \\
\text { ambos } \\
\text { principalmente las } \\
\text { clases populares y } \\
\text { turistas atraídos } \\
\text { por la arquitectura } \\
\text { colonial del casco } \\
\text { histórico y el valor } \\
\text { paisaístico y } \\
\text { ambiental de los } \\
\text { parques cercanos } \\
\text { a la barranca. }\end{array}$} \\
\hline & $\begin{array}{l}\text { Parque Natural } \\
\text { de Huentitán y } \\
\text { Parque Mirador }\end{array}$ & $\begin{array}{l}\text { Espacio con fuerte } \\
\text { carga simbólica } \\
\text { social como espacios } \\
\text { recreativos y de } \\
\text { esparcimiento, así } \\
\text { como la importancia } \\
\text { de las áreas verdes } \\
\text { como parte del } \\
\text { cinturón verde de la } \\
\text { barranca. } \\
\text { Espacios "cerrados" } \\
\text { que se encuentran } \\
\text { con una limitante } \\
\text { física entre su interior } \\
\text { y exterior, en este } \\
\text { caso por una reja } \\
\text { que limita y controla } \\
\text { su acceso. }\end{array}$ & \\
\hline $\begin{array}{l}\text { Espacio vivido } \\
\text { (experiencias }\end{array}$ & $\begin{array}{l}\text { Cruz de Plazas } \\
\text { y Parque } \\
\text { Morelos }\end{array}$ & $\begin{array}{l}\text { Espacio ligado a sus } \\
\text { características físicas }\end{array}$ & $\begin{array}{l}\text { Espacios con } \\
\text { buena } \\
\text { conectividad por }\end{array}$ \\
\hline
\end{tabular}




\begin{tabular}{|c|c|c|c|}
\hline \multirow[t]{2}{*}{$\begin{array}{l}\text { individuales y } \\
\text { colectivas) Soja }\end{array}$} & & $\begin{array}{l}\text { y los edificios que los } \\
\text { rodean. } \\
\text { Espacios de } \\
\text { encuentro popular } \\
\text { ciudadano y } \\
\text { espacios conectores } \\
\text { con el comercio y } \\
\text { turismo dentro del } \\
\text { primer cuadro de la } \\
\text { ciudad. } \\
\text { Espacio con } \\
\text { movimiento y tránsito } \\
\text { ciudadano durante } \\
\text { todo el transcurso del } \\
\text { día, lo que lo hace un } \\
\text { lugar más observado } \\
\text { y con mayor } \\
\text { presencia de } \\
\text { vigilancia oficial y } \\
\text { ciudadana. }\end{array}$ & \multirow{2}{*}{$\begin{array}{l}\text { la cercanía a } \\
\text { sistemas de } \\
\text { transporte público } \\
\text { masivo, Macrobús } \\
\text { para ambas zonas } \\
\text { y Tren Ligero y } \\
\text { bicicleta pública } \\
\text { para la zona } \\
\text { centro. } \\
\text { Buena } \\
\text { conectividad } \\
\text { interna entre los } \\
\text { espacios (menos } \\
\text { del cuarto de hora } \\
\text { entre uno y otro } \\
\text { caminando). } \\
\text { Constante } \\
\text { afluencia de } \\
\text { usuarios entre } \\
\text { semana, pero con } \\
\text { un pico mayor de } \\
\text { asistencia los } \\
\text { fines de semana o } \\
\text { durante eventos } \\
\text { culturales o } \\
\text { deportivos. } \\
\text { Espacios con } \\
\text { vitalidad y vida } \\
\text { pública vibrante } \\
\text { durante toda la } \\
\text { semana. }\end{array}$} \\
\hline & $\begin{array}{l}\text { Parque Natural } \\
\text { de Huentitán y } \\
\text { Parque Mirador }\end{array}$ & $\begin{array}{l}\text { Espacios de } \\
\text { encuentro con alto } \\
\text { valor paisajístico y } \\
\text { ambiental para la } \\
\text { ciudad, ya que se } \\
\text { encuentran cercanos } \\
\text { a la Barranca de } \\
\text { Huentitán, lo que } \\
\text { dota y provee un } \\
\text { valor de salud y } \\
\text { bienestar a la zona. } \\
\text { Espacios cercanos } \\
\text { peatonalmente no } \\
\text { solo a Huentitán sino } \\
\text { a otros barrios } \\
\text { aledaños. }\end{array}$ & \\
\hline $\begin{array}{l}\text { Espacio de las } \\
\text { prácticas } \\
\text { espaciales } \\
\text { materializadas } \\
\text { Soja }\end{array}$ & $\begin{array}{l}\text { Cruz de Plazas } \\
\text { y Parque } \\
\text { Morelos }\end{array}$ & $\begin{array}{l}\text { Espacios turísticos y } \\
\text { de comercio, así } \\
\text { como de } \\
\text { manifestación social. } \\
\text { Proponen una } \\
\text { programación } \\
\text { cultural variada } \\
\text { mensualmente }\end{array}$ & $\begin{array}{l}\text { Espacios para la } \\
\text { convivencia y } \\
\text { encuentro } \\
\text { colectivo. } \\
\text { Espacios para la } \\
\text { manifestación } \\
\text { cultural (eventos y } \\
\text { presentaciones). }\end{array}$ \\
\hline
\end{tabular}




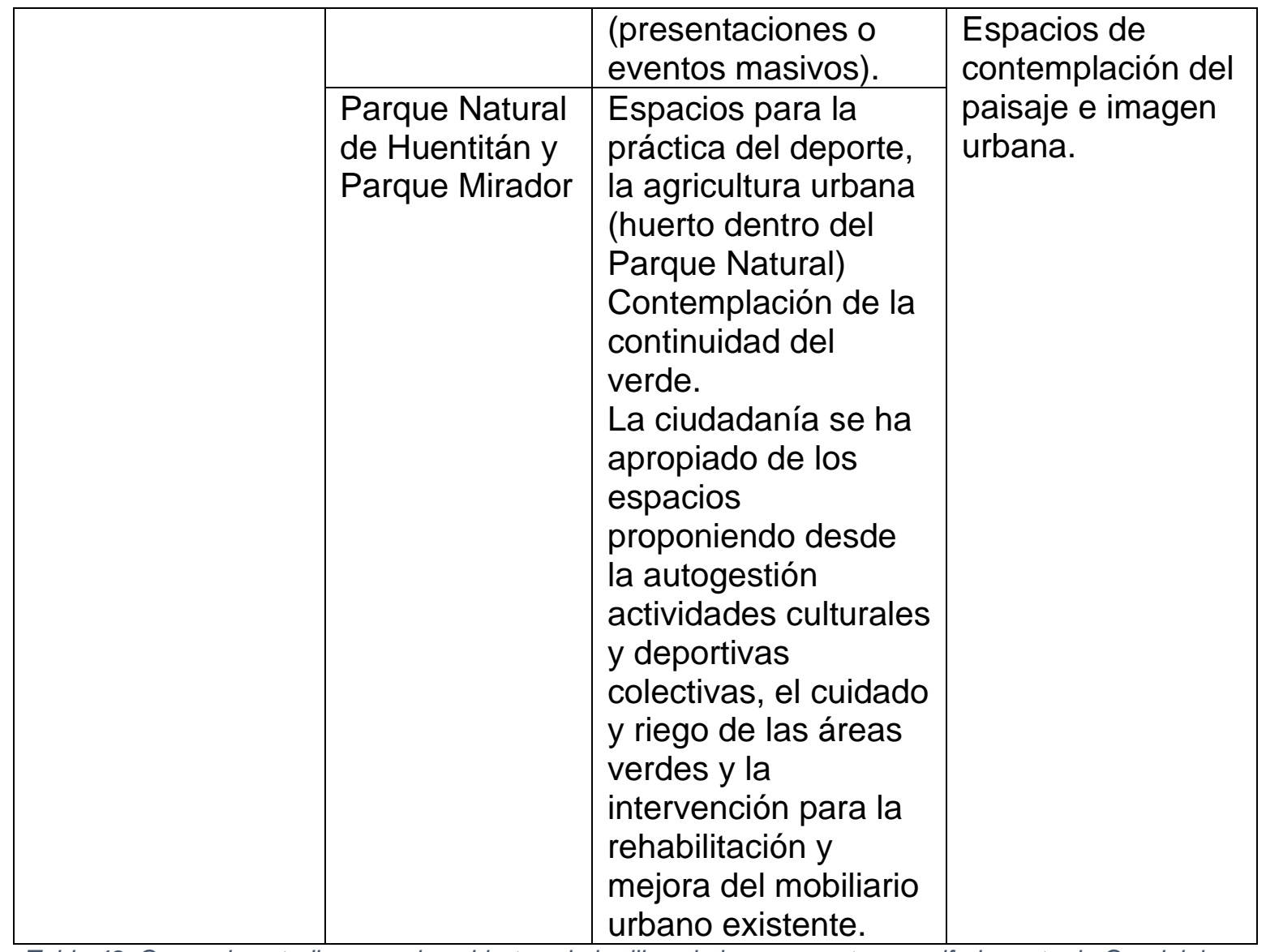

Tabla 48. Casos de estudio: espacios abiertos al aire libre de la zona centro y periferia norte de Guadalajara. Elaboración propia.

Como podemos observar en la tabla 48 de hallazgos y similitudes, se observa que en la Cruz de Plazas y Parque Morelos la ciudadanía otorga un uso al espacio más orgánico en función de los edificios y construcciones que los rodean, son espacios también para la manifestación social y cultural. Por su parte los espacios de la periferia tienen una carga simbólica social con una inclinación y tendencia hacia la apropiación, entendiendo a la apropiación desde la definición de la Real Academia de la Lengua Española y lo referido por Vidal Moranta y Pol Urrútia (2005) como la acción de tomar para sí mismo algo, haciéndose dueño de ello y darle su propio significado y propia construcción social, sumando también el cuidado autogestivo del espacio.

En cuanto a su morfología, las modificaciones y renovaciones de las Cruz de Plazas y Parque Morelos para mejora de su imagen urbana y contexto, no se sometieron a ningún tipo de consulta pública, que, a diferencia de Huentitán con la 
actualización de los planes parciales en 2018 hubo una consulta pública en la que se presentaban los megaproyectos para la zona Huentitán, como consecuencia de estas mesas y del factor de apropiación y pertenencia de la ciudadanía hacia los espacios fue que se llegaron a acuerdos para la remodelación de ambos parques, Mirador y Natural de Huentitán tras años de abandono.

Por el contrario, en la zona centro las formas de construcción, uso y apropiación están relacionadas a las funciones y actividades como espacios de estancia, paso y conectividad central, motivo suficiente para que las personas no desarrollen un vínculo de apropiación directo con el sitio, ya que, al encontrarse en el primer cuadro histórico de la ciudad, el gobierno es el encargado de darle mantenimiento constante y estar pendiente de las necesidades de estos espacios públicos. A diferencia de los espacios centrales los espacios de la periferia por su parte reflejan más sentido de apropiación y pertenencia de los vecinos y usuarios, esto debido a que hay grupos y asociaciones consolidadas que trabajan para el mejoramiento y mantenimiento de los espacios, tal es el caso de Huentitán Vive A.C, Huerto comunitario Huentitán y Civilidad para Transformar A.C. por mencionar algunas.

De acuerdo con las tablas de indicadores y la tabla 48 los espacios de la zona central tienen una buena accesibilidad, cuentan con servicio de transporte masivo cercano (Macrobús y tren ligero), estaciones de bicicletas públicas y cercanías con estacionamientos. La sociabilidad es buena, al ser espacios con constante flujo peatonal y el permitir la flexibilidad de usos para actividades sociales y culturales. En cuanto a la comodidad e imagen, en rasgos generales se percibe como buena en la Cruz de Plazas debido a que se encuentra en el corazón de la ciudad y está rodeada de edificios con alto valor cultural, social y patrimonial a diferencia del Parque Morelos que su imagen desde el ojo de sus usuarios se ve afectada por encontrarse en los límites del cinturón de tolerancia de la zona centro, dando en términos generales que estos espacios abiertos son buenos espacios públicos a la ciudadanía. 
Por su parte, los espacios periféricos tienen una buena conectividad al transporte público masivo, su sociabilidad es buena pero con mayor afluencia los fines de semana al igual que zona centro, por las medidas de extensión territorial las actividades y usos son bastante amplios debido a no es solo un lugar de encuentro y esparcimiento, sino un espacio para el deporte y la cohesión y regeneración del tejido social por la conformación y presencia de grupos deportivos (atletismos, clases de activación física) y de prácticas agroecológicas como en el caso del huerto urbano como símbolo de resistencia y apropiación ciudadana de lo público. En cuanto a su imagen y comodidad es excelente debido a que cuenta con amplias áreas verdes y arboladas y la cercanía entre ambos espacios y la Barranca está a 15 minutos caminando.

Respecto a la conceptualización del proyecto de espacio público participativo en la zona centro no suelen realizarse este tipo de ejercicios con la ciudadanía cuando se han hecho obras de remodelación o remozamiento urbano, esto debido a la complejidad y características de los espacios, que, a diferencia, en la zona periférica este tipo de ejercicios se han realizado por presión mediática y social de la ciudadanía, debido a que el apego y arraigo a las áreas verdes de estos parques es tan fuerte, puesto que son los únicos espacios públicos abiertos cercanos a la población de la colonia de Huentitán el Alto y Bajo y otras colonias aledañas como Lomas del Paraíso o Rancho Nuevo, lo que ha dado como resultado la rehabilitación de estos espacios, pero bajo un esquema que responde más a las necesidades y anhelos de los ciudadanos y usuarios y en el que se han llegado a acuerdos entre gobierno y ciudadanía respetando la importancia ambiental y de espacio público abierto que proporcionan y conceden estos parques para la ciudad.

Ya por último para cerrar con lo analizado, lo concluido en cada capítulo y lo abordado a lo largo de todo el trabajo de investigación, es necesario plantear nuevas formas de hacer urbanismo y formas de producción del espacio público más allá de la concepción y planificación de los técnicos expertos planificadores de ciudad, las ideas del nuevo urbanismo y urbanismo peer to peer (P2P) contrastan con las ideas de urbanismo tradicional, ya que se centra principalmente en la escala humana, 
involucrar a la ciudadanía en la planeación de sus entornos, promover la restauración y creación de entornos y comunidades diversas, transitables, compactas, vibrantes y de uso mixto.

El Nuevo Urbanismo desarrolló herramientas para cambiar la forma de planear, diseñar y desarrollar las ciudades el cual impacta de manera positiva en los residentes, ya que crea entornos conectados, caminables, redes de espacios y naturaleza necesarios para las actividades de ocio y con ello un estilo de vida más saludable que resulta en relaciones más significativas entre las personas y una ciudad más amigable, es decir, se debería de comenzar a producir el espacio de las ciudades centrado en la comunidad, su habitabilidad y hacer del espacio público su prioridad a diferencia del urbanismo tradicional en que a la ciudad se le da un uso mercantilista y que durante el siglo XX la mayoría de las ciudades fueron edificadas bajo la influencia modernista y la construcción basada en la densificación y priorización del uso del coche ante el uso del peatón por lo que el nuevo urbanismo busca una reapropiación de la ciudadanía.

Por ello a partir de estas formas de producción del espacio de la zona norte Huentitán en relación con la centralidad de Guadalajara se propondrán líneas de acción que respondan a una dimensión humana pero con producción física y simbólica como un llamado de atención a las formas de producción actuales del espacio, donde las ciudades en muchas ocasiones son proyectadas como construcciones aisladas y no como un lugar de red que fusione y conecte los espacios públicos, las calles y los edificios.

Como menciona Jan Gehl en su libro Ciudades para la gente:

"Tanto las ciudades nuevas como las existentes deberán realizar cambios cruciales en las variables y prioridades que colocan en la balanza a la hora de trazar un plano urbano. Poner las necesidades de la población que usa y vive en las ciudades por delante de todo, es una tarea primordial del futuro" (Gehl, 2016; 6) 
Gehl propone ciudades con escala humana, hacer ciudades con una dimensión humana en el planeamiento urbano, para ello propone proyectar ciudades con base en 4 objetivos:

1- Ciudades vitales

2- Ciudades sostenibles

3- Ciudades sanas

4- Ciudades seguras

Para este arquitecto urbanista una ciudad vital aumenta cuando se logra convencer a un mayor número de personas a caminar o que usen la bicicleta.

Una ciudad segura es aquella que se obtiene al aumentar la cantidad de personas a vivir y circular dentro del espacio urbano. Para alentar que las personas circulen y caminen más es necesario ofrecer atractivos como la posibilidad de realizar trayectos cortos, tener espacios públicos atrayentes y variedad disponible de servicios, ya que si hay movimiento y dinamismo en las calles hay más observadores.

Una ciudad sostenible se puede lograr al enfatizar el uso de transporte público, medios de transporte no automotores como la bicicleta es lo que él llama "movilidad verde", debido a que brinda aportes positivos a la economía y al medio ambiente debido a la reducción de recursos, emisiones de carbono y disminución de los niveles de ruido.

Un punto importante en la sostenibilidad de una ciudad para tomar en cuenta es que al fortalecer el uso de estos medios de transporte a la población se ve fortalecido cuando los usuarios se sienten seguros yendo de un sitio a otro, ya que tener una buena red de transporte y espacios públicos van de la mano.

La salud de una ciudad se incrementa cuando se ofrece a la población la posibilidad de circular y realizar sus actividades diarias ya sea en bicicleta 0 caminando, alentar a las personas a caminar como parte de su rutina es un componente importante en la población. 
La dimensión humana propuesta por Gehl refleja que existe una demanda por mejorar la calidad urbana y que es posible lograr mejoras espaciales para poder alcanzar ciudades vitales, sostenibles, sanas y seguras para las personas. Para ellos es necesario entender que las ciudades son humanas, ya que son humanos quienes viven en ellas y que comparten un espacio común, por ello parte de la filosofía de Gehl se basa en hacer partícipe a la comunidad en el proceso y así poder lograr de manera más satisfactoria los objetivos ya descritos.

Como cierre final de todo el trabajo de investigación desarrollado a lo largo de estas páginas se propone una propuesta breve y puntual de acción para un modelo futuro de producción del espacio público, morfología y todos los elementos que conforman a esta colonia de la ZMG, pero con un enfoque de escala humana que se integra a las propuestas de la producción física y simbólica en relación Huentitán - Guadalajara resaltando el valor de esta zona periférica, ya que los megaproyectos en la zona norte de la ciudad continúan y son voraces, en la que las autoridades y gobiernos tanto municipales y estatales anteponen las necesidades, demandas y peticiones ciudadanas ante los intereses privados de la derrama económica que proporcionaría esta zona privilegiada del municipio por su gran belleza y valor paisajístico.

\section{Huentitán: retos y oportunidades para la producción de espacio público con dimensión humana}

Como ya se estudió y analizo la forma de crecimiento y morfología de la ciudad de Guadalajara tuvo sus orígenes como una ciudad de casco fundacional Española y por ende una estructura de ciudad colonial, por lo cual desde sus orígenes la estructura y traza de la urbe correspondía a una producción del espacio física que prevalecía en su ordenamiento, desarrollo y evolución y no fue hasta el movimiento moderno que estas ideas dieron un giro, ya que durante la gobernatura de Gonzáles Gallo fue que se le quiso dotar de un valor de producción simbólica del espacio del centro histórico de la ciudad con la idea de la Cruz de Plazas como la sala de todos los tapatíos, pero respetando la idea de que para llegar a ese simbolismo era 
necesaria la producción física del espacio. El centro histórico de la Perla Tapatía está en constante cambio y renovación y su Cruz de Plazas no ha sido la excepción al ser uno de los espacios públicos más importantes de la ciudad, por su parte el parque Morelos también ha sido un significativo espacio público abierto verde, al ser el área verde (parque) más extenso y grande de la zona centro de la ciudad, motivo por el cual ambos espacios públicos son atendidos en cuanto a renovación, limpieza e imagen constantemente además de tener una buena conexión con el resto de la metrópoli al contar con estaciones de dos de los sistemas de transporte público masivo (ver análisis del capítulo 3)

En contra parte los espacios públicos abiertos verdes de la periferia norte se producen mayormente en relación con un valor simbólico de acuerdo a los resultados de análisis del capítulo 3 , que si bien los parques tienen elementos tangibles productos de la producción física, su valor de espacio reside en las personas por su aporte de áreas verdes, ya que estos parques forman parte del cinturón verde de la urbe y son unos de los pulmones de la ciudad en conjunto con la barranca de Huentitán, los cuales además brindan servicios de esparcimiento y ocio para esa zona de la ciudad sin necesidad de tener que trasladarse hasta el centro de la ciudad e incluso para colonias cercanas a ellos, ya que se localizan muy cercan del anillo periférico y conectan directamente con la Calzada Independencia que son dos grandes avenidas articuladoras de la ciudad.

Por tanto, como resultado de esta investigación se elaboró una serie de lineamientos generales con la intención de señalar la importancia de los espacios públicos de la zona norte de Guadalajara y como estos se deben de vincular como un eje integral para el desarrollo del diseño futuro de la ciudad desde la forma de producción del espacio mismo en su producción física, material y simbólica.

Estos lineamientos que se describen a continuación se orientan hacia el diseño urbano orientado a las personas, se retoman ideas de los modelos de humanización del espacio urbano (P2P, Nuevo Urbanismo y la dimensión humana), los cuales se enfocan en diseñar ciudades con una escala humana. 
Ya desde los años 40 con la carta de Atenas de Le Corbusier se hace manifiesto la importancia de las áreas verdes para las ciudades y su relación para la mejora de calidad de vida de las urbes para sus habitantes.

Las ciudades son procesos continuos de cambio que requieren de innovación, creatividad, adaptabilidad, colaboración y resiliencia, es por ello por lo que se debe planificar la gestión urbana para que los espacios urbanos de las ciudades respondan a las necesidades de las personas en los diferentes momentos de su historia urbana.

\section{A) CONECTIVIDAD}

Pensar en un territorio más integrado con espacios que se articulen unos con otros, en consiguiente:

- Renovación de las banquetas, banquetas libres, implementación de rampas en ambos sentidos de la vialidad de la Calzada Independencia en el tramo Huentitán San Juan de Dios (centro de la ciudad).

- Red de corredores internos ciclistas dentro de Huentitán que permitan conectar ambos parques, ciclovía sobre Calzada Independencia que conecte con el centro de la ciudad.

- Instalación de ciclopuertos dentro de estaciones Macrobús y colocación bici estacionamiento en Anillo Periférico (movilidad multimodal) para conectar ambas zonas de estudio.

- Renovación del camellón de Calzada Independencia desde Huentitán hasta San Juan de Dios (zona centro de la ciudad) colocando estratégicamente nodos de descanso para que las personas puedan ir de una zona a otra caminando si así lo desean. 


\section{B) MEDIO SOCIAL}

Proveer a los habitantes de la zona norte espacios sociales y simbólicos que hagan del barrio un espacio vibrante, pero sin alterar sus características físicas y medioambientales, por lo tanto:

- Renovación de la segunda sección del Parque Natural de Huentitán, pero con una metodología de diseño a escala humana.

- Revalorizar el espacio urbano de áreas verdes como espacio público por medio de señalética informativa en los parques de las zonas de estudio para denotar la importancia de conservar estas áreas verdes como espacios públicos de alto valor físico y social para la ciudad.

\section{C) MEDIO AMBIENTE Y SOSTENIBILIDAD}

Preservar las características físicas naturales y servicios medioambientales que proporciona la zona norte a la metrópoli como elementos articuladores que permitan el desarrollo óptimo de calidad de vida de sus habitantes, en consiguiente:

- Decreto de la barranca y los Parques Mirador y Natural de Huentitán como áreas naturales protegidas y establecer políticas verdes para su protección.

- Saneamiento del arbolado del Parque Mirador, Parque Natural de Huentitán, Parque Moelos y camellón de Calzada Independencia en el tramo MiradorSan Juan de Dios (centro de la ciudad).

- Manual de manejo y cuidado de las áreas verdes.

- Proyectar en contrapropuesta a la Cruz de Plazas una Cruz verde en la ciudad que contemple los espacios con mayor extensión verde de la ciudad; al Norte Barranca, Parque Mirador y Natural de Huentitán, al centro Parque Morelos, al Sur Parque Agua Azul y Parque de la Liberación (El Dean) al Poniente el Bosque de los Colomos y Parque Metropolitano y al Oriente con el Parque de la Solidaridad (ver esquema 19). 


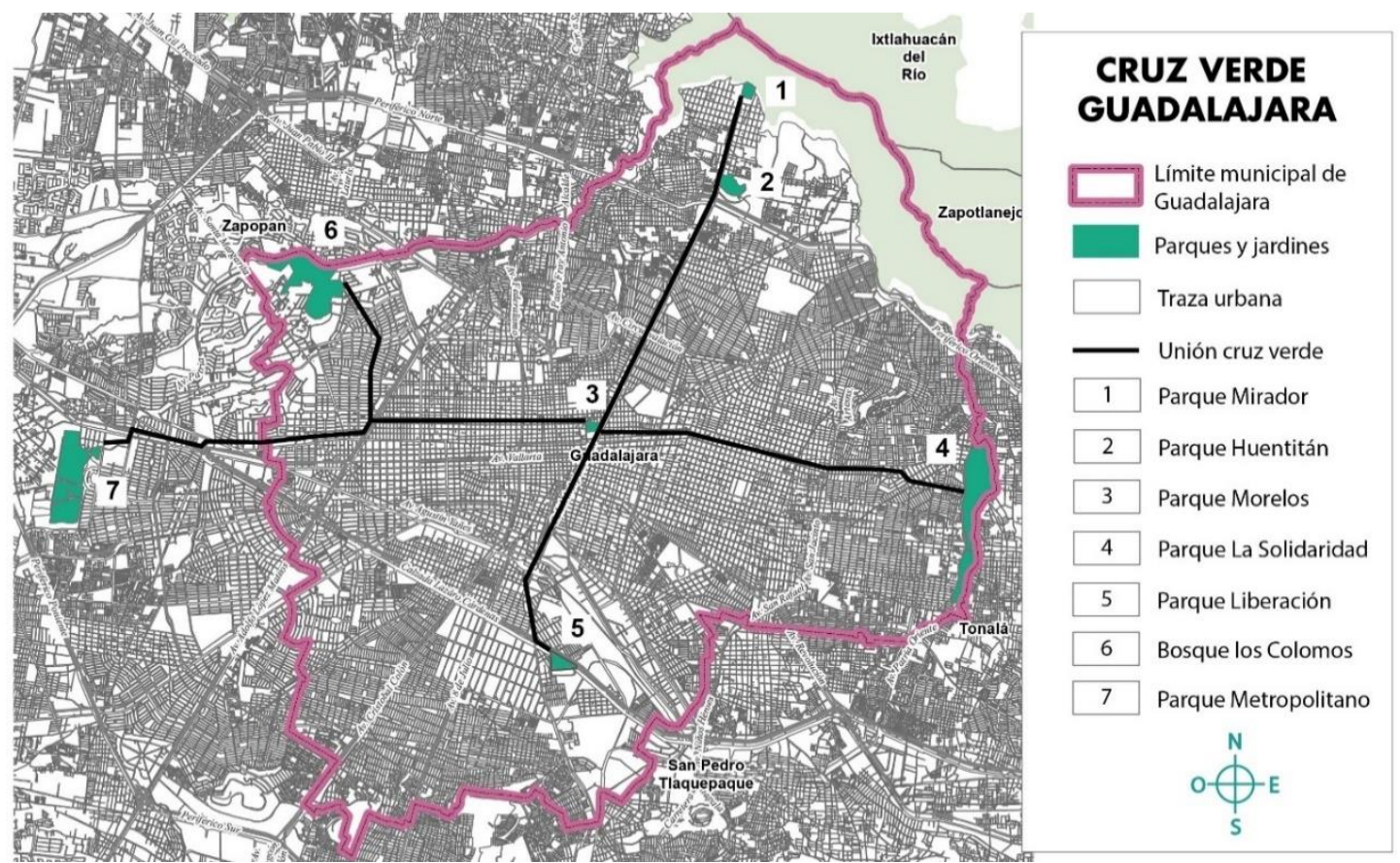

Esquema 19) Cruz verde de espacios públicos abiertos: Parque Mirador, Parque Natural de Huentitán, Parque Morelos, Parque de la Solidaridad, Parque Liberación, Bosque Colomos y Parque Metropolitano. Elaboración propia. Fuente: Límite municipal: Marco geoestadístico, INEGI, 2018. Vegetación densa: Uso de suelo, INEGI, 2015. Traza urbana: Marco geoestadístico, INEGI, 2018. Parques y jardines: Gobierno de Guadalajara, 2019.

\section{D) VITALIDAD Y HABITABILIDAD}

Establecer un orden urbano para la zona norte y centro de la ciudad encaminado a limitar la construcción de infraestructura habitacional innecesaria, aumentar las dimensiones mínimas de vivienda, controlar la demanda de servicios básicos y mitigar el cambio climático

- Regular el uso de suelo en cuanto a vivienda con relación a los servicios públicos que puede soportar cada zona.

- Establecer políticas de vivienda que regule el modelo de vivienda vertical y no permitir construcciones con más de 4 plantas que obstruyan el paisaje natural de la barranca.

- Modificar los reglamentos para evitar la construcción de Arenas o centros de espectáculo masivos dentro de Huentitán. 
- Fomentar la inversión pública y privada en un sentido orientado a generar infraestructura que promuevan la integración social y actividades verdes y que contribuyan a que Huentitán se posicione como uno de los barrios con mejor calidad de vida dentro de la ciudad.

Mediante la implementación de estos lineamientos de acción, se limitara el aumento de demanda de servicios, se limitara la construcción de edificaciones y viviendas innecesarias, se tendrán áreas conectadas entre sí y con el resto de la ciudad no solo por transporte público sino a través de medios no motorizados, se implementarán estrategias para que la ciudadanía conozca y preserven los servicios medioambientales y sociales de los espacios públicos de áreas verdes así como la riqueza de flora, fauna y pulmón de la ciudad de los parques Mirador, Natural, Morelos y Barranca. En conjunto todo esto ayudará al desarrollo de producción del espacio público con escala humana y así a aumentar la calidad de vida de los habitantes de la zona y por consiguiente una mejora para la metrópoli.

\section{A manera de conclusión} Inicie esta investigación motivada por comprender como eran los procesos de producir el espacio público en las ciudades, por los parques de Huentitán, colonia de la periferia de Guadalajara en dónde he vivido desde hace 26 años y a los cuales asisto regularmente, el comprender por qué el gobierno municipal y estatal planeaban proyectos en espacios de uso público y de disfrute ciudadano en esta zona de la ciudad, los cuales que han traído como resultado segregación y segmentación del uso de esos espacios para los habitantes de esta zona, en el que organizaciones y colectivos de la sociedad civil de Huentitán se manifestaban en contra porque el espacio público es eso, un lugar de carácter abierto para el uso ciudadano en que las personas se apropian, le dan valor y significados simbólicos. En contraparte los espacios públicos del centro de la ciudad como la Cruz de Plazas y el Parque Morelos cada administración están en constante remodelación y 
renovación que favorece a su valor histórico e imagen urbana de la ciudad como casco fundacional, como expresaba el arquitecto Díaz Morales; que todo el pueblo pudiera sentarse en el gran patio de su casa grande, siendo estos espacios centrales un gran patio en que conjuntamente debería tener también tener otros patios internos además del principal, en este caso los parques de las periferias de la ciudad.

Durante el desarrollo y al final de todo el proceso de investigación y después de leer a los autores y realizar trabajo de campo, en general lo descrito involucra en todo momento la producción del espacio en una manera física material y simbólica, pero quizá lo más interesante serán las maneras y los motivos en que se ha dado la producción del espacio público en cada una de las áreas de estudio de acuerdo con los diferentes momentos de crecimiento de la ciudad.

La Guadalajara vista a partir de la fundación de la ciudad que hoy habitan los tapatíos, constituyo en su centro una plaza pública, el primer espacio público para la ciudad de los españoles que fue localizado de acuerdo con las leyes de Indias como nodo articulador y que a la par daba forma y ordenaba el territorio, puesto que su función desde las autoridades y tecnócratas de la época era de valor cívico al tener a su alrededor los edificios de gobierno.

Conforme iba avanzando el proceso de investigación y análisis de información se logró dar respuesta a las preguntas guías planteadas.

1- ¿Por qué los espacios públicos periféricos se perciben como espacios menos relevantes que los espacios públicos centrales en la ciudad??

Los espacios públicos de Guadalajara en relación con el crecimiento de su traza urbana se fueron conformando acorde la ciudad iba creciendo, se comenzó a expandir de acuerdo a una relación con sus espacios públicos, en que los atrios de las iglesias y jardines eran puntos de reunión, es decir, existía una relación de importancia y vinculación entre el espacio público central de la plaza en concordancia con estos espacios que se iban formando en los límites de las periferias de la ciudad, en los cuales el simbolismo del espacio público lo otorgaba 
los mandos del clero como parte del orden para la ciudad, espacio público concebido para ser dominante, símbolo de poder y regulador civil que buscaba la homogeneización de la traza urbana porque todas las ciudades de origen colonial seguían este mismo patrón morfológico.

2- ¿Cómo fueron conformándose los espacios públicos de Guadalajara en relación con el crecimiento de la ciudad y su traza urbana?

La ciudad se fue expandido y como se desarrolló en la investigación y para fines prácticos de análisis se dividió en momentos determinantes; 1 - desde su fundación homogénea hasta las leyes de Reforma, 2- los primeros elementos modernizadores de la ciudad con el entubamiento del Río San Juan de Dios como una medida de higienización del Porfiriato y la migración de nuevos residentes extranjeros quienes se asentaron en la zona poniente sur de la ciudad, 3- Guadalajara y el movimiento moderno, el ensanche de calles y dotar de más espacios públicos de plazas al centro de la ciudad con la Cruz de Plazas y 4- la ciudad contemporánea de megaproyectos devoradores del espacio público de la periferia norte. Es notable y visible a lo largo del trabajo cómo el espacio público paso de ser en los orígenes (la plaza central) un sitio físico y de carácter cívico con el simbolismo de lugar de dominio del poder de la corona española a un sitio de encuentro y recreación que permanecía simbólicamente como un espacio de historia de orden y dominio para la ciudad, no fue hasta las leyes de Reforma que el espacio público de la ciudad se comenzó a transformar, ya que se expropiaron terrenos eclesiásticos para convertirlos en espacios públicos del disfrute ciudadano como lo fueron plazas, jardines y en la periferia poniente-sur como el caso de la Alameda Lafayette, en que estos nuevos sitios se tornaban de nuevos simbolismos para la ciudadanía dependiendo de donde se encontrasen ubicados, si se localizaban al centro o el oriente tenían una connotación más popular, pero si se localizaban al poniente se relacionaba con un simbolismo distinto para las clases con mayor poder económico que da pie a esta relación simbólica y física material de los elementos arquitectónicos y del mobiliario de los espacios públicos de estas zonas que refuerza el dicho popular "de la Calzada para allá", que hace referencia a que en el 
oriente vive la clase con menores ingresos y que en el poniente se encuentra la aristocracia (para este punto histórico la ciudad aún mantenía cierto ordenamiento en su traza urbana pero con algunas irregularidades físicas). Los espacios públicos en resumen tras analizar diversas fuentes se conformaron principalmente como espacios de encuentro que respondían a las necesidades de los ciudadanos en correspondencia a la ubicación donde se encontraban situadas las familias con un estatus más alto o más bajo, esto no quiere decir que los estratos de menor ingreso no pudiesen ir a gozar o disfrutar de los espacios del poniente de la ciudad como la Alameda Lafayette, sino que el acceso a la zona era más accesible para quienes contaban con un coche privado. No fue hasta el movimiento moderno que es necesaria la expansión de espacios públicos para el disfrute de todos los tapatíos, puesto que en el periodo anterior si bien ya había espacios públicos no eran suficientes por la cantidad migratoria de personas que comenzó a llegar por el auge industrial. Ya para la época contemporánea nuevamente las necesidades físicas y simbólicas para las personas en los espacios públicos cambia, pero mantiene ciertas cualidades presentadas desde la fundación; La Plaza central como espacio producido físico, simbólico y socialmente como un sitio de encuentro con valor histórico fundacional nodo articulador de poder cívico que debe mantener este significado, por lo que las remodelaciones y mantenimiento constante se mantienen presentes, por otro lado los espacios periféricos son y han sido vistos al largo de la historia urbana de la ciudad como espacios públicos de encuentro y esparcimiento para la ciudadanía cercana, sin embargo después del año 2000 se ha visibilizado más la intervención y participación ciudadana de las personas con acciones de involucramiento, ya sea en la mejora o intervención de manera autogestiva y organizada con la comunidad dado que sienten el espacio público como de ellos y por tanto se apropian de él, lo mantienen y lo cuidan, tal es el caso de los diferentes grupos y organizaciones vecinales de los Parques de Huentitán que usan estos espacios y los promueven con diversa acciones, actividades o manifestaciones para conservar su función y usos actuales. 
3- ¿Qué elementos de la construcción del espacio social, son visibles en la concepción material del espacio público?

De acuerdo con cada momento de la historia urbana los espacios públicos de Guadalajara contaban con ciertos elementos y características que los dotaban de cualidades únicas o similares a otros espacios y que de acuerdo a la percepción de los planificadores y su visión de las necesidades de cada momento histórico urbano debían cubrir ciertos aspectos que ellos consideraban adecuados para la ciudadanía, como ejemplo el de la construcción del Parque Morelos como un espacio para los tapatíos como primer espacio público de parque para la ciudad, o la Alameda Lafayette en el periodo de auge de las Colonias, la construcción del Parque Agua Azul en el sur de la ciudad para la ciudadanía que se estaba expandiendo hacia esa dirección de la ciudad, la ampliación y ejecución del proyecto de Cruz de Plazas para dotar de un gran patio en su casa grande a los tapatíos y los parques de Huentitán para la población el norte de la ciudad, estos espacios en su momento de desarrollo e implementación contenían elementos de mobiliario y diseño arquitectónico que de acuerdo con los arquitectos o ingenieros que los diseñaron los consideraban como un buen espacio público porque las personas iban a ellos y los utilizaban.

Con el paso del tiempo nuevas corrientes del urbanismo han propuesto que deben existir indicadores medibles para que se pueda evaluar si un espacio público realmente está cumpliendo su función y uso para la ciudadanía, por ello proponen y consideran que deben existir 4 puntos clave para que un espacio público se considere exitosos; conectividad, imagen y comodidad, sociabilidad y los usos y actividades, dado que un espacio bien conectado a una red de transporte y a otros espacios públicos, que tenga una imagen agradable que invite a las personas a querer permanecer en el lugar y que ofrezca comodidades como áreas sombreadas, bancas, iluminación, etc. en el que se vean más personas usándolo porque es un lugar atractivo por sus características físicas y que además ofrezca diversas posibilidades para su uso al realizar distintas actividades ya sea solo para descansar, ir a jugar con los niños, reunirse con los vecinos, etc. hacen que un 
espacio público sea considerado como exitoso, al contrario a otros espacios que en su composición morfológica física cuentan con los elementos de mobiliario y arquitectónicos necesarios para que las personas se reúnan, pero el espacio no respondiese a las necesidades de la comunidad debido a que puede que no esté bien conectado, no tiene buena iluminación nocturna, está descuidado, etc. son indicadores de que algo está fallando en ese sitio y que es necesario replantearlo y configurarlo de acuerdo a las necesidades de las personas. En el caso de la Cruz de Plazas al encontrarse en el centro del casco de la ciudad siempre ha sido un punto de encuentro desde la historia y hasta la actualidad para la ciudadanía y por su ubicación y características tiene indicadores que lo denotan como un buen espacio público, en el caso del Parque Morelos también por su ubicación y características tiene indicadores de ser un buen espacio público que poco a poco se ha ido recuperando para el disfrute de todos los tapatíos gracias al empeño y esfuerzo de las administraciones del gobierno municipal y a que las personas se acercan más a este espacio pesé a estar estigmatizado por encontrarse en el límite de la zona de tolerancia de la ciudad. Por su parte los parques de la periferia; Mirador y Natural de Huentitán, por los elementos que contiene y sus características físicas, materiales y simbólicas son buenos espacios públicos, no obstante no se perciben como parte de la red de espacios públicos de la ciudad al encontrarse fuera del anillo periférico que rodea la ciudad, pero pesé a ello son espacios donde la comunidad se ha apropiado de ellos y formado colectividad para defenderlos de proyectos que bien podrían plantearse en otras zonas de la ciudad o por lo menos tomar en cuenta los puntos de vista de la ciudadanía y vecinos de estos lugares.

Con estas herramientas de medición que proponen las nuevas corrientes contemporáneas de urbanismo y arquitectura se puede medir cualquier espacio público de la ciudad para así determinar si es un lugar de éxito y atractivo para las personas y si no, detectar la falla para determinar junto con los usuarios y vecinos cercanos que podría hacer mejor a ese espacio para que cumpla su función como un espacio público apropiado para la urbe ya que, es la ciudadanía misma la que dota de otras cualidades a estos espacios, puesto que los dinamizan, le otorgan 
valores simbólicos y lo vuelven un sitio vibrante y con vida que incita a ser usado y a que otras personas también lo usen, por lo cual estas herramientas son una guía útil para toda aquella persona interesada en intervenir el espacio público, ya sean académicos, expertos, amateurs o la misma ciudadanía.

Por otro lado los objetivos de esta investigación se lograron cumplir en cuanto a la importancia de los espacios públicos periféricos en relación con su centralidad en las ciudades, porque mediante un proceso descriptivo del crecimiento de la ciudad en relación con sus espacios públicos en cuanto su producción física y material en los distintos momentos históricos se connota su importancia como articuladores para la ciudad, debido a que iban delimitando el crecimiento y expansión del territorio urbano, además mediante el trabajo en campo se comprobó como estos espacios públicos como son los parques son sitios necesarios para la vida en las ciudades, donde la ciudadanía de las periferias siente un mayor arraigo y pertenencia al lugar, prueba de ello son los colectivos y asociaciones que se han conformado en Huentitán y que realizan actividades comunitarias de aprendizaje, defensa, recreación y esparcimiento, que en comparación con los espacios centrales como la Cruz de Plazas son espacios vistos más como lugares de identidad histórica y civil.

Este trabajo de investigación permitió a su vez explorar los espacios públicos, pero desde una perspectiva de acuerdo con indicadores para medir si un espacio público es considerado un sitio apropiado para la ciudadanía, esto fue mediante métodos cualitativos para analizar la sociabilidad, comodidad, imagen, accesibilidad, actividades y usos, lo que determino definir si las áreas de estudio eran consideradas espacios adecuados de la ciudad. Lo que respecta a la Cruz de Plazas si es un buen espacio público, ya que simbólicamente es el corazón de la ciudad por ser el centro de la fundación, el Parque Morelos no tanto al encontrarse en el cinturón de tolerancia del centro de la ciudad, por lo que aún queda trabajo por hacer ahí para que sea un lugar para todas las familias de los tapatíos. Los parques periféricos de Huentitán también son buenos espacios para la comunidad por sus características físicas y debido a que simbólicamente se les relaciona con pulmones 
para la ciudad y como espacios para el esparcimiento, recreación y convivencia, razón por lo que colectivos y comunidad usuaria han gestionado de manera independiente actividades y proyectos dentro de estos lugares como son; clases de yoga, huerto comunitario, clases de atletismo, espectáculos y sobre todo la defensa del territorio ante proyectos que quieren reducir o quitarle espacios a la comunidad. No obstante, sería bueno realizar en este análisis y cuestionar hasta cuando estas herramientas seguirán siendo útiles para medir la calidad de los espacios pues las ciudades están en constante cambio y en algún momento de la historia urbana estas herramientas de medición podrían quedar obsoletas ante las diferentes circunstancias históricas que pueden atravesar las comunidades y ciudadanía.

Durante el desarrollo de la investigación fue necesario involucrarse de manera directa e indirecta con una serie de actores que permitieran la generación de insumos, el haberme involucrado en diferentes espacios públicos de mi ciudad como investigadora, como tapatía y como vecina de las zonas de estudio periféricas me permitió dar cuenta que en el centro de la ciudad los espacios públicos estudiados son vistos como espacios cívicos en el que la percepción de las personas se relaciona más a que son espacios que el gobierno debe mantener y cuidar, ya que cada administración estos son renovados o intervenidos de alguna manera, y hasta cierto punto está bien porque son la cara y corazón de la ciudad, pero se requiere prestar atención a los espacios públicos periféricos como los parques Naturales de Huentitán y hacer más obvia la red de conexión de espacios públicos de la ciudad, ya sea mediante señalética, camellones peatonales, ciclovías, etc. puesto que son espacios donde la ciudadanía siente mayor apropiación, donde es más activa y hay mayor participación ciudadana por parte de vecinos y comunidad cercana a estos espacios públicos por lo cual los estudiosos y planificadores de las ciudades y de espacio público no deben subestimar a la ciudadanía, sino más bien verlos como aliados para que las ciudades se moldeen de acuerdo a los requerimientos humanos y no que la ciudad moldee a los ciudadanos para que se adapten a ella. 
Ya por último como cierre, durante toda la investigación fue evidente que la producción del espacio público en un aspecto físico material y simbólico no pueden percibirse como dos cosas aisladas, al contrario van de la mano, porque si bien el aspecto físico material le da forma y morfología a un espacio público, este espacio para la ciudadanía puede percibirse vacío si no tiene un simbolismo asociado a él, por ejemplo, Cruz de Plazas y Parque Morelos son sitios históricos y cívicos como los primeros espacios públicos, en contraposición los Parques de Huentitán son espacios de áreas verdes necesarias para la calidad medioambiental de la ciudad por lo que es necesaria su protección como espacios públicos y espacios promotores de movimientos sociales que pueden ingerir en la toma de decisiones en la planeación de la ciudad de manera directa, por esa razón el tema de la inclusión social y gobernanza sería un ideal para las ciudades futuras, también es importante resaltar que el involucramiento de la ciudadanía, de los estudiosos y expertos de producir los espacios públicos y la academia es fundamental para poder desarrollar propuestas de espacios públicos de calidad a través de la comunidad y sociedad civil, sin embargo hay puntos que resolver en cuanto a los métodos para que estas partes se involucren unas con otras y así generar un impacto real en la toma de decisiones de los espacios públicos de las ciudades que habitamos por tanto, esto último queda el beneficio de la duda y a la tarea de seguir realizando más productos de investigación con un lenguaje e interpretación sencillos que puedan ser puestos a disposición y al alcance para el uso de las comunidades, las personas y la ciudadanía y puedan dialogar con sus gobiernos locales para que produzcan y fomenten espacios públicos de calidad pero sobre todo, que no solo focalicen sus esfuerzos en los espacios públicos centrales, sino que prioricen también los espacios públicos de las periferias. 


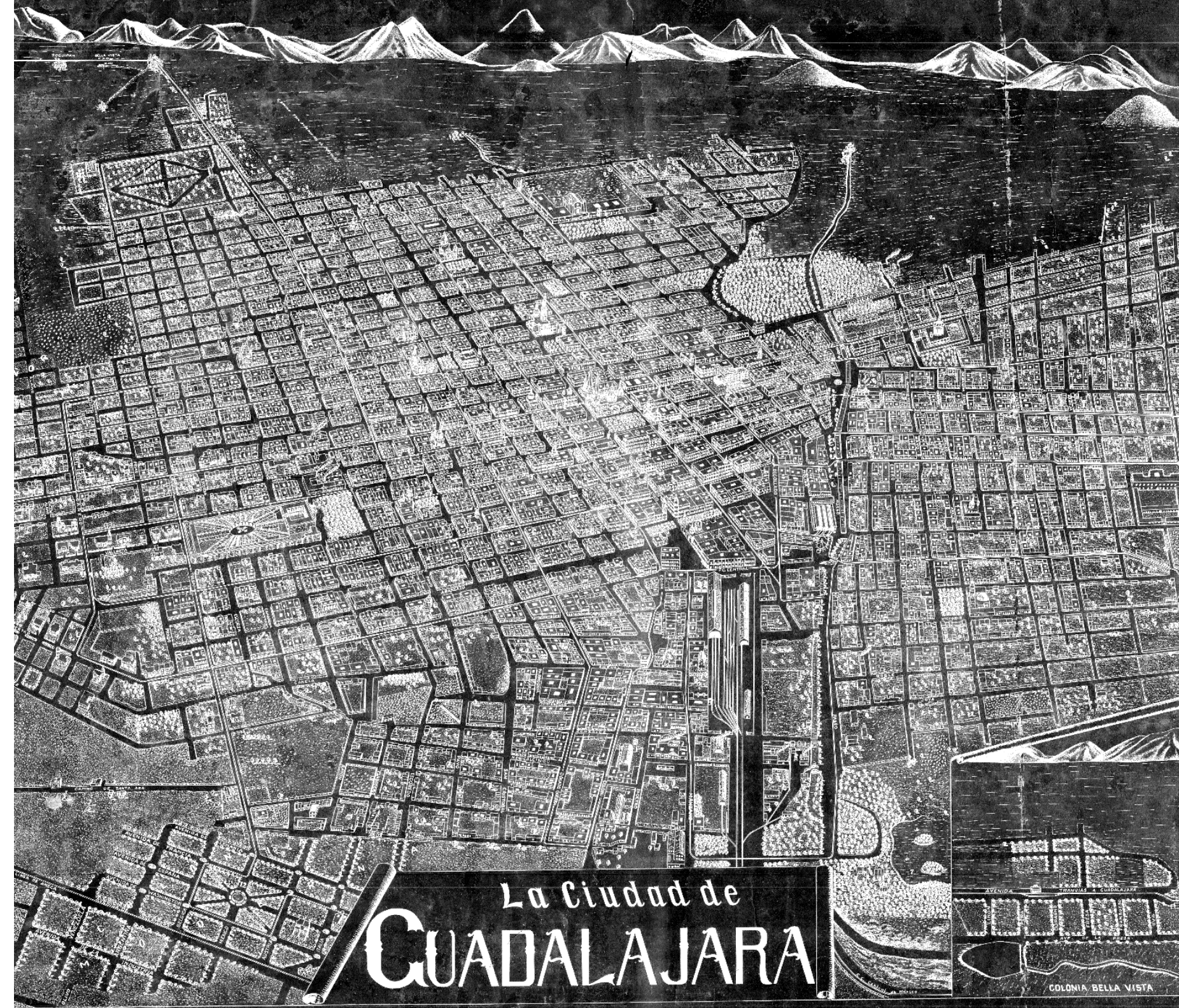

Plano de la ciudad de Guadalajara 1900. Fuente mapoteca archivo general del Estado de Jalisco. 
Matriz Teórico-Metodológica.

GUADALAJARA Y LA PRODUCCIÓN DE SU ESPACIO PÚBLICO: CENTRO Y PERIFERIA HUENTITÁN Y CRUZ DE PLAZAS

\begin{tabular}{|c|c|c|c|c|c|c|c|c|c|c|}
\hline \multirow{4}{*}{$\begin{array}{c}\text { Problemática } \\
\text { Los espacios públicos } \\
\text { periféricos se perciben como } \\
\text { lugares ajenos a los espacios } \\
\text { públicos centrales, ya que en } \\
\text { muchas ocasiones la } \\
\text { producción del espacio } \\
\text { público se relaciona como el } \\
\text { quehacer de expertos, } \\
\text { arquitectos, urbanistas, } \\
\text { planificadores urbanos, } \\
\text { politicos, existiendo un interés } \\
\text { mínimo de conocer a la } \\
\text { ciudadanía y sus realidades } \\
\text { para el diseño de sus } \\
\text { espacios públicos, lo cual } \\
\text { puede ocasionar espacios } \\
\text { desligados unos con otros y } \\
\text { por consiguiente un } \\
\text { debilitamiento en su } \\
\text { accesibilidad, usos o } \\
\text { apropiaciones por la carencia } \\
\text { de no integrar y conocer las } \\
\text { actividades de la sociedad al } \\
\text { momento de la toma de } \\
\text { decisiones en la producción } \\
\text { física material de espacios } \\
\text { públicos en las periferias de } \\
\text { las ciudades. }\end{array}$} & \multirow{2}{*}{\begin{tabular}{|l|}
\multicolumn{1}{|c|}{ Preguntas } \\
¿Por qué los espacios \\
públicos periféricos se \\
perciben como espacios \\
menos relevantes que \\
los espacios públicos \\
centrales en la ciudad?
\end{tabular}} & \multirow{3}{*}{\begin{tabular}{|l|}
\multicolumn{1}{|c|}{ Objetivo general } \\
Estudiar el espacio \\
público en el centro y \\
periferia de Guadalajara \\
para comprender cuáles \\
son los elementos o \\
configurantes \\
morfológicos, materiales, \\
físicos y simbólicos que \\
han permitido su \\
producción, lo anterior \\
mediante el estudio de \\
los procesos de \\
crecimiento de la ciudad \\
y en específico la \\
estructuración de \\
espacios públicos y su \\
relación con la expansión \\
de la metrópoli. El \\
estudio abarcará la \\
\end{tabular}} & \multirow[b]{2}{*}{\begin{tabular}{|l|} 
Objetivos particulares \\
Explicar la importancia \\
de los espacios \\
públicos periféricos en \\
relación con su \\
centralidad en las \\
ciudades. \\
\\
\end{tabular}} & \multicolumn{2}{|c|}{ Concepción teórica del espacio público } & \multicolumn{2}{|c|}{ Ejes de analisis } & \multirow{2}{*}{\begin{tabular}{|l|}
\multicolumn{1}{|c}{$\begin{array}{l}\text { Indicadores a } \\
\text { estudiar }\end{array}$} \\
Modelos de \\
ciudad. \\
Plazas. \\
Áreas verdes \\
pparques-jardines.
\end{tabular}} & \multirow{2}{*}{\begin{tabular}{|l|}
\multicolumn{1}{|c}{$\begin{array}{c}\text { Métodos de } \\
\text { analisis } \\
\text { cualitativos }\end{array}$} \\
$\begin{array}{l}\text { Cartografía, } \\
\text { fuentes }\end{array}$ \\
$\begin{array}{l}\text { documentales, } \\
\text { fuentes } \\
\text { bibliográficas }\end{array}$ \\
\end{tabular}} & \multirow{2}{*}{\begin{tabular}{|l}
\multicolumn{1}{|c|}{ Producto a obtener } \\
Modelos relacionales de \\
crecimiento y expansión \\
urbana de la ciudad de \\
Guadalajara con respecto a \\
sus espacios públicos en su \\
historia urbana.
\end{tabular}} \\
\hline & & & & \begin{tabular}{|l|} 
Espacio público y \\
definiciones de acuerdo a \\
lugar de actividades, \\
sistema de una red de \\
inafrestructura urbana de \\
comunicación, lugar de \\
encuentros y relaciones, \\
espacio fisico que \\
promueve la unidad \\
social.
\end{tabular} & \begin{tabular}{|l} 
Producción del \\
espacio. \\
\\
\end{tabular} & $\begin{array}{l}\text { Espacio } \\
\text { público. }\end{array}$ & $\begin{array}{l}\text { Dimensiones } \\
\text { del espacio } \\
\text { público } \\
\text { historico y } \\
\text { actual. }\end{array}$ & & & \\
\hline & \begin{tabular}{|l} 
¿Cómo fueron \\
conformándose los \\
espacios públicos de \\
Guadalajara en relación \\
con el crecimiento de la \\
ciudad y su traza \\
urbana?
\end{tabular} & & \begin{tabular}{|l|} 
Describir el crecimiento \\
de la ciudad de \\
Guadalajara, desde su \\
centro hasta su periferia \\
norte en relación con la \\
producción física \\
material de sus \\
espacios públicos.
\end{tabular} & \begin{tabular}{|l|} 
El estudio de la \\
morfología urbana.
\end{tabular} & Morfología. & \begin{tabular}{|l} 
Conforma \\
ción \\
espacial.
\end{tabular} & $\begin{array}{l}\text { Enfoque } \\
\text { físico } \\
\text { material. }\end{array}$ & $\begin{array}{l}\text { Elementos } \\
\text { arquitectonicos y } \\
\text { mobiliario urbano. }\end{array}$ & \begin{tabular}{|l} 
Análisis \\
situacional, \\
puntos de \\
observación, \\
paseos de \\
observación, \\
cartografía.
\end{tabular} & $\begin{array}{l}\text { Esquemas de elementos } \\
\text { físicos y morfologicos de } \\
\text { Cruz de plazas y parques; } \\
\text { Morelos, Huentitán y } \\
\text { Mirador. }\end{array}$ \\
\hline & \begin{tabular}{|l} 
¿Qué elementos de la \\
construcción del \\
espacio social, son \\
visibles en la \\
concepción material del \\
espacio público? \\
\end{tabular} & $\begin{array}{l}\text { fundación de Guadalajara } \\
\text { y la producción de } \\
\text { espacios públicos } \\
\text { periféricos. }\end{array}$ & \begin{tabular}{|l|} 
Analizar la sociabilidad, \\
comodidad, imagen, \\
accesibilidad, \\
actividades y usos de la \\
ciudadanía en los \\
espacios públicos \\
\\
\end{tabular} & \begin{tabular}{|l|} 
Geografía humanista., \\
organización espacial de \\
las actividades humanas \\
y las relaciones y \\
comportamientos entre la \\
sociedad y su entorno. \\
Etnografía urbana, \\
observación y \\
descripción para el \\
registro de datos de una \\
comunidad. \\
\end{tabular} & \begin{tabular}{|l|} 
Ciudadanía / \\
comportamiento y \\
percepción. \\
Autores: Jesús \\
Gonzáles, Santis \\
y Ganga, Yago, \\
Claudina Peralta, \\
Gayou y Kathrin \\
Wildner. \\
\\
\end{tabular} & \begin{tabular}{|l} 
Actores I \\
personas. \\
\end{tabular} & $\begin{array}{l}\text { Enfoque } \\
\text { simbólico }\end{array}$ & $\begin{array}{l}\text { Participación } \\
\text { ciudadana. } \\
\text { Usos y } \\
\text { actividades. } \\
\text { Apropiación. }\end{array}$ & $\begin{array}{l}\text { Análisis } \\
\text { situacional, } \\
\text { puntos de } \\
\text { observación, } \\
\text { encuestas, } \\
\text { paseos de } \\
\text { observación. }\end{array}$ & $\begin{array}{l}\text { Tablas y gráficas de } \\
\text { indicadores de calidad del } \\
\text { espacio en cuanto a } \\
\text { conexiones, comodidad e } \\
\text { imagen,usos - actividades y } \\
\text { sociabilidad. }\end{array}$ \\
\hline
\end{tabular}




\begin{tabular}{|l|l|l|l|}
\cline { 2 - 3 } \multicolumn{1}{c|}{} & \multicolumn{2}{|l|}{ Variable } \\
\cline { 2 - 4 } \multicolumn{1}{c|}{ SOCIABILIDAD } & \multicolumn{2}{c|}{} \\
\cline { 2 - 4 } \multicolumn{1}{c|}{ Concepto } & Conversando \\
\hline Indicador & Sentadas & Paradas & \\
\hline No. Hombres & & & \\
\hline No. Mujeres & & & \\
\hline No. Niños & & & \\
\hline No. Personas en grupo & & & \\
\hline No. De personas solas & & & \\
\hline
\end{tabular}

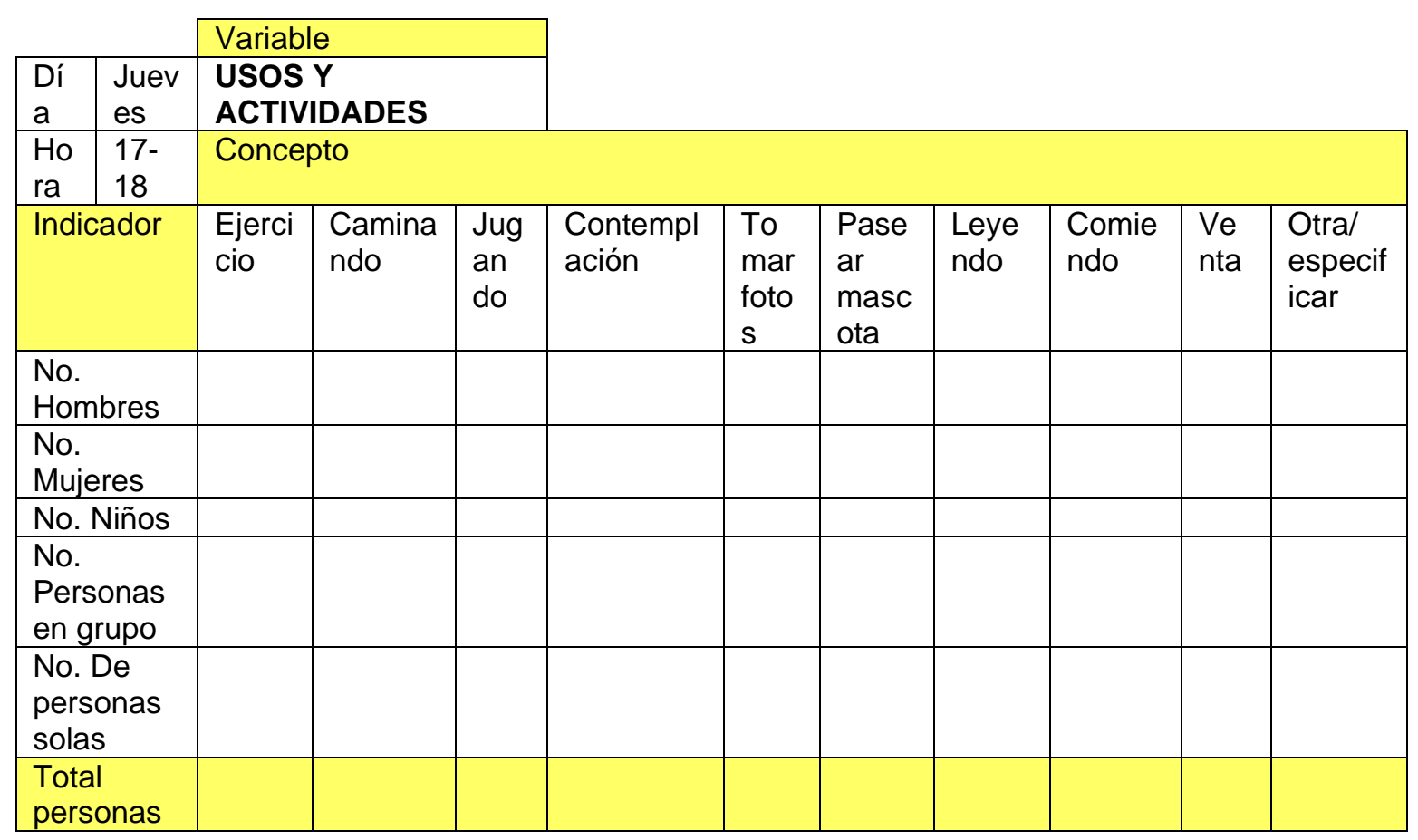




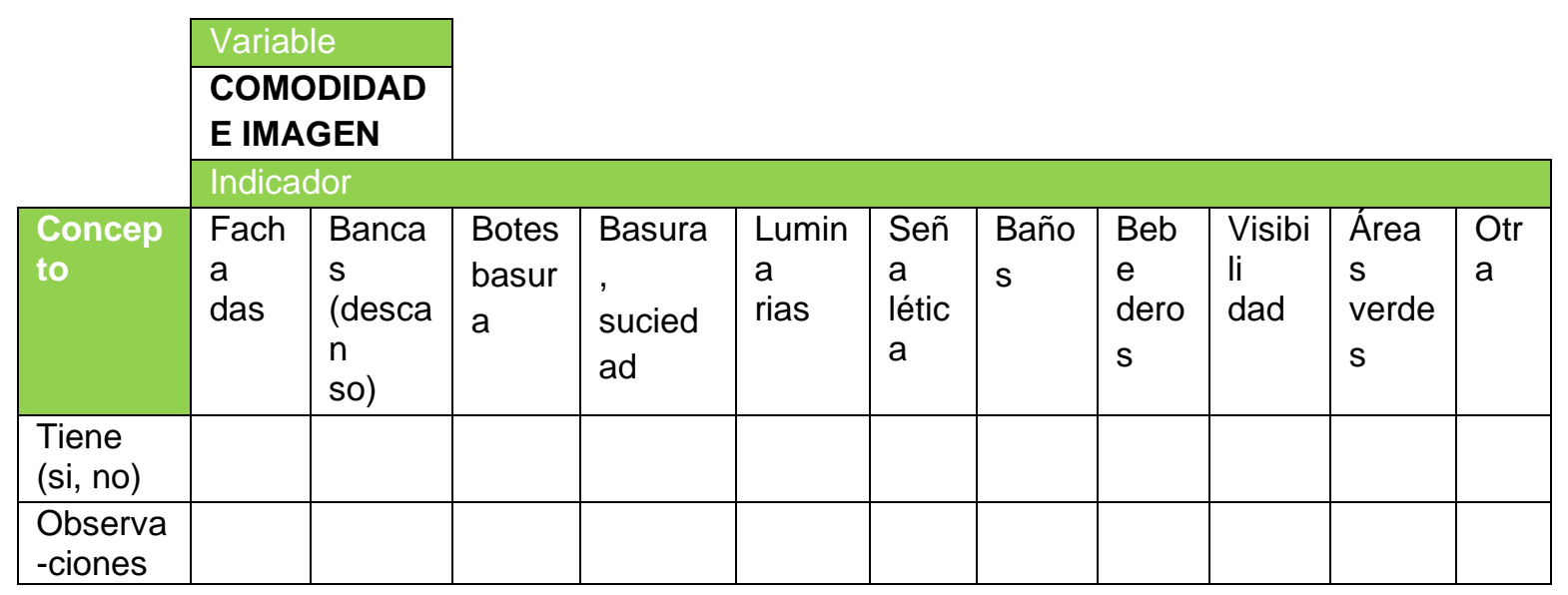

\begin{tabular}{|c|c|c|c|c|c|c|c|}
\hline & \multirow{2}{*}{\multicolumn{7}{|c|}{$\begin{array}{l}\text { Variable } \\
\text { ACCESOS Y Y } \\
\text { CONEXIONES } \\
\text { Indicador }\end{array}$}} \\
\hline & & & & & \multicolumn{3}{|c|}{ Indicador } \\
\hline Concepto & Parada bus & $\begin{array}{l}\text { Parada } \\
\text { tren }\end{array}$ & $\begin{array}{l}\text { Parada } \\
\text { BRT }\end{array}$ & $\begin{array}{l}\text { Bici } \\
\text { pública }\end{array}$ & $\begin{array}{l}\text { Bici } \\
\text { privada }\end{array}$ & Peatonal & Coche \\
\hline Tiene (si/no) & & & & & & & \\
\hline $\begin{array}{l}\text { No. De } \\
\text { elementos }\end{array}$ & & & & & & & \\
\hline Observaciones & & & & & & & \\
\hline
\end{tabular}

\section{Modelo de encuesta}

ENCUESTA PARQUE Indicar nombre del lugar

Sexo

Edad Ocupación

Lee cada pregunta y selecciona la opción con la que más te identificas.

ENCUENTRO (SOCIABILIDAD) Los textos subrayados en colores no aparecerán en el modelo de encuesta aplicado, ya que son solo una referencia de la variable a abordar.

1-Con qué frecuencia visitas este espacio?

( ) Todos los días ( ) 1-2 veces x semana ( )3-6 veces $x$ semana ( )1 vez x mes

2-Cuánto tiempo pasas en este lugar?

( )Menos de $30 \mathrm{~min}$ ( ) $30 \mathrm{~min}-1$ hora ( ) + de $2 \mathrm{hrs} \quad$ ( ) $3-6 \mathrm{hrs} \quad$ ( ) + de 6 hrs 


\section{(Acogedor)}

3- Cuando visitas este espacio sueles hacerlo solo o en compañía.

( )Solo ( )Acompañado ( ) Ambas

4- ¿Interactúas con la gente que también esta en este espacio? ¿Con quién?

( )amigos ( )Desconocidos ( )comerciantes otro

5- Perteneces a algún colectivo vecinal, asociación civil, grupo, o grupo deportivo.

Si ( ) cuál?__ No ( )

\section{USOS Y ACTIVIDADES}

6-Conforme a la siguiente línea de bienestar, qué tanto te gusta venir aquí.

\begin{tabular}{|c|c|c|c|}
\hline $\begin{array}{c}1 \\
\text { Cada cuadro } \\
\text { tiene un valor } \\
\text { del } 25 \%\end{array}$ & 2 & 3 & 4 \\
\hline
\end{tabular}

7-Selecciona los tipos de actividades que realizas cuando vienes a este espacio. Puedes seleccionar más de una opción.

( )Descanso ( )Esparcimiento/recreación ( )Convivencia/encuentro

( )Deporte/ejercicio otra

8-Por qué vienes a este espacio. Puedes escoger varias opciones.

( ) Lugar de paso ( )Permanencia (me gusta) ( ) actividades sociales

( ) cercanía otra

9- A cuáles de las siguientes actividades has asistido dentro del espacio. Puedes seleccionar más de una opción.

( )Talleres/cursos ( ) eventos sociales (fiestas, reuniones) ( ) Conciertos

( )Proyección de películas Otra 


\section{COMODIDAD E IMAGEN}

10-Conforme a la siguiente línea de bienestar, ¿Cómo calificarías tu experiencia en este espacio?
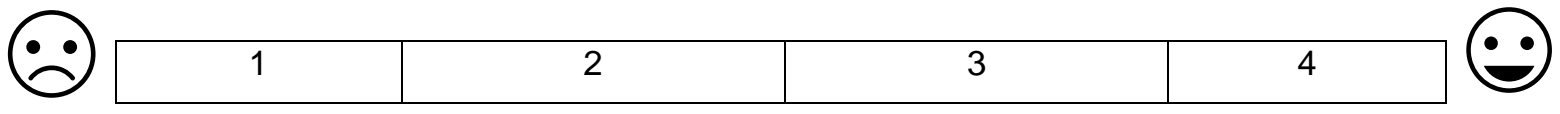

11-Cuáles son los elementos que le dan identidad a este espacio. Puedes seleccionar más de una opción.

( ) Sociales (actividades que realizas) （） Vegetación (áreas verdes)

( ) Hechos históricos (relatos, leyendas) ( )Arquitectura (acceso monumental, mobiliario, construido)

12-Conforme a la siguiente línea de bienestar, cómo evalúas la limpieza del espacio.

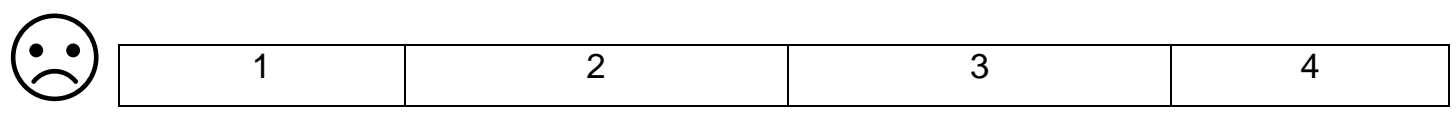

13-Conforme a la siguiente línea de bienestar, qué tan confortable percibes este espacio
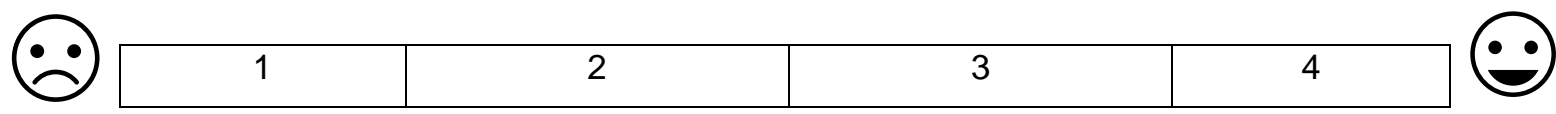

14- Conforme a la siguiente línea de bienestar, qué tan seguro percibes este espacio
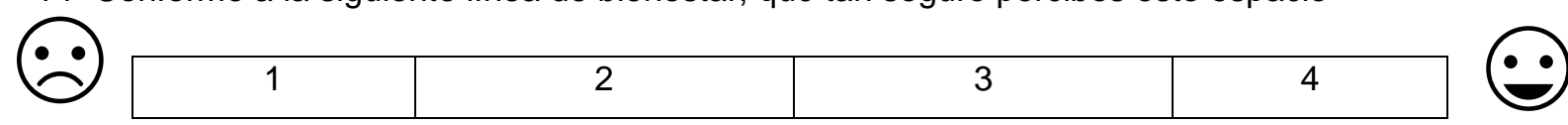

15-Consideras que este espacio es tuyo y por eso lo visitas y lo cuidas.

( ) si ( ) no ¿Por qué?

16-Con cuáles de los siguientes aspectos te sientes más relacionado y conectado con este espacio.

( )Aspectos sociales (relaciones afectivas, sentimientos, experiencias, actividades)

( )Aspectos urbanos (arquitectura, diseño, mobiliario, equipamiento)

( )Aspectos Históricos ( historias, mitos y leyendas) 


\section{CONEXIONES Y ACCESOS}

17-Qué tan cerca o lejos vives de este sitio

( )Mismo barrio ( ) Barrio vecino ( ) Otro barrio de la ciudad

18-Normalmente cuál es tu punto de origen para llegar a este lugar.
( ) Casa
( )Escuela
( ) Trabajo
( ) Otro

19-Cómo llegas a este espacio cuando lo visitas. Puedes seleccionar más de una opción.

( ) Caminando ( ) bicicleta ( ) transporte público ( ) motocicleta

( ) automóvil

20-Conforme a la siguiente línea de bienestar, consideras que este espacio es un lugar caminable para el peatón.
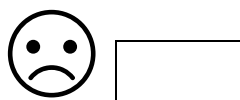

1

2

3

4

21-Conforme a la siguiente línea de bienestar, cómo evaluarías la accesibilidad para llegar a este lugar en transporte público o caminando.

0

\begin{tabular}{|l|l|l|l|}
\hline 1 & 2 & 3 & 4 \\
\hline
\end{tabular}

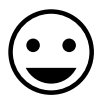

22-Conforme a la siguiente línea de bienestar, consideras que este espacio está conectado a una red de espacios públicos en la ciudad.

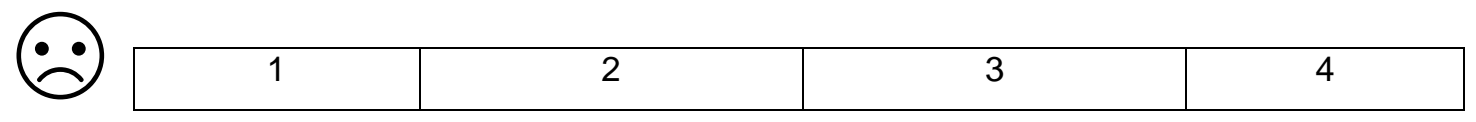




\section{Ejemplos encuestas aplicadas.}

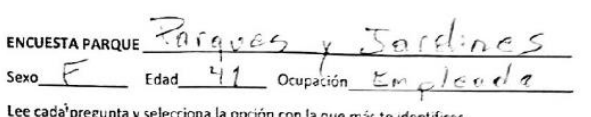

Lee cada'pregunta y selecciona la opción con la que màs te identificas.

1-Con qué frecuencia visitas este espacio?

(1) Todos los dias ( ) 1-2 veces $x$ semana $\left(\bigcup_{3}\right.$-6 6 veces $\times$ semana ( ) 1 vea $x$ mes

2-Cuánto tiempo pasas en este lugar?

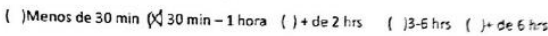

3. Cuando visitas este espacio sueles hacerio solo o en companili.

( ISolo I IAcompafiado W Ambas

4- ¿lnteractúas con la gente que también está en este espacio? ¿Con quièn?

Wamigos ( ) Desconocidos () komerciantes otro

5. Perteneces a algún colectivo vecinal, asociaciún civil, arupo c grupo deportivo.

sil $(X)$ cuals Aot:vote librelomudfot

6 Conforme a la siguiente línea de bienestar, qué tarto te gusta venir aquf.

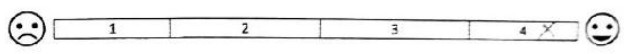

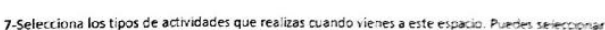
más de una opción.

() Descanso I )Esparcimiento/recteación I Konvinencia/encuentro (ADesone temsces

otra

8 por qué vienes a este espacio. Puedes escoger vartias opcrones.

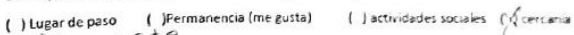

otra Deperte

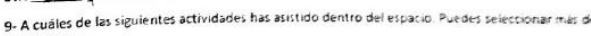

una opción

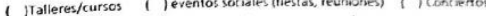

(xpropección de peliculas utrals) Defirts

19. Cime lezxs a este escracio cuando lo visitas. Puedes seieccionar más de una opción.

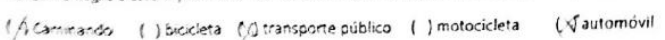
avcerarne a la sizuiente inea de bienestar, consideras que este espacio es un lugar caminable parat coxth

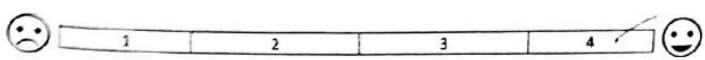

21. Contome a la s guiente linea de bienestar, como evaluarias la accesiblidad para llegar a este hugxe en transpome púbicos o caminardo.

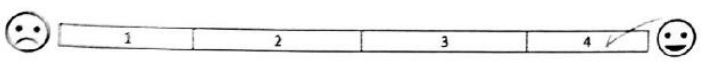

22 Conforme a la siguiente linea de bienestar, consideras que este espacio está conectado a una rad do ercacios públicos en la ciudad.

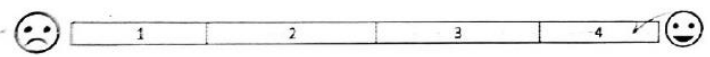

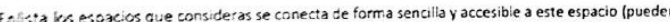
ser farcies, plazas, expianadas, camelliones).

Vuze ladepentence, ?.00logice, setio Hécer, Darive Mirador
10-Conforme a la siguiente linea de bienestar, ¿Cómo calificarias tu experiencia en este espacio?

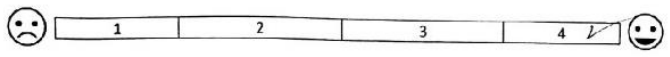

11-Cuáles son los elementos que le can identidad a este espacio. Puedes seleccionar más de una opción.

( ) Sociales (actividades que realizas) (oTVegetación (äreas verdes)

() Hechos históricos (relatos, leyendas) （ A Arquitectura (accesos monumentales, mobiliario, lo construido)

12-Conforme a la siguiente linea de bienestar, cómo evalúas la limpieza del espacio. $\odot$\begin{tabular}{|l|l|l|l|}
\hline 1 & 2 & 3 & 4 \\
\hline
\end{tabular}

13-Conforme a la siguiente línea de bienestar, qué tan confortable percibes este espacio

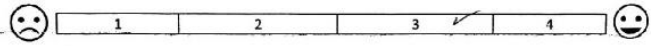

14- Conforme a la siguiente linea de bienestar, qué tan seguro percibes este espacio $\odot$\begin{tabular}{l|l|l|l}
\hline 1 & 2 & 3 & 4
\end{tabular}

15-Consideras que este espacio es tuyo y por eso lo visitas y lo cuidas. $(X)$ si ( ) no eporquér Por ser para espacimiento com unitar. 16-Con cuáles de los siguientes aspectos te sientes más relacionado y conectado con este espacio. (X)Aspectos sociales (relaciones afectivas, sentimientos, experiencias, actividades)

( ) Aspectos urbanos (arquitectura, diseño, mobiliario, equipamiento) ( Aspectos Historicos ( historias, mitos y leyendas)

17-Qué tan cerca o lejos vives de este sitio

() Mismo barrio (X) Barrio vecino ( ) Otro barrio de la ciudad 18-Normalmente cuál es tu punto de origen para liegar a este lugar. Nu Casa () Escucla ( ) Trabajo 1 ) Otro

encuesta parque Niador Lee cada pregunta y sclecciona la opción con la que más te identificas.

1-Con qué frecuencia visitas este espacio?

(1) Todos los dias () 1-2 veces $x$ semana ( $13-6$ veces $x$ semana (2) 1 vez $x$ mes

2-Cuánto tiempo pasas en este lugar?

( Menos de $30 \mathrm{~min}$ () $30 \mathrm{~min}-1$ hora (1) + de 2 hrs () 33-6 hrs (1) de 6 hrs

3-Cuando visitas este espacio sueles hacerlo solo o en companía.

1 ) Solo ( A Acompañado ( ) Ambas

4. ¿interactúas con la gente que también está en este espacio? ¿Con quién?

( )amigos ( ) Desconocidos ( )comerciantes otro AJC

5- Perteneces a algún colectivo vecinal, asociación civil, grupo o grupo deportivo.

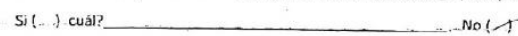

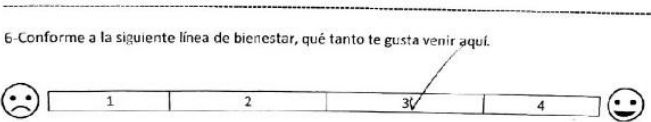

7-Selecciona los tisos de actividades que realizas cuando vienes a estc espacio. Puedes seleccion més de una opción.

LDescanso () Esparcimiento/recreación () Konvivencia/encuentro ( )neportejejercicio (1)

8.Por qué viencs s este espacio. Pueces escoger varios opciones

() Lugar de paso ()Permanencia (me gurta) () actividades sociales () cercania

otra porque une yuota el paisaje

9 A cuàles de las sigunientes accividades has asistidio dentro del espacio. Puedes seleccionar miss do una opcón

(1) ralleres/cursos ( ) eventos socinles (fiestas, reuniones) (J Junciertios

( ) Proyección dec pelicules Otrals 
10-Conforme a la siguiente línea de bienestar, ¿Cómo calificarias tu experiencia en este espacio?

$\mathscr{6}$\begin{tabular}{l|l|l|l}
1 & 2 & 3 & 4 \\
\hline
\end{tabular}

11-Cuáles son los elementos que le dan identidad a este espacio. Puedes seleccionar más de una opción.

(1 Sociales (actividades que realizas) ( T Vegetación (àreas verdes)

( ) Hechos históricos (relatos, leyendas) ( ) Arquitectura (accesos monumentales, mobliario, lo construido)

12-Conforme a la siguiente linea de bienestar, cómo evalúas la limpieza del espacio.

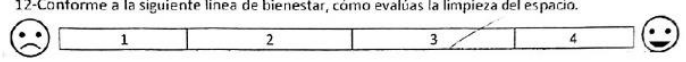

13-Conforme a la siguiente linea dc bienestar, qué tan confortable percibes este espacio

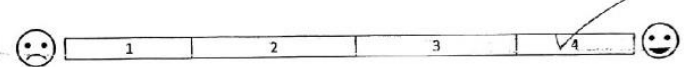

14- Conforme a la siguiente línea de bienestar, qué tan segura percibes este espacio $\bigodot$\begin{tabular}{l|l|l|l}
\hline 1 & 2 & 3 & L4 \\
\hline
\end{tabular} 15-Consideras que este espacio es tuyo y por esa lo visitas y lo cuidas. ( ) / ist ino ¿porque? Qbomos andar la naturaleza querosqueda 16-Con cuáles de los siguientes aspectos te sientes más relacionado y conectado con este espacio. ( ) Aspectos sociales (relaciones afectivas, sentimientos, experiencias, actividades)

( Aspectos urbanos (arquitectura, diseño, mobiliario, equipamiento)

A Aspectos Históricos ( historias, mitos y leyendas)

17-Qué tan cerca o lejos vives de este sitio

() Mismo barrio () Barrio vecino $/$ Otro barrio de la ciudad

18-Norma inente cudi es tu punto de origer para llegar a este lugar.

() Casa I) Escuela I Jirabajo (Jotro

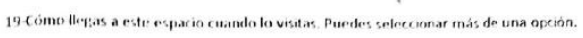

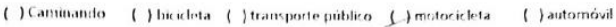
20 comterme a la siguicente linea de bienestar, consideras qun este espacio es un lugat caminable partacl peration

$\Leftrightarrow\left[\begin{array}{l|l|l|l|l}\hline & 1 & 2 & 1 & 3\end{array}\right.$

21. Conforme a la sequiente linea de biencs Lat, cómo evaluarias la accessibuldad para lingar a este lugat en transporte puiblico o caminando.

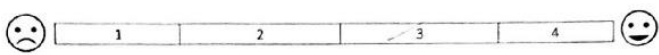

22. Conforme a la siguiente linea de bienestar, consideras que este espacio está conectado a una red de espracios publicos en la ciudad.

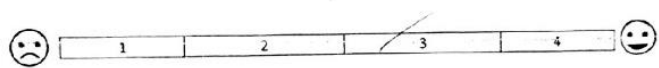

En ista los espacios que consideras se conecta de forma sencilla y accesible a este espacio (pueden set parques, plazas, explanadas, camellones).

Rures vades 


\section{BIBLIOGRAFÍA}

Álvarez Gayou-Jurgenson, J. (2003). Enfoques o marcos teóricos o interpretativos de la investigación cualitativa. En J. L. Álvarez Gayou-Jurgenson, Cómo hacer investigación cualitativa: Fundamentos y Metodología. México: PAIDOS.

Arenal, M. d. (2016). Guía de arquitectura Guadalajara. En M. d. Arenal, Guía de arquitectura Guadalajara (pág. 179). México: Arquine.

Ariceaga, A. K. (2004). Ignacio Díaz Morales. Colección monografías de Arquitectos del siglo XX, Número 1. En A. K. Ariceaga, Ignacio Díaz Morales. Colección monografías de Arquitectos del siglo XX, Número 1 (pág. 60). Guadalajara: Secretaría de Cultura del Gobierno de Jalisco. Centro Universitario de Arte, Arquitectura y Diseño de la Universidad de Guadalajara.

Avial, L. R. (1982). Zonas verdes y espacios libres en la ciudad. En L. R. Avial, Zonas verdes y espacios libres en la ciudad (págs. 15-48). Madrid: Instituto de estudios de administración local.

Barcelona, A. d. (10 de Julio de 2019). Ajuntament de Barcelona. Obtenido de Ajuntament de Barcelona: http://www.anycerda.org/web/es/any-cerda/fa150-anys/el-pla-cerda

Bauwens, M. (17 de Septiembre de 2010). P2P Foundation. Obtenido de P2P Foundation: http://blog.p2pfoundation.net/definition-of-peer-to-peerurbanism/2010/09/17

Benjamin, W. (2004). Libro de los pasajes. Madrid: Akal.

Borja, J. (2012). Revolución urbana y derechos ciudadanos:. En J. Borja, Revolución urbana y derechos ciudadanos: (pág. 42). Barcelona: Universitat de Barcelona.

Borsdorf, A. (2003). Cómo modelar el desarrollo y la dinámica de la ciudad latinoamericana. EURE, 37-46.

Capel, H. (2002). La morfología de las ciudades. En H. Capel, Morfología del espacio (págs. 19-23). España: Ediciones del Serbal.

Cardona, M. C. (2009). Historia Urbana Novohispánica del Siglo XVI. En M. C. Cardona, Historia Urbana Novohispánica del Siglo XVI (pág. 78). México: Universidad Nacional Autonoma de México. 
Castells, M. (2014). La cuestión urbana. En M. Castells, Los medios sociales urbanos (págs. 118-138). México: Siglo xxi.

Cerón, M. Y. (2014). Función de las plazas en la época prehispánica del altiplano Mesoamericano. RICHS Revista Iberoamericana de las Ciencias Sociales y Humanísticas, http://www.ricsh.org.mx/index.php/RICSH/article/view/22/82.

Certeau, M. d. (2000). La invención de lo cotidiano. En M. d. Certeau, La invención de lo cotidiano (págs. 15-150). México: Universidad Iberamericana.

Congress for the New Urbanism. (21 de Diciembre de 2019). https://www.cnu.org/. Obtenido de What is New Urbanism?: https://www.cnu.org/resources/whatnew-urbanism

Doñan, J. J. (2016). Revista Territorio. Obtenido de Hasta la Calzada, ahí donde nace.: http://www.revistaterritorio.mx/hasta-la-calzada.html

Dorantes, E. E. (2013). Plazas del centro histórico de Guadalajara: fundación, trasnformación e integración del espacio urbano. En C. Göbel, Diversas Miradas, la plaza pública en la de ciudad de hoy en día (págs. 35-36). México: Universidad Autónoma Metropolitana.

El Informador. (11 de Febrero de 2012). Donan predio para el Vivero Metropolitano. EL INFORMADOR, págs. https://www.informador.mx/Jalisco/Donan-predio-para-el-ViveroMetropolitano-20120211-0151.html. Obtenido de EL INFORMADOR.

EL INFORMADOR. (13 de Febrero de 2014). Fiestas de Octubre se mudan a la zona del antiguo Planetario. EL INFORMADOR, págs. https://www.informador.mx/Jalisco/Fiestas-de-Octubre-se-mudan-a-la-zonadel-antiguo-Planetario-20140213-0190.html.

Fierro, J. M. (2016). Ernesto Fuchs. En J. M. Fierro, Ernesto Fuchs (págs. 41-48, 101-112). Guadalajara: Arquitónica.

Galicia, S. P. (2016). Metrópolis México. En S. P. Galicia, Metrópolis México (págs. 21-28). México: Universidad Autónoma Metropolitana.

García, S. G. (1992). Nacimiento de la ciudad de Guadalajara. En L. R. García, Capítulos de historia de la ciudad de Guadalajara. Tomo I (págs. 15-35). Guadalajara: Ayuntamiento de Guadalajara.

Gehl, J. (2013). La humanización del espacio urbano. En J. Gehl, La humanización del espacio urbano (págs. 23-50). España: Reverté.

Gehl, J. (2014). Ciudades para la gente. (pág. 6). Buenos Aires: Ediciones Infinito.

Ghel, J. (2014). Ciudades para la gente. Buenos Aires: Ediciones Infinito. 
Gehl, J. (2016). La dimensión humana. En J. Gehl, Ciudades para la gente (págs. 3-29). España: Artes gráficas Palermo.

Göbel, C. A. (2019). Aproximaciones al espacio público. En C. A. Göbel, Aprendizaje Social en Espacios Públicos, CDMX (pág. 38). México: UAM.

Goitia, F. C. (1968). Breve Historia del Urbanismo . En F. C. Goitia, Breve Historia del Urbanismo (págs. 104-126). Madrid: Alianza .

Gómez, M. R. (2013). Evolución de la plaza en la estructura urbana. En M. R. Gómez, Diversas miradas. La Plaza Pública en la ciudad de hoy en día. (pág. 17). México: UAM Azcapotzalco.

Gómez, M. R. (2013). Evolución de la plaza pública en la estructura urbana. En C. Göbel, Diversas Miradas, la plaza pública en la ciudad de hoy en día (págs. 17-33). México: Universidad Autónoma Metropolitana.

González González, M. J. (2003). Geografia Humanista. En J. M. Ibáñez, Lógos hellenikós homenaje al profesor Gaspar Morocho Gayo (pág. 995-999). España: Universidad de León, Secretariado de Publicaciones y Medios Audiovisuales.

Guadalajara, G. d. (20 de Marzo de 2018). Gobierno de Guadalajara. Obtenido de Gobierno de Guadalajara: https://guadalajara.gob.mx/tags/parque-naturalhuentitan

Guadalajara, U. d. (25 de Diciembre de 2019). cuaad.udg.mx. Obtenido de cuaad.udg.mx: http://www.cuaad.udg.mx/?q=historia

Gobierno de Guadalajara. (10 de Julio de 2020). Gobierno de Guadalajara. Obtenido de Plan Municipal de Desarrollo y Gobernanza, y construyamos la Guadalajara que quieres": https://guadalajara.gob.mx/tags/participacionciudadana

Hernando-Chicote, D. (2019). El concepto de espacio en Martin Heidegger. (Trabajo Fin de Grado). Universidad de Navarra, Pamplona.

Huezo, A. G. (2005). Guía Arquitectónica Zona Metropolitana Guadalajara. En A. G. Huezo, Guía Arquitectónica Zona Metropolitana de Guadalajara (págs. 29,33,34,35, 56). Guadalajara: Secretaria de Cultura Jalisco.

INEGI. (1995,2005, 2010). Instituto Nacional de Estadístuca y Geografía.

Institue of Geography. (Enero de 2021). Universität Heidelberg. Obtenido de Universität Heidelberg: https://www.geog.uniheidelberg.de/human/index_es.html

Jacobs, J. (2011). Muerte y vida de las grandes ciudades. En J. Jacobs, Muerte y vida de las grandes ciudades (págs. 55-83). España: Capitán Swing. 
Lefebvre, H. (2013). La producción del espacio. En H. Lefebvre, La producción del espacio (págs. 16-149). Madrid: Capitán Swing.

Llardent, L. R. (1982). Zonas verdes y espacios libres en la ciudad. Madrid: Instituto de estudios de adimistración local.

Lynch, K. (1985). La buena forma de la ciudad. En K. Lynch, La buena forma de la ciudad (págs. 17, 36-44, 61-63, 23-33). Barcelona: Gustavo Gilli.

MILENIO. (20 de Agosto de 2019). Rechazan sede de Fiestas de Octubre en Huentitán, págs. https://www.milenio.com/politica/comunidad/fiestasoctubre-2019-guadalajara-rechaza-sede-huentitan.

Mora, M. A. (19 al 24 de julio 2009). Indicadores de calidad de los espacios públicos urbanos, para la vida ciudadana, en ciudades intermedias. $53^{\circ}$ Congreso Internacional de Americanistas. Los pueblos americanos: cambios y continuidades. La construcción de lo propio en un mundo globalizado., (pág. 5). Ciudad de México.

Morales Yago, Francisco José (2012). LA GEOGRAFÍA DE LA PERCEPCIÓN: UNA METODOLOGÍA VÁLIDA APLICADA AL CASO DE UNA CIUDAD DE TIPO MEDIO-PEQUEÑO. EL EJEMPLO DE YECLA (MURCIA). Papeles de Geografía, (55-56),137-152. [fecha de Consulta 13 de Febrero de 2021]. ISSN: 0213-1781. Disponible en: https://www.redalyc.org/articulo.oa?id=407/40726731012

Moreno, E. L. (2001). La cuadrícula. En el desarrollo de la ciudad hispanoamericana. Guadalajara, México. En E. L. Moreno, La cuadrícula. En el desarrollo de la ciudad hispanoamericana. Guadalajara, México. (págs. 22-181). Guadalajara: Universidad de Guadalajara e Instituto Tecnológico de Estudios Superiores de Occidente.

Muxi, J. B. (2000). El espacio público: ciudad y ciudadanía. En J. B. Muxi, El espacio público: ciudad y ciudadanía (págs. 8, 11-15, 21-31). Barcelona.

New Urbanism. (21 de Diciembre de 2019). newurbanism.org. Obtenido de New Urbanism: http://www.newurbanism.org/newurbanism.html

Partida, J. C. (27 de Octubre de 2009). La fundación Guggenheim desiste de sus proyectos para construir museos en México y Brasil. La Jornada, pág. 7. Obtenido de Periódico La Jornada.

Partida, J. C. (14 de Noviembre de 2011). Protestan por destrucción de áreas verdes en Guadalajara. La Jornada, pág. 35.

Peralta Martínez, Claudina (2009). Etnografía y métodos etnográficos. Análisis. Revista Colombiana de Humanidades, (74),33-52.[fecha de Consulta 16 de 
Febrero de 2021]. ISSN: 0120-8454. Disponible en: https://www.redalyc.org/articulo.oa?id=5155/515551760003

Ramirez Kuri, Patricia. Espacio público, ¿espacio de todos? Reflexiones desde la ciudad de México. Rev. Mex. Sociol [online]. 2015, vol.77, n.1, pp.07-36. ISSN 2594-0651.

Ramirez Kuri, Patricia. Espacio público, ¿espacio de todos? Reflexiones desde la ciudad de México. Rev. Mex. Sociol [online]. 2015, vol.77, n.1, pp.07-36. ISSN 2594-0651.

Ramírez Kuri, Patricia (2007). La ciudad, espacio de construcción de ciudadanía. Revista Enfoques: Ciencia Política y Administración Pública, (7),85-107.[fecha de Consulta 16 de Febrero de 2021]. ISSN: 0718-0241. Disponible en: https://www.redalyc.org/articulo.oa?id=960/96000704

Ramírez, V. (21 de Marzo de 2019). W Radio. Obtenido de W Radio: http://wradio.com.mx/emisora/2018/09/06/guadalajara/1536259698_934480 .html

Real Academia Española. (10 de Septiembre de 2018). RAE. Obtenido de RAE: http://dle.rae.es/?id=8RodkE6

Rodríguez, D. (28 de Octubre de 2018). ntrguadalajara.com. Obtenido de Mirador Independencia, un lugar para admirar: https://www.ntrguadalajara.com/post.php?id_nota $=111410$

Ruiz, G. S. (2008). Planeación Moderna de Ciudades. En G. S. Ruiz, Planeación Moderna de Ciudades (págs. 55-60). México: Trillas.

Salazar, J. H. (2010). Uso y apropiación de los espacios públicos. Medellin: Universidad Nacional de Colombia Sede Medellín.

Santis Arenas, Hernán, \& Gangas, Mónica (2004). La aproximación humanística en Geografía. Revista de Geografía Norte Grande, (31),31-52. [fecha de Consulta 13 de Febrero de 2021]. ISSN: 0379-8682. Disponible en:

https://www.redalyc.org/articulo.oa?id=300/30003103

Santos, E. d. (30 de Julio de 2017). parquesalegres.org. Obtenido de parquesalegres.org: http://parquesalegres.org/biblioteca/blog/elementosque-componen-los-espacios-publicos/

Segovia, O. (2007). Gestión participativa de espacios públicos: tres experiencias. En O. Segovia, Espacios públicos y construcción social. Hacia un ejercicio de ciudadanía (págs. 101-104). Santiago de Chile: Ediciones SUR. 
Soja, E. W. (2008). Postmetrópolis. En E. W. Soja, Postmetrópolis (págs. 10-90). Madrid: Traficantes de sueños.

Solís, H. C. (2012). La dinámica de crecimiento de Guadalajara. En H. C. Solís, Superada la informalidad de nuevos desafíos (págs. 17-46). Guadalajara: Universidad de Guadalajara.

Spaces, P. f. (13 de Junio de 2019). Project for Public Spaces. Obtenido de Project for Public Spaces: https://www.pps.org/article/que-criterios-determinan-unbuen-espaciopublico?fbclid=IwAR3NoZcwquTUn6BR8LNxqOoxEisjq28gbfOKofEcM16Lg ZyEZOYv0cf5k4A

Sprandley, J. P. (1979). La observación participante. En J. P. Sprandley, The Ethnographic Interview. EEUU: Hardcourt

Torres, R. M. (1979). Iglesias y edificios antiguos de Guadalajara. En R. M. Torres, Iglesias y edificios antiguos de Guadalajara (pág. 107). Guadalajara: Ayuntamiento de Guadalajara.

Transversal, P. (13 de Abril de 2018). Archdaily.mx. Obtenido de La Triple Dimensión: una metodología para el diseño colaborativo del espacio público: https://www.archdaily.mx/mx/892474/la-triple-dimension-unametodologia-para-el-diseno-colaborativo-del-espacio-publico

Unidas, N. (10 de 10 de 2018). Naciones Unidas. Obtenido de www.un.org: https://www.un.org/development/desa/es/news/population/2018-worldurbanization-prospects.html

Unidas, N. (13 de Diciembre de 2019). Naciones Unidas. Obtenido de Objetivos de Desarrollo Sostenible.:

https://www.un.org/sustainabledevelopment/es/objetivos-de-desarrollosostenible/

Urbano, E. A. (9 de Octubre de 2015). http://elasuntourbano.mx. Obtenido de http://elasuntourbano.mx: http://elasuntourbano.mx/de-quien-es-el-espaciopublico/

Vázquez, D. (1992). La urbanización de Guadalajara. En A. d. Guadalajara, Capitulos de historia de la ciudad de Guadalajara tomo I (págs. 39-68). Guadalajara: Ayuntamiento de Guadalajara.

Vázquez-Piombo, P. (2015). El Desarrollo urbano en Guadalajara.

En Cruz González Franco, L.(coord.) Historia de la arquitectura y el urbanismo mexicanos, vol. IV. El Siglo XX, tomo II. En la antesala del tercer milenio. México: FCE, UNAM, FA, pp.329-340. 
https://rei.iteso.mx/handle/11117/5055

Vidal Moranta, T. y. (2005). La apropiación del espacio: una propuesta teórica.

En T. y. Vidal Moranta, La apropiación del espacio: una propuesta teórica. Barcelona: Universitat de Barcelona.

Villaseñor, T. (16 de Diciembre de 2018). INFORMADOR. Alfaro inauguró el Parque Natural de Huentitán, págs.

https://www.informador.mx/jalisco/Alfaro-inauguro-el-Parque-Natural-deHuentitan-20171216-0062.html.

Wildner, K. (2004). En La plaza mayor ¿centro de la metrópoli? Etnografía del Zócalo de la ciudad de México (págs. 15-29). México: Universidad Autónoma Metropolitana.

INDICE DE IMAGENES

Ilustración 1) esquema de modelo radiocéntrico..................................32

Ilustración 2) Ciudad medieval bajo el modelo radiocéntrico.........................34

Ilustración 3) intervenciones Bulevar de Haussmann y el centro de París.........35

Ilustración 4) Estructura ciudad Colonial..........................................39

llustración 5) esquema de ciudad hispanoamericana............................40

Ilustración 6) Estructura ciudad Sectorial..........................................41

Ilustración 7) Estructura ciudad Polarizada.......................................42

Ilustración 8) Estructura ciudad Fragmentada....................................44

Ilustración 9) Rubrica de indicadores para determinar qué criterios

determinan a un buen espacio público .......................................... .49

Ilustración 10) Elementos para la medición de la Calidad Ambiental Urbana.....53

llustración 11) Capilla del señor de la Ascensión...................................108

Ilustración 12) Fragmento del límite Guadalajara al norte con

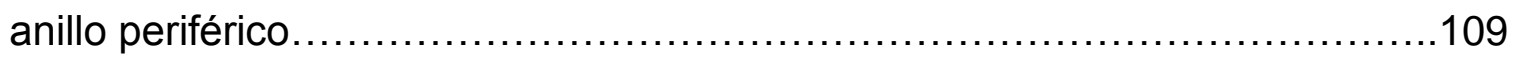

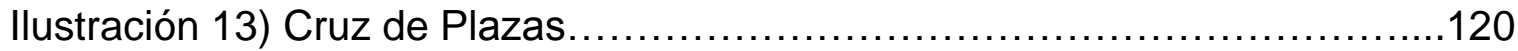

Ilustración 14) Foro del Parque Mirador, al fondo la Barranca de Huentitán......153

Ilustración 15) Tapial divisorio de obras del museo parque Mirador..............154 
Ilustración 16) Domingo por la tarde en el Parque Mirador.......................163

Ilustración 17) Función de circo en el Foro del Parque Mirador....................174

Ilustración 18) Pista de tartán en interior del Parque Natural Huentitán...........176

Ilustración 19) Clase de activación física en el pergolado del

Parque Natural un lunes a las 18 horas.........................................182

Ilustración 20) Huerteros del Huerto comunitario Tlacuache en

la construcción de una cama biointensiva.

Figura 1) Proyectos estratégicos Metropolitanos contenidos

dentro del PIDEU.

Diorama 1) Secuencia fotográfica de plaza Liberación en diciembre

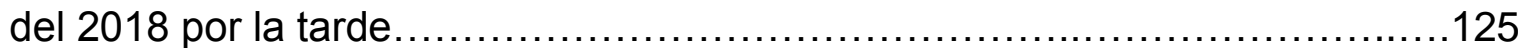

Diorama 2) Secuencia fotográfica de plaza de Armas aun con obras de remodelación

Diorama 3) Secuencia fotográfica Rotonda de los Jaliscienses

llustres diciembre del 2018 por la tarde.

Diorama 4) Secuencia fotográfica Plaza Guadalajara Enero del 2019

por la tarde.

Diorama 5) Secuencia fotográfica Parque Morelos Enero del 2019

por la tarde

Diorama 6) Secuencia fotográfica Parque Mirador Enero del 2019

por la mañana

Diorama 7) Secuencia fotográfica Parque Natural de Huentitán Enero

del 2019 por la mañana.

Gráfico 1 y 2) Rango usuarios de encuestas aplicadas en el Parque

Mirador

Gráfico 3, 4, 5 y 6) Resultados de la encuesta aplicada con relación a los accesos y conexiones del parque Mirador. 158 
Gráfico 7,8 Y 9) Resultados de la encuesta aplicada con relación a los accesos y conexiones del parque Mirador.

Gráfico 10,11, 12 y 13) Resultados de la encuesta aplicada con

relación a la imagen y comodidad del parque Mirador.

Gráfico 14, 15 y 16) Resultados de la encuesta aplicada con

relación a la imagen y comodidad del parque Mirador.

Gráfico 17 y 18) Resultados de la encuesta aplicada con

relación a la imagen y comodidad del parque Mirador.

Gráfico 19, 20 y 21) Resultados de la encuesta aplicada con

relación a la imagen y comodidad del parque Mirador.

Gráfico 22, 23, 24 y 25) Resultados de la encuesta aplicada con

relación a usos y actividades del parque Mirador.

Gráfico 26 y 27) Rango usuarios de encuestas aplicadas en

el Parque Natural de Huentitán.

Gráfico 28, 29, 30 y 31) Resultados de la encuesta aplicada con

relación a los accesos y conexiones del Parque Natural de Huentitán

Gráfico 32, 33 y 34) Resultados de la encuesta aplicada con relación a los accesos y conexiones del Parque Natural de Huentitán

Gráfico 35, 36, 37 y 38) Resultados de la encuesta aplicada con relación

a la imagen y comodidad del Parque Natural de Huentitán

Gráfico 39, 40 y 41) Resultados de la encuesta aplicada con relación a

la imagen y comodidad del Parque Natural de Huentitán

Gráfico 42 y 43) Resultados de la encuesta aplicada con relación a

la sociabilidad del Parque Natural de Huentitán.

Gráfico 44, 45 y 46) Resultados de la encuesta aplicada con relación a la sociabilidad del Parque Natural de Huentitán.

Gráfico 47, 48, 49 y 50) Resultados de la encuesta aplicada con relación a usos y actividades del Parque Natural de Huentitán 
INDICE DE MODELOS

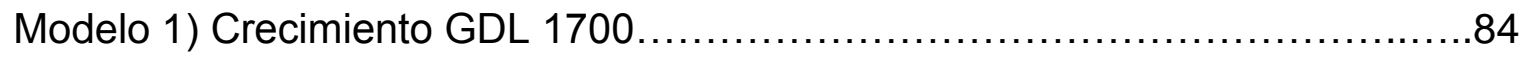

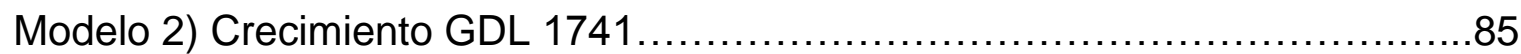

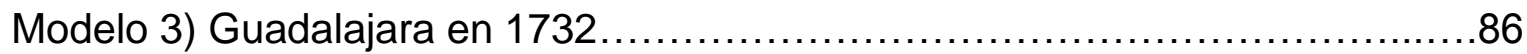

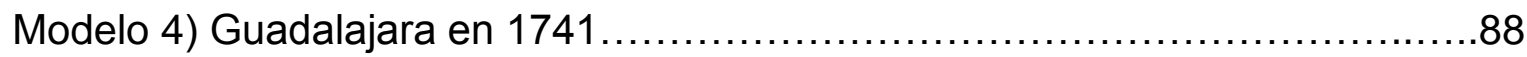

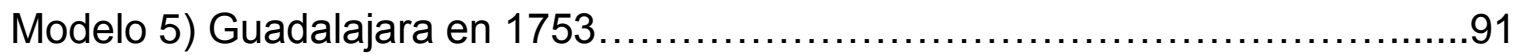

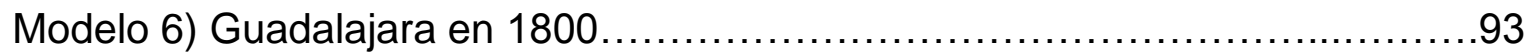

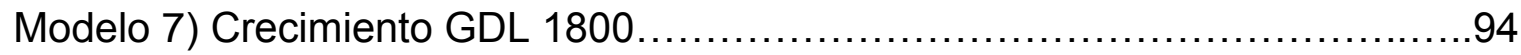

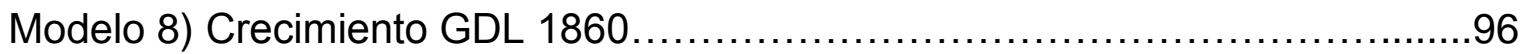

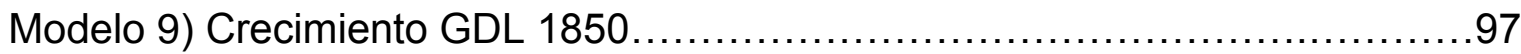

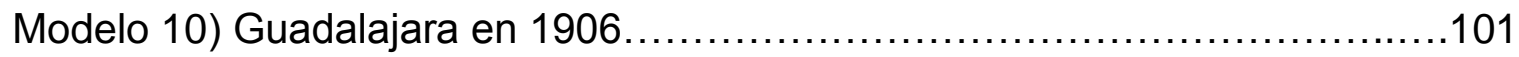

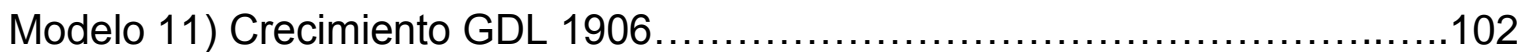

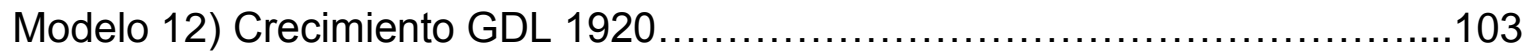

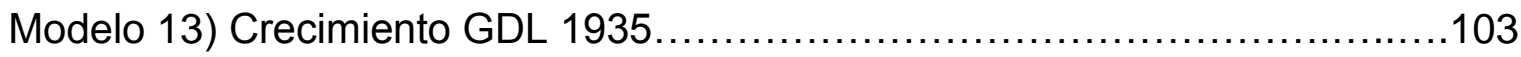

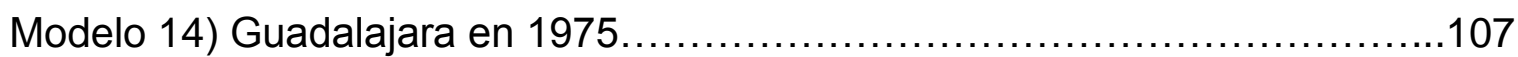

INDICE DE MAPAS

Mapa A. Ubicación áreas de estudio de la investigación..............................12

Mapa 1) Mapa Guadalajara- Nochistlán..........................................76

Mapa 2) Diferentes fundaciones de Guadalajara..................................77

Mapa 3) Guadalajara y su región en la fundación....................................80

INDICE DE ESQUEMAS

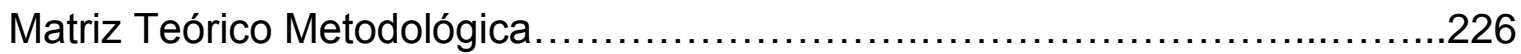

Esquema A) Categorías analizadas en el estado de la cuestión del arte..........63

Esquema 1) Elementos a analizar en la investigación............................32

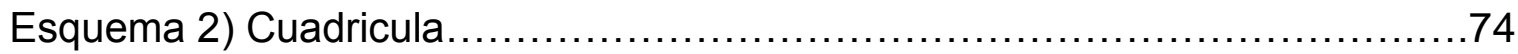




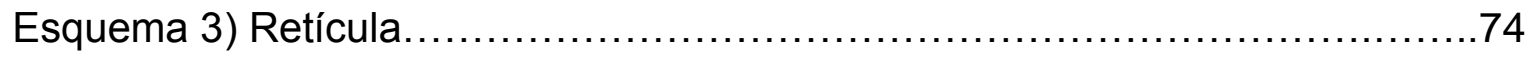

Esquema 4) Estructura territorial de la ciudad colonial...........................75

Esquema 5) Elementos físicos y morfológicos que conforman plaza Liberación. 123

Esquema 6) Áreas de atracción en Plaza Liberación..............................127

Esquema 7) Elementos físicos y morfología que conforma

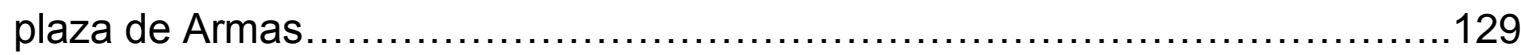

Esquema 8) Áreas de atracción en Plaza de Armas..................................133

Esquema 9) Elementos físicos y morfología que conforma Rotonda de los Jaliscienses Ilustres............................................................... 135

Esquema 10) Áreas de atracción Rotonda de los Jaliscienses llustres...........138

Esquema 11) Elementos físicos y morfología que conforma Plaza

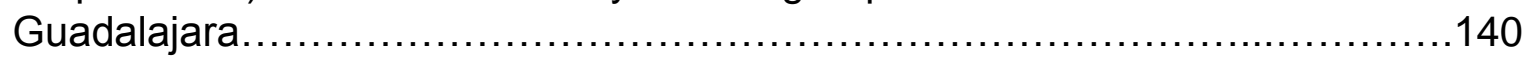

Esquema 12) Áreas de atracción Plaza Guadalajara..............................143

Esquema 13) Elementos físicos y morfología que conforma

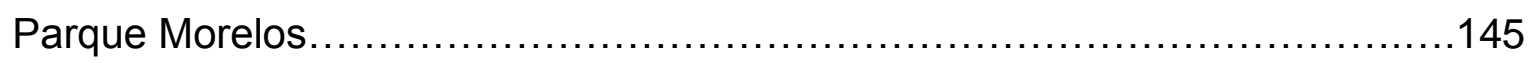

Esquema 14) Áreas de atracción Parque Morelos...............................150

Esquema 15) Elementos físicos y morfología que conforma

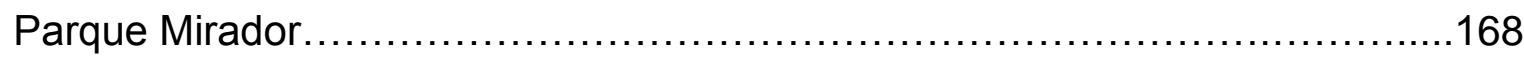

Esquema 16) Áreas de atracción Parque Mirador.................................175

Esquema 17) Elementos físicos y morfología que conforma

Parque Natural de Huentitán........................................................ 191

Esquema 18) Áreas de atracción Parque Natural de Huentitán...................200

Esquema 19) Cruz verde de espacios públicos abiertos: Parque Mirador,

Parque Natural de Huentitán, Parque Morelos, Parque de la Solidaridad,

Parque Liberación, Bosque Colomos y Parque Metropolitano.....................215 
Tabla A) Elementos morfo-arquitectónicos.....................................25

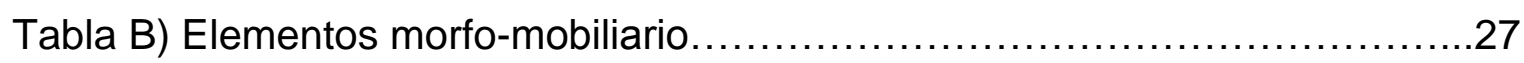

Tabla C) Distribuciones espaciales del espacio público...........................31

Tabla D) Tradiciones nacionales del estudio morfológico histórico.................57

Tabla E) Relaciones de contactos en el espacio urbano..........................60

Tabla F), Actividades exteriores en la ciudad...................................61

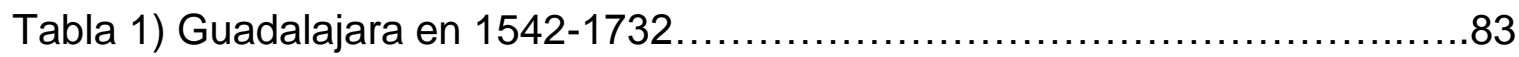

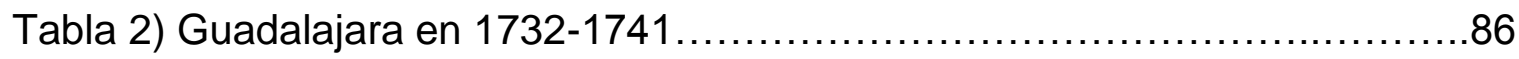

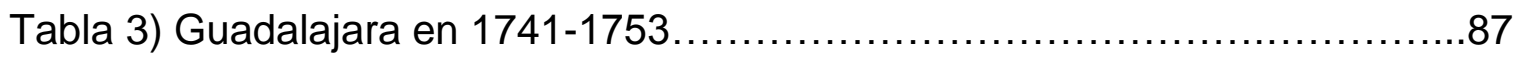

Tabla 4) Guadalajara en 1753-1800 ............................................

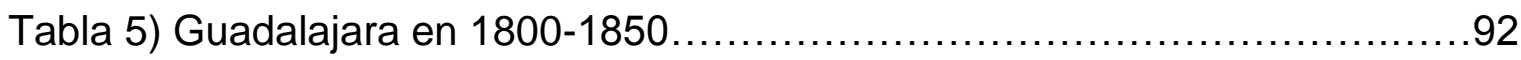

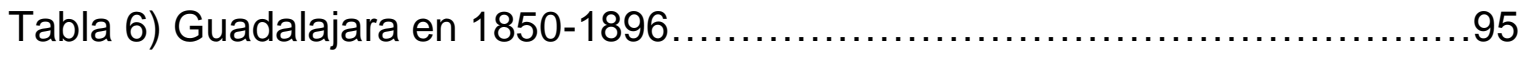

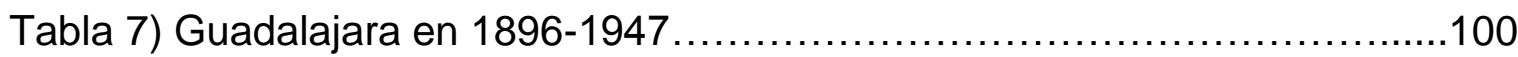

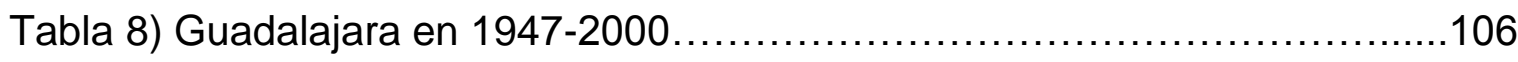

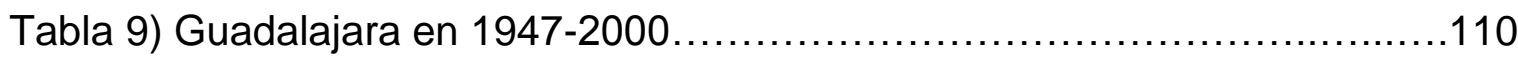

Tabla 10) Tabla de Variable: Accesos y conexiones de Plaza liberación..........124

Tabla 11) Tabla de Variable: Comodidad e imagen de Plaza liberación..........124

Tabla 12) Tabla de Variable: Accesos y conexiones de Plaza de armas..........130

Tabla 13) Tabla de Variable: comodidad e imagen de Plaza de armas...........130

Tabla 14) Tabla de Variable: accesos y conexiones Rotonda

de los Jaliscienses llustres........................................................

Tabla 15) Tabla de Variable: comodidad e imagen Rotonda

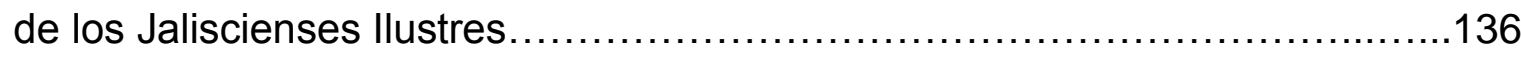

Tabla 16) Tabla de Variable: Accesos y conexiones de Plaza

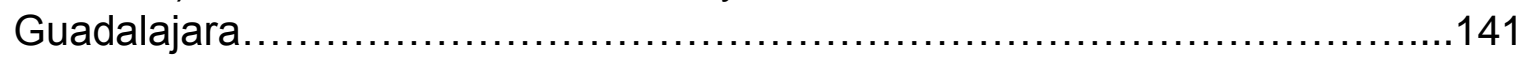

Tabla 17) Tabla de Variable: Accesos y conexiones de Plaza

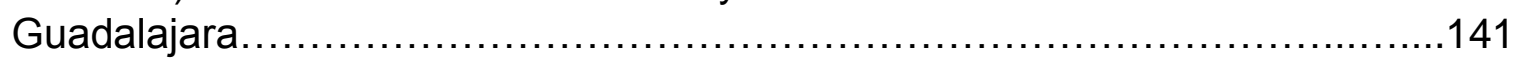

Tabla 18) Tabla de Variable: Accesos y conexiones de Parque Morelos..........147 
Tabla 19) Tabla de variables: Imagen y comodidad de Parque Morelos. 147

Tabla 20) Tabla de Variable: Accesos y conexiones de Parque Mirado 156

Tabla 21) Tabla de variables: Imagen y comodidad de Parque Mirador. 160

Tabla 22, 23, 24 y 25) Tabla de variables: Sociabilidad

Parque Mirador en distintos horarios y días

Tabla 26 y 27) Tabla de variables: Sociabilidad

Parque Mirador en distintos horarios y días

Tabla 28) Tabla de variables: Usos y actividades

Parque Mirador en distintos horarios y días.

Tabla 29) Tabla de variables: Usos y actividades Parque Mirador

en distintos horarios y días

Tabla 30) Tabla de variables: Usos y actividades Parque Mirador

en distintos horarios y días.

Tabla 31) Tabla de variables: Usos y actividades Parque Mirador

en distintos horarios y días

Tabla 32) Tabla de variables: Usos y actividades Parque Mirador

en distintos horarios y días 172

Tabla 33) Tabla de variables: Usos y actividades Parque Mirador

en distintos horarios y días.

Tabla 34) Tabla de Variable: Accesos y conexiones del

Parque Natural de Huentitán.

Tabla 35) Tabla de variables: Imagen y comodidad del

Parque Natural de Huentitán.

Tabla 36, 37, 38 y 39) Tabla de variables: Sociabilidad

Parque Natural de Huentitán en distintos horarios y días 186

Tabla 40 y 41) Tabla de variables: Sociabilidad Parque Mirador

en distintos horarios y días.

Tabla 42) Tabla de variables: Usos y actividades Parque Natural 
de Huentitán en distintos horarios y días ...................................196 Tabla 43) Tabla de variables: Usos y actividades Parque Natural de Huentitán en distintos horarios y días......................................196 Tabla 44) Tabla de variables: Usos y actividades Parque Natural de Huentitán en distintos horarios y días.....................................197 Tabla 45) Tabla de variables: Usos y actividades Parque Natural de Huentitán en distintos horarios y días.......................................197 Tabla 46) Tabla de variables: Usos y actividades Parque Natural de Huentitán en distintos horarios y días.........................................198 Tabla 47) Tabla de variables: Usos y actividades Parque Natural de Huentitán en distintos horarios y días.....................................198 Tabla 48) Casos de estudio: espacios abiertos al aire libre de la zona centro y periferia norte de Guadalajara ............................................. 